Western University

Scholarship@Western

Digitized Theses

Digitized Special Collections

1974

\title{
The Expectations Of Stock Market Participants For Selected Stocks
}

John Telesephore Bart

Follow this and additional works at: https://ir.lib.uwo.ca/digitizedtheses

\section{Recommended Citation}

Bart, John Telesephore, "The Expectations Of Stock Market Participants For Selected Stocks" (1974). Digitized Theses. 763.

https://ir.lib.uwo.ca/digitizedtheses/763

This Dissertation is brought to you for free and open access by the Digitized Special Collections at Scholarship@Western. It has been accepted for inclusion in Digitized Theses by an authorized administrator of Scholarship@Western. For more information, please contact tadam@uwo.ca,

wlswadmin@uwo.ca. 


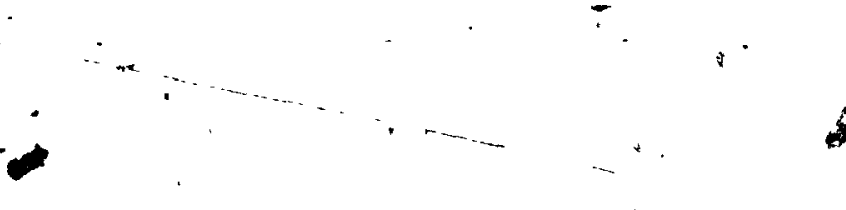

ABSTRACT
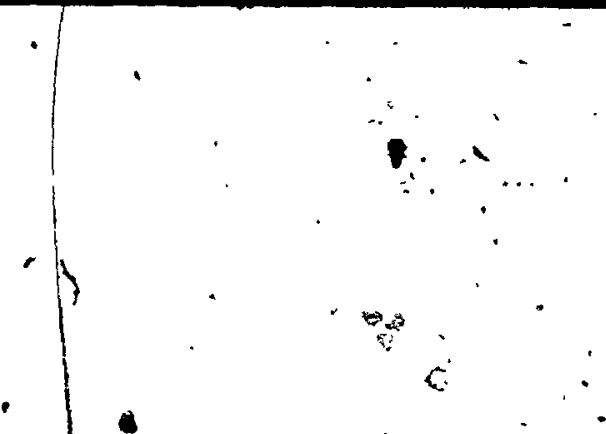

This study investigates the nature of investors expectations of.financial return from common.stocks. Three research questions are embodied in the scope of the study. (1) Do investors expect higher rate of return from higher risk stocks? (2) Do the risk return characteriftics of investor expectations differ according to whether the investor. is a buyer, seller, or 'owner of the stock?'

(3) Are the : expectations of investors consistent with the proposition that all publicly available information is fully reflected in the price of a stock?

Empirical data for this research were obtained fróm. a sample of four types of stock market participants (buyers, " sellers, oyners, and security analysts) for three selécted conmon stocks (a utility, a petroleum based stock, and a mineral resource stock). During the period March 19 to April 13, I973, approximately 800 individual investors and 15 security analysts responded to a mail questionnaire that measured their price and dividend expectations for the stock that they had just brought or sold, owned, or followed. (analysts). Expectations were obtained in the form of discrete probability distributions.

Inter- and intra-stock comparisons of the parameters of measured expectations led to the conclusions that: invesfors expect a higher return from higher risk stocks; gellers of a stock expected a lower return than either, buyers or owners of the stogk; and, that all publicly available information was not.fully reflected in the price of the three stocks at the time of the study. However, these conclusions are subject to qualisications regarding their applicabjlity to different types of return (pricé, dividend, and total. return), to different expectations time horizons, and- to different parameters of return expectations. 
In acknowledging thọse' individuals who made this research possible I wish to thank professor D vid C. Shaw, Imy thesis advisory for his continuous support and guidance throughout all phases of this study. Professor shaw encouraged my earliest work in thẹ area of investor expectations and was of great assistance in the development of this research topic.

Professors Rus\$el M. Ḱnight and James C. Hatch gave generously of their time and energy in all phases of this study. Professor knight was particularily helpful with methodological considerations.

I am'also indebted to Mr. Huntly W.F. McKay, Vice-president of the Toronto stock Exchange for his enthusiasm and asisistance during the data collecting phase of this research. The investment dealers and selected companies involved in.this study are also thanked for their critically important cooperation in making this thesis possible.

Funding for this research and my doctoral program was provided by the Richard Ivey foundation, Shell canada Limited and the Institute of citizenşhip. The contribution of these organizations is certainly appreciated.

My wife, Eleanor, has shared in this experience and in my entire grädúate program. For her encouragement ånd perseverance it is fitting that this thesis be dedicated to her. 
CERTIFICATE OF EXAMINATION. . . . . . . . . . . .

ABSTRACT

ACKNOWLEDGEMENTS:

ACKNOWLEDGEMENTS .

TABLE OF CONTENTS.

LIST OF TABLES

LIST OF FIGURES.

CHAPTER I INTRODUCTION

1.1. EMPIRICIAL PERSPECTIVE

1.2 RESEARCH OBJECTIVE

1.3. METHODOLOGY

1.3.1 Operational Implications of Research Methodology.

1.3.2 Sampling of Investors

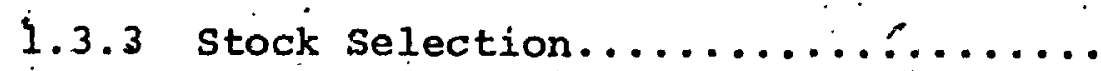

1.3.4 - Data Anaìysis

$\therefore 10$

1.4 SUMMARY OF CONCLUSIONS

i 1.5 SUMMARY OF IMPLICATIONS AND RECOMMENDATIONS.

1.6 OUTLINE OF THE STUDY $\therefore$

CHAPTER II - EXPECTATIONS PROPER.

2.1 EXPECTATIONS DEFINED.

,

2.2 THE ELEMENTS OF AN EXPECTATION

2.2.1 The Indtyidual 



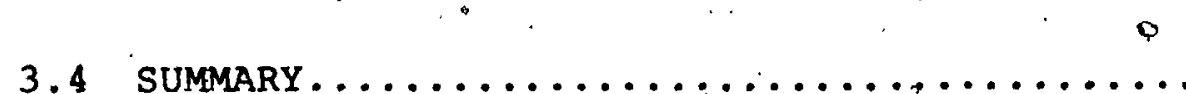

CHAPTER IV - THE MEASUREMENT OF FINANCIAL RETURN EXPECTATIONS

4.1. THE METHODOLOGY OF OPERATIONALLY DEFINING

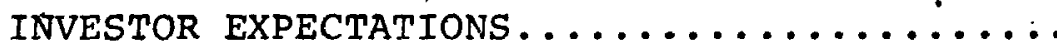

4.2 THE SUBJECT (\$) OF INVESTORS' EXPECTATIONS...

4.3 THE "OUTCOMES" OF INVESTORS' EXPECTATIONS...

4.3.1 The Outcomes Defined............. 81

4.4 THE NATURE OF THE WEIGHTS.............. 86

4.5 THE TIME HORIZON OF EXPECTATIONS............. 95

4.6 RESOLUTION OF ALTERNATE DEFINITIONS......... 97

4.6.1 Empirical Criteria.............. 97

4.6.2 Empirical Testing of Validation. 101

4.7 SWMMARY......................... 103

CHAPTER $V$ - METHODOLOGY..................... 105

5.1 OPERATIONAL CONSTRAINTS OF. THE ELICITATION OF INVESTOR EXPECTAMIONS.

5.2. STOCK SELECTION................... , 108

$5: 3$ INVESTOR SAMPIING................... 112

5.4 SUMMARIZING AN INVESTOR'S EXPECTATIONS...... " 113

5.4 .1 The Mean.................... 113

5.4.2 The Standare Deviation........... 119

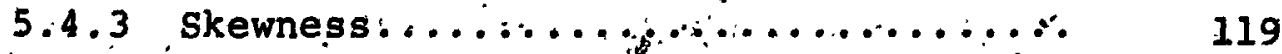

5.4 .4 Total Expected Return............. 121

5.4.5 The Standard Deviation of the Total Expected Return. 
5.5 SUMMARIZING THE. PARAMETERS OF INVESTOŔS' EXPECTATIONS ....................

$5 . \overline{6}$, STATISTICAL HYPOTHESES TESTS $\ldots \ldots \ldots \ldots \ldots \ldots$

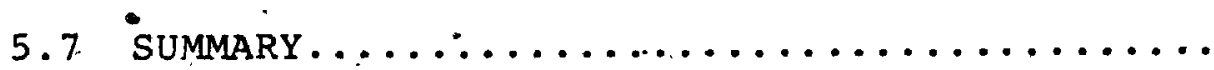

6.1 OVERVIEW OF MEASURFD EXPECTATIONS.........

6.1 .1 Response Types...............

6.1 .2 Relative Shape of Price and Dividend Expectations..................

6.1.3 Types of Investors Associated With The Three stocks................

6.1.4 Comparative Yields on Dther Invest-

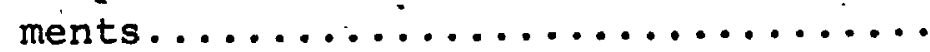

6.2 RESPONDENTS' TIME HORIZONS .............

6.2 .1 Time Horizon Comparisons..........

6.3 PRESENTATIONS OF MAJOR FINDINGS..........

6.4 PRICE EXPECTATIONS................

6.4.1 Inter-st Comparisons of Investors" Price Expectations...............

6.4.2 Intra-stock Comparisons of Investors' Price Expectations...............

6.4.3 Inter-Stock Comparisons of Investors' Price-Expectations with Control For. The Type of Investor and The Time Horizon.....................

6.4.4 Inter- and Intra-stock Comparisons Involving Security Analysts' Price Expectátions .................. 
6.4.5 Summary of Inter-and Intra-Stock

Comparisons of Price Expectations....

6.5

DIVIDEND EXPECTATIONS

181

6.5.1 Inter-stock Comparisons of Investors'

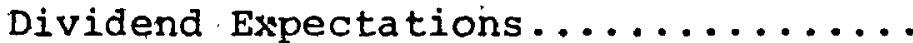

6.5.2. Intra-stock Comparisons of Investors Dividend Expectations............

$6.5 .3^{\circ}$ Inter-stock Comparisons of Investors' Dividend Expectations with Control for The Type of Investor and The

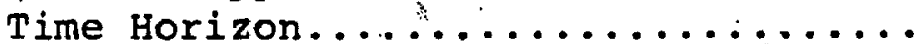

6.5.4 Inter- and Intra-Comparisons Involving Security Analysts' Dividend Expectations.............

6.5.5 Sumary of Inter-and/Intra-stock Comparisons of Dividend Expectations.

6.6 TOTAL RETURN EXPECTATIONS.............

6.6.1. Inter-stock. Comparisons of Investors' Total Return Expectations.............

6.6.2 Intra-stock Comparisons of Irivestors'

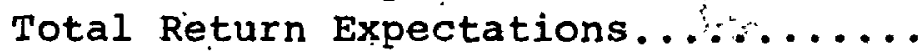

6.6.3 Inter-Stock Comparison of Investors' Total Return Expectations with Control for the Type of Investor and The Time Horizon.

6.6.4 Inter- and Intra-stock Comparisons Involving Security Analysts' Total Return Expectations..............

6.6.5 Summary of Inter- and Intra-Stock Comparisons of Total Return

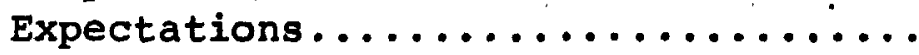

6.7 SUMMARY OF MAJOR FINDINGS $\ldots \ldots \ldots \ldots \ldots \ldots$ 
6.7 .1 Inter-Stock Findings.........., 222

6.7.2 Intra-Stock Findings........... 223.

CHAPTER - VIII SUMMARY AND CONCLUSIONS..........., 224

7.1 EIMITATIONS OF THE RESEARCH DESIGN......... 224

7.2 SUMMARY OF MAJOR FINDINGS............ 226

7.2.1 Inter-stock Findings............ 226

7.2.2 Intra-stock Findings............. 227

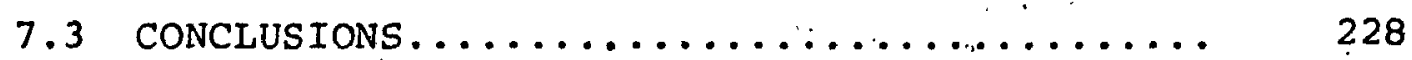

7.3.1 Inter-stoct Conclusions.......... 228

7.3.2 Intra-Stock Conclusions.......... 230

7.4. Implications $\ldots \ldots \ldots \ldots \ldots \ldots \ldots \ldots \ldots \ldots \ldots \ldots \ldots$

7.4.1 Financial Theory and Research....... 231

7.4 .2 Corporate Finance............. 235

7.4 .3 The Investment Industry................... 238

7.5 RECOMMENDATIONS FOR FURTHER RESEARCH....... 239

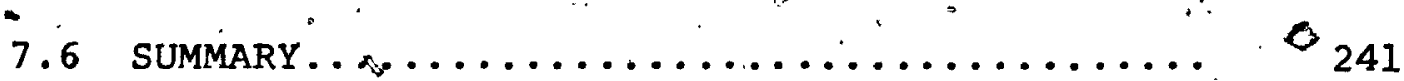

BİBLIOGRAPHY $\ldots \ldots \ldots \ldots \ldots \ldots \ldots \ldots \ldots \ldots \ldots \ldots \ldots \ldots \ldots \ldots \ldots \ldots \ldots$

APPENPIX I. MEASURING INVESTOR EXPECTATIONS $\ldots \ldots \ldots \cdot \cdot 248$

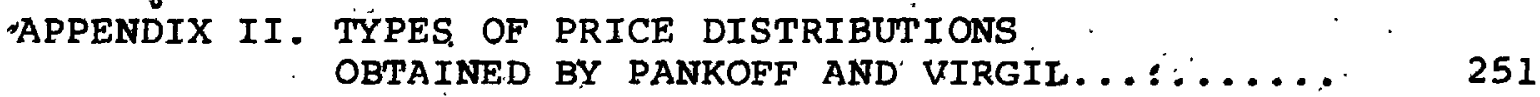

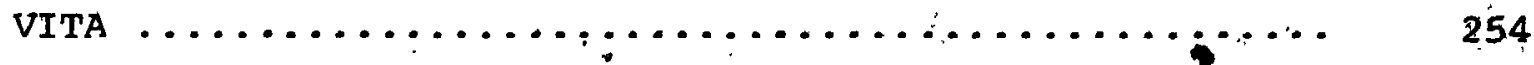

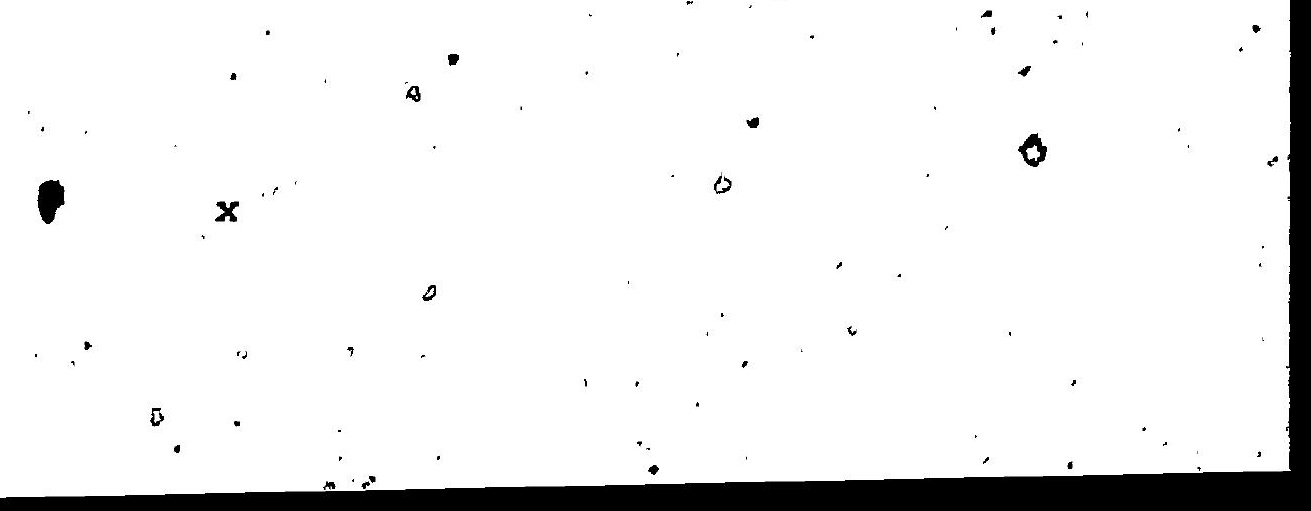




\section{I S T O F T A B L E S}

Table

Déscription:

Page

5.1 Stoçk Movement Stetistics

5.2

An Example of Summarizing a Measured

Expectiation

$6.1^{\circ}:$ Types of Responses to Expectation Questions

6:2 Types of Responses to. Expectation Questiøns: 'Pankoff and Virgil study

6.3 Relative Uncertainty of Price and - Dividèna Expectations?

Relative Downward Deviaitions (Cumu - "

6.4 lative Probability) From (Fhe Current Price and Dividend Levels

6,7 , size of common stóck Portfolio

$6.8 \quad \because$ Reasons for Purchase or Ownership

6.10 Sex of Respondents

6.11 Sumarý of Yíelds on "various Investments."

During. The Time of the study

6.12 Respondents' Time Horizons

6.13 "Comparisons of Market Participants "Time Horizons

6.14\% Inter-stock Comparisons of Summarized Investor Price Expectations . 
Inter-stock Comparisons of Summarized Investor Dividend.Expectations By Type of Investor: One- and Two-Year Horizons

Inter-Stock Comparisons of Summarized Investor Rividend Expectations BY Type of Investor: Ĺonger Than Two-Year Horizons

Inter-stock comparisons of Summarized Security Analysts' Dividend Expectations.

6.31 Comparisons of Analysts' and Investors' Summarized Dividend Expectations

6.32 Inter-stock Comparisons of Summarized Investor Total Return Expectations

Intra-stock comparisons of summarized Investor Total Return Expectations?

Intra-stock comparisons of summarized Investor Total Return Expectations: One

and Two-Year Horizons

Intra-stock comparisons of Summarized Investor Total Return Expectations: Longer Than Two-Year Horizons

Inter-stock comparisons of summarized Investor Total Return Expectations By. Type of Investor

Inter-Stock comparisons of summarized Investor 'Total' Return Expectations By Type of Investor: One- and Two-Year Horizons

Inter-stock comparisons of Summarized Investor Total. Return Expectations BY Type of Investor: Longer Than Two-Year Hor izons 


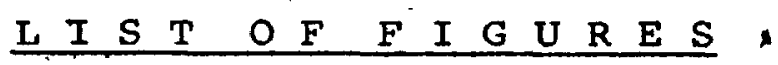

Figure

3.1

3.2

3.3

3.4
Description

The Risk-Return Trade-Off Function The Two-parameter Efficient Frontier The Portfolio Selection Model Graphical Representation of Differences in the Magnitude of Intra-stock Return Expectation gs

6.1. Types of Expectation Responses

6.2 Average Risk and Return of Price Expectations

6.3 Average Risk and Return of Pice Expectations by Type of Investor

6.4 Average Risk and Return of Total Return Expectations

6.5 Average Risk and Return of Total Return Expectations by Type of Investor
Page

42

46

47

59

130

159

166

204

210

$x i \dot{y}$ 
The author of this thesis has granted The University of Western Ontario a non-exclusive license to reproduce and distribute copies of this thesis to users of Western Libraries. Copyright remains with the author.

Electronic theses and dissertations available in The University of Western Ontario's institutional repository (Scholarship@Western) are solely for the purpose of private study and research. They may not be copied or reproduced, except as permitted by copyright laws, without written authority of the copyright owner. Any commercial use or publication is strictly prohibited.

The original copyright license attesting to these terms and signed by the author of this thesis may be found in the original print version of the thesis, held by Western Libraries.

The thesis approval page signed by the examining committee may also be found in the original print version of the thesis held in Western Libraries.

Please contact Western Libraries for further information:

E-mail: libadmin@uwo.ca

Telephone: (519) 661-2111 Ext. 84796

Web site: http://www.lib.uwo.ca/ 


\section{CHAPTER I}

\section{INTRODUCTION}

This study investigates the nature of investiors' expectations of financial return from common stocks. The purpose of the research was to empiriçally investigate whether or not investor expectations are consistent with theoretical propositions-which underlie much of the theory of value. The study.focussed on an analysis of the price, dividend, and total return expectations of four types of, stock market participants - buyers, sellers, owners, and security analysts. - for three selected common stocks. These market participants provided price and dividend expectations for the selected stocks in térms of subjective probability distributions. Inter- and intra-stock comparisons of the parameters of these distributions were made to determine if the nature of investor expectations was consistent with that proposed in financial theory.

\section{$1.1^{\circ}$ EMPIRICAL PERSPECTIV́E}

The concept of investor expectations is central to the theory of capital asset valuation. The theory of asset valuation atitributes two generalized properties to a financial asset; its "lucrativity" and "risk". 1 .

${ }^{1} \mathrm{~J}$. Marschak, "Money and the Theory of Assets," Econometrica, 6, (October, 1938), p. 311 . 
For a particular asset these properties are "a function of investor expectations about the underlying real or financial flows . . associated with a particular instru- . ment". ${ }^{2}$ In the case of equity investments van Horne ${ }^{3}$ and other authors bave modeled an investor's future financial return expectations as involving a set of multi-outcome, probabilistic, future cash flows that might accrue to the investor as the result of capital appreciation (realized or unrealized) and dividend income.

In empirical valuation studies investors' financial return expectations are traditionaily represented by proxies that have been developed from published financial data. Keenan has very clearly summarized the shortcomings of this approach to obtaining measures of investors' expectations and in particular has concluded

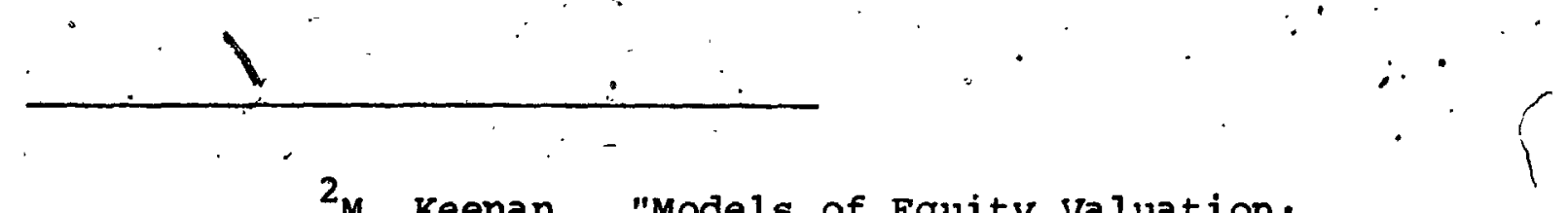
The Great Serm Bubble" The Journal of Finance, (May 1970), p. 259:

- ${ }^{3}$ J.C. Van Horne, Financial Management and Policy, 2nd ed. (Englewood Cliffs: Prentice-Ha1l, 


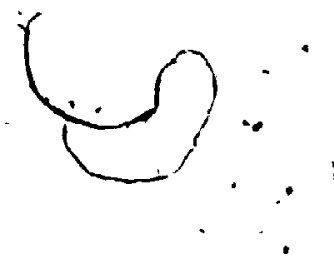

If measure variables of investor expectations are to be developed we may have to engage in survey sampling of transactors. Although there has been some classroom experimentation on economic perception; decoding of data masses, and wealth directed decision making, there has been relatively little field work done. It does not seem likely that in this uncertainty situation we will be able to sharply specify investor expectations without having some data inputs from investors. 4

. Robichek has indicated a similar concern for empirical investigations of the valuation process.

A common impediment to researchers is the disparity, between the theory of valuation and practice. Theoretical models may or may not be appropriate representatives of real life... we must attempt to become more familiar with the manner in which investors approach the stock valuation problem in practice and then relate these approaches to theoretical models. ${ }^{5}$

More recently Friend has pointed to the need for data inputs

from investors to advance the development of the concept - of the cost of equity capital'

The-problem is to estimate the 'required rate of return on common equity since it is relatively easy to measure- the required rate for senior securities. Unfortunately we can have little confidence in the estimates of the required return. on equity or on total capital generated by these models since there is no ultimate check in the form of a figure known to be reasonably reliable at any point in time. To achieve any real progress in this area in the near-ter future, it seems to me to be necessary to survey a comprehensive sample. of investors to. deter/4ne the anticipated rates $\checkmark$ of return on individual stocks which. they buy,

4 Keénan, op. cit., p. 262

${ }^{5}$. Robichek, "Risk and the value of "securities", Journal of Financial and buantitative Analysis, (December; 1969), p: 531 . 
sell or otherwise follow. Currently a.high proportion of the manajers of large investment portfolias regularly make suçh estimațes

in their decision raking process. It is of course the ex ante required rates of -return rather. than the ex post realized rates which are relevant 6 the measurement of the cost of capital. 6 ...

Thus Keenan, Robichek, and Friend have indicated the need to

obtain data inputs from investors in order to strongly specify investors' expectations in terms of the range of variables employed in the valuation process and the actual measurement of those variables.

1.2

RESEARCH OBJECTI!E

The objective of this research is to investigate the nature of investor expectations of financial return through the use of data inputs provided by individuals who buy, se11, or otherwise follow, (owners, analysts) seledted common stocks. The scope of this'investigation centers on the ability of the parametric representation of investor expectations ţo distinguish among various stocks.

". In essence, the scope of this study involves an investigation of the risk-return properties of selected stocks as reflected in the magnitude and shape characteristics of investors" expectations regarding the future price and annual dividends of these stocks.

6rwin Ftiend, "Mythodology in Finance", The Journa 1 of Finance, (May,' 1973), p. 270 . 
Three research questions are embodied in the H: scope of this study.

(a) Do investors expect a higher rate of return from higer-risk stocks in relation to the return expected from relatively low-risk stocks?

(b) Do the risk-return characteristics of investor expectations for a stock differ according to whether the investor is a buyer. seller, or owner of the stock?

(c) Are the expectations of investors, who are associated with a particular stock, consistent with the proposition that all pủblicly availabie information is fully reflected in the market price of that stock?

The foregoing rèsearch objective involves interand intra-stock comparisons of investiors' expectations of financial return: as a pxerequisite. to these comparisons the financial return expectations of investors must be measured. Thiree methodological approaches to the. measurement of expectations are general ly recognized.

(a) one can assume "that expectations are based in a particular way on what has happened in the past; for instace, expected risk might be assumed to be some function 
of historical risk defined in a particular way .... This method is open to the objection that thère is no way to check these assumptions".

(b) one could "deducépeople's expectations and. preferences from their actual decisions on the assumption that they act rationally in accordance with their beliefs and preferences. The trouble with this... method is that it is usually impossible to separate the effects of their expectations. from their preferences". 8 Additionally.. this presumes observation of individuals in a choice situation which effectively restricts the methodology to experimental situations.

(c) One could" usé the "direct approach, and... seek information from investors themselves by

7c.M. Sprenkle, "Warrant Prices as Indicators of Expectations and, Preferences" in R.H. Cootner, ed.. The Random Character of stock Market Prices, (M.I.T. Press, 1964), P. 413 .

8, cit. 
means of interviews; questionnaires and the like". 9

The research methodology adopted in this study was direct measurement of expectations by means of a maili questionnaire. Given the research objective, the above methodology for obtaining investors' expectations leads to three primary operational" considerations; the operational definition of

- financial return expectations, the sampling fräre of investors to be surveyed, and the selection of stocks for inclusion in this study. Each of these considerations is discussed.in the following subsections.

1.3 .1 The Operational Definition of Expectations An operational definition of an expectation must identify the subject(s) of the expectation and describe the content (uncertain conssequences) of the expectation. In the case of common stocks, the subjects of financial return expectations are clearly future price change and dividend income. At question in an operational definition of expectations is the manner in which uncertain conseguences are described. 10

In this study, three pqssible representations. of uncertain consequences tere pretested on a sample of investors. As a result of this test uncertain conséguences - in price and divideñd expectations were defined as interval${ }^{9}$ J.W. Ange11, "Uncertainty, Likelihoodsi and Investment Decisions, "The Quarterly Journal of Economics, (February, 1960); p.3.

10 K.J. Arrow, "Alternative Approaches To The Theory of Choice in Risk Taking situations, "Econometrica, (May, 1951), 406. 
outcomes "qualified by a discrete (versus continuous) subjective probability assessment..

\section{$1.3 .2 \because \quad$ The Sampling Frame}

The sampling frame of investors selected for

this study was defined as including all owners of, and transactors (buyers and sellers) in a particular stock during a given peiriod of time. This population of investors was selected primarily because such investors $\infty$ uld reasonably be expected to hold expectations for a stock that they owned" or had recently traded. As Van Horne has noted:

$\therefore$ the demand schedule for the stock is determined by the values interested investors ascribe to it." we use the word "interested" rather than "all" investors because only a limited number of investors form judgements on a particular stock. An investor is able to follow only a portion of all stocks available in the market. For any. given stock, most

- investors in. the market simply have no judgements: consequently they cannot be - considered potential buyers. 11

Lintner makes an even more restrictive assessment regarding the 'following' of particular stocks. based on the fact that information is not instantaneously. and costlessly available to everyone. "Even major institutional investors with large staffs only attempt to "follow" two or three hundred stocks out of the many thousands available, and "small" investors aré entirely ignorant of

$$
{ }^{11} \text { Van Horne, op. cit., p. } 23
$$


all but a very small number of stocks". 12

Operationally, investors were identified as being buyers or sellers of particular stocks through the cooperation of sixteen investment dealers. Owners of the selected stocks were identified from the current shareholder lists of the selected companies. In addition to. this sampling of individual investors, a sample of security analysts who 'followed! the selected stocks was also surveyed.

$1.3: 3$ Stock Selection

To investigate the three research questions presented in section 1.2 common stocks selected for this study had to represent different, a priori risk situations. Furthermore, the stocks had to meet a number of criteria ${ }^{13}$ to avoid biasing responses. The most constraining criteria was that the stocks generate a sufficient number of trades fduring a relatively short period of time.

Three stocks were ultimately selected for this study; all were among the twenty most active stocks on the Toronto stock Exchange in 1972: one was a utility stock."

12 John Litner, "The Aggregation of Investors' Diverse Judgements and Preferences in Purely competitive Security Markets", Journal of Financial and Quantitative Analysis., (December, 1969): P. 398.

${ }^{13}$ These criteria are detailed in chapter $v$. 
(Stock $A$ ), one a mineral resource stock. (Stock $B$ ), and the third was a petroleum stock (stock C). 14

$$
\text { Data Analysis. }
$$

The expectations data gathered in this study consisted of a respondent-supplied time horion for the particular stock with which he was associated and, a distributional representation of his beliefs regarding poss-s ible price changes and changes in the stock's annual dividend-by the time of his horizon. Each of these price and dividend distributions were annualized to yield an average rate of change, expected in the price and annual dividend of the stock. Additionally the standard deviation and skewness of these distributions were computed. The internal rate of return implicit in a respondents' price and dividend distributions and an approximate variance of that return" were also computed.

To investigate the aindicated research questions these parameters of investors'price and dividend expectations were aggregated and compared on both an inter-stock and an intra-stock basis (as required by the research questions): Where applicable one- or two-tailed $t$ - tests were employed to investigate the significance of inter- and intra-stock

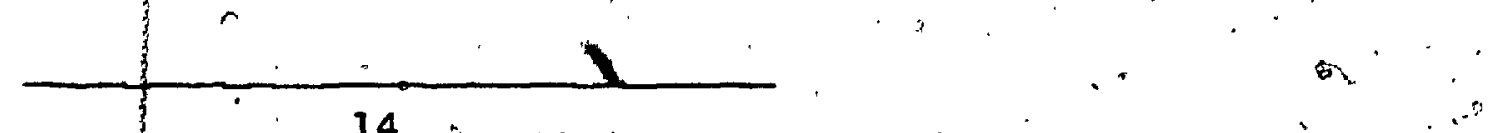

14 A condition of obtaining corporate cooperation in this study was that the participating companies would not be identified by name in any publication of the study's findings. 


\section{7 \\ differences in averages of expectation \\ parameters. $\because$}

This study was designed"-to provide insight into. answers to the research questions posed in section 1.2 . Essentially the findings of this study support the following conclusions.

(a) Investors do expect a higher return from higher risk st deks.

(b) The risk-return "characteristics of buyers", sellers', and owners' expectations do differ.

(c) The expectations of investors who are associated with a particular stock are not consistent with the proposition that all publicly available information is fully reflected in the maxket price of that stock.

However, these concluşions are subject to substantial qualification regarding their applicability to different types of return (price, dividend, and total return), to different expectation tim horizons, and to different parameters of return expectations, These qualifications are detadi of in chapter VII.

1.5 SUMMARY OF IMPLICATIONS

The results of this study have implications . . The results of this study for financial theory and research, corporate financial practices, and the investment dealer industry. 
In terms of its implication for financial theory this study has.supported theoretical representations of inyestor expectations employed in valuation theory. In terms of research methodology this study has indicated the feasibility of obtain ing ex ante data inputs from a crosssection of individual investions to investigate ex ante phenomena such as investor's" required rates of return and perceptions of risk.

The primary implication of this study for corporate financial practices stem frón the grantification of investors' expectations inlan objective "and consistent manner. 'specifically, this research indicates the feasibility of measuring a firm's cost of equity capital by direct measurement of the expectation's of individuals who buy, sell, or otherwise follow the firm"s stock. Such a determination of a firm's cost of equity capital is particularly reletant to regulated firms where considerable effort is expended to justify rate increases on the basis of a firm! cost of capital. The practical ardacademic support for the survey measuremẹt of a firm's cost of equity capital is detailed in chapter VII.

The implication of this study for the investment dealer industry jis based on the finding that individual tnvestors and security analysts dia not häve entirely consistent expectations for the same stocks. That is, there 18 eviaende that supports the proposition that the market- 
place'for these stocks was not efficient at the time of the study, , prices. did nat fully reflect all publicly available information). No evidence was available to indicate whether differences in information or in the transformation of information (or both) was the cause of differences in expectations. The causes of the indicated inefficiency should therefore be pnvestigated.

1.6 OUTLINE OF THE CONTENT OF THE STUDY

In Chapter II the construct of expectations is introduced and developed to provide a general context within which the specific notion of investor expectations will be discussed.

Chapter III draws on the ideas presented.in

Chapter II to develop the concept of investor expectations of financial return in the case of common stocks. In chapter III the areas of capital markets theóry encompassed in the research questions detailed in section 1.2 are developed and empirical hxpotheses presented to investigate: thes research questions:

Chapter IV addresses the issues involved in measuring investor expectations and the alternate ways of doing so. Thịs chapter is really a review of historic methodology, and theory regarding the measurement of expectations in an objective and consistent manner. 
Chapter $V$ involves a resolution of the alternate methods of measuring expectations and details the methodology employed in this study to answer the stated research questions.

In Chapter vi the results of investigating the nature of investors 'expectations are presented in terms. * of the empirical hypotheses specified in chapter III: chapter VII involves a summary of this study's. findings, the fonclusions that were drawn from these findings, and the implications of these conclusions for researchers, corporate managers and the investment industry. 
CHAPTER II

EXPECTATIONS PROPER

This chapter describes the content and nature of "expectations" in order to provide a framework of terms and ideas to be utilized in subsequent consideration of expectations in the context of the investment decision (Chapters III \& IV). This review of the literature pertaining to expectations involves:

(a) The recognition of expectations-as a nonobservable concept.

(b) The identification and description of those elements involvea in an expectation; namely. the individual, the evidence, and the set of perceived outcomes.

(c). The characterization of expectations gs continuous phenomena.

(d) The characterization of expectations as being interdependent.

\section{$2: 1 \quad$ EXPECTATIONS DEFINED}

A variety af definitions haive been put forward in the literature to capture the essence of the construct generally referred to as "expectations" " or "anticipations". Meredith has broadly defined expectations to be "propositions.. 
with a future reference" ${ }^{l}$ Katona considers expectations as those "attitudes that represent the extension of the time perspective" ${ }^{2}$ Georgescu-Roegen states that, "Expectation".. is the state of mind of a given individual with respect to an assertion, a coming event, or any other matter on which absolute knowledge does not necessarily exist". 3 shackle, defines expectations as "conceptions of outcomes looked on actossible": 4 Ozga defines expectations as "attitudes, dispositions, or states of mind which determine our behavior or at least accompany it" ${ }^{5}$ and Friend as. " a qualitative or quantitative attitude held by an economic unit with respect to the future value of any economic variable". 6 :

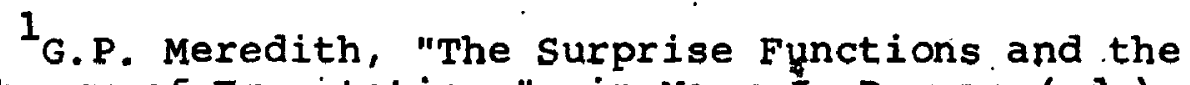
Epistemic Theory of Expectations", in Mary J. Bowman (ed.) Expectations, Uncertainty and Business Behavior, Social Science Research Council. (New. York, 1958), p. 7,4.

\section{${ }^{2}$ G. Katona, Psychological Analysis of Economic} Behavior ' (New York: McGraw-Hil1, 1951),p. 60 .

${ }^{3} \mathrm{~N}$. Georgescu-Roegen, "The Nature of Expectations and. Uncertainty", in. M.J. Bowman (ed.), Expectations, p. 12.

${ }^{4}$ G.L. Shackle, Decision, order and Time in Human

- Affairs (Cambridge University Press, 1961), p. 32 .

${ }^{5}$ S.A. Ozga, Expectations in Economic Theory, (London: Weidenfeld and Nicolson, 1965),p."23.

6. Friénd, "Critical Evaluation of surveys of Expectations, Plans and Investment Behavior," in M.J. Bowman (ed.), Expectations, p. 189. 
All of the foregoing definitions (and, others. found in the literature) identify. at least two attributes of expectations; namely, that they are' 'of the mind' (hence not directly observable) and pertain to the future. Being of the mind an expectation is an experience, that is, something that one may be able to identify by introspection as an expectation of rain, profits, etc. Thus, "expectations proper" 7 are to be distinguished from other ex anté data such as budgets," contracts, forecasts, plans, etc., which, while pertaining to the future, are not 'of the mind'. Rather, these data are of a definite form that can" be directly observed. 'Such data may be considered as formal representations of expectations only to the extent that they accurately reflect the forecaster's or planner's. attitudes about future events and, even then, only in situations free of the intention to deceive or conflicting attitudes on the part of the forecaster or planner.

of particular importance $j^{n}$ the foregoing definitions is the conceptualization by some authors of expectations as $j^{\text {attitudes' }}$ and by others as 'states of mind', 'conceptions', or 'hypothesés'. This distinction between these definitions is of fundamental importance in studying expectations per $\because \quad$ se versus expectations confounded with thotivation. 8

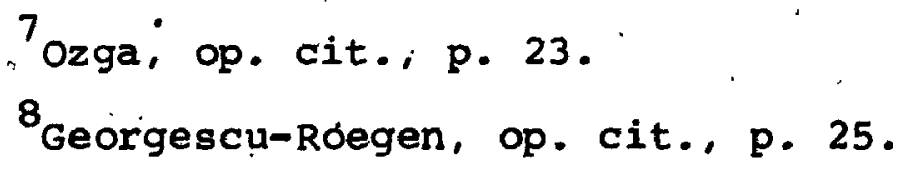


- The study of expectations, per, ser is the study

of the cognitive dimension of 'attitudes held by' or

'states of mind of' individuals about a particular subject.

In contrast, the combination of the affective and cognitive

dimensions of attitudes is intrinsic to the study of

choice among alternatives.

2,2

THE ELEMENTS OF AN EXPECTATION

An expectation is characterized as consisting

of three elements: the individual - the one who expects;

the evidence - what one knows; and the "próspect" - the individual's view of the future. 9 The prospect of expecta-

tion is the result of the interaction of the individual

and the evidence, and, is ultimately the subject of this study.

\subsubsection{The Individual}

Chambers has described 'the one who expects' as "a complex organism capable of perception; reflection, and action". 10 The first two of these processes are of particular importance to an understanding of the formation of expectations since they encompass the essential elements of cognition. As described by Chambers

${ }^{9}$ See̊: Georgescu-Roegen, óp.cit., and ozga, op. cit.

${ }^{10}$ R.J. Chambers, Accounting Finance and Management, (Syaney, 1969), p. 479. 
perception is the observing or sensing in any way of characteristics of the environment or of the organism itself. At any time the environment and the organism itself offer for perception an extensive array of things and events. As the sensory devices are limited, the span of attention is limited, so that at any time only some of the perceivable things are in fact perceived; only some become the focus of attention. 11

\section{In the process of perceiving oneself and the}

environment Gestalt psychology proposes the hypothesis that the individual perceives his environment as a 'whole' which gives meaning to its various elements rather than ds individual elements takẹ separately and combined into a 'whole'.12 if for example one were to look at a line-drawing of a man, one would not perceive every line in the drawing but răther a picture of a man; the addition or deletion of a number of lines to or from the drawing would be unlikely to affect one's perception of the man in the picture. Chambers, conceptualizes the process of reflection as follows

Reflection includes all mental operations, such as relation, comparison, recollection and calculation. Relation is the apprehension of connexions between things perceived including causal connexions. Comparison is reflection on the similarities or differences between things. Recollection is bringing to immediate conscious attention things that have been perceived in the past. Calculation is:the manipulation of qualities and quantities for the purpose of apprehending connexions, of making comparisons or contrasts.. The operations of relation and comparison give rise to arrangement, classification and systeliatization. The capacity for recollection of specific things and events varies inversely with the number of specific unreląted things perceived; and directly with the extent of reflection on and systematization of things perceived."13

$11_{\text {Loc. cit. }}$

$12 \mathrm{G}$. Katona, The Mass consumption society (New

York, McGraw Hill, 1964) 
Thus, individuals are viewed as having "the power to sense-their own condition and the impact of it on its environment, - . the power to discriminate, to learn, and to reason, : . But all of these powersoare limited even in the case of persons who are unimpaired, by unusual . . psychological deficiencies." 14 For example, one of the more important constraints on the affluent individual is time, "which, when applied to investing, would tend to restrict the amount of reflection.

\subsubsection{The Evidence}

The evidence involved in the formation of an expectation has been defined.as "all knowledge of the ,individual at the time"; ${ }^{15}$ and more narrowly as "a set of statements which provide explicit answers to factual questions abeut conditions that give rise to the prospect". 16 While ozga intends the latter definition as an 'operational definition', the former is'not capable of operationalization since it would appear to be impossible to ever obtain an. unbiased list of all knowledge that an individual calls on in any particular situation.

The breadth, of each of the two definitions, however, highlights the multivariate nature of knowledge ... where knowledge is defined, to include:

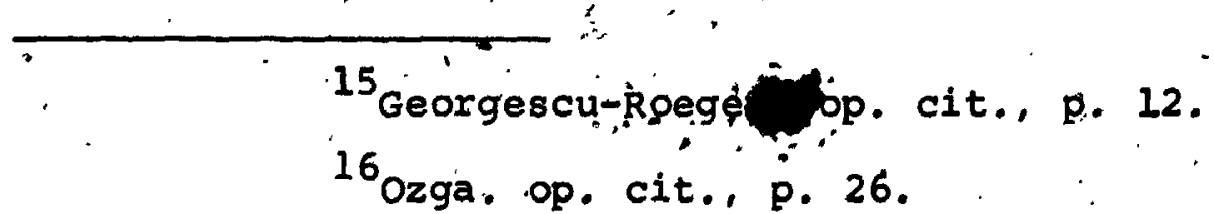


"knowledge of the properties and laws of material objects and event $\$$, and the characteristics of
human ingenuity".

"knowledge of the consequences. of past action, not simply of past experience, but on the extent to which past.experience has been the subject of reflection for the purpose of discerning cause and effect relationships": 18

"knowledge held by an individual about his own affairs - or of conditions about him!".

"opinions that are known or may eventually prove to be wrong.". 20

Thus defined, knowledge includes both fàctual

and relational 'information' (e.g. generalizations) about the environment (and events therein) and the fndividual. since "knowledge" is viewed as the "prefrequisite to intelingent anticipation: 21 exclusion" of one type of knowledg $\$$ from consideration in an operational definition does not eliminate the influence of such information on the formation of expectations.

\section{Relational information or generalizations are}

hypothesized relations or connections between possible events, at least one of which pertains ta the future. The characteristic of this type of information that ibibits its formalization in the evidence is that generalizations or relations result from an inductive, process and are therefore never known in an absolute-sense. Thus they are necessarily the subject of reservations about the degree to which a

${ }^{17}$ Meredith, op. cit., p. 80 .

18 R.V. Chamber, Accounting Finance and Management, (Sydney; 1969), p. 487.

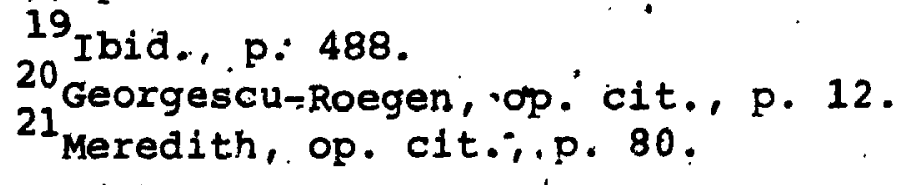


a generalization "is acceptaple as a basis for prediction of. instances of events to which it refers". 22 In fact these reservations are a major source of 'uncertainty' about the future and, as will be indicated, are manifested in the nature of the events expected. The term 'incertainty' as used in this study is defined as "a state of mind involving a feeling of incomplete knowledge or cantral of conditions relevant to decision making". 23, 24

The above definitions and description of the evidence indicates the scope of information that may be brought to bear on the formation of any particular view of the future. In addition to the uncertainţy generated by reservations held about generalizations, uncertainty also results from the recognition that even factual knowledge is never known in an absolute sense. That is, using Ozga's terms, "we do not know exactly what ques,tions to ask. . It is impossible to say once and for all, which questions are relevant". 25

22 ozga, op. cit., p. 29.

23 W.E. Henry, "Personality Factors in Managerial Reaction to Uncertainty". in M.J. Bowman, Expectations, p. 90.

${ }^{24}$ This subjective interpretation of uncertainty is to be distiruguished from both "pure risk" and "pure uncertainty" as defined" by Luce and Raiffa. Rather subjective uncertainty is some mixture of the two extreme types of situations and characterized by the influence of an individual's judgment being applied to the situation at hand. (Ozga, op. cit.. p. 58.)

$$
{ }^{25} \text { Ozga, op. cit.. p. } 3.1 \text {. }
$$




\subsubsection{The Prospect}

Thus far a perceiving and reflecting individual

has been postulated; the evidence has been characterized as being of virtually unlimited scope and subject toreservation. These two elements affecting an expectation are now hypothesized as interacting to produce an expectation. That is, an individual is viewed as transforming the evidence into a prospect by a process of inference whereby hypotheses are formed about the occurrence of future phenomena. 26,27 The prospect of an expectation regarding a particular subject (e.g. rain, profits, career, etc.) is. conceived as consisting of more than one possible view of the future occurrence or state of the subject (hereafter referred to as "outcomes"). Since individuals are presumed to have less than perfect knowledge of the future, it is further hypothesized that outcomes in the prospect are "never without reservation. - Thus to each outcome there is always attached a certain weight which qualifies it to a greater or smaller extent". 28 That is, an individual's feelings of uncertainty about the ultimate occurrence of any particular outcome are reflected in the weight he attaches to the outcome. shackle has conceptualized the equivalent of the prospect as a "bundie" of "mutually.

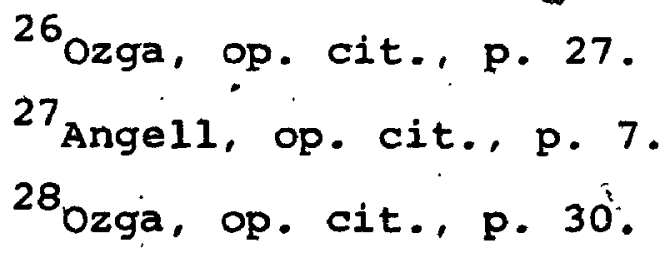


exclusive hypotheses, only, one of which, at most, can be true". 29 The nature and number of the outcomes in a prospect is determined by the nature of the subject and by the "dreative effort" 30 or "imagination" 31 of the individual, For example, an expectation about future profits from a-vepture might involve only three outcomes (i.e. some, none, or negative profits). Alternativeily, the particular individual hay conceive of various amounts of profit (e.g. $+\$ 10,+\$ 8,+\$ 0,-\$ 5,-\$ 15)$ rather than categorias. Imagination or creative effort is con-' strained however to "congruity with, what seems in some degree possible" 32 or to "confirmation" by the evidence. 33 Thus the process of inference whereby the individual transforms the evidence into the prospect, is viewed as being constrained by his perceptions of what is 'reasonable' to expect in the light of the evidence. ${ }^{34}$ Nothwithstanding a set of outcomes being considered as reasonable, some are conceivably perceived by the individual as being. more

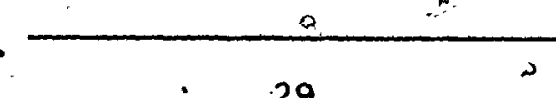

${ }^{29}$ G.L. Shackle, Economics of Pleasure, 2nd ed. (Cambridge University Press, 1968)! P. 121. . 30 ozga, op.cit., p. 51

$\Rightarrow{ }^{31}$ G.I. Shackle, Decision order and Time.

(Cambriage University press, 1961), p. 9.

$$
\begin{aligned}
& 32 \text { Ibid., p. } 11 \\
& 33 \text { ozga, op. 'cit. \& p. } 51 \text {. }
\end{aligned}
$$

${ }^{34}$ see a lo .Meredith's notion of the "pattern of evidence of rational likelihood". op. cit.." 80. 
congruous or confirmed by, the evidence than others. 35

The influence of an individual's perceptual

faculties on the range and degree of qualification of the outcomes indicated above is related to his perception and reflection on the less than absolute evidence that he brings to bear on the subject of the expectation. Fon' example: of two individuals presented with the same set of ${ }_{3}$ data and opinion deemed relevant to the particular subject, one might perceive the "whole' evidencé as being more or less 'favorable' than the other to future instances of the subject. Thus, the range of réasonable instances imagined would Iikely be different. Even however, in the face of an identical range of reasonable outcomes being perceived, it is unlikely that the two individuals would perceive any one outcome as meriting more or less congruity or confirmation, givent the evidence.

The foregoing example is reflective of the hypothesis that the outcomes; their qualifications, and the evidence (either factual or relational) are parts of the same whole that individuals perceive in the process of expecting: "To expect means to see that whole. And as

${ }^{35}$ E11sberg suggests that in problems of choice, under uncertainty, the individual feels mopesor less "ambiguous" about, the weights associated with his estimates of relative likelihoods of events because of the ambiguity of his information. This feeling of ambiguity is in the nature of "one's degree of "confidence', in an estimate of relative likelihoods". Daniel Ellsberg, "Risk, Ambiguity, and the Savage Axioms," Quarterly Journal of Economics, v. 83 (1969)! pp. 643-669. 

$\therefore$

wheeling flight of birds and you can see this extrapolation at work". 37 Henry's conception of man as an "expectant being" is analogous to Meredith's idea. 38 whille Meredith believes most of one's actions are regulated by "conscious", expectations he further proposes that "their continued existence is not conditional upon consciousness".) rather "they exist... . in some stored condition, available for evocation when relevant", such as. when "we attend to them". 39 Instances' requiring 'attending' to expectations include thosé involving changes therein.

Taking the "time of the expectation" as the point in time that an expectation is formed about the future situation or occurrence of a subject (e.g. weather) and the "time of the subject" as the time to which the expectation refers (e.g. tomorrow), expectations are viewed as undergoing more or less "adjustment" as the time of the expectation approaches the time of the subject. 40 ' Both the outcomes rationally imagined eariier and their associated qualifications may be altered as previously perceived evidence is augmented by new. information and/or changing perceptions of the whole evidence." In in investing framework Angell notes this phenogienon of changing expectations as-being akin to "the investor - . (wearing) glasses whose colour often seems to . alter, even in the absense of any substantial change in the

37 Meredith, op. cit., p. 75.

38 Henry, op. cit., p. 86 .

${ }^{39}$ Meredith, op. ctt., p. 77 .

${ }^{40}$ ozga, op. cit,' p. 41 
currently known 'objective facts'." 41

Thus while expectations about a particular subject may not always be in the conscious mode, they are presumably brought to this state for alterations as the situation demands or the individual chooses to do so. - In part, the length of time that a particular expectation is held (i.e. possible outcomes and weights remain the same) is a function of the "mechanism". generating

- the processes, and conditions; by which future events result. 42 For some types of future eventg the individual's behavior is part of the mechanism determining the occurrence of events (e.g. futuce income) 43 while for others ( $\dot{e} . g$. the weather) the individual's influence is non-existent 44 and the mechanism neither known nor meriting a stabillity assumption. Thus, the more unstable and resistant to individual influence, the shorter the time that expectations are likely to be held without alteration.

\begin{tabular}{ll}
\hline & $41_{\text {Angell, op. cit., p. 24. }}$ \\
& 42 ozga, op. cit., p. 35. \\
& 43 Expectations involving this type of mechanism
\end{tabular} are referred to as "internally oriented" expectations in that they involve the future course of action of the individual. himself. See: F. Modiglianni and $\mathrm{K}$. Cohen. "The Signiflonce and Use of Ex Ante Data", and R. Mack, "Business Expectations. and the Buying of Materials", in M.J. Bowman, Expectations, p. 151 and p. 106 respectively.

${ }^{44}$ Expectations involving this type of mechanism are referred to as "externally oriented" expectations in that they refer to the future course of action of subjetts beyond the direct influence of the individual. "See: Modiglianni and Cohen, op. cit., p. 153, and Mack, op. cit., p. 108. 
Additionally, the length of time that an expectation, orice formed, will be held is likely to be determined by the rather, practical constraint on the time and effort that an individual will allocate to reassessing the evidence, the outcomes and their weights. 45

In short, expectations, once formed, may be altered as the result of ehanging perceptions and reflections L. of the same or different evidence, the existence of an uncontrollable or non-stable underlying mechanism, and the cost in terms of time. and effort involved in adjusting expectations. : Between alterations to expeçtations they may be stored in a state of mind other than consciousness.

2.3 .2 Interdependence of Expectations "Thus far in individual has been characterized as holding only one expectation consisting of a set of outcomes and their ațtached weights. In reality, however, individuals hold expectations simultaneously about any number of stbjects sóne of which may be influenced by expéctations about others. For example, the outcomes in the prospect of an expectation about the profits one will receive from a venture will be influenced by expectations about the cost and revenues that, will be incurred. Expectations about costs and revenues will, in turn, be influenced by expectations about the availability of labour, competitive Investment Decisions," The Journal of Finance; (March,1971) p. 71 . 
actions, selling prices, etc.

The coexistence of 'intermediate' and 'terminal'

expectations raises the issue of the consistency of expectations atrany,point in time and over time.as well.4.

Consistency is an issue to the extent that individuals wish. to behave consistently in the light of their expectations of future gains. Therefore, if an individual were to consider investing in a particular venture with the anticipation of gain, he would presumably strive to the consistent in his expectations; otherwise the gain might not be forthcoming. For example, if he were to expect revenues from the venture to decrease and, costs to increase then it would be logically inconsistent to expect profits to increase: Hen the decision to participate in the venture in the expectation of gain would presumably be influenced by the consistency. of an investor's expectations.

2.4 SUMMARY

In this chapter, "expectations, proper", about a particular subject were described as being the result of an individual perceiving and reflecting upon evidence that bears on the future occurrence of instances of the subject. Expected outcomes are the result of a creative or

46 see: Ozga, op: cit., p. 40, and G.L. Shackle, Detision, order and Time in Human Affairs, Cambridge (University Press, 1961), Chapter.XXIV. 
imaginative effort constrained to some measure of reasonableness (e.g. congruity, confirmation). With every outcome is associated a qualification or weight reflecting the individual's subjective feelings of uncertainty about the ultimate occurrence of the particular outcome.

Furthermore, expectations were characterized as being of a continuous nature although subject to more or less frequent periodic changes. Different types of expectations were also proposed, one type being those terminal expectations that were in fact dependent on the so-called intermediate expectations. 
CHAPTER III

\section{INVESTOR EXPECTATIONS}

The concept of investor expectations is central to the theory of equity valuation. As noted earlier, Keenan, 1 Robichek ${ }^{2}$ and Friend ${ }^{3}$ have all'indicated the need to obtain data inputs from investors in order to strongly spēcify investors' expectations in terms of the range-of variables employed in the valuation process.

In this chapter the role of expectations in the valuation of common stocks will be discússed. Empirical hypotheses are presented that, will investigate the ạbility. of the parametric representation of investors' expectations to distinguish among various stocks. That is, these hypotheses will delineate the scope of an investigation of the ability of the parametric specification of investors' expectations to aistinguish stocks on the basis of their risk and return properties.

1

$1_{\text {Keenan, op. cit. }}$

${ }^{2}$ Robichek, op. cit. ${ }^{3}$ Friend, op. cit. 
Individuals who invest in stocks are viewed as holding expectations on two related subjects.

(a) Investors expect to be befter-off by making investments than by not making any investments. ${ }^{5}$. Smith has interpreted being "better-off" in the sense that investors "expect the future flow of satisfaction cor means of obtaining "expect the future flow of satisfaction for means of obtaining satisfaction) resulting from a decision to invest when appropriately discounted to the present, to exceed the satisfaction presently obtainable": "Where money is the means of acquiring goods and services capable of yielding satisfaction the inducerient to invest is, in general, the expectation of monetary gain. 6

(b) Investors expèct to invest in any particular security for a more or less specific period óf time. 7

\section{4 "Holding" in the sense of Meredith's continuous} expectations. (op. cit., p. 81).

\section{R.J. Chambers, Accounting Finance and Management} (Sydney, 1969), p. 600 .

${ }^{6}$.G.Smith, "Uncertainty, Information, and Investment Decisions," The Journal of Finance, (March, 1971), p. 69.

${ }^{7}$ G.L. Shackle, Decision, order and Time in Human Affairs, (Cambridge, 1961), p. 223. While the question of an individual's time horizon has not been addressed empirically, the time most conmonly mentioned in the literature appears to be about 3 to 5 years. H.M. Markowitz, portfolio Selection, (New York, 1959); B.G. Malkiel, "qquity Yields, Growth, and The Structure of Share Prices", American Economic Revlew, (Dec.., 1963). 
Shackle describes, a forward time horizon as "the most" disțant future date with which in some particular manner, the decision maker concerns himself". By implication, the individual ignores all future possible developments beyond this more or less definite date. Shackle's rationale for such a horizon is that it is imposed upon the imaginative creation of the future, by uncertainty which becomes more and more unbounded by considerations of what is possible, the more remote the date concerned. ${ }^{8}$ Thus, there may appear

$i$ to be nothing that does not appear to be possible at the time of the expectation if one looks far enough ahead. The above concept of a time horizon does not preclude the possibility of an"individual, at any particular Hme, expecting different possible outcomes for a subject of an expectation at more than one future date. Sauvain. has proposed that there is actuaily-"an element of both the short-term and the long-term in every esțimate of the future. . . The analyst who'is considering Dow Chemical common as a purchase for long-term holding is not likely to ignore prospective developments oxer the next year or so that would affect mäket price". 9

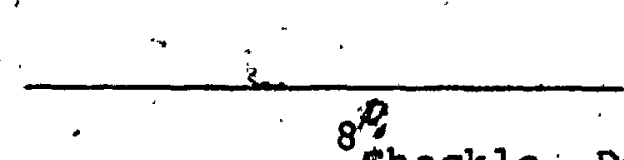

Shackle; Decision, op. cit., p. 223-224

9 H. Sauvain, "Investment Management, - 2 nd ed. (Englewood Cliffs, 1959) in R.G. Smith, Op.Cit. p. 70. 
$3 . \dot{2}$

\section{INVESTOR EXPECTATIONS AND VALUATION}

The notion of.expecting to be better-off financially by a more or less specific period of time is a fundamental proposition of the theory of equity valuation. Broadly stated, valuation theory attributes two generalized properties to a financial asset that determine its value: the asset.'s "lucrativity" (return) and its "risk". 10 For a given asset, these properties are a function of "expectations about the underlying real or financial flows:. . associated with a particular instrument. 11

This conceptualization of value and its dependence on expectations directly incorporates the notion of being better-off in the monetary sense via the financial return of án asset. The time dimension of the expectation is similarly represented by both the return and risk properties of the assets in. that risk and lucrativity are functions of the "flows" associated with the asset.

Since the practice of equity valuation is pursued by individuals, the risk and return properties . of an asset are a function of the expectations of individuals for the particular asset. For example, an asset can properly be said to have a certain ex ante ris.k property at a point in time only on the basis of an individual's (or group's) expectations for the financial flows that

\footnotetext{
${ }^{10}$ Marschak, op. 'ciț., p. 311 .

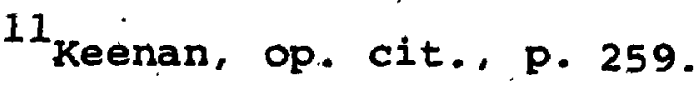


they associate with the particular equity. That is, whatever the properties that are ascribed to a common stocks, these properties exist only in the minds of individuals. 12

$3.2{ }^{1} \quad$ The parametric valuation Model ${ }^{13}$

Given this general valuation framework

the risk and return properties of an asset that give rise to its value have been operationally defined via the behaviorial assumption of expected utility maximization. 14 'For utility that is solely derived from wealth and monetary income a general utility function is defined for certain cash inflows received at time $j ; U\left(V_{j}\right)$. Although not expressed in an explicịt form, this function is assumed to have characteristics such that a Taylor series expansion of it will give the approximate value of litility at a particurlar value of $v_{j}$. If $E\left(v_{j}\right)$ - the expected inflow.which is a possible value that, the cash inflow can assume, is taken as the appropriate constant value of $\mathrm{v}_{j}$ in the Taylor series expansion then the approximate utility of this

$\infty$

12 Researchers in the area of equity valuation have developed proxies for investors' return expectations. These surrogates are generally based on published financial data and implicitly assume that in the long-run investors receive what they expect. See for example: F.D. Ardettir "Risk and the Requirea Return on Equity," Journal of Finance, (March 1967), p. 19 .

13. The following development of the specification of the parametric valuation model draws heavily on: $W . H$. Jean, The Analytical Theory of Finance,' (Holt 'Rinehart; and winston, 1970), Chapter 4.

${ }^{14}$ For an excellent presentation of the 'expected utility maximum' see: Markowitz, op. cit.r Chapter 10. 
inflow is given by Equation. (1).

(1)

$$
\begin{aligned}
& U\left(V_{j}\right)=U\left[E\left(V_{j}\right)\right]+U^{\prime}\left[E\left(V_{j}\right)\right] \quad\left[V_{j}-E\left(V_{j}\right)\right]
\end{aligned}
$$

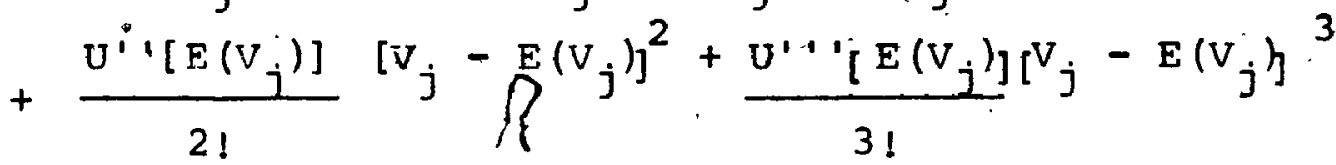

$$
\begin{aligned}
& \text { - },+ \text { terms with higher order } v_{j}-E\left(v_{j}\right) \text { components } \\
& \text { The expected value of the utility for an }
\end{aligned}
$$

uncertain cash flow can be obtained by taking the expected value of both sides of Equation (1) to yield:

$$
\begin{aligned}
& E U\left(v_{j}\right) \doteq U\left[E\left(v_{j}\right)\right], U^{\prime}\left[E\left(v_{j}\right)\right] E\left[V_{j}-E\left(V_{j}\right)\right] \\
& +\frac{U^{\prime} \cdot\left[E\left(v_{j}\right)\right]}{2 !} E\left[v_{j}-E\left(v_{j}\right)\right]^{2}+\frac{U \cdot \cdot\left[E\left(v_{j}\right)\right]}{3 !} E\left[v_{j}-E\left(v_{j}\right)\right]^{3} \text {. } \\
& \text { t. terms with higher, order } E\left(V_{j}-E V_{j}\right) \text { components } \\
& \text { - Interpreting the right-hand side of Equation }
\end{aligned}
$$

(2) indicates that the expected utility of an uncertain

cash flow is a function of the utility of the mean expected cash inflow $E\left(V_{j}\right)$, the second moment of the distribution of possible cash flows, $\left[v_{j}-F\left(v_{j}\right)\right]^{2}$, the third moment of the distribution of possible cash flows, $\left[V-E\left(V_{j}\right)\right]^{3}$, and higher order moments of the distribution. ${ }^{15}$ since the moments of a distribution of possible cash flows are unique to a particular distribution, a distribution of possible cash flows can be summarized in terms of these moments. The central tendency of the distribution can be summarized by the mean,.

${ }^{15}$ The second term of Equation (2) has no effect on the utility of the expected cash inflow since $E\left[V_{j}-E\left(V_{j}\right)\right]$ equals zero. Also the deriviative components of the terms in Equation (2) are constants. 
$E\left(V_{j}\right)$; the variability of possiblè outcomes around the mean" by the second moment (variance) of. the distribution, $\left[V_{j}-E\left(V_{j}\right)\right]^{2}$; the asymietry of possible outcomes (skewness/third moment) of the distribution, $\left[V_{j}-E\left(V_{j}\right)^{3}\right.$; and so forth...... Given that investors attempt to maximize their expected utility by investing in securities, the specific form of their utility function determines the number of moments of the distribution of possible cash inflows that are relevent to operationally defining the returp and risk properties of : a particular asset. For example, if risk averse investors are assumed to be concerned with only the magnitude and variability of expected returns then a second-degree polynomial would completely specify their utility of wealth function; that is, $U^{\prime \prime},\left(v_{j}\right)$ and higher derivatives would necessarily be zero. The same result is also obtained if it is assumed. that expected cash inflows are normally distributed. 17

A major objection to the specifiçation of a risk averse investor as having a quadratic utility function is that at some level of wealth the slope of the utility function

${ }^{16}$ For example, the fourth moment $\left[V_{j}-E\left(V_{j}\right)\right]^{4}$, is a measure of the "peakedness" of the distribution of possible returns and is alternately referred to as the kurtosis of the aistribution.

17 E.F. Fama, and.M.H. Millér, the Theory of Finance. (Holt Rinehart and Winston, 1972), p. 217 
becomes negative which violftes the assumption that marginal utility must always be positive. ${ }^{18}$ Thus, a quadratic utility function is at best an approximation to the true utility" function of a risk averter.

Accepting the assumption of a quadratic utili.ty function for risk averse investors results in the expected. utility of an investment being an increasing function of the magnitude of the expected return and a decreasing function of the variability of the return. The implication of this latter characteristic of exfeted utility is that for an asset to retain its appeal under conditions of increasping variability of return; the expected return term in Equation (2) would have to be greater by at least an off-setting amount. The increase in expected return necessary to rettin the attractiveness is defined as the risk premium for the investment. For a single security Ardetti 19 has defined this risk premium $\left(\theta_{j}\right)$ as a function of the variance $\sigma^{2}$ of the expected return:

$$
\dot{\theta}_{j} \approx \frac{\sigma^{2}}{2} \frac{\dot{U} \cdot(w)}{U^{\prime \prime !}(w)}
$$

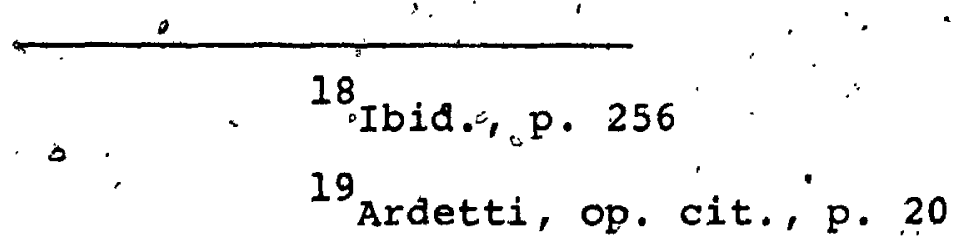


This representation of risk as the variability.

* per se about the expected value of a distribution of possible returns is open to criticism. van Horne states that "it is obvioús that the risk to an, irvestor is not dispersion per se but the possibility of downward deviation from the "expected.value of return". "van.Horne further notes that even the expected value is not necessarily the appropriate benchmark for all investiors or even some intvestors. -Rather, risk might be better described as the fractile of the probability, distribution below, for example, the market price of the stock at the time of the purchase. 21 . Machol and Lerner have propôsed that risk. in a chance-constrained problem might be better defined as the cumulative próbability of return" falling below some level of "ruin". 22,23

20 Van Horne; op. cit., p. 25; see also: F. Modigliani and G.A. Pague, "An Introduction to Risk and Return:* Concepts and Evidence", Financial Analysts Journal (March - April, 1974) pp. 70-73

21 van Horne, 1óc. cit.

22 R.E. Macho1, and E.M. Lerner, "Risk, Ruin and Investment Analysis," Journal of Financial, and Quantitative Analysis," (December; 1969), pp. 473-92.

${ }^{23}$ For other possible measure of risk, see: Markowitzi op. cit., and ozga, op. cit.: 
average, return than sellers. Conversely; for the same expected magnitude of future feturn, buyers are defined as being more optimistic if they expect les@ risk than seliers. 30

The preceding intra-stock hypotheses can bé extended to the question of the relative optimism of the expectations of owners of a particular stock by recognizing that for everystock there exists a population of market participants comprised of owners and non-owners. Within these two groups, the mpst optimistic individuals tend to become buyers of the stock while the least optimistic tend to become sellers (including short-sellers). In an efficient marketplace the set of expectations held by each of these two roups is based on the same information and hence, would be expected to ifvolve the same range of expectations. If such is the case, the most optimistic expectations for both groups should-be the same; similarly, the least optimistic expectations should be indistinguishable. Thus, aggregates of non-owner-buyers and owner-buyers would tend to have the

$\downarrow$ same range of expectations just as aggregates of non-ownernon-buyers and owner non-buyers would be expected to have the

30 As in the case of inter-stock comparisons of expectations, these intra-stock hypotheses focus on the element of the total risk premium that derives from the expected variability of return expectations. 
$4 ?$

FIGỤRE 3.1 $\Omega^{\circ}$

THE RISK-RETURN, TRADE-OFF FUNCTION

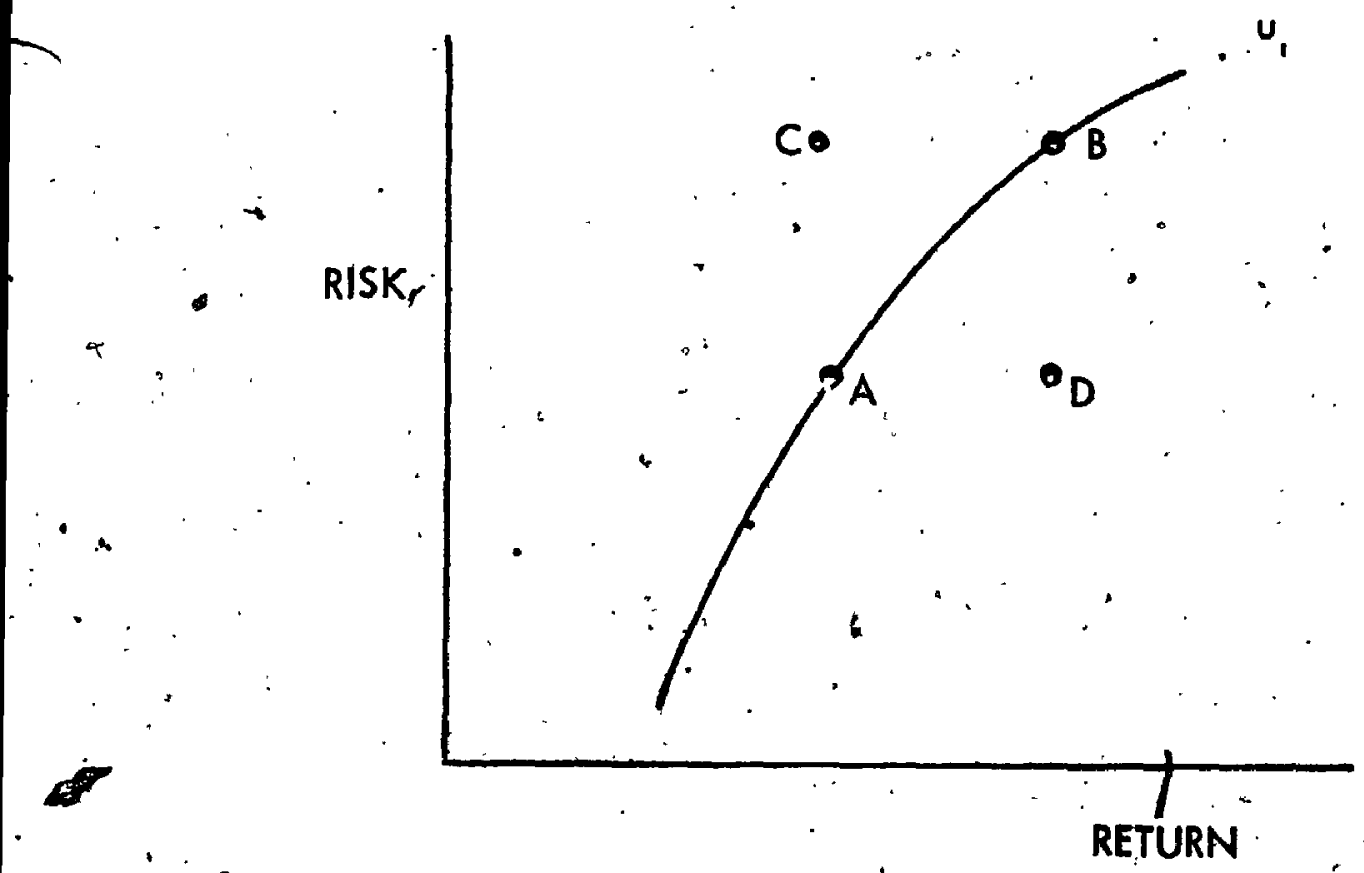

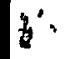


on $v_{1}$. since risk-averse investors prefer less risk to more risk for a given level of return, the risk-return combination represented by $c$ would be less desirable than that at $A$. Thus $C$ would be on a lower-utility indifference curve than A. Similarly for a given level of risk, investors prefer more return rather than less and therefore the riskreturn combination at $D$ would be preferred to that at $A$. combination $\mathrm{D}$ would therefore be in a higher-utility. indifference curve than $A$. The above representation of the risk-return trade-of made by investors in the market place implies that investors wili buy those securitief that offer the greatest return for a given level of risk or, alternatively. those securities that offer the lowest level of risk for a given return. Depending on the degree to which the investor is a isk averter, he will operate in a higher or lower risk-range of risk-return combinations available in the market place. Similarly, individuals will seli securities that are inconsistent with their preferences for risk, and return.

\section{2 .3}

\section{Portfolio considerations}

In the foregoing discussion of the implications of the parametric valuation model the implicit assumption was made that individuals invest in a particular security on 
the basis of the risk and return properties of the asset in isolation rather than as a contributing element to the risk and return of a portfolio of assets. It can be shown that depending on the covariation of returns in a portfolio of securities, the total risk (variability) of the portfolio of assets can be less than the sum of the variabilities of the constituent assets. 25 . The total return and variability of a two-security portfolio of assets are given by

$$
\text { - } E\left(v_{t}\right)=\sum_{i=1}^{2} \bar{w}_{i} v_{i}
$$

where

$$
\begin{aligned}
v_{t} & =\text { total return } \\
v_{i} & =\text { the return from the } i^{\text {th }} \text { security } \\
w_{i} & =\text { the proportion of a portfolio's value }
\end{aligned}
$$

(4) $\operatorname{var}\left(v_{t}\right)=\sum_{i=1}^{2} w_{i}^{2} \operatorname{var} v_{i}+2 w_{1} \cdot w_{2}{S D_{1}}^{2} S_{2} \cdot \operatorname{Cor}_{1,2}$ where

$$
\begin{aligned}
& \operatorname{var}\left(v_{t}\right)=\text { variance of the totai return } \ldots \\
& \operatorname{var}\left(v_{i}\right)=\underset{\text { variance of the return expected from }}{\text { the } i} \text { security } \\
& \text { SD } \quad \begin{array}{l}
\text { square root of } \operatorname{var}\left(\mathrm{V}_{\mathrm{f}}\right) \doteq \text { standard } \\
\text { deviation }
\end{array} \\
& \operatorname{Cor}_{1,2} \begin{aligned}
= & \text { correlation between the returns of } \\
& \text { securities } 1, \text { and } 2 \text {. }
\end{aligned}
\end{aligned}
$$

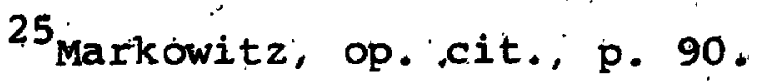


The risk-return possibilities of portfolios of securities (including single-security portfolios) in the stock market are represented in Figure 3.2 .

-Here the solid line represents those portfolios that are efficient in the sense of providing the highest level of return for a given level of risk and the lowest level of risk for a given level of return. portfolios to the right of the efficiency frontier are not possible because there is no set of $w_{i}$ values that will yield a portfolio with a rate of return and risk to the right of the efficient set of portfolios. portfolios to the left of the efficient set are infinite in number and can provide either aphigher level of risk for a given level of returm. - or a lower level of return for a given level of risk.

The preference features implicit in the concepts of an efficient fröntier of investments and indifference curves have been integrated to provide a normative model for investment behavior: Figure 3.3 depicts this integration. In Figure 3.3 the maximum-utility indifference. cyrves for a very risk-averse investor $A$, and a moderately risk-averse investor $B_{\text {ine }}$ shorr at their point of tangency : to the efficient frontier CD. The end-point limits of the efficlent frontier represent the risk-return potential from 
4.5

FIGURE 3.2

THE TWO-PARAMETER EFFICIENT FRONTIER

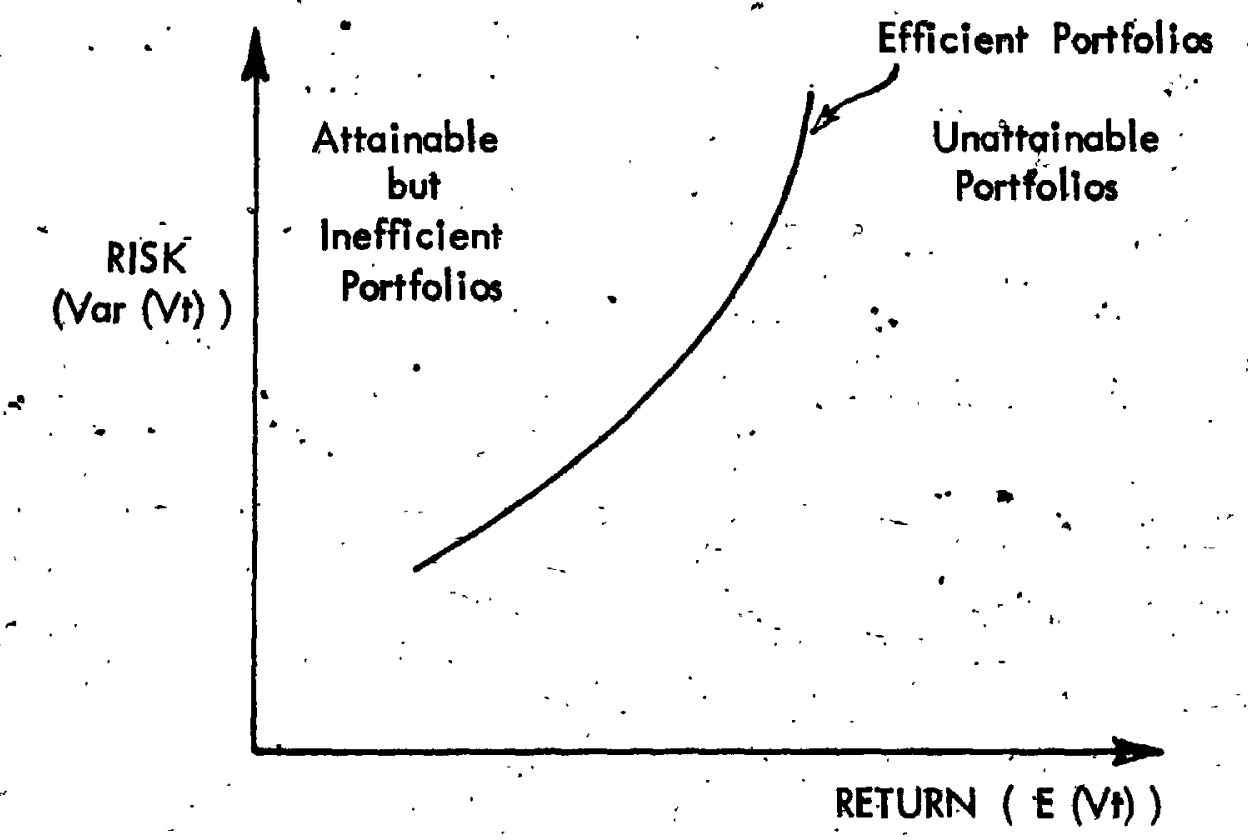


s FIGURE 3.3

\section{PORTFOLIO SELECTION MODEL}
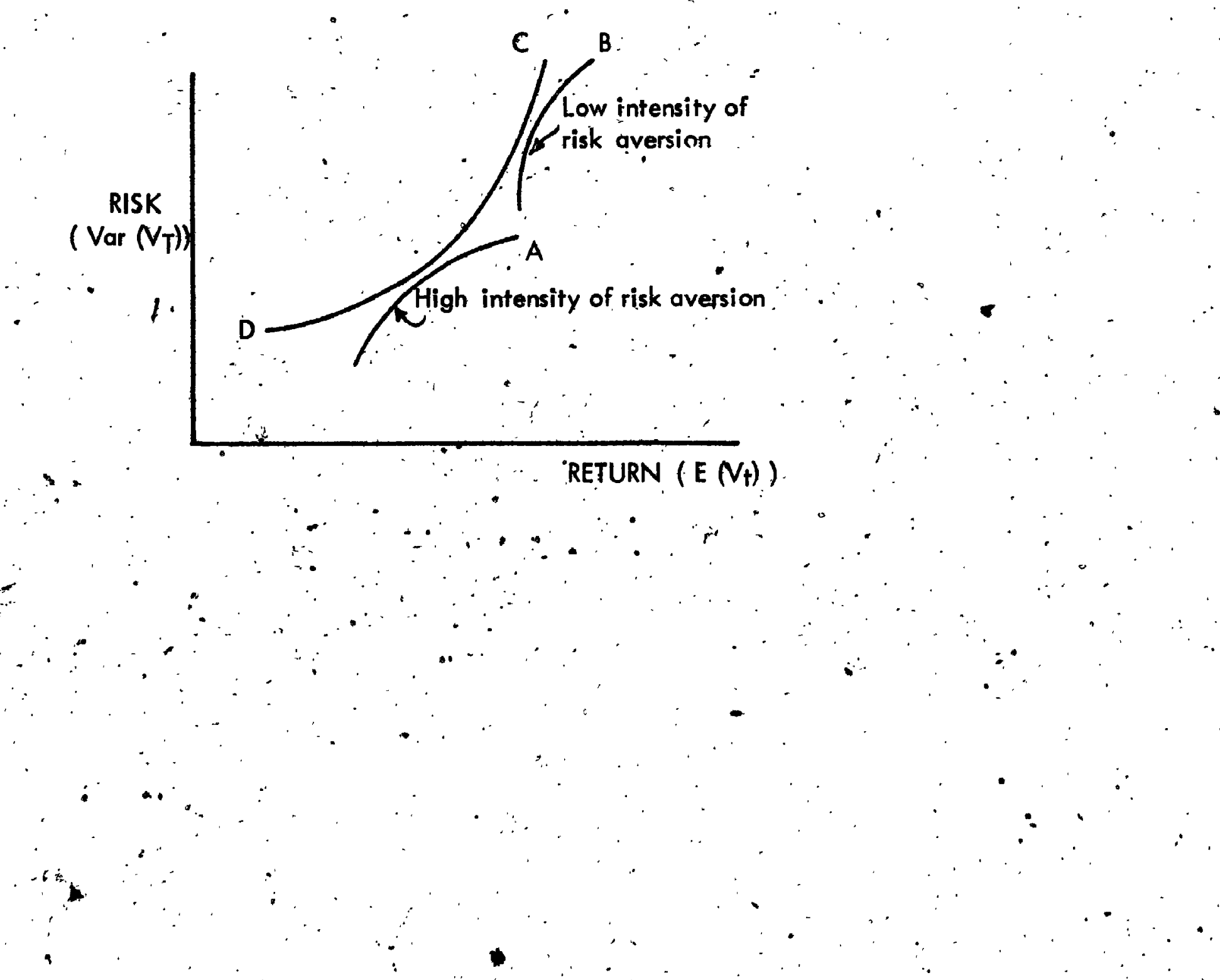
the least and most risky single-securityoportfolios available in the market place.

In interpreting the implications of the foregoing integration of investor preferences for risk and return and the Interaction with portfolio thoory" it should be noted that the operative variables are expected risk and expected returin rather than ex post variables. Thus, ex post, a definitive efficient frontier could be specified while ex ante any specification of an efficiency frontier is by definition subjective and therefore uniquely determined by the expector.

In the above context buying or selling a security is represented as making adjustments to. an individual's portfolio of securities in accordance with the contribution of a security to the total return of the portfolio and its overall variability. Both buyers and sellers would be moving to a new, and presumably higher, level of utility to either improve the return of their portfolio for a 'given level of risk, or, reduce the risk of the portfolio for a given level of return. It is widely held belief that, given the risk-reducing properties of a 'well' constructed. perfolio, the risk premium for an individual security does. not depend solely on the relative variability of the expected. return of the security; rather, the risk premium also. depends on the covariability of a particular security's 
return with an investor's overall portfolio. In this portfolio context the risk premium $\theta_{j}$, for security $j$ is defined by van Horne as

$$
\theta_{j}=\frac{R_{p}-i}{\sigma_{p}^{2}} \quad\left(r_{j p} \sigma_{j} \sigma_{p}\right)
$$

where $\mathrm{Rp}$ is the expected value of return for portfolio $p, i$ is the risk free rate, $\sigma_{p}{ }^{2}$ is the variance of the probability distribution of posisible returns for the portfolio and the term $\left(r_{j p} \sigma_{j}^{\sigma}, p\right)$ is the covariance of returns for security $j$ with those of the portfolio. 26

Adler hàs noted that the effective or total risk premium for a single security can be determined uniquely only if there exists but one portfolio: for all investors with known total returns and variance; to which it can belong. ${ }^{27}$

Alternatively the effective risk premium associated with a particular security as perceived by a particular investor can only be determined if the returns and variances of other

$$
{ }^{26} \text { Van Horne, op. cit. p. } 33
$$

27 Michael Adler; "On Risk-Acjusted Capitalization Rates and Valuation by Individuals," The Journal of Finance, (Sept., 19.70) 
securities in his portfolio are known. In the absence of this additional information regarding an individual's portfolio, the scope nf this study focuses on the parametric representation of an investors' expectations as if investors 1 were unaware of the implications of an individual security's covariability with his portfolio.

\section{$3.2 .4 \quad$ Summary}

The foregoing development of the two-parameter model and its integration in normative decision theory provides a description of how investors should make decisions

- regarding securities. In essence, this model indicates that in an uncertain world investors attempt to maximize their expected utility of wealth by selecting from among the available investment alternatives those investments that are expected to provide the highest expected utility given the constraints imposed by the extent of their risk aversion and the availability. of alternatives in the market place. The central proposal in this model is the recognition of the necessity to make risk-return trade-offs on the basis of the expected magnitude of the reture and variability of that return. 
As indicated earlier the objective of this

research is to investigate the consistency of investor expectations with theoretical propositions regarding the content, form, and behavior of these expectations. In the preceeding sections the general nature and the parametric representation of investor expectations was shown to. occupy a central position in the theory of asset valuation and choice. These theoretical phecepts imply a series. of propositions regarding the content, form, and behavior of investors' expectations for common stocks.

Empirical hypotheses to investigate these propositions arre discussed in the following paragraphs.

$3.3 \cdot 1$ Inter-stock Hypotheses

The primary hypothesis to be tested in this study is stated bélow.

Hypothesis 1.1

The magnitude of stock market participants' financial return expectations for a more risky stogk will. be greater than those for a less risky stock.

This hypothesis is derived directly from the foregoing valuation model and could be described as "the risk premium "hypothesis". That is, a risk premium in the form of expected return must be associated with stocks whose future. i return is expected to involve more variability than that from 
alternate securities. "This "hypothesis focuses on the element of the total risk premium that derives from the expected variability of return expectations.

A stronger statement of the above hypothesis

would require not only that the expected return be greater for higher risk but also that for a given risk-differential

between stocks, the expected return-differential would be more than proportionately greater.

Hypothesis 1.2

The magnitude of stock market participants'. ' financial return expectations for a more risky stock will be more than proportionately greater than those for a.; less risky stock.

The term "market participants." employed in the above" hypotheses is defined to embrace the population of individuals that have, or may reasonably be expected to have, expectations for the financial return that a particular stock might provide in the futyre. As indicated. in chapter $I$, this study involves the expectations of four types of market participants associated with a particular stook during a given period of time; namely, buyers, sellers, owners, and security analysts.

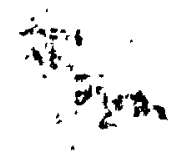


stock comparisons of the financial return expectations of aggregates and disaggregates of market participants associated with a particular stock. That is, the return expectations of all market partiqipants associated with stock $\mathrm{x}$ can be compared with the return'expectations of all market... participant associated" with stock $Y$; the return expectations of just buyers of stock ${ }^{n} \mathrm{x}$ can be compared with the return expectations of buyers of stock $Y ;$ and so oir.

The return expectations compared involve in turn: price expectations; dividend expectations and cotibined price and dividend expectations. The specific nature of the relevent."financial return expectätions." is discussed in Chapter IV. Similarily, the operationalization of the terms "magnitude" and "risk" is reserved for chapter $v$.

\subsubsection{Intra Stôck Hypolpeses}

Empiracil tests of the foregoing hypothesis based on the return expectations of a sample of market participants associated with a particulak stock would yield valid risk return rankings of the particular stocks only if there was 


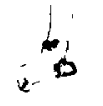

reașon to bielieve: (1) that all market participants.

associated with particular stock had identical return.

expectations for the stock; of; (2) that return expectations

were randomly distributed among participans. In this

latter case, the set of expectations represented by buyers

"would be indistinguishable from the set represented by"

sellers, owners, analysts or any other subsample of market

pärtcipants

since expectations of financial return are the

result of indiviguals perceiving and transforming evidence into a set of more or léss passible future outconjés, it "is" unreasonable to anticipate all market participants as having idéntical expectations for the return from a stock (chapter, II). In the absence of market participanț having identical.

expectátions, some participants will, by definition, have more "optímistic". expectations than others: îliliams has propose'd that participañts (in a sing.le-security. marketplace). having the most optimistic expectatians of future return will peld to be purchasers of the stock whize those having." the least optimistic expectations will tend to be sellers of the stock! 28

$28^{\mathrm{J}} \mathrm{B}$. Wili ass , The Theory of Investment Values (jifew York, A.M. Kellý, 1965). 
In a multiple-security marketplace williams' proposition would be expected to hold if: (1) the market is efficient in the sense that all publically available information about a stock is reflected in the expectations of market participants, (2) "the same set of investment alternatives is visible to ail subsets of market participants, ${ }^{29}$ and

(3) ail subşetgo of market partiĉ̀ipants associated with a particulair stock are similar with respect to financial resources, needs, and analytical abilities:

The relative optimism of buyers, sellers, and owners expectations can be empirically investigated by Intra-stock comparisons of their financial return expectations. The'primary intra-stock hypothèses are presented'below.

"The visibility assumption is necessary to distinguish between relative and absolute optimism in a multiple-security market. For example, an ifidividual with one set of investment alternatives may view a particular stock, $\cdot \mathrm{x}$, as providing relatively high return $\mathrm{vis} \mathbf{a}$ is the other stocks in his set. However, a second individual. if he has a different set of investment alternative returns that dominates the set of investment alternatives available to the fifst individual, might view stock $X$ as providing a relatively low return. Thus if different subsets of market participants, had different investment alternatives stuch as tho'se of the first and, second. individuals, seliers. could be indicated as having larger absolute expect tions for $\mathrm{x}$ than buyers. 


\section{$\sqrt{3}$}

Hypothesis 2.1

All other thing being equal, the magnitude of buyers' expectations of futupe financial return from a particular stock will be greater than that of sellers. Hypothesis 2.2

All other things being equal, the risk of the future financial return expected by buyers of a particular stock will be less than that of seliers.

The use of the qualifier "all other things being equal" refers specifically to the aforementioned market efficiency, stock visibility and investor-characteristic. assumptions. Additionally, the qualifier also includes the other parameters of investors' expectations not' explicitly involved in the particular. hypothesis.

As in the case of the inter stock hypotheses the return expectations compared involve, in turn: price expectations, dividend expectations; and combined price and dividend expectations: Additionally the specific nature of the relevent "financial return" expectations and the terms "magnitude" and "risk" are detailed in chapters: Iv and $v$ :

Given the earlier noted aversion to "risk: a two-parameter representation of expectations; and the necessity of investors to make risk-return trade-offs, buyers are defined as being more optimistic than sellers if, for the same lèvel of pércejved risk, buyers expect greater 
average, return than sellers. Conversely; for the same expected magnitude of future feturn, buyers are defined as being more optimistic if they expect les@ risk than seliers. 30

The preceding intra-stock hypotheses cạn bé extended to the question of the relative optimism of the expectations of owners of a particular stock by recognizing that for everystock there exists a population of market participants comprised of owners and non-owners. within these two groups, the most optimistic individuals "tend to become buyers of the stock while the least optimistic tend to become sellers (including shart-sellers). In an efficient marketplace the set of expectations held by each of these two Goups is based on the same information and hence, would be expected to ifivolve the same range of expectations. If such is the case, the most optimistic expectations for both groups should be the same; similarly, the least optimistic expectations should be indistinguishable. Thus, aggregates of non-owner-buyers and owner-buyers would tend to have the same range of expectations just as aggregates of non-ownernon-buyers and owner non-buyers would be expected to have the

30 As in the case of inter-stock comparisons of expectations, these intra-stock hypotheses focus on the element of the total risk premium that derives from the expected variability óf return expectations.

(a) 
same (and less optomistic) range of expectations. Hence, in the aggregate buyers' expectations are anticipated as being more optimistic than those of non-buyer, non-selling owners. However, the expectations of these non-transacting owners would be expected to be more optimistic than those of sellers: "othêrwise, these owners would become.séllers of the stock. These propositions are presented graphically in Figure' 3.4 .

As the result of the foregoing propositions, two additional intra-stock hypotheses are proposed.

Hypothesis 2.3

All other things being equal, the magritude of owners' expectations of future financial return will be greater than that of sellers but less than that of buyers. Hypothesis 2.4 .

All other things being equal, the risk of the future financial return expected by owners will be less than that of sellers but greater than that of buyers.

3.3 .3 Implications of Intra-Stock Hypotheses For The existence of confliciting expectations amorig market participants associated with any particular stock requires "that this influence be controlled for in inter-stock comparisons 
GRAPHICAL :REPRESENTATION OF DIFFERENCES IN THE MAGNITUDE OF INTRA-STOCK RETURN EXPECTATIONS.

d) Range of Owners' Expectations (aggregates:)

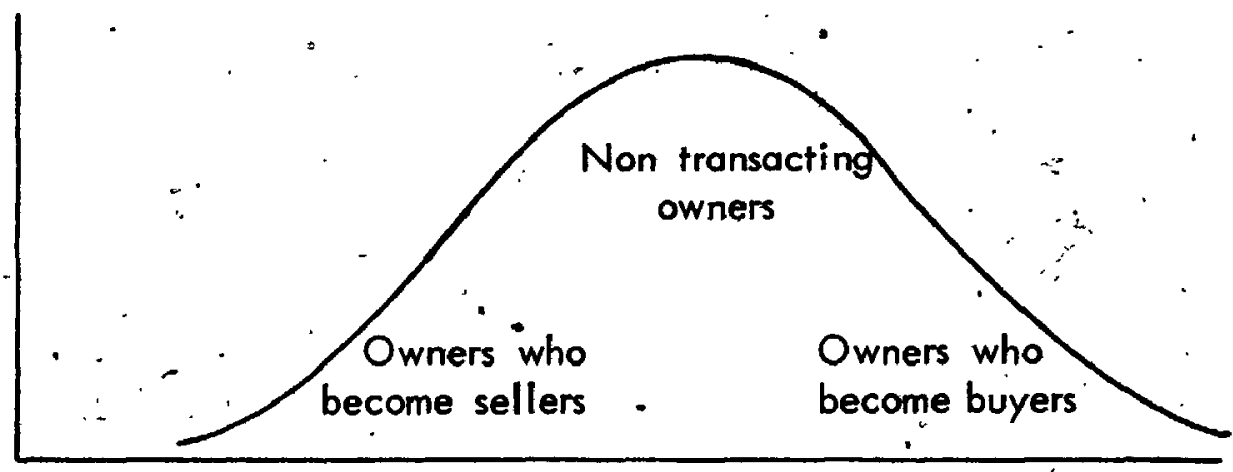

INCREAS̃ING EXPECTED VALUUE OF EXPECTATIONS

b) Range of Non-Owners! Expectations (aggregates )
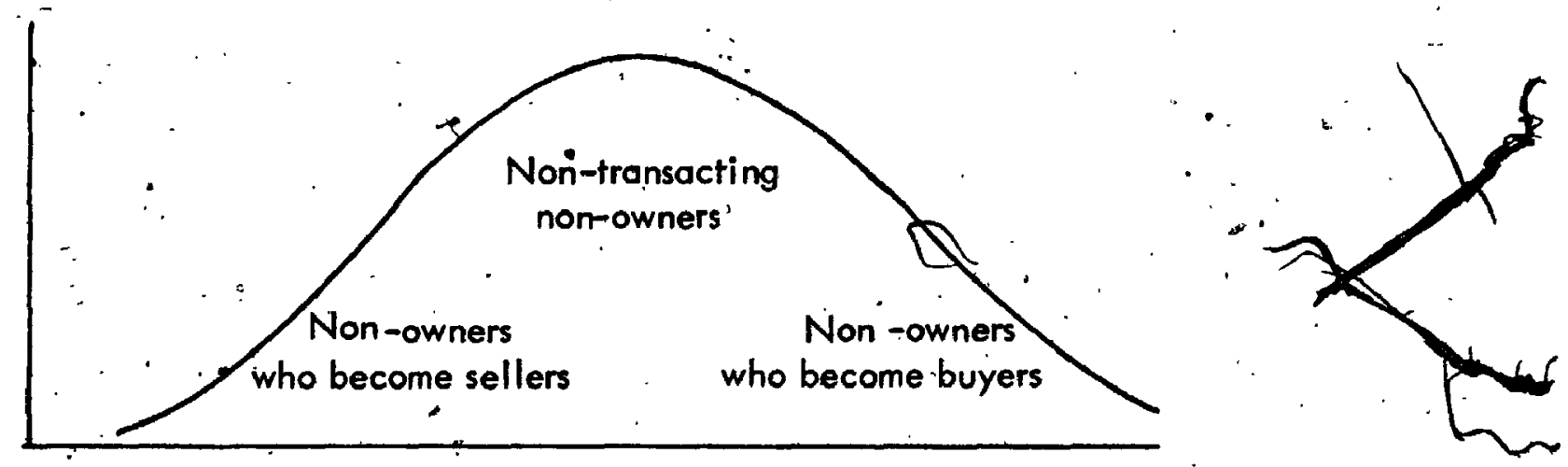

INCREASING EXPECTED VALUE OF EXPECTATIONS

c) Ranges of Buyers', Sellers', and Owners'Expectations :

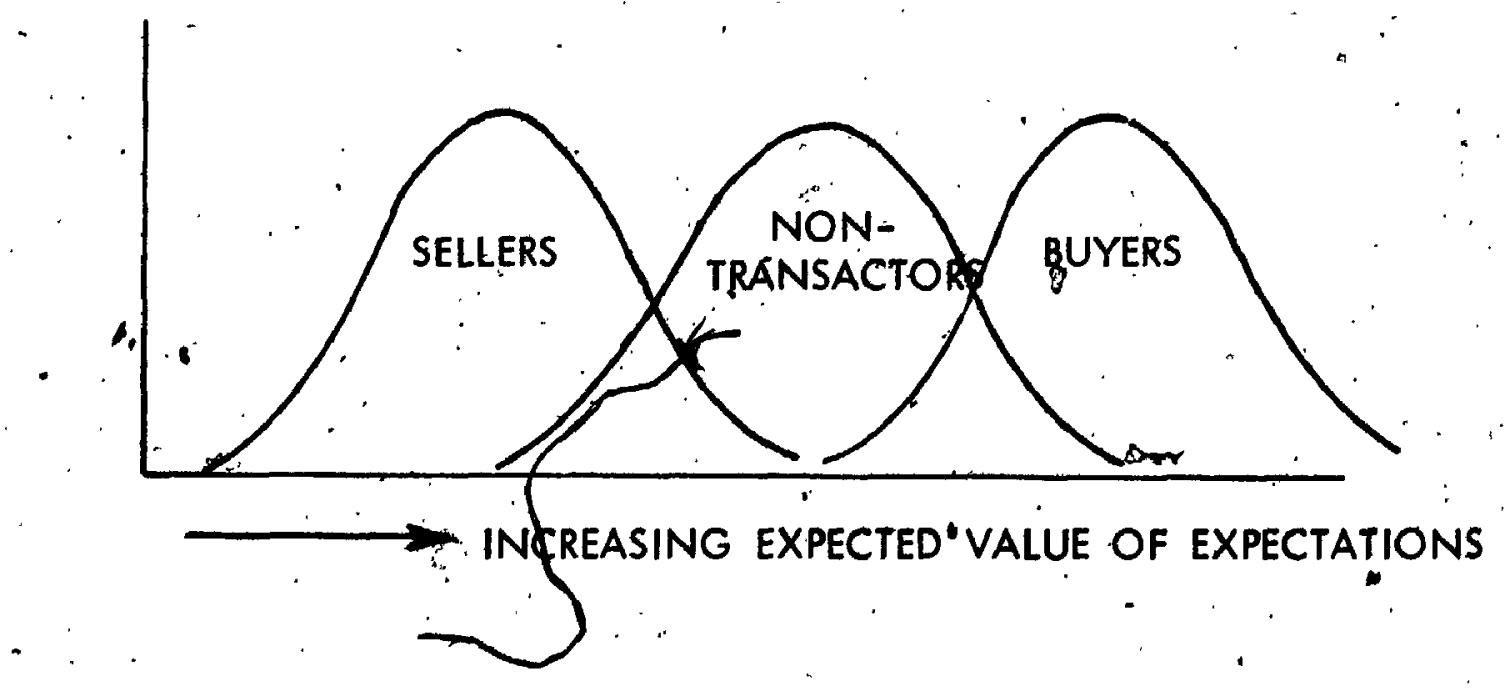


involving the expectations of aggregates of market partifipants associated with the particular stock. If this influence were not controlled for in empirical tests of the risk-return trade-offis associated with various stocks, thén a.preponderance of one type of market participant in the sample of market participants for a particular stock could influence the relative ranking of the stock. For example, if stock $x$ was in fact a riskier stock than $Y$ yet the sample of market participants associated with $x$ was comprised riainly of sellers of $\mathrm{X}$ while' the sample of market participants assoc- iated with $Y$ was comprised mainly of buyers of $Y$, the average expected return for stock $x$ could be indicated as being less than that expected for B due solely to sampling factors.

To control for unbalanced representation of various types of market participants in the aggregate sample of market participants associated with a particular stock, Hypotheses, 1.1 and $1: 2$ can be tested by type of market participant as well as for aggregatts of market participants: These comparisons would then involve the expectations of, for example, buyers of A versus buyers of $B$, buyerrs of $A$ versus buyers of $C$, and so oh. 


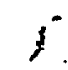

3.3 .4

Implications of Time Horizons For Inter- and Intra-stock Comparisons

In the preceeding section the need to control

inter-stock comparisons of expectations for the type of market participant was noted in response to possible - differences in expectations among the various classes of market participants. In this section the need to control both inter - and intra-stock comparisons for the time horizons of investors' expectations is noted:

Thus far, the discussion of investor expectations has centered on the shape of the distributions of expeated. returns. "Implicitly, it has been assumed that all market particlpants' expectafions for ahy and all stocks involve the same future period. That is, returns could be compared as either absolute dollar returns in the case of identically priced stocks or as percentage changes in, for example; market prices, in the case of dissimilar priced stocks. However, the introduction of the time dimension into the expectation requires that expectations be "notmalized" with respect to time.

The: need to incorporate the time dimension of the expectation is evident from a consideration of the impact of time on the magnitues of an investors expectation. If for example, an investor expected a $\$ 40$ stock to double in price 
over a period of 5 years while a second investor expected the same stpck to double in price over a one-year period, non-normalized expectations would indicate that the two investors were equally optimistic for the return from the stock. This resulf would however be misleading since the investor with the shorter horizon is patently more optimistic than the' -individual with the -longer time horizon. Annualizing the expected returns however would result in the shorter-term expectation being indicated as being more optimistic than the longer term, expectation: $100 \%$ per annum versus approximately $15 \%$ per annum.

However, annualizing expectations can also obscure differences in expectations. For example, if an individual expected a $\$ 40$ stołk to double in price in one year while a second individual expected the same stock to triple in price in two years, fie shorter term elpectation would be indicated as being more optimistic than the longer term expectation: $100 \%$ per annum versus approximately 758 per annum. * Results such as those indlcated in the above examples stem from the reinvestment-assumption implicit in comparisons of annualized rates of lasin over different time horizons; namely, that reinvestment occurs at the inalcated Internal rate of return. Thus, in the immediate example above, the ghort term investor 18 assumed to be 
able to reinvest principle and return from year-one at the marginal rate of $100 \%$ per annum either, in the stock in question or in some other investment vehicle. In effect, the reinvestment assumption broadens the scope of investigation to include not only thq expected return fram a particular stock in a given period of time but also the investor's future as well as present investment alternatives.

To abstract from these broader considerations, the reinvestment assumption can be controlled for by controlling comparisons of expectations on the basis of their time horizons. Thus both inter- and intra-stock comparisons of expectations enumerated earliér will be made on market participants whose expectations involve approximately the same future time' period.

$\circ$

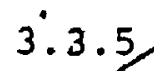

Investigation of the Market Efficiency Assumption

The foregoing presentation of the relative

optimism of buyers', owners' and sellers' expectations assumed

that differences in expectabions result from different interpretations of the same information rather than monopolistic access to specific information. Either or both of these conditions could result in more and less optimistic expectations for a particular stock: 


\section{The strong form of the efficient market}

hypothesis ${ }^{31}$ is concerned with whether all available information is fully reflected in the price of a stock in the sense that no individual has a higher expected return than others because he has monopolistic access to some information. The seimi strong-form efficiency of the marketplace for a particular stock can be investigated for aggregates of individuals by establishing a control group of market participants whose expectations for a stock could reasonably be expected to émbrace al1 publically available information pertaining to a stock as well as a "considered" interpretation of this information. A group of security analysts who "follow" a particular stock can be construed as having these characteristics. Comparing. the expectations of market participants associated with a particular stock with the expectations of security analysts for the same stock would indicate the extent to which individuals have different powers of interpretation and/or information. Knowledge of expectations alone cannot identify the specific

${ }^{31}$ The theory of efficient markets is concerhed with whether or not stock prices fully reflect avaibable information about a stock. at any point in time. The strong form of the efficient market model defines "available information" as all. available information, the semi-strong model as all publicall $\bar{y}$ available information, and the weak-form model as simply the set of historical'price sequences. See; E.F. Fama, "Efficient Capital Markets: A Review of Theory and Empirical Work," Journal of Finance (May 1970), pp. 383-423. 
cause of differences in expectations; however, the proposed comparisons would indicate the extent to which inconsistencies in the marketplace for a particular, stock do exist. "In a strong-form efficient market inconsistencies of the above nature would not be expected to exist.

Fama $32^{\circ}$ has conctuded that "corporate insiders and specialigts are the only two groups shose monopolistic acess. to information has been documented. There is no evidence that deviations from the strorig form of the efficient markets model permeate down any further through the investment community" . In view of this conclusion the nüll hypothesis is adopted in testing. for. inconsistencies between analysts' and individual investors' expectations for a particular stock. Hypothesis 3

\section{A.. Market participants' expectations of financial} return expectations for a particular stock are consistent with those of security analysts for the same stock. The above hypothesis is a further intra-stock comparison of expectations and similarly involves both the risk and return properties of expectations.

The rejection of the null hypothesis for analysts * and participants' expectations raises the issue of the specification of the risk-return trade-offs between various 
stocks via security analysts' expéctations. Inter-stock

Hypotheses 1,1 and $1,2^{\circ}$ test for trade-offs on the basis of

market participants' expectations lexcluding security

analysts). However, inefficiency in the market place in-

dicated by: rejection of Hypothesis 3 could lead to trade-

offs being indicated by analysts that are different from

those indicated by market participants. Whether or not differences

in market participante' and analysts" expectations are substan-

tial enough to result in a different ranking of stocks can

be investigated by inter-stock comparisons 'of analysts' expectations in addition to those indicated for Hypotheses $1 \cdot 1$ and 1.2

3.3.6 The Third Moment of Investor Expectations

" In the foregoing development of inter- and intrastock hypotheses regarding the nature of investor expectations. only, the first two moments of investors' expectations were' involved in these hypotheses. In effect, it has beep assumed

$\because$ thus far that return expectations, were narmally distributed or that investors had quadratic utility funcitions.

This assumption has been questioned by several authors and empirically investigated birdetti. Ardeti has argued that the risk premium demanded by an investor for f.33

Ardetti, op. cit., p. 19. Ardetti has argued that a wealthy man, would demand a higher price for a lottery ticket offering the chance of a $\$ 20,000$ gain or a $\$ 10,000$ los than, would a poor man. 
accepting increased risk is not independent of his wealth; rather, the risk premium is proposed as decreasing as wealth increases. Ardetti has postulated that the coefficient of the third moment term in Equation (2) must be positive rather. than zero.as implied by a quadratic utility function. - The resultant implication of this argument is that the utilit of an investment is increased by the presence of positive symmetry. (right skewness), in the aistịibution of possibie pay-offs and decreased by the presence of negative symmetry (left skewness $)$ Positive symmetry or right skewness çan be interpreted as indicating - the presence of a relatively lárge positive gain (in rela-" tion to the mean of the expectation) and limited negative" gain, (in relation to the mean) in the distribution of

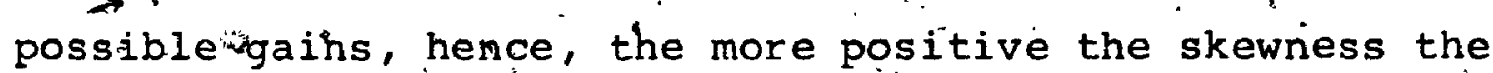

'. more optimistic the expectations. 1

"The incorporation of the third moment of the distribution of possible pay-offs in the expected utility of an investment "Eequires "that the earlier noted implication of a quadratic útility function be restated. Given ris? aversion and a decreasing, risk premium, in' relation to wealth', the expected return of an asset under conditions of increasing risk would have to incréasé by an offsetting, amount 
eąch alternative). For'a given mean and variance, preference is was evidenced for the positively skewed alternative over a neqatively skewed and a symmetric distributioh of possiole
returns. However, both the negatively skewed and smmetric distributions inciuded the possibility of a loss while the positively skewed altèrnátive did not. Recognizing this situation, Alderfer and Bierman developed two new, no-loss alternatives having virtually the same mean $(\$ 1.0$ and $\$ 0.995)$, slightly different variances $(\$ 0.5$ and $\$ 0.524$ respectively), but hàving very, different skewness 10.00 and 79.04 respec'tively). Aqain subjects' strongly preferred the high, skewness -alternative even in the face of slightly irrcieased risk. ${ }^{35}$ Thus? the third moment of the distribution of pay-offs $\therefore$ indicated as possibly being a relevant characteristic of the

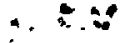
distribution.

$\because \cdots$

The relevance of the thin moment of expectations - in the valuation moded is also attested to by the widely

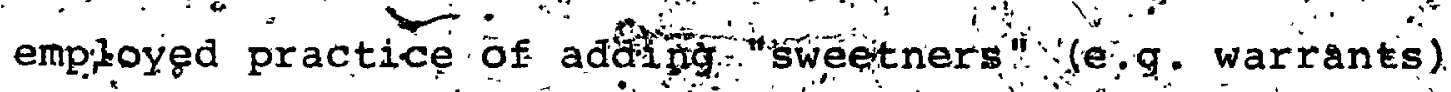

35 coombs and pruitt ped two autcome alterratives that resulted in the same finding of okewhes s preference: when mean and variance were held" consfant. Sëe:

:C.H. Coombs and D.G Pruitt, "Components of Risk in Decision Making: Probability and variance preferences," Journat " of Experimental Psychalogy, $(1960)$, p. 265 
to new issues of securities or, probiding for a conversion .feature on debt issues. In effect, such próvisions tend to increase the positive skewness of the distribution of possible return as weli as the mean and variance of the distributipn. 36 .

In recognition of the rationale and empirical. evidence supporting the relevance of the thitrd moment of the distribution of expected returns the preceeding intraand inter-stock hypotheses can be extended to include the "skewness of investors' expecţations. That is, the term." "positi"ve skewness" can be inserted in place of "magnitude" in the set of inter- and intra-stock hypotheses presented earlier, for price and dividend expectations taken separately. Data necessary. to ajproximate the skewness of investors combined price and dividend expectations 37 was not collocted in this study and therefore inter- and intra-stock compaxisons of this aspect of return expectations were not possible.

${ }^{36}$ Jean op.. cit. . p. $179 ?$

37 Ibid. pp: $185-187$. 


\section{C.}

In the present chapter the central role of expectations in the theory of yalue and. choice has been outlined along with the rationale for the parametric representation of expectations.

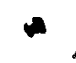

The, discussion centered initially on the general

expectations of investors who were presented as expecting to be "better-off at some future time as the result of fore-. going present consumption. This notion of being "better-off" was then developed in the context of the classical properties of capital assets; namely, their "lucrativity" and "risk". Combining the concepts with the behavioral assumptions of diminişhing marginal ulility for wealth and expected utility naximization lead to the expression of investor utility as an increasing function of the expected magnitude of the cash flows from an investment and a decreasing function of the expected variability of the expected flows."

The interaction of investor preferences for risk and return "with the set of efficient investment alternatives available in the market place was outlined in rejating the parametric valuation model to the normative theory of choice in an uncertain environment.; 
"Having established the perspective in which to viéw expectaclions, a series of hypotheses was detiled

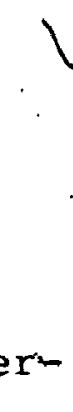
and-intra-stock risk premiums as reflected in the magnitude and the "positive skewness of investors" expectations of financial return. As indicated it wa's found necessary-to - control inter-stock comparisons for the type of investor associated with a particular stock and control both inter and intra-stock comparisons of expectations for the time horizon of the expectations. Additionaliy, a test of the semistrong-form market efficiency assumption implicit in the inter- and intra-stock hypotheses was proposed.

$$
\text { In the next Chapter, the question of the oper- }
$$

ational definition of investor expectations, will be addressed to fully specify the eñpirical hypotheses deveioped in this: Chapter. Basically this operationalizatiot will inwolye identification of the elements and relative nature for the financial eturn that investors expect from common focks. 


\section{CHAPTER T.V \\ THE MFASUREMENT OF FINANCIAL RETURN FXPECTATIONS,}

In the preceding chapter empirical hypotheses were'proposed to investigate the nature of investors' . financial return expectations. These hypotheses were not fully operationalized in that the term "financial return expectations." was not defined in measureable terms.

In the present chapter the measurement of investor expectations is considered in the contextm of prequiously, employed or 'suggested approaches to quantifying" expectations :- Essentially, this discusion will consider and select from aloternate operational definitions for the subjects, outcomes, and weights of investors'expectations of . financial return.

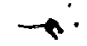

4.1 THE METHODOLOGY OF OPERATIONALLY DEFINING INVESTOR FXPECTATIONS

To operationally define the subject of an expectation and the elements in the related prospect requires that they be described in terms of the operation by which they are to be ascertained. In general, two types of operations could be employed; namely, introspection, or, observation of behavior: In the absence of the opportunity to observe behavior, it is necessary to formalize the above, constructs in terms of the operation of introspection. 
Introspection as a scientific operation has been criticized on the grounds that the "results of it cannot be either.confirmed or refuted by anyone gxcept the person who is the subject of it". ${ }^{\circ}$ while such a criticism is valid, the ultimate test of any operational definition is the extent to which the behavior of the construct (as defined) is consistent with the appropriate theory.

To operationally define investors' financial return expectations so that they. may be ascertained by introspection involves defining the outcomes of the subject and.the associated weights in terms appropriate this operation. such definitions are provided in the $\rangle$ following sections.

4.2 THE SUBJECT (S) OF INVESTORS' EXPECTATIONS The concept of being "better-off"in the future

- as the result of deferring posent consumption is most likềly ca multi-dineñsional concept. That is, in dadition to being better-off in the "sense of one's monetary position, other " nön-monetary considerátions mạ be relevant, e.q. those. arising from a 'controlling interést' in a stock or psychoo. logical factors such as status, excitement, op̣ even being

lozga, op. cit., .p. 16. Ozga has summarized the criticisms of the operation of observation usually employed in the context of a 'gambling situation'. The'major criticism of interest to this study is the inability of abservation to distinguish between an individuai's affective feelings for the outcomes"and the associated weights. (Ibid. : Pp : .87-94) 
able to attend annual meetings and exercising one's voting rights. In this study only the monetary dimension of being botter-off, the financial return, will be investigated. In the case of comman stocks, van Horne has modeled an investors' finandial return expectations as being multioutcome expectations about the future cash flows that may accrue to him in the form of capital appreciation and dividend income. 2 Thus the subjects of infestors' expectations of financial return may involve two cashflow elements.

It should be noted, however, that different investors may be more interested in one element of return than another as we 11 as the timing of the return. As Smith has noted

Some investors are compelied/by their circumstances to place chief emphasis on the regularity of future income.' Others may seek. primarily to preserve the principal of their accotuts. And still others can afford to seek. a large if fluctuating income, even though "athgreater risk to the safety of "their principal. Moreover, some investors are prepared to invest for long periods, and the necessity of realizing their investments in the short 'run is minimized; whereas others wish only to invest for short periods, so that the. expected freedom to liquidate their investments promptly and without los's is important to them. While the relative emphasis or concern that investors place on capital appreciation and dividend income will vary.with the circumstancies' of the individual and hence, influence his aversion to risk; in the ensuing discussion it is assumed that investors associated with a part/cular 


\section{1}

stock are not oblivious to thie two, elements of return if both elements are potentially involved in the return. That is, a stock!s market participants hold expectations for both elements, of cashflow.

$4: 3$

$-$

\section{THE" "OUTCOMES" OF INVESTORS! FXXECTATIONS}

As indicated above, various types of investors are viewed as sholding expectations about the future return available-from a particular stók. . For example, an ipvestor might hold apy expectation about the market price of a $\$ 20$. stock, one Ýan hénce. "The prospect of such an expectation. might contain many or a few, more or , less precise outcomes. That is, one investor may hold a prospect containing such possible outcomes as: "probably increașe; might stay the same; might decrease".. Alternately, another investor might hold a prospect containing such possible outcomes as : not much chapce of increasing beyond $\$ 35$ "slight possibility of increasing to $\$ 30-\$ 35$; fairly good possibility of increasing to $\$ 25-\$ 28$; very probably will aricrease to $\$ 24 ;$ almost sure to increase to $\$ 22 ;$ slight chance of aropping to $\$ 18$; nat much chance of aropping below $\$ 16$.

In the first instance both the weights and the subject of the outcomes aré less "precise" than in "the second, Even when the out'donfes'are specified in dollar terms thère may be gaps in the range of dollar values con cerned as well differences in the pexceptions of outcomes 
with near outcomes being thought of' as discrete values and more distant outcomes as ranges of values.

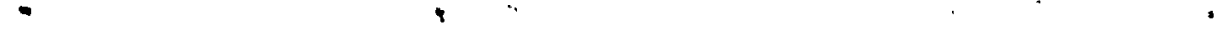

Neither of these two sets of outcomes is intended to define how any particular investor may perceive the future price of a stock. Rather they are put forward to suggest the direction in which extremes may occur. Assuming a market plàce wherein investors perceive and reflect upon information that bears on the potential return from a stock, 'the more 'knowledgeable' and 'concerned' investors may have expectations approximating the more precise prospect indicated above ${ }^{\circ}$ Carter goes further and proposes that "in, order to make choices between different ways of enfloying fünds, an investor will have to 'put a figure' to ideas like 'will go up' and 'will go up. à lot'. "4

In theory at least, the possible outcomes that a stocks's price might take-on are al1 positive numbers increasing from zero to an infinitely large number. Carter's position and that of others is, however, that

The human mind does not. I think carry very i easily a picture of a continuous variable. $\downarrow$. Attention w\$ll at once be concentrated on - typical outcomes in imagined future situations. . The number of typical outcomes depends in part on the liveliness of the imagination in conjuring up alternative future

$\because$ situations, and in part on the image-date (i.e. on the time available for disturbing elements to enter in). 5
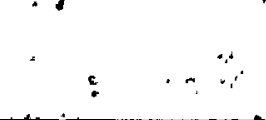

4C.F. Carter.. "A RevisedeThéry of Fxpectations", The Economic Journal: (Dec..1953)! p. 811

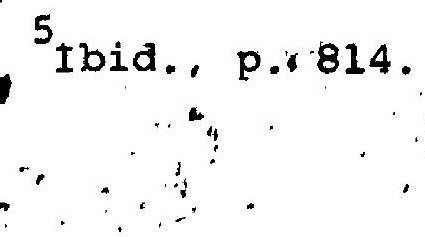


The effect of the "imaige date" on the range of typical outcomès imagtned is. illustrated by carter's example:

Suppose I buy 100 shares of standard Motors at $6 \mathrm{~s} 6 \mathrm{~d}$. The outcome, in terms of capital value at any given date in the future can be looked at as one of. a range of 'conceivable values' at that date. Looking at an hour' hence, the range will be narrower - perhaps 6s. to $7 \mathrm{~s}$. For six months it will be wider - 4s. to 12s. Looking ahead five years it might be nil to 20 s. 6

simplification of the possible outcomes to one or more typical values is a widely held proposition in the literature although the number of outcomes that result from simplification is the subject of substantial disagreement. For example, súggested simplifications include simplification to one or a range of outcomes such as the mean, most likely, highest possible, range, most likely gain (loss) outcome or range of outcomes, focus gain (1oss). 7

In the preceding examples of outcomes in a prospect of price explectationsh the outcomes were described in tewng of the market price of the stock at some future 'fdate. "It should however be noted that investors might.. generate outcomes that would be better described in other terms' such as: the percentage changes per year; the absolute percentage change over the entire, period of investment horizon; the amount of price appreciation (beffore or aften tax) to be received per' year or over the investment horizon; from one or all owned shares of the stock; or other such descrip- 
tions.

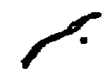

Analogous descriptions of outcomes in expecta-

tions about future dividend receipts could also be developed representing different degrees of precision. Again, a diverse range of' a ltternate descliptions of the outcomes is possible and similar to that for price-outcomes. For. example, dividend expectations may be in terms of the incolne (before or after tax) to be received per year or over the invêstment horizon, for oné or 'all owned shares of the stock, the percentage change per year in the annual. (or quarterly) dividend, the dividend yield, or other such descriptions.

While the foregoing indicates two separate elements of return expectations. (i.e." price and dividend expectations) this formulation should not be interpreted as implying that all investors have separate price and dividend expectations: some may, and" some may not.' However, given the distinctly different nature of the dividend and price return provided by stocks it isinecessary to recognize these differences in measuring financial return expectations. ${ }^{\prime}$. In the case of investors having return expectations with outcomes representing combinations of price and dividend return, outcomes may be described-as possible percentage returns per year for one or mere yoars,

8 The fationale for proposing that the price and dividend elements of total return are fundamentally different in character is expanded upan in section 5 . 
with each outcome compased of $x \%$ of capital gains and y\% of dividend yield per year. As indicated .earlier such joint" outcomes are presumably based on some combination of priçe and dividend expectations.

As will bé det́ailed subsequently. there"ia very little indication in the literature as to the actual way in which investors perceive qutcomes.

A Thus far, various types of investors has been characterized as holding more or less precise price and - dividend expectations in which the outcomes could be described in a variety of ways. 1 other things being equál. those irrvestors who perceive their state of being better-off as bèing. best achieved by capital gains (dividends) might have more spécif'ic price ("aividend) expeatations than dividend (price) expectations: "For' example, thóse investors who are particularly. interested in the regularity of future income from a stock might, reflect on the nature of past dividend payments imore; than on past price changes, and in so doing arrive at an expectation that dividend payments might be increased by some more or less specific amount in the near future. In contrast, their reflections on the future price of the stock may be less conclusive to. them in terms of specific price movements in the future. possibly because" of less understanding of factors affecting." the future pricé of the'stock, or because of a genéral notion of the long-run price of the stock not: decreasing. As was indicated earlier, investors may hold expectations, on the 
same,subject but for a different ahd earliner time in the future than that tof the insestment horizon. The outcomes in such shorter term expectations may also be described in apy one of many "odssible ways.
1.
4.3 .1
4 ..

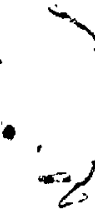<smiles>CCOC(=O)OC1C(CC)C1CC</smiles>

The above variety af ways in which outcomes can

be described has unfortunately not been empirically inves"tiated to determine which one way might be 'most apprapri-.

ate' for describing the outcomes in price and dividend expectations. N8r by implication. is there a consensus among 'researchers in terms' of the descriptionsthat they have used. In the following paragraphs the descriptions of "

$\therefore$ atcomes used or suggested in the literature are revigwed with" a view to assessing their applicability for this stody. Markowitz and Angëll combine the price appriciation and income elements of returh into one expectation. in which outcomes àre expressed as percentage return per

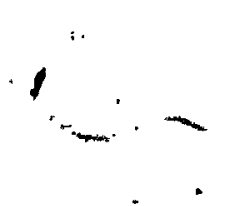
upit of time. 9,10. Additionally" both prefis such gutcomes" by a qualifier such as "at least" or "or less". For example, "Angell describes dividénd outcomés sưch as "at least 6. per. ment a year.for 10 years" and pricécútcomes as "at least

9 Markowitz, fo. cit.

10 Angell, op. cit: p. ir." 


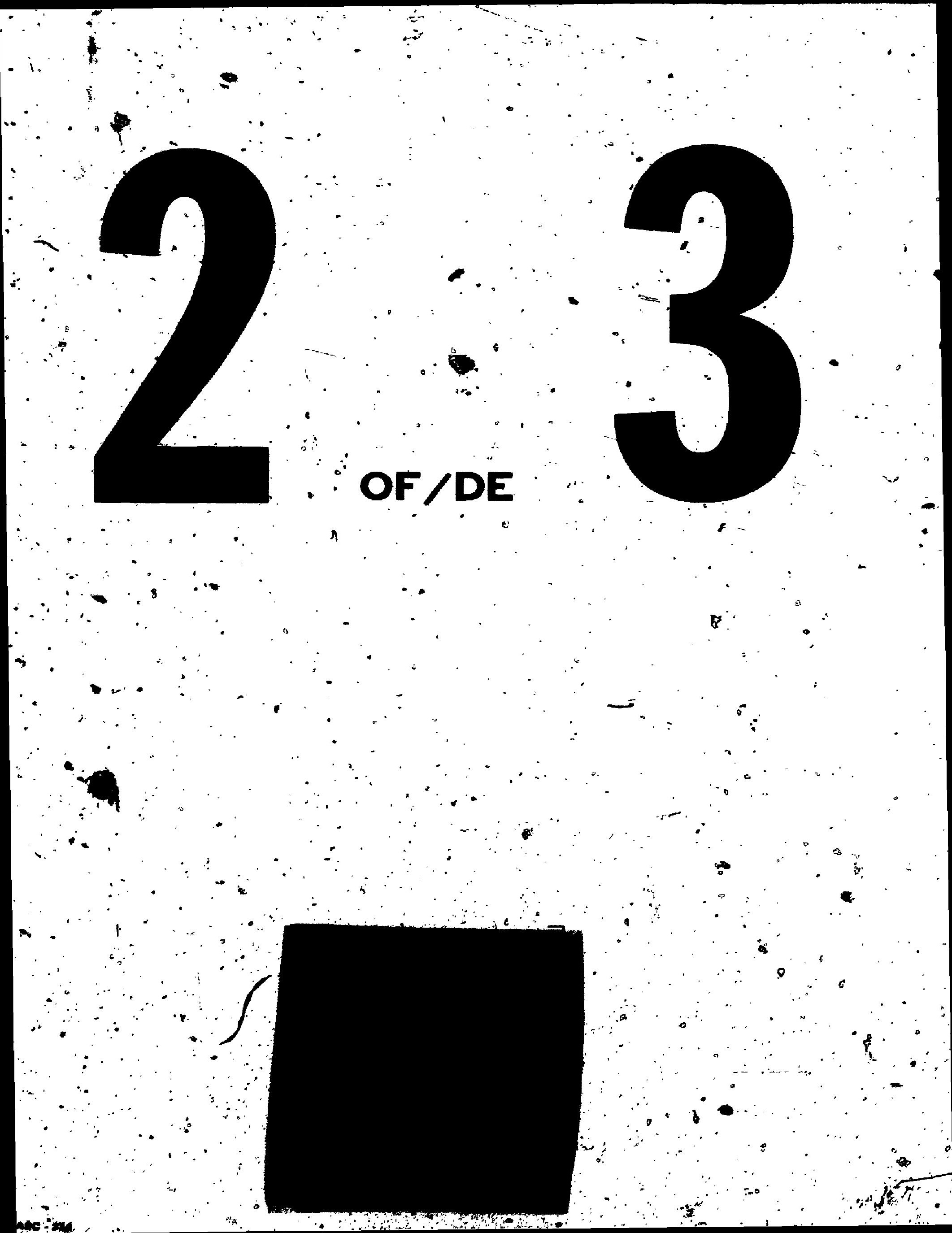


$25 \%$ by the end fon years". Schlaifer, although not addressing investor expectations, similarly suggests a prefix to outcomes in describing ex ante ñotions about the future. $11^{\circ}$

winkler has suggested that oftcomes in an expec-tation of the future price of a stock might be best described as intervals of possible values:" "For a stóck sejling in the $\$ 5-\$ 20$ range, intervals of width of $\$ 1$ might be chosen : . In the $\$ 50-\$ 100$ range, intervals of width of. $\$ 4$ might be used". 12

In contradt with the above descriptions of outcomes - usually discussed in terms of analysts' expectations. - . - empirical researchers have tended to ignore the use of prefixes on outcomes as well as the peasurement of the dividend portion of financial return. Rather, they have measured the expected price at a particular time in the future:

\section{Pank off and virgil had 27 security anajysts} make both a sitrile future price estimate for a number of stocks and $a^{\prime}$ ix-interval probability distribution for the percentage change in a stóck's price during a one-year period: "The six mutually exclusive and exhaustive inter$11_{R}$ Schlaifer
(Uncertainty, Preliminary Edition, $1 / 01$. 1. (McGraw Hill. 12 R. Winkler, "The Quantirretion of Judgement: Some Methodological suggestions". Journal of the American Statistical Assoication, (DeC, 1967) P. .1105. 
vals were $(-\infty ;-20 \%),(-20 \% ;-10 \%),(-10 \% ; 0 \%),(0 \% ; 10 \%) ;$ $(10 \% ; 20 \%)$, and $(i 20 \%+\infty) "$. In effect, a qualifier.

is implicitly attached to each bound; for the upper bound "less than or equal to" and for the lower bound "greater than". 13

Westerfield had over one hundred college students forecast the 'most likely' price, the 'most likely' price holding the DJIA constant, and an upper and lower limit on the price of a naffber of securities for several one-jear time periods. 14 .

Tünovsky employed two sets of short-term expectations (covering different periods of time) of Minformed business economists" on the consumer Price Index in the United states. ${ }^{15}$ while it is not clear how the possible outcomes were described, they do not appear to have been prefixed as noted above. Instead, they seem to have been single value estimates of the Index.

In addition to theşe studies that have dealt with 'price'expectations a number of other researchers have attempted to measure expectations on related subjects.

${ }^{13}$ I.D. Pankoff, and R.I. Virgil, "some Preliminary Findings from a taboratory Experiment. on the usefulness of Financial Accounting Information to security Analysts". Empirical Research in Accounting (1970) p. 13.

.14 . Wesferfield, "A Behavorial Approach to the Investment Management Decision and to the securities Markets". PhD Dissertation, The University of California, Los Angeles; (1968).

${ }^{15}$ S.J. Turnovoky, "Empirlcal Expectations on the Formation of prive Expectations," Journal of the American Statistiçal Assoclation, (Decop 1970) Applications section p. 1441. 
mates "from security analysts of five investment firms of "an average annual rate of growth expected to.occulin the next five years" in the earnings per share for 185 companies. ${ }^{16}$ similarly, Eton and Gruber coilected analysts' forecasts of future earnings per share for two and.threeyear periods for 180 corporations. 17 These forecasts were apparently single-value estimates of the magnitude of earnings per share at the indicated time horizons.

There is little consistency evidenced among the above examples of résearch and suggestions for dealing with expected price or other, future outcomes. Basically, differences in definitions of outemes have to do with:

(a) the number of outcomes considered in the prospect; and, $f$

(b) the words used to describe the outcomes. These differences, the general tendency to ignore dividend -expectations, and the fact thyt the descriptions of expectatións were generally made with anajysts in mind do not provide any clear direction as to the description of. outcomes that might be most appropriatè for measuring , investorg' expectations viáa mail questionnaire. However, is

${ }^{16}$ J.G. Cragg and B.G. Malkiel, "The consensus and Accuracy of some Predictionis of the Growth of corporate Earnings," Journal of Finance (March, 1968), p. 68 .

17 E.J. Elton, and M.J." Gruber, "Earníngg Estimates and the Accuracy of Expectational Data," Management scierice (Apri1; 1972), . P.' B-409: 
in view of the considerations of the subjects of investor expectations discussed earlier in.this chapter and the nature of expectations in general discussed in Chapter 2 , the various measures and suggestions indicated above are amenable to adaptation for this study. "That is, recognizing the possible diversity of the way. in which investors may penceive of the return from owning a stock and the hypothesized nature of expectations proper, any description of outeomes for the purpose of study must attempt to be flexible to accommonote differences among individuats. Thus, ? the prospect of an expectation about the capital return portion of an investor's' return is formalized as consisting of a number of more or less-possible outcomes which are tentatively defined as mutualiy exclusive intervals of the.possible market prices per share that a stock may have by the time of any particular investment horizon. This definition explicitly incorporates the notion suggested by winkler and used by pankoff and virgil that outcones be considered as ranges of possible values. 18, ig It also speeifies outcomes as absolute values in the interest of simpilcity rather than percentage changes

18. L. Winkler, "The Quantification of Judgement: Some Methodological-suggest1ons;" Journal of the Americán statistical Association (Dec:, 1967), p, 1105

19 pankoff and virg1i; op. cit. 
and provides for a multi-outcome prospect. Furthermore, this definition specifies expectations as being "by" a

* time in the future rather than nat" a time in the future to better reflect the contingent nature of an investors's investment horizon for a particular, stock."

The prospect of an expectation about the dividend portion of an investor's return is similarly formalized as consisting of a number of more or less possible outcomes which are tentatively defined as mutually exclusive intervals of possible cash dividends per share per year that may be paid by the time of any particular inve'stment horizon. As in the case of the price expectation, the number and size of the intervals would be determinded in relation to the existing level of the cash dividend per share per period.

Although not indicated in the foregoing, these definitions of outcomes in a price or dividend expectation were developed in con'junction with the definition of the weightg associated with these outcomes. The interrelated. nature of the definitions of the outcomes, and welghts will be discusged in the next section.

4.4 THE WATURE OF TER WEIGETS

The preceding vection ha been concerned with the description of the outccues in words that are relevant to Inventors perceptions of outcones." An th the case of 
definitions of the outcomes, the definition and elicitation of the weights associated with the outcomes by the operation of introspection involves choosing the worls by which the weights are to be described and elicited. Different writers have suggested different sets of words depending on their particular conception of the nature of the weights.

Two different types, of descriptions have beén proposed. One type describes the weights as the degree of (positive) belief in the occurrance of the particular outcome (e.g. savage, ${ }^{20}$ Angell, $21 i^{\circ}$ and schlaifer ${ }^{22}$ ) and will be referred to as the "probabilistic school". The second type describe the weights as the degree of disboifief in the occurrance of the particular outcome (i-e. shackle ${ }^{23}$ ).

The essence of the probabilistic Appraach is summed up by Angeli as the reconciliation of uncertainty into risk:

(Niley, 1954).

20 I.J. Savage; The Foundation of statistics

${ }^{21}$ Angei1, op. cit.

${ }^{22}$ schlaifer, op. cit

${ }^{23}$ G.I.S : Shackie, Decision, Order and Time

(Cambridge, 196i), Chapter 10. 
the investor tolses to deal with the problems of uncertainty as if they could be handled by use of the technique of mathematical. expectation or by some. modification thereof: that. is, as' if truremincertainty could somehow be transmuted, find could be replaced by a statement presenting a distribution of possible outcomes with a coefficient of probability. attachied to each outcome, and itself having" prediction value. 24

Thus weights are interpreted as probability. weights. In contrast the non-probabilistic approach restricts the scope of introspection to experiences and sènsations and, in so doing, excludés positive belief from being a legitimate subject of introspection. The experience that shackle employs to describe the state of (mind embodying the degree of confirmation is that of "surprise". Shackle's opinion is that at the tifie of the subject, the sensation that one experiences at the occurrence (non-

i occurrehce) of some event previously judged to be impossibie (perfectly possible) is surprise. surprise is experienced because one previously disbelieved in the occurrence of the event ag the result of the recogition of sone disabling circumstance. At the time of the expectation; however, one can only imagine the surprise that one would experience at the time of the subject if a particular outeome did not come off: therefor -shack le proposeg the "degree of potential surprese" as the approprtate welght for an outcome. 
The degree of potential surprise is characterized as a continuous psychic variable, allowing many, or perhaps'all conceivable, degrees of possibility to be distinguished, named, and ordered, and even perhaps located against a fixed packground scale or grid of accepted fixed levels so as to be treated as measurable.

As Indicated earlier, consistency is required among terminal and intermediate expectations. Also, the weights must, be consistent within any set of outcomes of either type of expectation. Thus by defining weights as probabilities, elicited welghts must adhere to the rules of prabability calculus; specifically,the Rules of Addition and Multiplication of Probabilities. Herein resides a major criticism of the probabilistic approach wich sterts

from the observed non-additivity of subjective probabilities: While shackle has developed criteria for consistency of potential surprise, there is no such additipity" requirement. 25 The significance of the adaitivity requirement $\rightarrow:$ in the controversy oyer the 'right' way to describe indiviauals: feelings of uncertainty is reflected in an assessment of the validity of the criticisms levelled against the prom babilistic approach. All of the cititicisms orlginate in the condition of additivity that if violated leads to logical - Inconsistencles in the as igned weights. That le, probabit ${ }^{25}$ For a critique of shackle's cónsistency rules, iee ozga, op: eit.' pp.-96-106. 
lity is limited in total amount so that generally speaking the greater the number of outcomes "the smaller the share. For example, whenever an outcome is considered to be "perfectly plausible", credible, or posşible, the weight should be at its maximum, i.e. unity. However, if more than one outcome is perfectly plausible (i.e. profit of $\$ 10$ and of \$11) then assigning unity to both would violate the rule of addition. The courter to this arguement however is that the absolute levels of probability are irrelevant for decision. purposes, If one desired that all probabllities should sum to unity then one need only multiply all absolutè probabilities by an appropriatefactor. Winkler has proposed such a "normalizing of thedy. In defense of the use of subjective probabilities, it should also be noted that a major restriction on the applicability of potential surprise concept results from its non-additive nature. For example, decision theory requires an aditivity requirement; otherwise, an individual would be indifferent to the number of cards in a deck if he were trying to draw, say, the queen of hearts. Arrow has evidenced a similar objection to Shackle's theory when he expressed the view that "the elfmination of all probability elements 
from Shackle's theory tannot be regarded as satisfactory". 27 Angell has added"a further critiçism to that portion of Shackle's theory which postulates that an investor may simultaneously attach zero degrees of potential surprise to both a particular gain oufcome (or range of gain outcomes) .and a particular loss outcome (or range of loss outcomes). Angell notes that "the investor is presumably neither irrational nor philosophically indifferent to worldly matters: the is unlikely to regard both a particular gain and a particular loss as outcomes ò zero surprisingness" 28

In sumary, shackle's concept of the weights associated with outcomes does not appear to be superior to the probabilistic approach and in some aspects it appears inferior. His reflections on the ability of introspection as a vehicle forfeliciting cognitions or positive beliefs is interesting and warrants further study which unfortunately is beyond the scope of this research.

\subsubsection{Eliciting the Weights.}

The precision with thich probability welghts can be ranked by introspection has been questioned on the grounds ':-

${ }^{27}$ Arrow, op. cit., p. 405 .

28 Angel1, op. cit., p; 5 . 
that "we do not feel or see any numbers when we think of outcomes . . as qualified". Höwever, one may be able to arrive at numerical values for these weights if the "proper questions" are asked. 29 The proper questions are those" that pertain to differences in the weights assigned. Several different sets of questions have been employed or suggested in the literature.

(a) Consumer survey research has simply) -asked the subjects to indicate how certain or uncertain they are that they will undertake a partiçular action. In some instances individuals were provided with a scale of probabilities and corresponding words or phrases, e.g.. Hughes and Naert ${ }^{30}$ and the U.S. Bureau of the Census.31,

${ }^{29}$ Ozga, op. cit.; p. 84.

$30^{\circ}$ G. D. Hughes, and P.A. Naert, "A ComputerControlled Experiment in Consumer Behavior".; The Journat of Business.

${ }^{31}$ U.S. Bureau of the Census, corrsumer Buying Indicators: Recent Purchase of Coro and other Durables and Expectatiens to Buy during the Months Ahead, Survey Data through 1969 , Current population Reports, series p. 65 , no. 25., March 11, 1969 (washington, D.C.: Government. : Printing office, 1969), p. 6. 


\section{$\therefore$}

The scale used by Fughes and Naert is provided.

below:

\section{Probahility sctie}

Certain that the specitic event will occur. $\ldots \ldots \ldots . \ldots 99 \div 100$

Almost sure $\quad \ldots \ldots \ldots \ldots \ldots \ldots \ldots .81-90$

- Very probable

$71-80$

$\therefore o$

Probable

$61 \div 70$

Good. possibility

$51-60$

Fairly good possibility

$41-50$

Fair possibility

$31-40$

Some possibility

$21-30$

slight possibility

$11-20$

Very slight possibility

a.

No chance that the event

will occur

$\because \cdots$

(b) Motivational research has provided.

experimental subjects with probability scales and asked them to indichte, for-example, their subjective probabilities of success at a particuilar task: Feather employed a 5 -inch scale flumbered from $0-100$ in equal steps of twenty with the statement. "no chance at all" at one extreme of the scale; the statement; an even chance" at the middle of the scale; and the statement, "completely certain" at the other extreme of the scale". ${ }^{32}$.

32 i.T. Feather, "The R lationship of Fxpectations of Success to $n$ Achievement and. Test Anxiety," Journal of Personalie and social Psychology (1965), p. 121 . 
(c) Winkler has suggested that probabilistic weights for multi-outcome price expectations could be assessed as a discrete of continuous distribution of outcomes using outicomes defined as intervals of possible prices or discrete possible prices respectively. 33, pankoff and virgil employed the former methodology. for assegsing probability weights but instead of using intervals of price's they used intervals of percentage change in price. 34 .1

$$
\text { (d) Similar to the suggestion by vinkler, }
$$

schlaifer has proposed a method for the "direct judgmental assessment of probability distributions". 35 based on an assessment of cumulative rather than discrete probabilities. Schlaifer suggests that this method of assessing cumulative probabilities is not only less time consuming, particularly in the case of large number of outcomes, but aiso, the issue of non-additivity may be avoided. Angell, while not as elaborate gas schlaifer, has. suggested the same general procedure for "the assessment of investor:s expectations. 36 of the foregoing examples of methouds of eliciting probabitistic weights assogiated with outcomes? that used

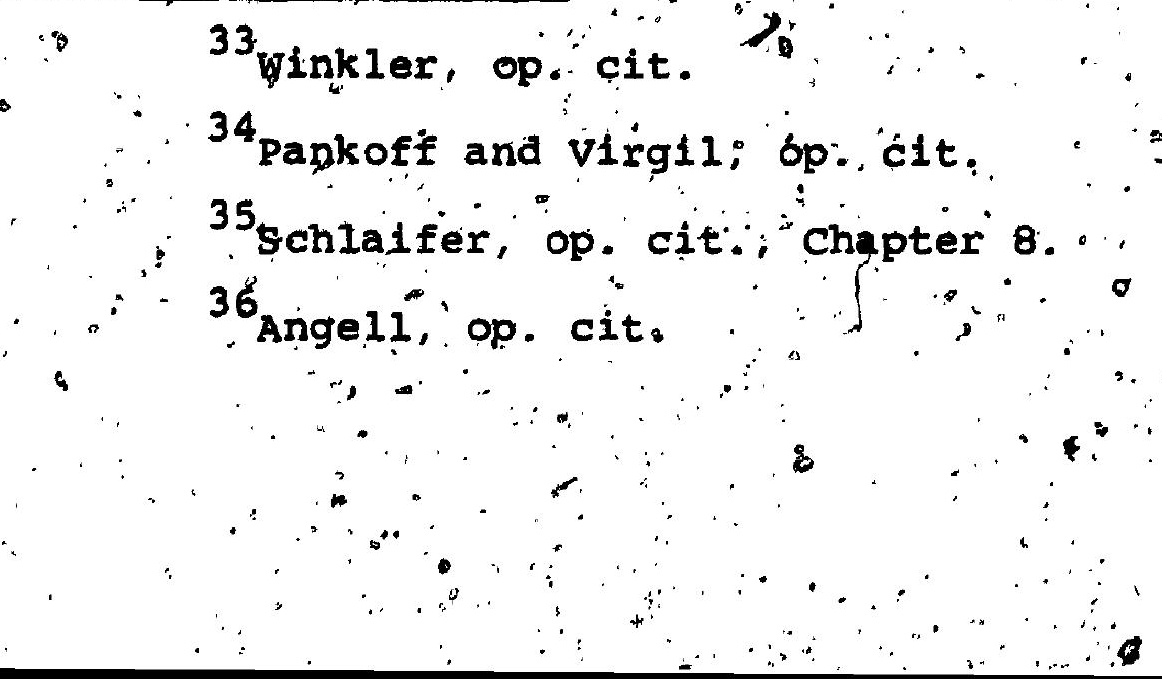


'by Hughes. and Naert and suggested by winkler appears to be the most suitaple for eliciting weights from randoily. selected individuals. That is, a discrete probabilistic scâle dós not require the presumption of statistical sophistication of respofidents.

$0^{\circ}$

\section{THE TIME HORIZON OF EXPECTATIONS}

In the preceding.discussions: of the subject's

$\therefore$ of investors. expectations and the operational definitions. of the outcomes arialights in the prospects iof these subjects, the time- hoxizon of expectations was âssumed to be given. However, as indicated in chapter III, the tịme horizon applied. to an expectation has a "substantial impact on the magnitude and uncertainty of the expectation. "Hence, the 'tine' horizon of the expectation must be incionporated into the operationalization of the construct of expectations to provide a, frame of reference.

In operationally defining the time horizon of an expectition the distinction must be made between thé period of time than an owner of a stók might expecit to continue to own the stowk and the most tistant point in time for which an owner mix have an expectation about the price and/or aiviaend of a stock. The period of time from the present to the most aistant point in time for which an owner might have an expectation is not necésarily the game as the period of time that he might expect to continue to. 
hold the stock. For example, an investor might, invest temporarily excess funds in a particular stock with the expectations that he might liquidate his investment in order to purchase a new car in one-year. However, this et same investor might hold an expectation for the same stock at a more or less precise point in time beyond one year. - If the scope of this study were restricted to the expectations of only buyers or owners of particular stocks, either the holding; period or the time to the most

$\therefore$ distant time of an expectation could be used to anchor expectations. Hơwever, the inclusion of security analysts' and sellers lexpectations in the study precludes the use of a time horizon associated with stock ownership: such a reference point would simply be irrelevant to analysts ąnd seilers who did not have an ownership interest in the stock. Thus, for the purpose of this study the time horizon of an expectation is defined as the most remote point in time in the future for which an individual holds a return. expectation. The relevence of this reference point for return expectations is independent of the ownership-ifite of the expecting individual.

Adoption of this definition of the time horizon of expectations for completing the operational definition of expectations does not provide for individua le waying different.time horizons for the different elements of financial return: That ig; it 1s assumed that an individual's most remote price expectation and his most remote. 
dividend expectation are roughly coincident in time. To. the extent that price and dividend expectations are causally related, this assumption is considered to be reasonable:

4.6 RESOLUTION OF ALTERNATIIVE DEFINITIONS

Aṣ indicated earlier, the description of the outcomes, the means of eliciting the weights, and the reference of expectations to a more or lass specific time in . the future are interrelated considerations. That is, if one were to elicit probabilistic weights by means of a - cumulative on discrete description of outcomes, it woulg" be necessary to describe putcomés in appropriate terms, e.g. "equal to or leśs than" "between" various values. In view. of the alternate specification of outcomes indicated eariier and the related interpretation of indicated possibili-i ties, investigations were undertaken to select that means of eliciting expectations from individual investors that provided a reasonable representation of investors' expectations. To make this judgement regarding alternate descriptions, empirical criteria were developed and tested by interviewing investors and conducting a mail survey of recent purchasers, of a listed common stock.

\subsection{7.}

Empirical Criteria

To assess the extent to which the measured expectations refiected investors' expectations two objective 
criteria were employed. These criteria pertained to the relative shape and magnitude of the measured price and dividend expectations. The rationale for these criteria is based on the fundamentaliy different nature of the . behavior of cash dividends and the market price of common stocks referred to earlief in ênis chapter. This rationale is developed below.

In a world of uncentainty, the variability of a cómmon stock's dividènd return can reasonably be expected to be less than that of the capital return. This fundamen$\because 4$. thl 1 ifference is attributed to the managed nature of a company $\because$ annual dividend.

The dividend paid by a company is a managed ariable under the direction of the firm's board of direcvariable under the direction of the firm's board of directors and is therefore, not directly under the influence of stock market participants:" In cgntrast, the price of a stock is not a variable under the direction of the firm's board but wether fluctuates in response to a variety of influences. Recognizing the managed return of dividends. K.V. Smith has proposed and developed empiricall evidence supporting the "increasing stream hypothesis of corporate dividend, policy" which states that-

The board of directors deliberatély avoids dividend cuts if at all possible and attempts to construct over time an.increasing, or at least a non-decreasing, record of cash dividena payments. 37

${ }^{37}$ K.V. Smith, "Increasing Stream Hypothesis of Corporate Dividend Policy;" California Management Review (Fa11, 1971): P. 57. 
Smith's support for this hypothesis was based on an investigation of the dividend change history of approximately 900 companies during the period $1949-1966$

The implications of Smith's pragmatic hypothesis for inviestor expectations of future dividend cash flows are significant." If investors are or. become aware of the past behavior of the dividend cash flow from a stock which has had a non-decreasing 'dividend, then their expectations of future dividend changes could reasonably be expected to have a lower bound approximately coincident with the existing dollar-dividend (ignoring stock splits).

In contrast, investor recognition of the unmanaged nature of a \$tock's price behavior would not bound their expectations for future price change at the current price of the stock. Thus, while investor expectations of the future price behavior of a stock that was associated with a non-decreasing dividend could reasonabiy be expected to involve variability below the present price of the stock, expectations for the stock's dividend could be anticipated as involving at least less variability below the present dividend value.

The above discussion, regarding the variability of price and dividend expectations below the present price and dividend rates does not resolve the isisue of the similarity of the variability and other momental characteristics $\because:$ of price and aividend expectations of a common stock. To 
address the larger question of differences in that variability betwe price and dividend expectations it is necessary to propose that the managed nature dividends also precludes unlimited upside dividend potential where no such constraint-is theoretically imposed on the upside behavior of stock prices: If investors recognize this. proposition, then it could al $\$ 0^{\circ}$ be anticipated that expected variability Above the present dividend level reflected in investors' expectationswould also be less than that reflected in investors' price expectations. Thus, total variability reflected in price expectations would be, expected to be greater than that reflected in dividend expectations. Two empirical hypotheses result from the foregoing considerations and are premised on the presumption of a stock for which Smith's hypothesis is appropriate, and, investor awareness of the managed nature of a stock's dividend vis a vis its market price. Hypothesis 4.1

An investor's price expectations for a particular stock should reflect greater uncertainty (variability) . than his dividend expectation. Hypothesis 4.2

An linvestor's dividend, expectation should reflect less downward vartation from the current dildend rate than his price expectation in relation to the currentwhrket price. 
It should be noted that the above two hypotheses are directed specifically at expectations for stocks whơse annual dividends are consistent with the increasing stream hypothesis: No a priori relationship̊s between price and dìvidend expectations for stocks paying a fluctuating dollar dividend is implied by the increasing stream hypothesis.

4.6.2 Empirical Testing of validation criteria

In essence, the investigation of alternate ways of describing outcomes and weights consisted of interviewing individual investors and subsequently mailing questionnaires to.204 recent purchasers of a publicly traded stock. The data provided by these investigations was analysed in accordance with the foregoing bypotheses. This peliminary study involved investigating three descriptions of weights and outcomes for price and dividend expectations for an investor-supplied time horizon. One description asked for was in terms of a three point sumary of expectations involving an investor-supplied upper limit, lower limit, and must likely value of à return element (Beta.description). The seçond asked for a multoutcome description in the form of a cumulative probability. distribution (cumulative description). "The third asked for a multi-outcome description in the form of a discrete probability distribution (Discrete description). Investors who were asked to provide a cumulative or discrete description of their price and dividend expectations were provided with 
a probability)scale (similar to that employed by Hughes and Naert) and 23 mutually exclusive interval outcomes for cach return element: The type of description asked of a partioylar investor was randomly determined.

As $a$ result of this investigation, the discrete description of invęstor expectations was found to be superior in terms of conformance with the foregoing two hypotheses. This judgement was based on the observed evidence of beta descriptions resulting in dividend expectations having greater variability than the correspondipg prince expectations. Additionally, investors frequently failed to distinguish between the upper limit and the most likely value for a price or dividend description. Furthermore, investors beta descriptions appeared to be truncated in relation to both the cumulative and discrete diescriptions. \% The discrete description was judged as being superiór to the cunulative description on the pasis of the incidence of cumilative, descriptions resulting in dividend distributions having greater variability than the corresponding price distribution. Furthermore, a number of investors who were asked for a cumulative description of their epectations completed the questionnaire as if a discrete distribution had been asked for. This difficulty Wth understanding cumulative probability concepts was evidenced by one respondent who wrote; "Your wording of this question is confusing - 'less than $\$ 150$ ' could mean 
anything from $\$ 150$ to $\$ 1.00$. If you had said between $\$ 120$ and $\$ 150$ for questions. I could have answered it

4.7 SUMMARY

The objective of this chapter was to.operationally define the remaining undefined term employed in the hypotheses" specified in chapter III; namely "financial return expectations". Essentially this objective involved : applying the concepts developed in chapter If pertaining to expectations in general to the special case of inyestor expectations.

Initially, consideration was given to specifying the subject(s) of inveştors' expectations as being dividend income and capital changes. If was then noted that future expected outcomes of these subjects could be defined in several different ways. Furthermore, it was noted that the definition of outcomes and the definition of the weights associated with the out omes were intedependent. As a result of arguments for-and-against different definitions of outcomes andweights, investors price and dividend expectations were formalized as consisting of a number of mow or less possible (probabilistic) outcomes which were' tentat vely defind as mutually exclusive intervals of possible prices (dividends) that a stock might have by a more or less brecise time in the future.

This tentative operational definition of investors: expectations was investigated in relation to 
4

104

cumulative and beta descriptions of expectations in accordance with two hypotheses regarding the relative shape of price and dividend expectations. The results of this investigation indicated that of the three methods, that involving a discrete description of expectations was most consistent with the hypothesized shape criteria.

In the next chapter the methodology of obtaining the expectations of market participants for a selected group of stocks is presented along with the method of . analysizing these" expectations for inter-and intra-stock differences.' 


\section{CHAPTFR .V \\ METHODOLOGY}

In chapter IV the operational definition of . the hypotheses developed in chapter III was completed. with the 'specification of. the method for measuring investors' expectations of financial return. The methodology of measuring and analyzing investor expectations for séveral stocks is detailed in the present Chapter. Essentialiy. methodological considerations pertain.to the standardization of the measuring dévices for a selection of stocks, the selection of stocks for study, the data collection procedures, the method of summarizing measured expectations, and the statistical analysis of inter-and intra-stock differences in expectations.

\subsection{OPERATIONAL CONSTRAINTS ON THE ELICITSTION OF INVESTOR EXPECTATIONS}

As indicated in Chapter IV empirical evidence supports the employment of a discrete distribution to describe investors' expectations. "In adopting this method of eliciting expectations for testing the hypotheses developed in chapter III, several practical considerations must be taken into consideration when developing questionnaires for several stocks. For each stock involved in a study of this nature, the number and relative range of outcomes provided for both price and dividend expectations must be approximately identical. This consideration is 
necessary to avoid biased responses resulting from asking "different" questions either across stocks, or, for price and dividend expectations for any particular stock.

Furthermore, the number and range of outcomes to be provided in a set of expectation questions in essence determine the sensitivity of the measuring instrument. Here, sensitivity is reflected in the ability of the measures to distinguish different perceptions of risk and return. The more outcomes commented on by respondents and the smaller the interval involved in the outcorne, the more sensitive the measuring. instrument will be to small differences in expectations of risk and return. offsetting the desirability of a highly sensitive measuring device is the unfavorable effect that a very detailed set 'of questions is expected to have on the response rate to expectation. questions.

The resolution: of this conflict in priorities in the case of investor expectations is uitimately a matter of judgemerit and experience. Preliminary investigations indicated that response rates of approximately $25 \%$ could. be obtained with approximately 20 interval outcomes.

As a result of these considerations, the following guidelines were adopted in constructing questiónnaires designed to elicit invéstors expectations of future price and dividend behavior. The results of these guidelines are presented in Appendix I.

(a) To elicit an' investors" time horizon in a manner independent of the ownershifp status. 
of the indirviual, an indirect, procedure was adopted. Questions $3 a, 3 b^{\circ}$, and $3 c$ Appendix Ij.

(b) Nineteen mutually-exciusiye intervals would be used for distributions. Intervals would encompass a range providing for roughly a $400 \%$ increase, and a $100 \%$ decrease froff the eurrent value of the return element. (price or dividend).

J. (c) Interval sizes would varyisintervals nearest the current value of the return element being smaller than those more distant from the current value: This procedure was " necesary to minimize the number of possible. outcomes that the respondent was required

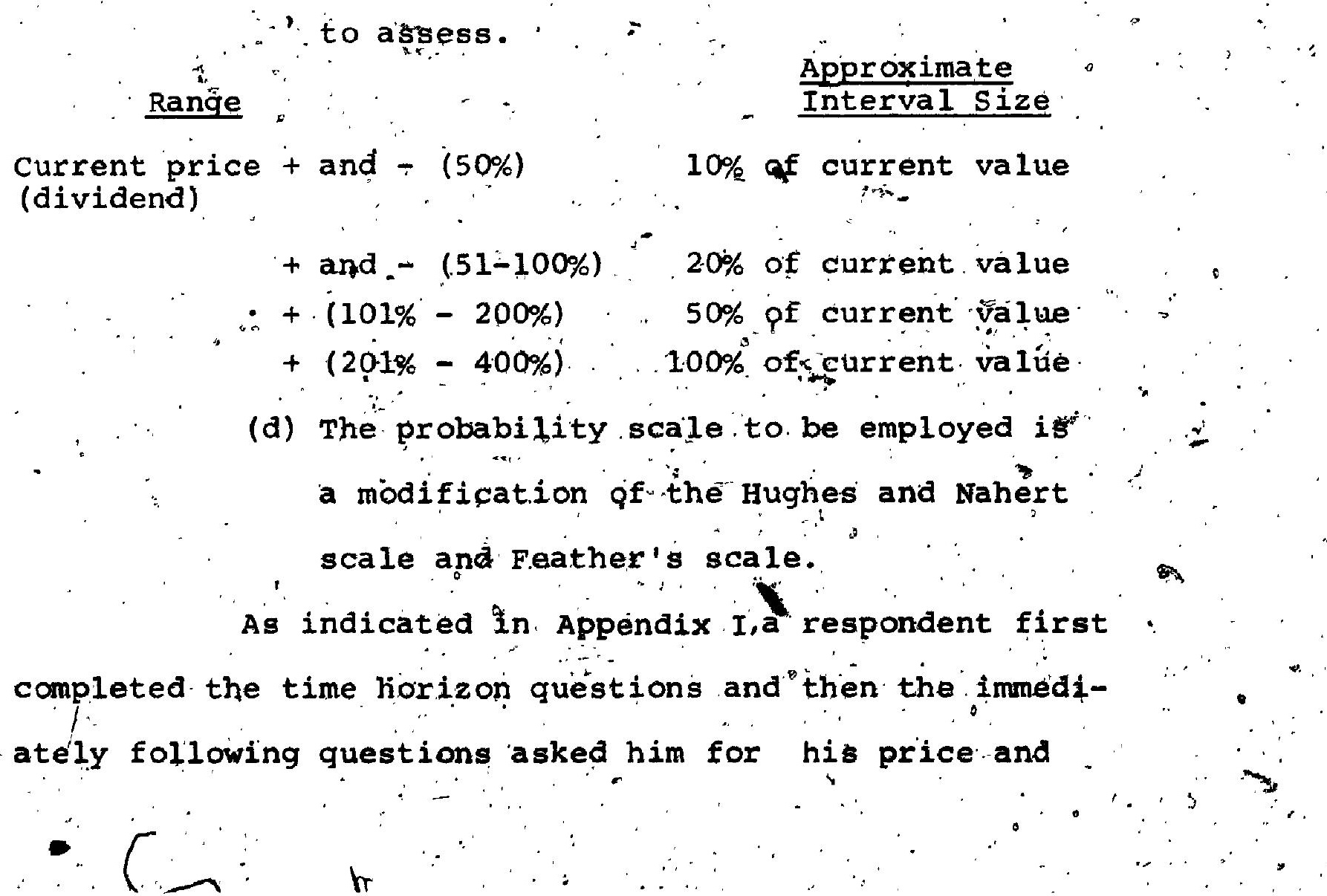


divideng expeftations in relation to that time horilon.

5.2

\section{STOCK SELECTION}

The riuber and "nature of stocks selected for

this investigation of investors' expectatfons of financial. return'was constrained by sêteral operational and theoretical considerations.

- In effect, budgetary limitation dictated that. no more than three stocks could be involved in the study. Furthermore, the co-operation of the investment community nècessary för this study was considered to be möre readily availaple if the admigistrative demands inherent in the - study wëre minimized.

Given these budgetary and administrative limitations the actual selection of stocks to be investigated was contingent upon obtaining the co-operation of - the senior management of three companies whose stock could be expected to satisfy four basic conditions.

a. (a) The çommon stock of the several comparies had to represent different rigk categories withect, to the nature of the finanoial return expected. Irọm these stpcks. Given that the reseârch cquestions of this study attempted to distinguish stocks on the basis of their risk characteristics, selection of stock representing different 'risk sit-' uations was a necessary condition to begin 


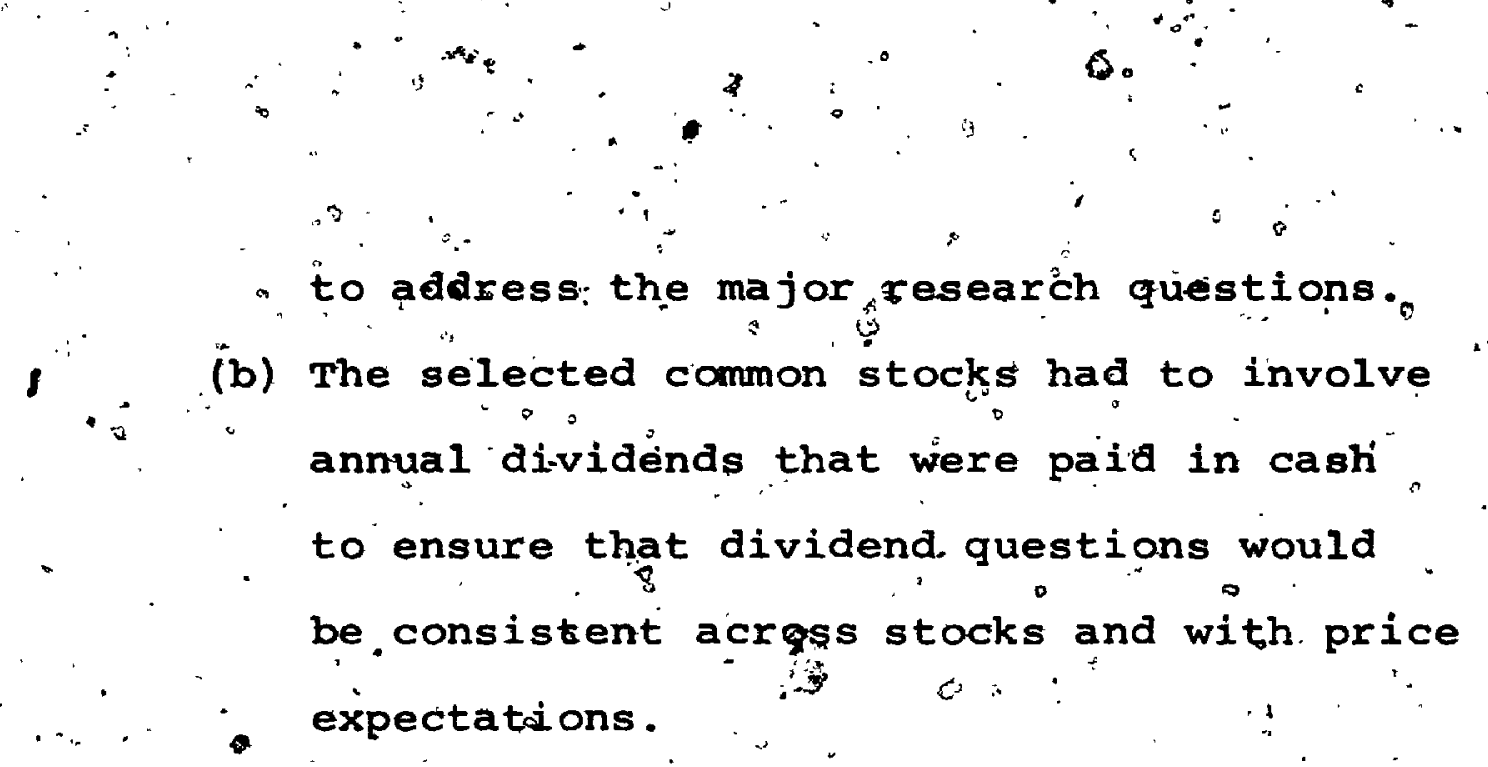

(c) The comnon-stocks of the several companies had to be actively traded in the market place to ensure that án adequate numbèr "of transactions could be expected during. a relatively short period of time.

(d) The common tocks of the companies had to be widely held to provide for the opportunity

- of obtaining a fepresentative oross-section of expectations for a particular stock. is:

The actual selection of stocks took place during a two-month period beginning in January 1973 and involved an examination of the daily number of trades made in il stocks listed on the roronto stock Exchange: This investigation led to a limited list of śtocks which satis-o fied the condition of being suffiflently actively traded to merit initial consideration for selection. Three stocks were ultimately selected in consultation with co-operating investment dealers and inspection of beta coefficients ${ }^{1}$.

$\therefore$. IAlthpugh beta coefficientis reflect the systematic volatility of a gtock's price in telation to the market index and not the total risk (systematic and non-systematic components), this data, was taken ints the stock selection process as a proxy for the felative total risk of the three stocks: 
Market behavior statistics for these stocks arepresented in Table 5:1. All three of the indicated stocks were among the top twenty stocks in canada in terms of dollar volume of trading in 1972. stock A was a frajor utility, stock B - a metals respource company, and stock $C$ a petroleum resource company. Based on the beta coefficientis stock A was indicated as being the least risky; stock B the most risky; and stock $c$ as being of Intermediat risk in relation to $A$ and $B$.

\section{As indicated in chapter III the research} hypotheses deal with relative ex ante rískiness as measured. by the variance of expectationg rather than relative ex post riskiness such as that provjde by beta coefficients. Thus it was necessary to asséss the relative riskiness of future. returns from the selected stociks. For the three stocks, stock A was judged (in consultation with the co-operating investment dealers) as offéring the least risky future return. No conclusive judgement was made regarding the future relative riskiness of the returin from stocks $B$ and c. Both were assessed as being more risky than stock $A$ but in view of, the then existing uncertainty, in the resource industries, neither stock would be specified as being more riskiy than the other.

These fudgements have substantial implications for the statistidal testing of the inter-stock hypotheses presented in chapter III. Essentially, these judgements $x$ 
Table 5.1

STOCK BEHAVIOR STAT.ISTICS $(a)(b)$

$\begin{array}{rrrrr}\text { Company } & \text { Alpha } & \text { Beta } & \frac{\mathrm{R}^{2}}{.} \\ \text { A } & -.347 & .412 & 28.8 \\ \text { C } & .010 & .821 & 24.4 \\ \text { B } & - & -.003 & 1.054 & 40.2\end{array}$

(a) Computed from the Financial Research Institute monthly price file for 99 Canadian stoçks for the period January 1963 to January $\$ 973$.

where

$$
\therefore P_{t}^{s} / P_{t-1}^{s}=a i p h a+b e t a \cdot\left(P_{t}^{m} / P_{t-1}^{m}\right)+e
$$

$$
\begin{aligned}
\mathrm{P}_{t}^{\mathrm{s}}= & \text { monthly closing stock price } \\
\mathrm{P}_{t}{ }^{\mathrm{m}}= & \text { monthly closing level of the Toronto } \\
& \text { Stock. Exchange Industrial. Index. }
\end{aligned}
$$

(b) A stock's beta coefficient is determined by plotting changes in the stock's price ágainst changes in a market index; the slope of the 'resulting line is the stock!s beta factor. Whepn risk is defined as volatility per se in relation to the market index the beta coefficient is an objective proxy for the relative' risk of a security. The alpha or intercept of the stock's characteristic line indicates, the percentage change in the stock's price that is due to factors other than the market itself. See Modigliani and Pogue op. cit. 
alloy directional significance tests of the applicable hypotheses for stock $A /$ Stock $B$ and stock $A /$ stock $C$ interfstock comparisons of expectations. In contrast only non-directional statistical test,s could be:applied in the case of stock B/Stock c inter-stock comparisons.

5.3 INVESTOR SAMPLING

As indicated in Chapter III this study's researth hypotheses pertained to the expectations of buyers, sellers, owners, and security analysts associated with the selected stocks. Investment dealers co-operated. in the study by transmitting questionnaires to buyers, sellers and analysts. The selected companies co-operated by transmitting questionnaires to owners of their stock.

Sixteen investment dealers participated in the study by mailing questionnaires to individual cliegnts who transacted in (bought or sold) any one of the three stocks during the period March 19, 1973 to April 13, 1973. 2 The sixteen investment houses involved in this study repressented both large and small retail and institutional firms. While procedures varied among dealers for Identifying individual transacţors, questionnaires were generally

2.". . .

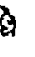
to require only ten trading days, however, reduced transactions in the three selected stocks just prior to and during the study resulted in the study involying 20 trading days. Only twelve of the sixteen firms participated for the full 20 days 
mailed by dealers to their clients from one to three days after the day of the transaction. ${ }^{3}$ security analysts employed by these firms completed similar questionnaires during the cime of the study.

Each of the three selected companies forwarded questionnaires to a sample of imdividual investors - randomly drawn from their shareholder lists. 4

.5 .4 SUMMARIZING AN INVESTOR'S EXPECTATIONS

(4) The sumnary; statistics of an investor"s expectation that were of interest in this study were the mean, the standard deviation, and the skewness of each investor's price and dividend expectation and the 'mean and standard deviation, of the combined return: The computation of these staristics is outlined in the following subsections.

5.4 .1 The Mean The expected value of a distribution was computed by :

(a.) annualizing the mid-points of each of the 19 interval-outcomes to reflect the investor-provided time horizon: i,e. determining

. 3The sixteen investment dealers were not randomly selected from all possible investment dealers because of budgetary and administrative considerations.

4 An attempt to screen out child recipients of the questionnaires on the basis of size of shareholdings eliminated mailings to shareholders owning less than ten shares. 
the compound rate of change from the base value of a price or dividend to the value of each interval mid-point:

(b) normalizing the probabilities assigned to each of these interval-outcomes by the investor so that the normalized probabilities summed to unity.'

(c) computing the arithmetic and geometric means of the particular distribution as indicated below.

$\overline{\mathbf{x}}=\sum_{t=1}^{k} \cdots p_{i} x_{i}$

and $G=\prod_{i=1}^{K} x_{i}^{i} P_{i}$,

where $K=$ the number of non-zero normalized probabilities, $\leqslant 19$,

$\mathrm{x}_{\mathbf{i}}{ }^{\prime}=$ annualized interval mid-points for the $i^{\text {th }}$ interval, $\mathrm{p}_{i}=$ normalized investor-assigned probability for the - : $i^{\text {th }}$ intervaI

$$
\sum_{i=1}^{k} \quad p_{i}=1
$$

$\bar{x}$ - the arithmetic mean expected rate of change, and, $G=$ geometric mean expeqed rate of change: A simplified example involving a three point distribution will illustrate the calculations involved in computing the mean value of a hypothetical price expectation. A base price of $\$ 25.00$ and a time horizon of 1 year are assumed. The base price actually employed in" the study 
was the closing. price of the stock on the day preceeding the date in which the investor completed the questionnaire. Price intervals and assigned probabilities are presented. - in Table 5.2, columns (1) and (2) respectively.

Interval mid-points shown in column (3) of Table

5.2 were computed by averaging the extreme values defining the interval range. These mid-points were annualized by computing the compound rate of return implied by the base price, the interval mid-point, and the indicated time horizon.. The annualized interval mid-points are indicated in column (4) of Table 5.2 and are in the units of compound annual rates of change in the price of the stock: It is these rates of change $\left(x_{i}^{\prime} s\right)$, weighted by the corresponding normalized probábilities $\left(p_{i}{ }^{\prime} s\right)$, that were used to compute the moments of the price distribution.

Normalized probabilities are shown" in column (5) of Table 5.2 and are computed by dividing assigned probabilities by their sum. The above computational procedures employed to arrive at a meán price or dividend expectation resuit in an investor's price or dividend expectation having the units of 'annual campound rate of change' expected: Alternatively, these same results - at least in the case of the arithmetic mean - could have been obtained by computing the mean of the interval mid-points and then determining the compound annual rate of growth in the base price (alvidend) necessary to artive at the 
mean price or dividend by the horizon of the investors' expectation. Howeve:=, had this procedure been employed the mean of the dist:ibution would have been in one type of units (rate of change) and the corresponding standard deviation in a second type of units (dollars).

At this point it should be noted that the

reason for computing both the arithmetic and geometric mean of price and dividend distributions is also related to the annualization of the interval outcomes. "Essentially, when working with distributions involving rates of change, a spurious correlation may result:between the mean and variance of the distribution if the distribution is skewed. Ardetti has reported that'. ". Professor Merton Miller has pointed out that a natural positive correlation exists: between the arithmetic meaf and the variance when the distribution (of annual rates of return) is skewed. I In

$\because$ fact, the covariance between the first and second moments is directly proportional to the third moment - cov $\left(u_{1} u_{2}\right)=\frac{1}{n} u_{3}$. This spurious correlation result is less likely when the geometric mean is used".

The implication for this study of the foregoing. observation pertains to the measure of central tendency that should be used in comparing the expected magnitude (rate of change) price or dividend expectations If 
Table 5.2

AN EXAMPLE OF SUMMARIZING

A MEASURED PRICE EXPECTATION

(1)

Price Interval (\$)

$41-50$

$31-40$

$15-30$
(3)

Interval Mid-Point

(\$).
(4)

Annualized Mid-Points (Rate of change)
Assigned
Probajoility.

$\therefore$
.82

.42

$-.10$
(5) 0

Norma lized Probability

22.5

$\frac{20}{120}$

$35 \cdot 5$

45.5

60

Arithmetic Mean Expected Price $(\overline{\mathrm{p}})$

$$
\overline{\mathrm{P}}=\begin{gathered}
333 \times 45.5+.500 \times 35.5 \\
15.1515
\end{gathered} \quad \begin{gathered}
.167 \times 22.5 \\
3.7575
\end{gathered}
$$

.333

.500

.167

1.000

\section{Arithmetic Mean Expected Rate of Change*}

$=(.333 \times 1.820+.500 \times 1.42+.167 \times .90)-1=.466$

Note: $\$ 25.00 \times 1.466 \doteq 36.66$

Geiometric Mean Expected Rate of Rrice Change*

$$
G=\left(\begin{array}{c}
\left.1.82^{1 / 3} \times 1.42^{1 / 2} \times 1.90^{1 / 6}\right) \\
1.221^{1} \times 1.0 \\
1.1917-0.9826
\end{array}\right) .429
$$

Note: $\$ 25.00 \times 1.429=\$ 35.72$.

*Annualized mid-points are converted to Holding. Period Returns to avoid computational difficulties encountered when negative rates of return are involved. 
there was no need for concern'about a spurious correlation between the magnitude and the variance of a distribution of annualized rates of return then the arithmetic mean of investors' expectations could be compared in. inter-or intra-stock hypothesis tests. This mean rate when applied to a base price or dividend would result in the same mean price or dividend that would have resulted had the interval mid-points not been annualized but simply averaged: However, concern for a spurious correlation between the mean and variance requires that inter-and intra-stock comparisons of these characteristics of ptice-or divigfend expectation involve the geometrie mean of distributions. It should be noted however that the geometric mean tends. to understate the rate of change that is indicated-by the arithmetic mean. . In the example presented in. Table 5.2 the geometric mean was in fact smaller than the arithmetic mean: Latané and Tuttle have noted that, "For any ; distribution, thei geometric mean will be less than the ? arithmetic'mean except wheén all vaìues of the distribution. are equal. $\therefore$ the greater the dispersion, the greater the spread between the two preans". 6

(1) The dilemma posed by the possible correlation between the arithmetic mear ard variance of an expectational ${ }^{6}{ }_{\text {HXA. Latan }}$ and Portfolio Management (Ronald Press, New York, 1970) p. 212 
distribution and the understatement of the true expectation by the geometric mean was resolved by employing the geometric mean in hypotheses tests involving the mean of price and dividend expectations. Hypotheses tests involving the internal rate of return implied by the price and dividend expectätions employed the arithmetic mean of these distributions.

5.4 .2 The Standard Deviation As a measure of dispersion (risk) of an individual's price or dividend distribution the standard deviation (S) was computed as follows:

$$
i s=\sum_{i=1}^{k} p_{i}\left(x_{i}-\bar{x}\right)^{2}
$$

The standard deviation is in the same units as those' of the mean of the distribution; namely, 'compound anniali rate of change.?

\section{$5.4 .3 \Leftrightarrow$ skewness}

- The skewness (SK) of an individual's price or dividend expectations was computed in terms of the semi-variance of the distrioution: 8

2 7 The stindard deviation for the example given in Table 5.2 is 0.310 ; had the geometric mean been used the standard deviation would have been 0.313 . 


$$
S k=\frac{s^{2}}{2 \times s_{L}}
$$

-where $s^{2}=$ the total weighted sum of the squared deviations.

where $S_{I}=$ the weighted sum of the squared deviations belcw the mean

A skewpess of 1.0 indicates that the sum of the squared deviations below the mean is equal to the sum of the squared deviations above the mean;-that is, the distribution is per fectly symmetrical. A skewness greater than 1.0 indicates that the distribution is skewed to the right (high-end) while a skewness less than 1.0 indicates that the distribution is skewed to the left (low-end). 9 The measure of asymmetry was used in preference to the thira moment of a distribution because of the added information provided." For example, a skewness of 1.20 as measured in the abore. form indicates not orily that the distribution is skewed to the right but additionally that $41.67 \%(1 /(2 \times 1.20)$ of the sum of the squared deyiations are below the mean of the distribution. In contrast a third

9 The example presented in Table 5.2 indicates a phenomena that may occur when the geometric mean is_used to compute the variance of a distribution. Since $G \leqslant \bar{x}$, squared deviations about $G$ may be gredter than those about $\bar{x}$, and therefore the skewness computed on the basis of $G$ will be larger than if computed on the basis of $\bar{x}$. In this example the skewness computed on the basi of deviations above $G$ was 1.04 , indicating a distribution skewed to . . the right; when computed on the basis of deviations about the arithmetic mean., the skewness was 0.88 indicating a distribution that wis skewed to the left. These conflicting

- results were resolved by reference to the original interval mid-point data which had a skewness of 0.88 . That is, use of the geometric mean in computing variances and semi variances could result in substiantialiy biased results. 


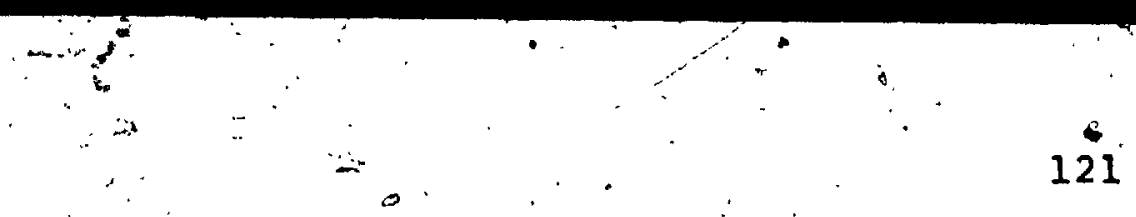

moment of .20 while indicating a positively skewed distribution, does not provide the above additional information. s

5.4 .4 Total Expected Return

The total return expected by an investor.

before taxes and commissions and assuming annual receipt and reinvestment of dividend income was computed as the internal rate of return $(r)$ implied by an individual's price and dividend distributions.

$$
\text { 'PO }=\frac{E_{A}\left(D_{1}\right)}{(1+r)^{1}}+\frac{E_{A}\left(D_{2}\right)}{(1+r)^{2}}+\cdots \frac{E_{A}\left(D_{t}\right)}{(1+r)^{t}}+\frac{E_{A}\left(P_{t}\right)}{(1+r)^{t}}
$$

where Po = base price of the stock

$t=$ the number of annual periods involved in the individual's expectation time-horizon.

$E_{A}\left(D_{t}\right)=$ the dividend expected to be received at the end of the $t$ th period based on

- the arithmetic mean annual rate of change expected in the dividend.

$\because$ $E_{A}\left(P_{t}\right)$

$=$ the price expected to be realizeable at the end of the $t^{\text {th }}$ period based on the arithmetic mean annual rate of change expected ithe price.

If fractional time horizons were indicated the individual was assumed to receive the appropriate fraction of the expected annual dividend. 10

10 If an ihvestor provided only a price, distribution it was assumed that he did not expect the stock's annual gividend to change and therefore the current dividend was used for all $D_{t} ! s$. By implication this assumed the aividend distribution would iave' a zero variance. N1ternately if only a dividend expectation was provided and individual was assumed to have a single point price distribution with zeco variance. 
s.

5.4 .5

The Standard Deviation of the Total Expected Return

"The standard deviation of an investor's combined

return ( $S_{c}$ ) was approximated by

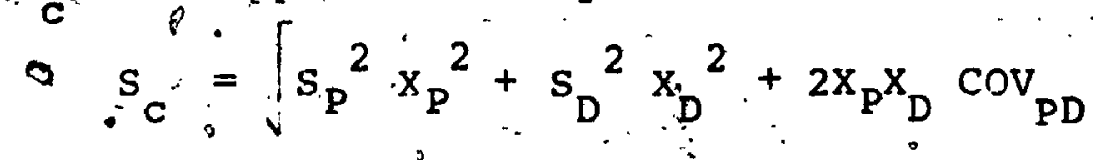

where $S_{P}=$ the standard deviation of an investor's price distribution (section 5.4.2)

$S_{D}=$ the standard deviation of an investor's dividend distribution (section 5.4.2) $\mathrm{X}_{\mathrm{P}}=$ the fraction of the total return 11

$F X_{D}=$ the fraction of the total return provided by "dividend income, 11 .

and $\operatorname{cov}_{P D}=$ the covariance of the"price and dividend, $6^{9} \mathrm{~g}^{\circ}$ elements of the totad return

$=I_{\mathrm{DP}} \times s_{\mathrm{D}}^{\prime} \times S_{\mathrm{OP}}$ where $\mathrm{r}_{\mathrm{DP}} \cdot$ is the correlation between the price and dividend elements of totgl return:

The formulation of the standard deviation of

the total return is an adaptation of the standard mathematical model used to compute the standard deviation of a two-security portfolio. 12 adaptation of this model to the situation s.

1'If an individual had a price expectation greater than zero the dividend portion of the total return was computed as $x_{D}=r-x_{E}$ where $x_{P}$ is the mean expected rate of price change. If the individual had a negative price expectation the dividend portion" of the tótal return was computed as:

$x_{p}=|r|+\left|x_{p}\right|$. Depending on the type.

of price expectation that an individual had his gros's return ( $T{ }_{D P}$ ' was then computed as $T_{D P}=\dot{x}_{D}+\left|x_{P}\right| \cdot T h u s$ $x_{v}{ }^{D p} x_{D} / T_{D p}$ and $x_{p}=x_{p} / T_{D p}$

12 Markowitz, op. cft., p. 89. 
Qf two elements ôf returñ from a single security fepresents a substanital deviation from the two-security portfolio analogy. The interpletation of the weighting terms $x_{P}$ and $x_{D}$ changes from the fraction of the total portfolio value invested in edch of two securities to the fractions of the total return that derive from the capital change and dividend elements of the total return. Furthermore thie estimation of the covariance between the price and dividend elements of return is subject to the constraint that investors were not asked to provide data rega the prige and aividend elements of expected return. - Thus the - standfrd deviation of total expected return as computed above can ofly be interpreted as an approximation to the variability of total return that an investor might have expected. 13 Two estimates of the córrelation between price and dividend behavior were made, on $\equiv$ based on the historical correlation between annual price and divideñd changes and the second based on the observed corrẹlation betwẹen expected annual price : and dividend changes.

The historical orrelation between price and dividend chánges during the period 1952-1972 were as follows: Stock A. 0.164; Stock B, 0.530; and stock C. 0.168: These correlations' were significant at the .10 levei only in the case of stock B. The correlations between the measured price and dividend expectations were as follows:

13 Jeain has shown that the. skewness of a two security-portfolio of dependent returins can be computed if the "; curvilinear association of the two returns is kpown: In the absence of data neoessary to approximate thi as acolation, a skewness computation was not undertaken. Jean! op cit. pp . 185-187. 
stock A, 0.532; stock B, 0.196; and stock C, 0.514 .

All three corfelation coefficients were significant at 1 the 0.041 lèvel or better. Thus investôr perceptions of the association betreen future price and dividend changes was indicated as being weakest for stock $B$ and much stronger for stocks $A$ and $C$.

The contrast in results between forward-looking and histofical data indicates that investors' perceptions of the assoriation between price and dividend changes are not consistent with the past record of performance for at least two of the three stocks ( $A$ and $C$ ), and in fact. - the relative strength of the correlation based on expectations data is opposjete to those based on historical datawith the price-dividend association being strongest for stock. B.

This incinsistency of correlation coefficients is open to a number ö́f rationalizations. For example, investors may not-be aware of the historical assocition between price changes and dividend change or, "if they. $+=$ are aware, they may be expecting a significant change. Abterffatively, a twenty-year relationship in the past may - not be the retrospective time horizon of individual investors. That is , inalividual investors may be lboking back over à. very short period. 0 ;ime and at the limit, totally ignoring the previous relationship between the stock's annual picice change and annual dividend change. 
5.5 - SUMMARIZING THE PARAMETERS OF INVESTORS" EXECTATIONS.

$\therefore$ To test the inter- and intra-stock hypotheses specified in chaptgr III regarding the mean, variance, and skewness of expectafions for the selected stocks, it was necessary to aggregate the above parameters of expectations of investors jssociated with the selected stocks.

For example, to compare the standard deviation of price expectations of investors associated with stock A with the standard deviation" of price expectation of investors associated with stock $B$, an average standard deviation $(\bar{S})$ was computed for stock $A\left(\bar{S}_{A}\right)$ and stoćk B $\left(\overline{\mathrm{s}}_{\mathrm{B}}\right)$ :

$$
\bar{S}_{A_{i}}=\sum_{i=1}^{N_{A}} \quad S_{A i} / N_{A}
$$

$\begin{aligned} \text { wher } \Leftrightarrow \mathrm{N}_{\mathrm{A}}= & \text { the number of investors associated with } \\ & \text { stock } \mathrm{A} \text {. }\end{aligned}$

$\because \mathrm{s}_{\mathrm{A}} \because=$ the standard deriation of the $i^{\text {th }}$

Additionally the standard deviation (SD) of this distribution of standard deviations was computed.

$$
S D=\frac{\sum_{i=1}^{N_{A}}\left(S_{A i}-\dot{S}_{A}\right)^{2}}{N_{A}-1}
$$

Analagous formulations were constucted for computing the average and the standard deviation of the mean and skewness parameters of investors. expectations. 
Statistical. comparisons of averages of expectations' characteristies were accomplished by one-or two-tailed ' $t$ ' tests where appropriate. Given populations of unequal variances (assumed) a ' $t$ ' statistic cannot be computed for differences in sample means. Instead an approximation to $t \mathrm{~m}^{2} y$ be computed ( $\left.t^{\prime \prime}\right) .14$

$$
t^{\prime}=\frac{\left(M_{1}-M_{2}\right)-\left(u_{1}-u_{2}\right)}{\left(\mathrm{sD}_{1}{ }_{1} / \mathrm{N}_{1}\right)+\left(\mathrm{SD}_{2}{ }^{2} / \mathrm{N}_{2}\right)}
$$

where: $u=$ population mean

$$
M \doteq \text { sample inean }
$$

- This statistic $\left(t^{\prime}\right)$ is not distributed as student's $t ;$ however, the probability for $t$ ' can be approximated by treating it as $t$, but with degrees of freedom (df) given by

$$
d f=\frac{\left[\left(S D_{1}^{2} / N_{1}\right)^{2}+\left(S D^{2}{ }_{2} / N_{2}\right)\right]^{2}}{\left(\frac{\left(S^{2}{ }_{1} / N_{1}\right)^{2}}{N_{1}}+\frac{\left(S D_{2}^{2} / N_{2}\right)^{2}}{N_{2}}\right.}
$$

Throughout the analysis of inter- and intra-stock differences in expectations, differences were considered to be - Tignificant' if the probability of obtaining a $t$ ' statistif was equal to or less than $10 \%$ for both pner and two tail tests.

${ }^{14}$ W.J. Dixon and F.J. Massey Jr.., Introduction to Statistical Analysis 3rd Ed. (McGraw Hill, 1969), p. 119 . 
The methiodology of this study was presented in this Chapter. Essentially, methodological considerations involved developing an consistent expectations - measüring device that would be applicable across ali three stocks involved in this study. These stocks were selected on the basis of several criteria and if consultation with the investment dealers cooperating in this study. This Chapter further dealt with the details of the computations involved in summarizing the central tendency, variability and asymmetry of invęstor price, dividend, and total return expectations. Finally the nature of the statistical tests of significance empioyed in the study was presented along with the decision to accept as. significant, difference in expectations that were indicated as having only a $10 z$ or less chance of occurring. 
The results of testing the empiriçal hypothesis proposed in Chapter III are reported in the following. sections. Essentially these tests involved inter-and intra-' stock comparisons of expectations of samples of market participants assóciazed with three different stocks. stock'A is a major utility; stock B; a mineral resource company; and Stock c a petroleum resource company.

$6.1:$ OVIRVIET OF MEASURED EXPECTATIONS Approxinately 2700 questionnaires were mailed to investors during the period March 19 - April 13, 1973. Four hunared questionnaires were sent to orners of each of the three stocks involved in the study and approximately 1500 were-serit to buyers, and sellers. In total 828 were returned resulting in a gross response rate of approximately 318. of these returns, 24 questionnaires were completely unanswered fror a variety of reasons (death, total reliance on professional advice, lack of interest, etc.). From the renaining 804 questionnaires, 723 (90\%) price expectations and $684(85 \%)$ dividend expectations were jugged to be usable, of these usable expectations 683 respondents provided 
both a usable price and dividend expectation; that is 40 individuais who provided usable price expectations did not provide $a^{-}$: usable dividend expectation. Thus the minimum usable : response rate to the mailing. was approximatley $25 \%$.

\section{1 .1 Response Types}

Among the 804 usable returned questionnaires

several distinct types of responses to the expectation items were noted. Examples of these variations are provided! in Figure $6.1^{\circ}$ and the frequency of occurrence sutrmarized in Table 6.1.

As indicated in the accompanying Table and. Figure, approximately $68 \%$ of investors responded to the price expectations questions in the manner that had been anticipated. That iss, the perceived possibility of both positive and negative deviations from the present price decreased to zero as the magnitude of the deviation increased: A further $24 \%$ of respondents provided some variation of this type- of response with the single most significant variation $(12 \%)$ being distributions that were truncated at the high end (but not at the low end) of the scale of future values. This finding indicated that the range of values provided in the questionnaire for upward price changes was either inadequate or that investors "upward* expectations for possible future changes in price were unbounded. The summary statistics computed for this type 
FIGURE 6.1

TYPES OF EXPECTATION RESPONSES.

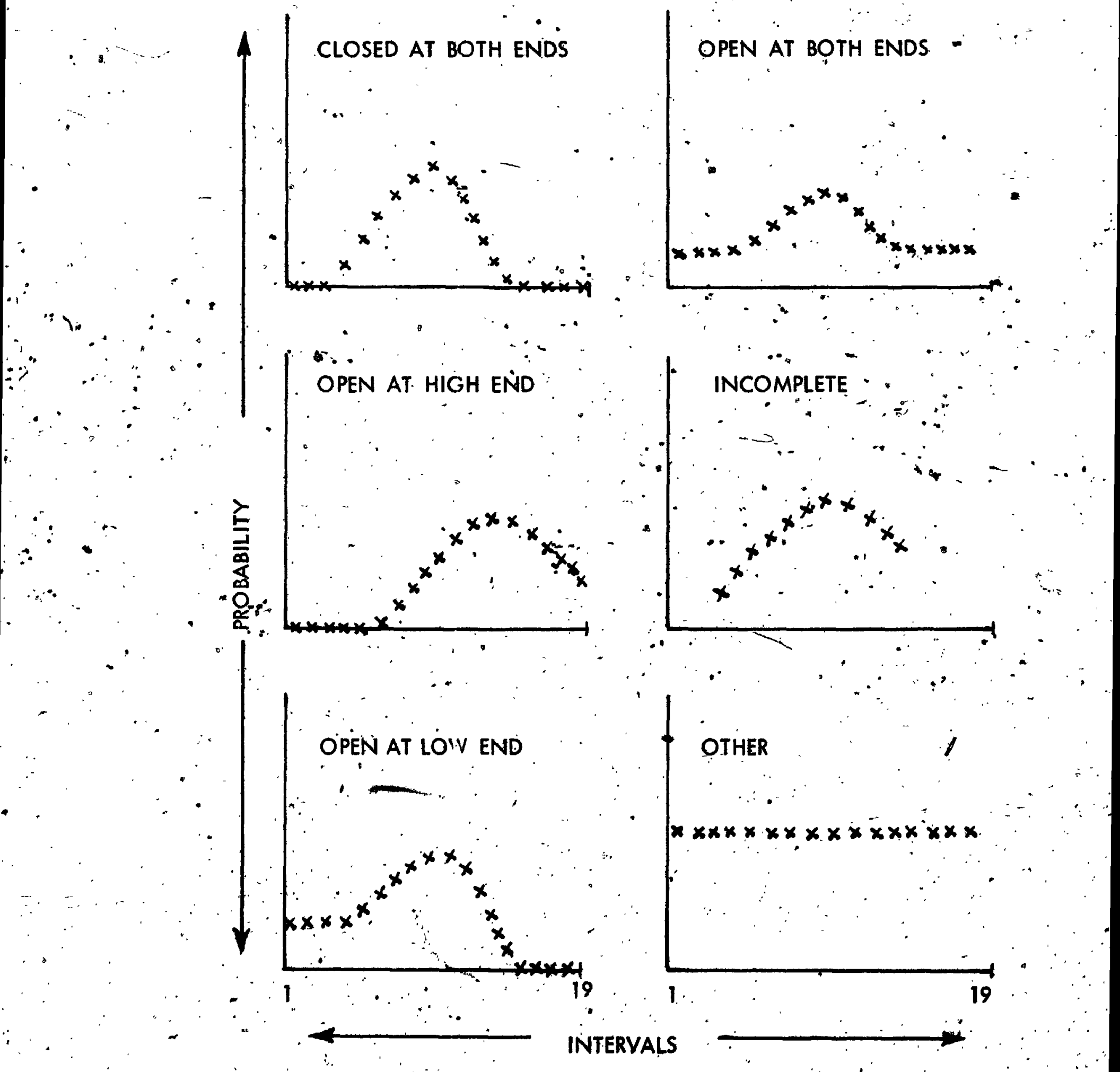


of expectation:would therefore result in a smaller mean, standard deviation, and skewness for these distributions. Comparison of the response types across' the three stocks indicate that the frequency of 'open at high end' responses was least for Stock $A$, intermediate. for Stock $B$ and - greatest for stock C. Hence, understatement of distribution statistics would tend to be greatest for stock $c$ and - least for stock A:

Non-response to the price expectations questions was found in approximately $9 \%$ of the returned questionnaires indicating that respondents either did not comprehend the meaning of the questions; , were unwilling to give the questionnaire the required time, or did not have any particular expectation of price change.

The above pattern of results was also found for dividend expectatians'. However, the incidence of dividend expectations that were closed at both ends was lower in the aggregated and consistently less across all: three stocks than in the case of price expectations. similarly the incidence of non-response was uniformly greater in the case of dividend expectations than price expectatiors.

$\rightarrow$ It is interesting to note that the six-interval price change distributions obtained from securtty analysts by pankoff and virgil exhibited similar variations 
in the form of respondents expectations. These distributions are presented in Appendix II.

6.1 .2 Relative Shape of Price and Dividend Expectations To further. the general description of measured price and dividend distributions, the relative shapes of the distributions were compared in accordance with the hypotheses prèsented in Chapter IV. Hypothesis 4.1 (restated)

An investors' price expectations for a particular stock should reflect greater uncertainty (variability) than his dividend expectations.

The results of testing this hypothesis are - presented in rable 6.3. A binomial test ${ }^{2}(p \neq .5)$ on the total of respondents having a greater standard deviation of their price expectations than their dividend expectation supports the validation hypothesis peyond the .0000 level. Hyothesis 4.2 (restated)

An investors' dividend expectation. should reflect less downward variation from the current dividend rate than ${ }^{2}$ s. Siegel, Nonparametric statistics, MccrawHi11. New York, 1956) p. 40 
Table 6.3

RELATIVE-UNCERTAINTY OF

PRICE AND DIVIDEND EXPECTATIONS

$R$

Relative

Uncertainty

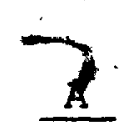

Company

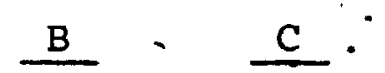

TOTALS

1. Price standard Deviation Greater than Dividend Standard Deviation

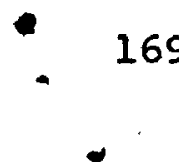

142

75

386

2. Dividend standard Deviation

Greater than

Price Standard

110

56

269

Deviation

3. Price and

Dividend

Standard Deviation

Equa 1

13

9

6

28

Totals

28.

261

137

683 
than his price expectation in relation to the current market price.

The results of testing this hypothesis are presented in Table 6.4. In interpreting the results of this test it should be noted that stock ${ }^{\circ} B^{\prime} s$ dividend did not fit the increasing'stream hypothesis; that is, during the past several years the dollar-dividend had decreased. A binomial test $(p=.5)$ on the total of respondents having price expectations with greater probability of downware deviations than corresponding dividend expecta-

( 'tions supports" the validation hypothesis beyond the $=003$ level. Thits result was found when the expectations for stock B were included and excluded from the binomial tests. Thus, on the basis of the criteria outlined in the above hypotheses the expectations that were measured were con- 4 sistent with theoretical propositions regarding their shape.

\section{1 .3} Qpes: of Investors Associated with the Three Stocks While the primary concern of this study was

- with investors' expoctations of financial return, selected non-expectational data were also collected in the questionnaires. Inter-stock comparisons of this data are presented. 


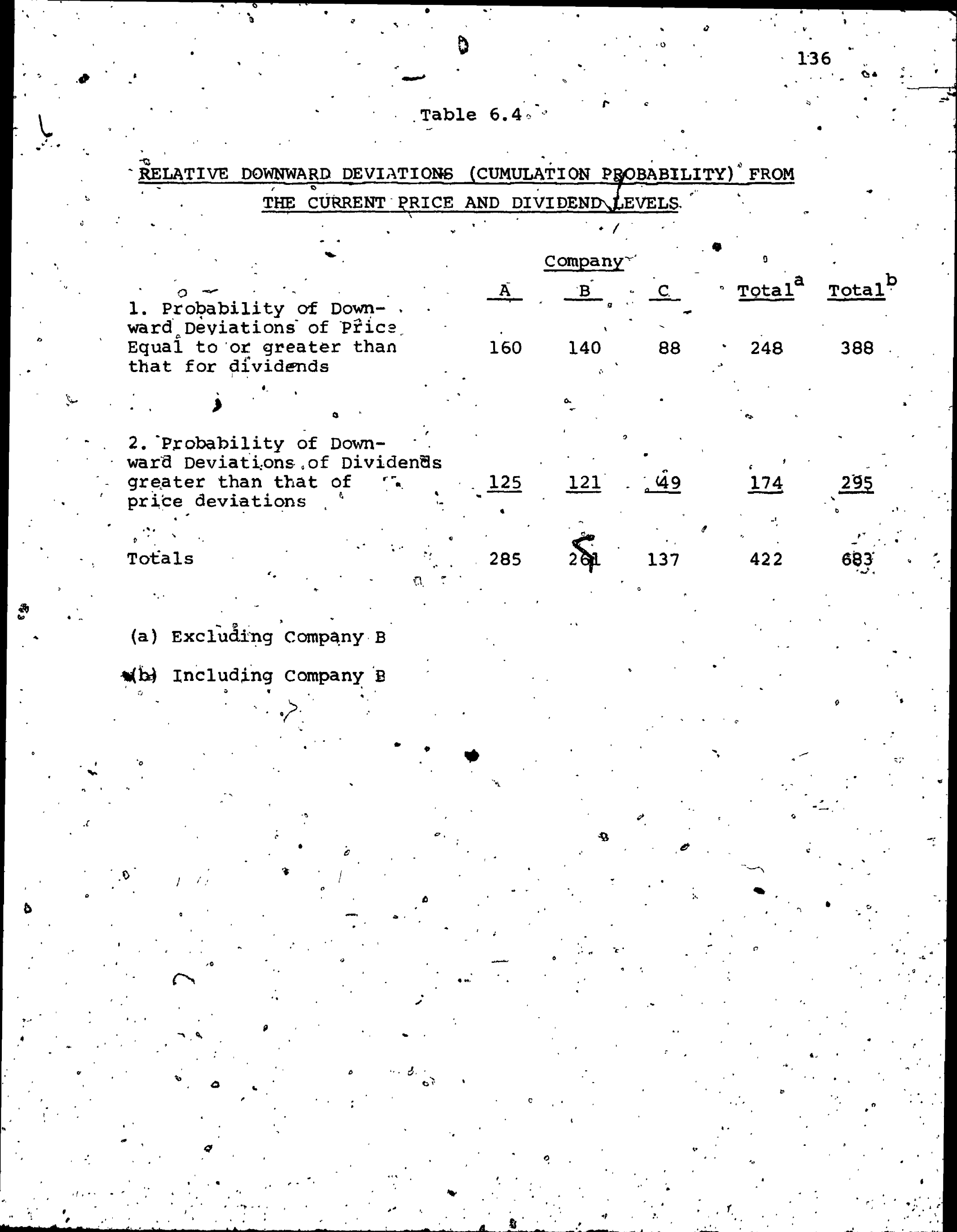


in Tables 6.5 throuch 6.10 to provide perspective with which to view the expectational results. Chi-square tests 3 of the data in these tables indicated that significant .., differences across stocks were found at the .10 olevel or better for several socio-economic inviestor characteristic. Chi-square tests indicated that:

(a) The age of market participants is not ind ppendent of the stock with which they are assiciated (.02 level)." Inspection of the data indicates hat investors associated with stogk $B$ are generally younger than those associated with either stock $A$ or $C$ (Táble 6.5$)^{5}$

(b) The annual income of market participants is not independent of the particular stock with which they are associated (.001 level). Investors associated with stock B tended to have larger annial incomes thán investors associated with eithér stock $A$ or: C (Table 6.6 ) of the "latter "two stocks, investors associated $\therefore$ with stock $c$ tended to have larger incomes than investors assogiated with stock $A$ $($ Tabl $, 6: 6)$ ${ }^{3}$ Ibia. $\because$ po 174. 
138

$\therefore \quad \therefore \quad$ AGE OF RESPONDENTS

0

Table 6.5

$$
\begin{aligned}
& 34 \text { years and } \\
& 17.5 \\
& \text { in. } 5 \\
& =17.4 \\
& 20.6 \\
& 16.2 \\
& 22.6 \\
& 25.5 \\
& 55-64 \\
& 20.5 \\
& 25.7 \\
& 7.6
\end{aligned}
$$$$
65 \text { and over }
$$

Number

.8

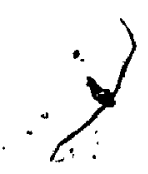


Table 6.6

\section{ANNUAL GROSS INCOME OF RESPONDENTS Y}

A

$\because \frac{\text { Company A }}{(\varepsilon)}$

$\frac{\text { Company B }}{(8)}$

Company $\mathrm{C}$

(z)

$\because$ Under, $\$ 5 ; 000$

19.8

10.3

20.1

$5: 001-10,000$

$16 \cdot 4$

14.0

14.0

$10,001-15,000$

2.6 .0

21.6

18.3

$15,001-25,000$

25.4

29.1

17.0

$25,801-50,009$

$j .0 .5$

over $\$ 50,000$

1.9

$j^{8.5}$.

21.3 .

6.5

9.1

Number

323

292 
Table 6.7

\section{SIZE OF COMMON STOCK PORTFOLIO}

$\frac{\text { Company } \ddot{\mathrm{A}}}{(\%)} \cdot \frac{\text { Company B }}{(\%)} \cdot \frac{\text { Company C }}{(\%)}$

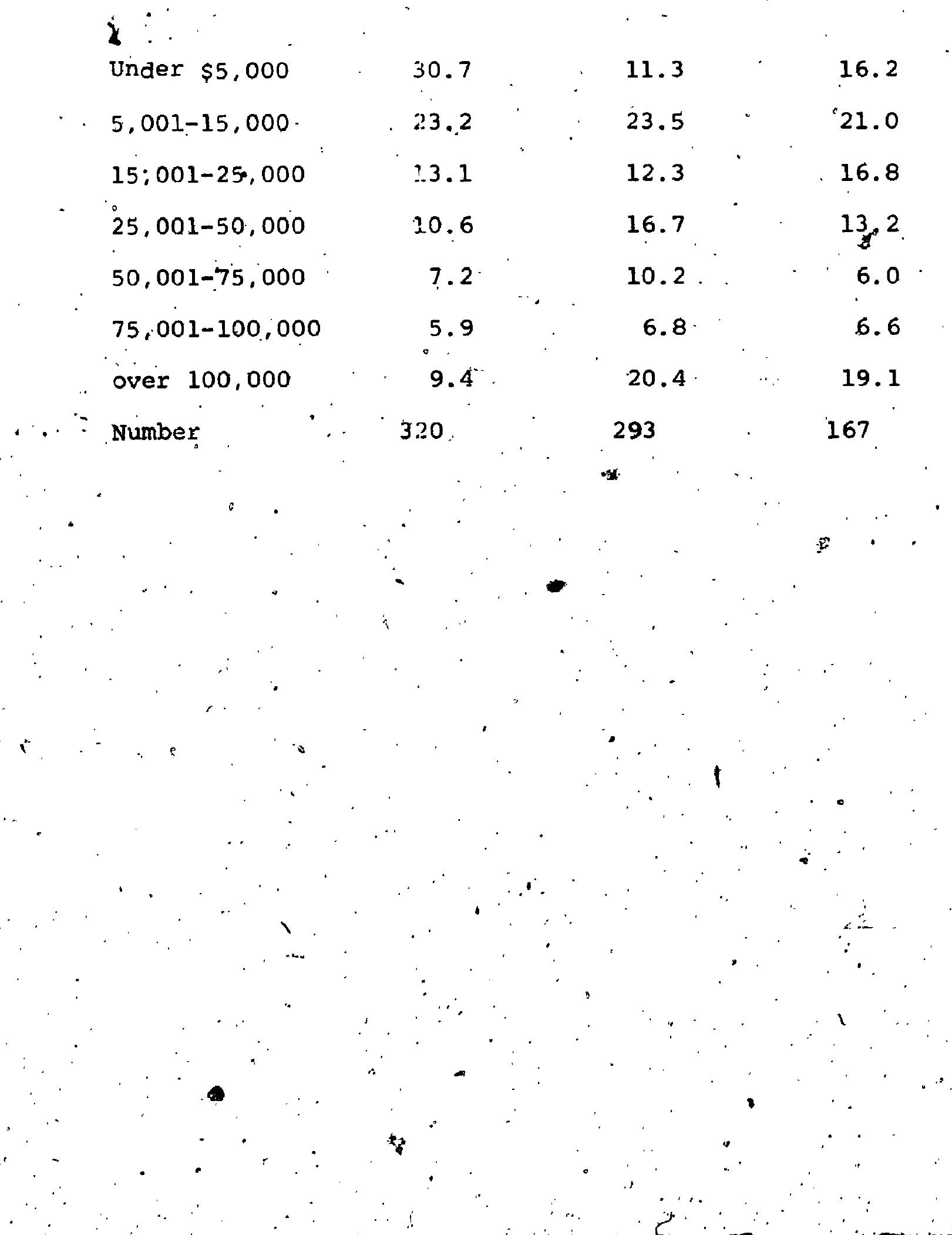


Table 6.8

REASONS FOR PURCHASE OR OWNERSHIP

$\frac{\text { Company A }}{(\%)} \cdot \frac{\text { Company B }}{(\%)} \quad \frac{\text { Company C }}{(\%)}$

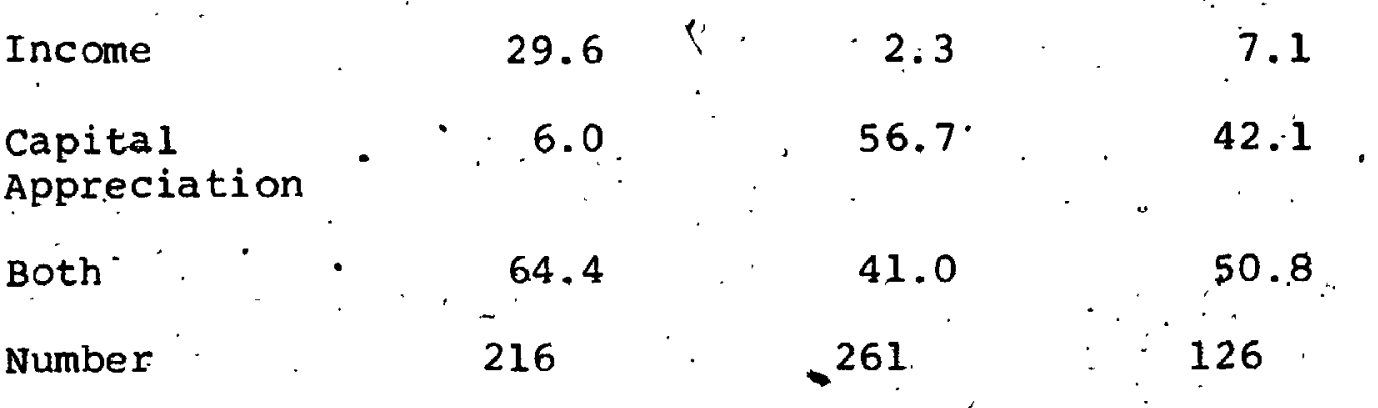

Table 6.9

REASONS FOR SELLING

$\frac{\text { Compàny } A}{(\%)}$

Company B

(\%)

Company C

(\%)

Consumption

41.7

14.3

15.6

Invęsting

38.9

57.1

55.6

other

19.4

28.6

28.9

Numbẻr

108

45

35 


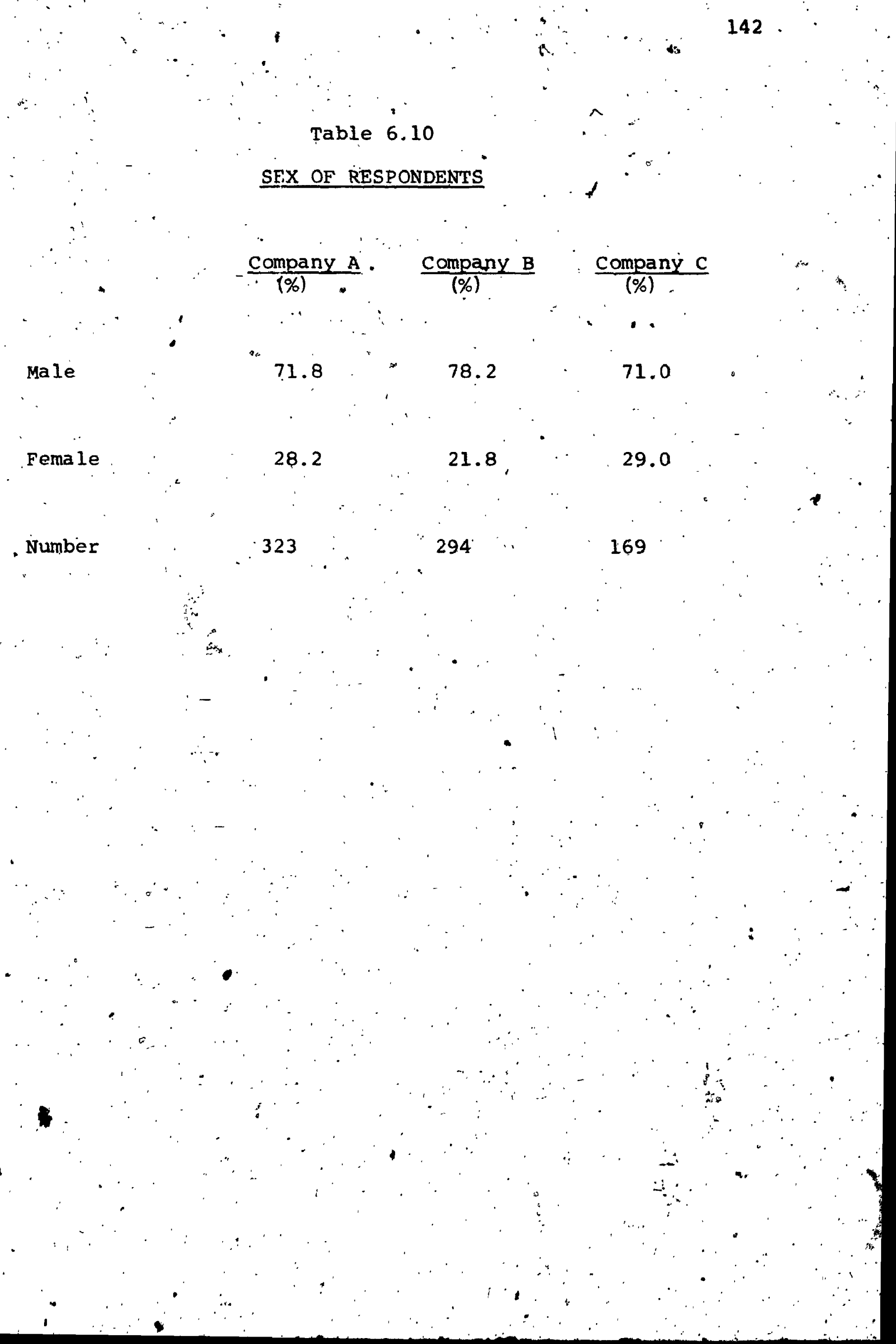


(c) The size of market participants" common stock portfolio is not independent of the particular stock with which they are associated (.001 level). Inspection of the data in Table 6.7 reveals that those investors associated with stock $B$ tended to have larger (dollar value) common stock portfolios than investors associated with either stock A or $\mathrm{C}$.

(d) Market participants! reasons for orning or buying a particular stock are not independent of the stock with which they are associated (.001 leve1).. Investors associated with Stock $A$ tended to be more dividend-income. oriented than investors associated with either stock B or stock C. Investors assocíated with stock $\mathrm{B}$ tend to he more capital-appreciation orientated than investors associated with Stock C: (Table 6.8$)^{\circ}$.

(e) Market participants ' reasoñs for selling a particular stock are not independent of the stock with which they are associated 1.01 o leve1): Investors selling stock $A$ are doing so primartly for consumption purposes while those 
seliing Stock B or C are doing so primarily for reinvestment (Table 6.9).

(f) The sex of market participants is not independent of the stock with which they are associated $(.05$ level). More males are associated with Stock B than with either Stock A or stock C (Tabie 6.10).

In summary the above findings support the proposition that different types of investors are associated with the various stocks involved in this study. In essence this non expectational data indicates that investors associated with stock $B$ are: generally younger, have larger. annual incomes and common stock portfolios, and are more capital gains oriented than investors associated with either Stock $A$ or $\mathrm{C}$. Furthermore, investors seiling stock $A$ are doing so primarily for consumption purposes while those seling stock $B$ or $C$ are doing so mainly for reinvestment purposes.

The abcue profile of investors associated with stock B intuitively seems to fit the description of Individuals who would be better sufted for investing" in riskier securities than individuals associated with stocks A or C. 
6.1 .4

Comparative Yields on Other Investments

The returns available on a variety of saving/in-

vestment instruments available in Canada during the $t$ of the study are provided in Table 6.11: These returns

- are presented to provide additional perspective in which to view the méasured magnitade of price, dividend, and.

total return expectations of the three stocks. involved in this study:

$6.2 \quad$ RESPONDENTS ' TIME HORIZONS

* As indicated in chapters III and IV, a respondent-supplied tine horizon is an integral characteristic of a respondent's, expectations: Initial data analysis indicated that the time horizon could have a very substantial impact on the magnitude and uncertainty of an investor!'s summarized expectations. For example, one purchaser of stock $c$, who had a time horizon for that stock of one month, expected a mean annual rate of capital appreciation of $737 \%$ with a standard deviation of $1564 \%$.

Computational results such as this were found only in cases of individuals having very optimistic and very short-term expectations, and were due to the reinvestment assumption implicit in the jompounding model. since such results would distort an average of mean annual rates of change, investors: expectations involving a time horízon of less than ore year were excluded from the subsequent analysis. The result 
Table 6.11

SUMMARY OF YIELDS ON VARIOUS INVESTMENTS

DURING THE TIME OF THIS STUDY

Whàt Money Earns Now**

SHORT-TERM MONEY

'MARKET - SECURITIES

Canada treasury bills

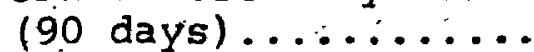

Do. (180 days)

Bank certificates of

Zesposit ( 90 days) .

Do. (180 days) . A....

Do. (364 days) .......

Trust company deposit

receipts ( 90 days) ..

Finance company

papér (90-days) $\therefore \ldots$

Do. (180 days) $\ldots$...

Do. (364 days) ......

Commercial paper 190

days ) .............

Bankers' acceptances

(90 days) ..........

Day loans ...........

Prime rate $. . .8 . .$.
Recent:

yield $\%$

4.48

$4: 81$

$53 / 8$

$53 / 4$

6.

$53 / 8$

$51 / 2$

$53 / 4$

$\therefore$

FEDERAL GQVERNMENT BONDS :

Canada: $5 \%$ due 1973

Do. $4 \frac{1}{2} \%$ due 2.983

Do. $5 \frac{1}{4} \%$ due 1990

LONG-TERM PROVINCIAL BONDS:

Alta: Municipal Financing

Corp.

Manitoba Hydroelectric

Ontario .............

Quebec

LONG-TERM MUNICIPA'L BONDS:

Toronto ............

Montrea 1

.80

7.94

7.86

8.00

5.40

4.45

$61 / 2$

5.10

7.03

7.44

7.95

8.12

7.97

7.94

8.17

LONG-TERM CORPORATE BONDS:

Bell Canada ........

Domtar ttd. .........

Union Gas Co. of

Canada .............
Month ago

yield :

4.10

4.42

5. $1 / 8$

$51 / 4$

$51 / 2$

$51 / 8$

5

$51 / 2$

$51 / 2$

5

4.85

40

5.00

$6: 98$

7.31 .

$7 \cdot 75$

7.95

7.85

8.00

7.93

8. 12

7.86

7.94

8.12 
$\boldsymbol{\gamma}$

Table 6.I1 (cont'd)

STOCKS :

Recent Month ago yield \% , yield \%

Av. yield 64 common

industrials*.........

Do. 18 preferred and .

3.45

3.48

A shares*...........

Reál estate mortgages:

N.H:A. single family..

N.H.A. mental projects Conventional ........

N.H.A. net investment

yield ..............

SAVINGS. DEPOIITS :

Chartered bank

(chequable) ..........

Do. (nonchequable)....

Trust companies

(chequable) ..........

Do: (nonchequable)....

TERM MONEY :

Trust \& Loan co. GIC/

debentures $(1-2$

$\because$ years) $\ldots \ldots \ldots \ldots \ldots$.

po. $(3-5$ years) $\ldots \ldots$.

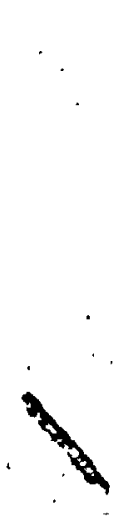

6.13

6.34

$\begin{array}{rr}9-9 & 1 / 2\end{array}$

$9-9 \quad 1 / 4$

$9-9 \quad 1 / 2$

8.875

$9-91 / 4$

*Moss, Lawson \& Co. averages:

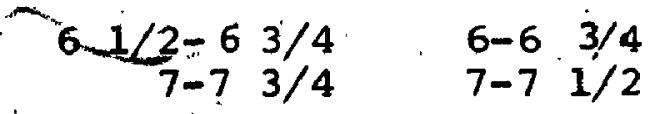

N.H.A. mortgage investments available from Gairdner \& Co.

* Source The Financial post, April 14, I973. 
of this exclusion are presented in Table 6.12. Also included in Table 6.12 are the results of grouping expectations by two time horizons: one-and two-year horizons, and,three or more year horizons. "Such a grouping was indicated in chapter II as being necessary in order.: to control inter- and intra-stock comparisons of expectations for differences in time horizons. Other possible groupings were considered but rejected since isimultaneous control for time horizons and the type of investor in hypotheses tests would have resulted in some comparisons involving fewer than ten respondents.

\section{2 .1 Time Horizon Comparisons}

The data in Tablé 6.13 indicates the result of comparing investor time, horizons by stock and by type of márket participant aftex exclusion of lessuthanone-year horizons.

In the aggrégate (buyers, sellers, and owners) investors associated with stock $A$ or stock $\mathrm{C}$ had an average time horizons of 4.4 years and 4.3 years respectively. Investors associated with stock B had "significantly 10.05 level) shorter, time horizons: 3.5 years.ón average. In contrast, analysts' time horizons were relatively short A. for both stocks $B$ and $C$ and" longest för stock $A$. In general 


\section{RESPONDENTS' TIME HORIZONS FOR}

USABLE EXPECTATIONS

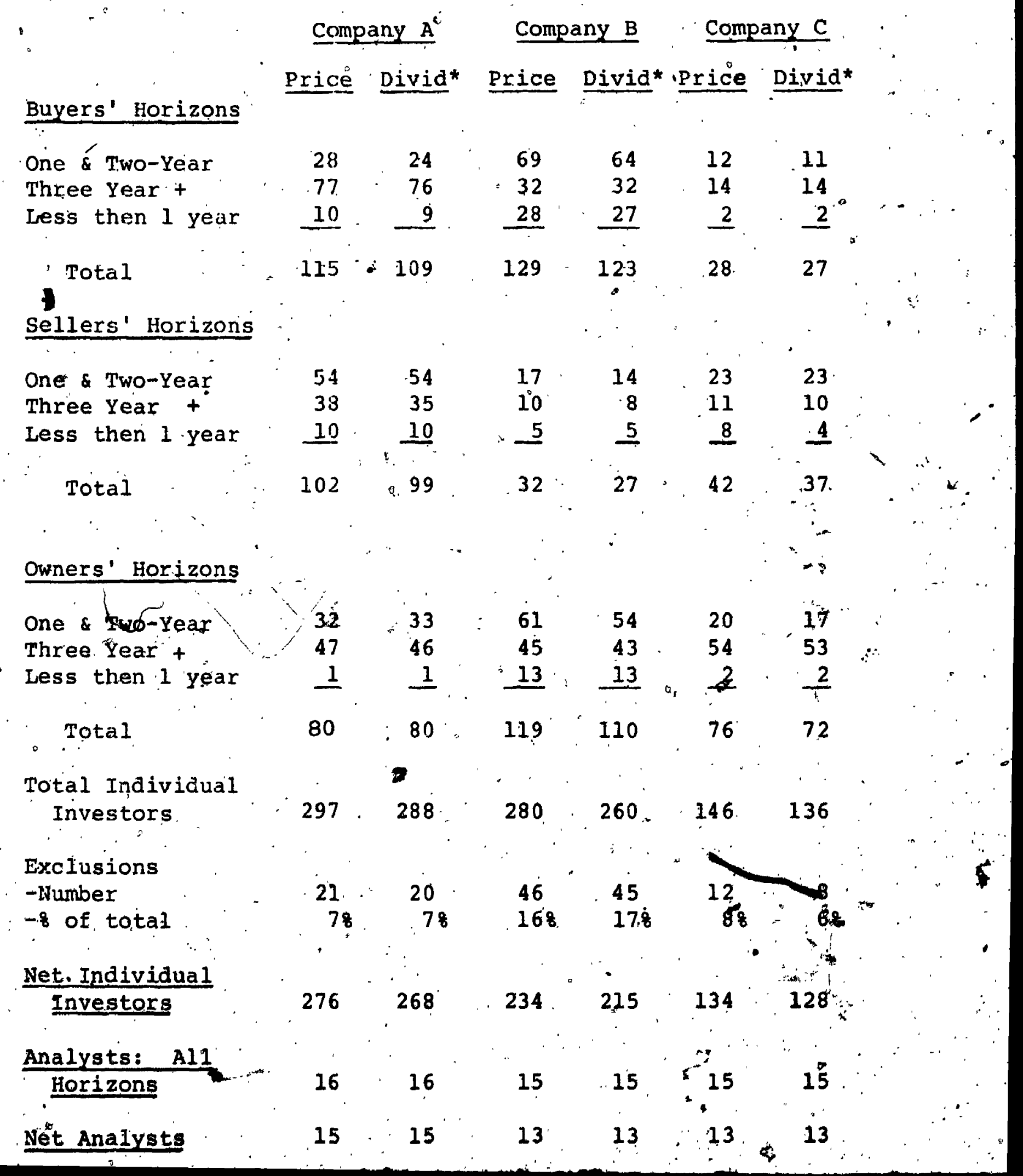


Table 6.13

'COMPARISONS OF MARKET PARTICIPANTS' TIME HORIZONS (a)

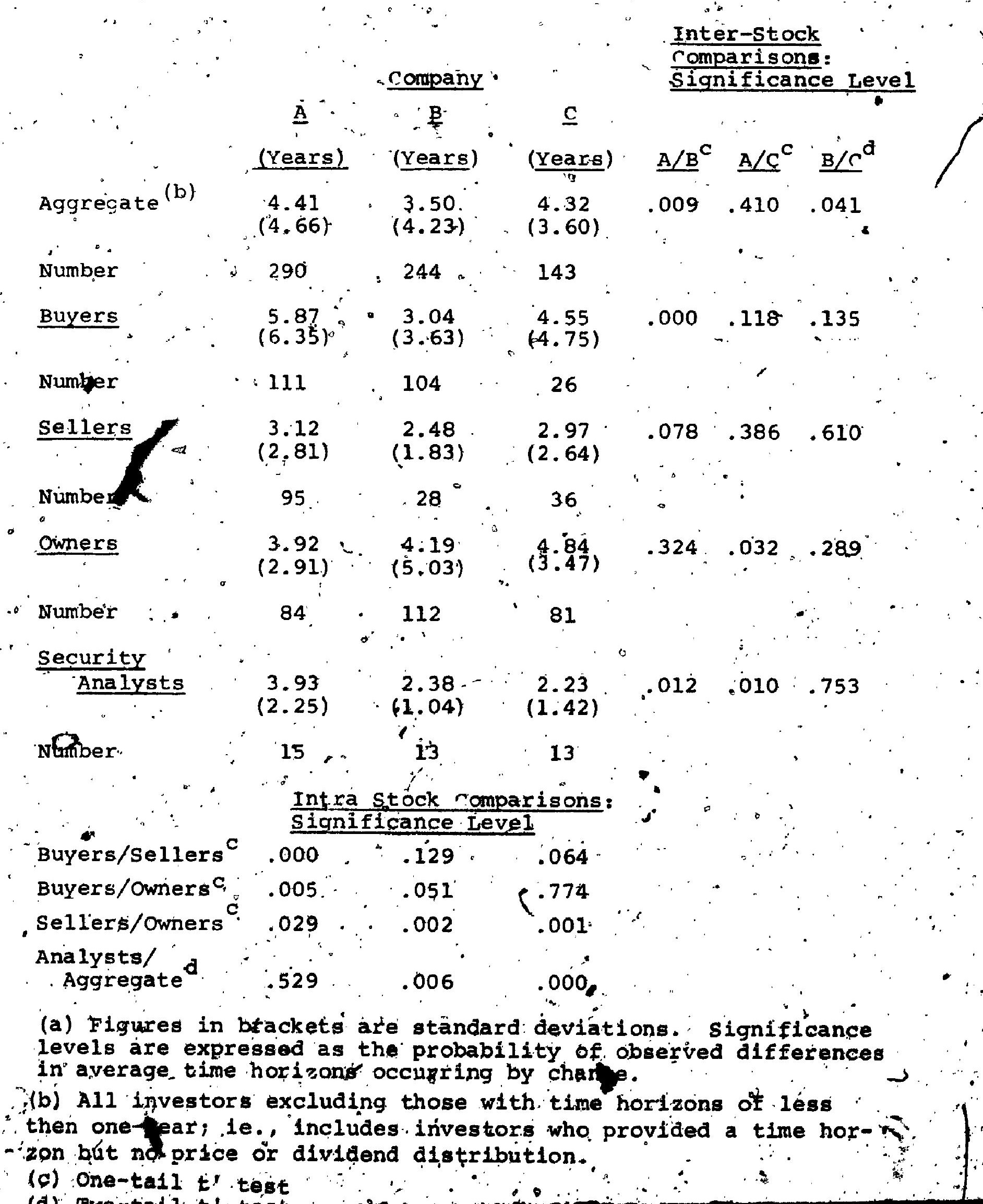


security aralysts' time harizons were, shorter than individual investors 4

Ap aduitional finding indicated in Table 6.15

is that sellers have consistently shorter time horizons than either buyers or ówners: Sieliers of stock B had 'the fortest harizons averaging 2.5 years selleprs of stochat the longest harizons averagtig 3 '1 years; and, sellew of stock $C$ had about the same time horizon as thoseffor stock A - 3:0 years. No eledr pattern emerged : in comparisons of buyers and owners tîme horizons. 5

6.3 $\quad \cdots \quad$ PRESENTATION OF MANOR FINDIINGS

In chapter III two sets of empiricál hoptheses were proposed; those pertaining to inter-stock and intrastock differences in expectation statistics. "As was noted" inter-stock cómparisóns required controls for both the type of investor associated with a particular stock and

${ }^{4}$ If an expector's time horizon is postulated as being inversely related to his perception of the, riskiness of a stock's. future return then the ordering ' of aggregates of individuals' time horizons. would indicate that: stock B was relatively more risky" than both stock $A$ and stock $\dot{C}$. Ranking security apalysts " time-horizons howeyen would indicate only, that Stock A was less risky than stock B und stock $c$. .

${ }^{5}$ If an expectoris time horizon is interpreted as bejo "inversely related to his perception of thempkiness of $a$ 'stock's- future return then this :finding would suggest that seliers view their respective stocks as being more risky than either buyers ox owners: Additiona 111 one could spéculate that potential sellers of aistock could befidentified from among the shareholder popilation 'by chanqes in owners. time horizons for that stock. 
the time horizon of the expectation. 6

The results of hypotheses tests pertaining to ? price expectations are presented in sections 6.4 those pertaining to dividend expectations in section 6.5; and those involving expectations of total retru in sections $6: 6$. The sequence of hypotheses tests tapplied to price expectations is outlined below for illustrative purposes...

a) Inter-stock Hypotheses

For each stock the mean price expectations of all investors associated wh that stock were averaged. This'average was then compared to the oorresponding average for each of the other "two stocks. A lirectional t'. test' - was used in the case of stock $A /$ Stock $B$ and stock A/Stóck C comparisons and a noph-directional test for stock B/stock f comparisons "Thus the atverage mean price expectation. of all investors (buyers, sellers, and owners) associated with stock $A$ was compared with the average mean price expectationof all investors associtated with stogk $B$ and so on. -

${ }^{6}$ control for the type of investor was necessary for inter-stock comparisons because of the possible dis-. proportionate representation of vuyers, selièrs, or ówners in the aggregate sample of market particlpants associated. with a particular 'stock. Control for the time horizon of expectations was necessary becausse of the substantial imparct that the time horizon of an expectation has on the computed summary statistics of an investor's expectation. The just noted differences in time horizons among the different types of investors and across stocks reinforces the decision to control for time horizons in inter- and intra-stock comparisonth. 
The above procedure was then applied to the standard deviation and the, skewness of investors' price expectations.

b) Intra-stock Hypot:heses

(i) for each stock the mean price expectations of all buyers were averaged and compared sequentially. with the corresponding average for each of the other two types of investors - seller's and owners. A directional. t' test was employed for Buyer/seller, Buyer/Owner, and Seller/Owner compairisons.

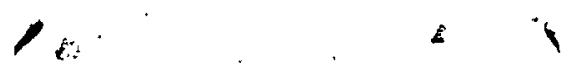

(ii) The above comparisons of price expectafions were then repeated with buyers, sellers; and owners classified according to whether or not" they had short-term (one-and two-year) or long-term (more than two-years) time horizons.

Thus the average mean price expectation of shortterm buyers of stoc's A was compared sequentially with the average mean price expectation of short-term sellers of stock $A$ and short-term owners of stock $A$. These comparisons were then repeated for stock B and stock $C$.

All of the foregoing intra-stock comparisons were then applied to the standard deviation and the skewness of investor $s^{\circ}$ price expectations.

c) Controlled Inter-stock Hypotheses

The inter-stock comparisons indicated in (a) above were repeated with control exerted for the type of investor a nad then for bothe type of investor and the 
time horizon of the expectation.

(i) Control for the Type of Investor

For each stock the mean price expectations of

buyers of the stock were averaged and compared to the corresponding average for each of the other two stocks. This procedure was then repeated for sellers' and owners' price expectations.

Additiorally the above procedures were then applied to "the stancard deviation and skewness of investors' price expectations.

(ii) Control for the Type of Investor and the Time Horizon of the Expectation.

The above comparisons of type-of-investor-controlled Inter-stock comparison were then repeated with buyers, seliers and owners flassified according to whether or not they had short-term or long-term time. 6. horizons.

- $\quad-\therefore$ Thus for each stock the mean price expectation of short-term buyers were averaged and compared with the corresponding average for each of the other two stocks. Thi's procedure was then repeated for long- term buyers. - After comparing huyers' expectations in this manner, 'indentiçal comparisóns were mate of sellers' and owners' price expectations.

In addition; the above procedures were applied to the standard devilation and skewness of investors price expectation's. 
d) Inter-Stock Hypotheses and-Analysts' Expectations' The inter-stock comparisonstin (a) above were replicated using security analysts' expectations instead of individual investors' expectations.

e) Intra-stock Hypotheses and Analysts' Expectations

For each" stock the mean price expectations of " " al1 individual investors associated with that stock were averaged and compare to the corresponding average of security analysts price expectations. A non-directional $t^{\prime}$ test was employec in these comparisons.

This proceudre was then applied to the standard deviation and skewness of investors' and analysts' price expectations.

Upon completion gf the foregoing five sets of comparisons for price expectations, these comparisons were repeated for dividend expectations and expectations of total return.

6,4

PRICE EXPECTATIONS

Investous i price expectations were afialyzed for inter-and intra-stock differences In the sequence outlined In section $6: 3$.

6.4 .1 Inter-s=ock comparisars of Price Expectations The results of inter-stock pair-wise comparisons of the mean, standard deviation, and skewness of 
investors' expectations are presented in Table 6.14 and discussed in the. following paragraphs.

a) stocks $A$ and $B$

The rate of growth expected in the market price of stock B was significantly (.000 level) more optimis- . tic (12:8\% per annum) and more uncertain $(15.0 \%)$ than the prict expectations for stock A $14.5 \%$ per annum and $7: 7 \%$ respectively).

In addition to the greater magnitude of the expected return, the price expectations for stock $B$ reflected greater right skewness (1:128) than those for stock A (1.083).

b) Stocks A and C

The rate of growth expected in the market price of stock $C$ is significantly (.000 level) more optimistic $(6.8 \%$ per annum) and uncertain $(11.8 \%)$ than the price expectations for stock A (4.5\% per annum and $7.7 \%$ respectively). 'Additionally the price expectations for Stock C were significantly (.070 level), more right-skewed than those for stock $A$.

stocks B and C

The rate of growth expected in the market price of stock B was significantly (.001 level) more optimistic (12.8\% per annum) and more furcertain (1.5\%) than in the case-of stock C $16.8 \%$ per frnum and $12 \%$ pectively). 
Table 6.14

INTER-STOCK COMPARISONS OF SUMMARIZED

INVESTOR PRICE EXPECTATIONS (a)

Company

$\frac{\text { Expectation }}{\text { Parameters }} \quad \therefore \quad$ B $\quad$ C $\quad \underline{A}$ of Comparisons

Average

Mean (b)

$\begin{array}{lcc}.045 & .128 & .068 \\ (.063) & (.121) & (.071)\end{array}$

$.000 \quad .000 \quad .001$

Average std.

.077

.150

$(.074)$

(.111)

.118

$(.092)$

.000

.000

.003

Deviation

Average

skewness (c)

$1.083 \quad 1.128$

$(.476)$

$(.339)$

1. 137 .

(.269)

.106

.070

.776

-

Number -

276

234

134

(a) The "Average Mean" and "Average std. Dev." are in üits of annual rate of change. Figures in brackets are standard deviations.' Significance levels are expressed as the probability of observed differences in averages occurring by chance. Stock $A / S t o c k \cdot B$ and stock $A / S t o c k$ C significance tests involve one-tail t' tests; stock B/Stock C tests involve a-non-directional $t$ ' test.

(b) On a hiștorical basis the average annual rates of price change for the period 1952-1972 are: stock A (.011), stock B (.082), and stock C (.095). These rates of change are not directly comparable with the figures presented in this table since the historic data does not incorporate the mix of time horizons inherent, in the expectational data.

(c) The skewness coefficients indicated that the percentages of the total squared deviations to the left of the arithmetic mean of the price distributions are: $46.2 \%$ for stocks $\mathrm{A}$. $44.3 \%$ for stock B, and $43.9 \%$ for stock C. 
In contrast with earlièr results the asymmetry factor. was not significantly different between stocks B and dalthough the right-skewness for stock $c$ was slightly greater than that for stock $B$.

d) Discussion

The above findings for each of the three stocks are summarized in Figure ' 6.2 which plots the expected return and risk of each of the three stocks in risk-return space.

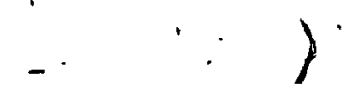

Based on the differences' in the risk-return characteristics of aggregates of investors associated with each of these three stocks, stock $B$ is indicated as being the most risky of the three stocks in terms of expected future price appreciation, stock. A the least risky, and stoock $C$ intermediate to stocks $A$ and $B{ }^{7}$ This finding is consistent with the relative riskiness of the three stocks as indicated by the beta coefficients presented in chapter $v$. In fact, the data indicates that as the risk.increases, the optimism increases more than proportionately. Specifically, the "sensitivity" of the average mean to changes in the : average standard deviation is, less (.960) between stocks A

\section{${ }^{7}$ The earlier observed fact that proportionally} more price expectations for stock $c$ were open at the highend than for stocks $B$ and $A$ would tend'to understate the differences bretwéen Stocks $A$ and $C$ and Stocks $A$ and $B$.

8 "Sensitivity" is defined here as the ratio of the percentage change' in the average mean expectation between two stocks to the percentage change in the average standard deviation between the two stocks. 
159

FIGURE 6.2

AVERAGE RISK AND RETURN OF PRICE EXPECTATIONS

(Reference: Table 6:14)
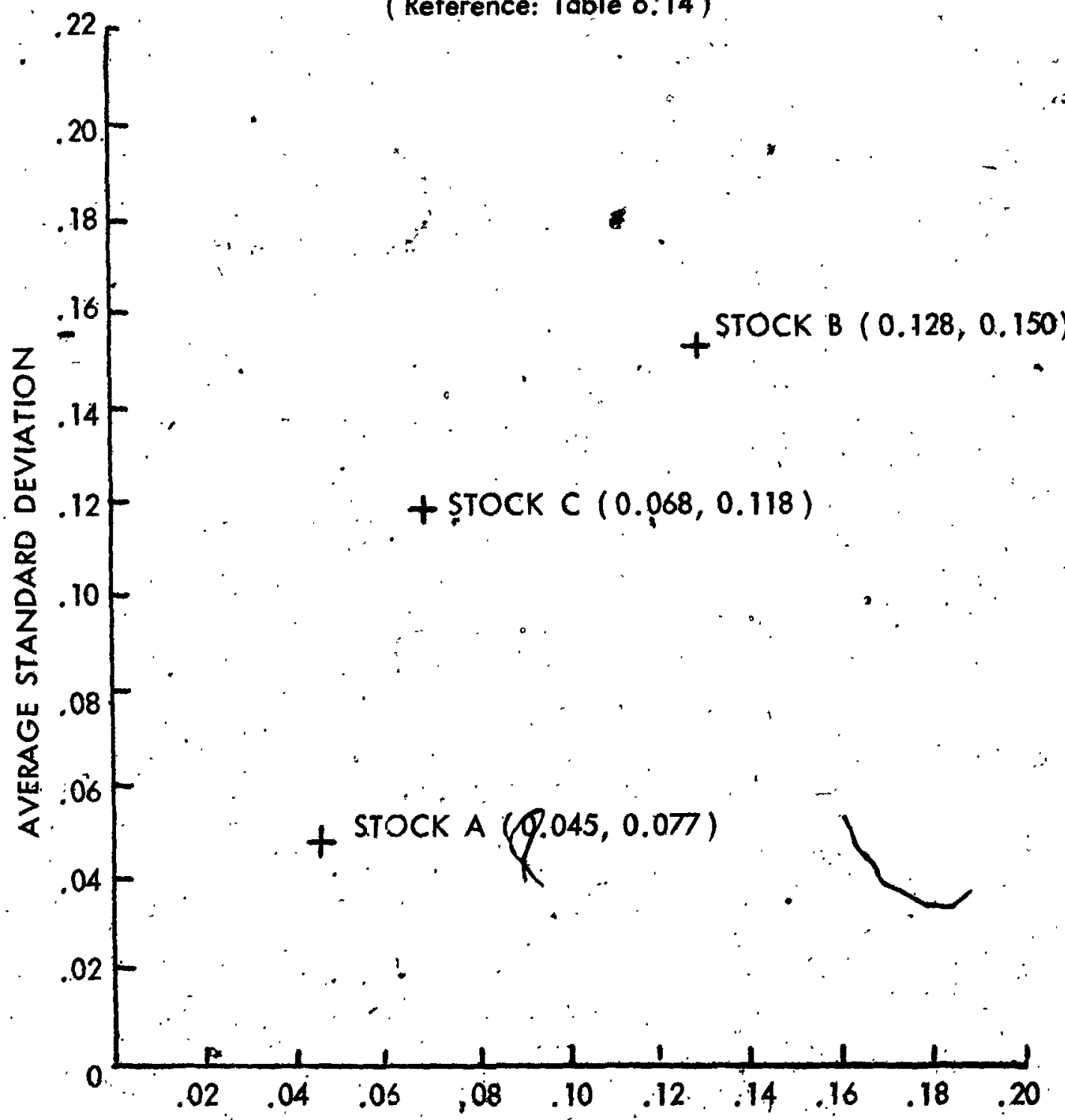

AVERAGE MEAN - 
and $C$ than that between stocks $C$ and $B(3.254)$.

Thus the above findings support the hypothesis

(1.1) that the magnitude of stock market "participanțs'

price expectations for a more risky stock is greater

than that for a less risky stock where risk and expected

price return are defined accondilg to the two-parameter

valuation concept.. The data also supports the stronger

form of the above hypothesis (1.2); namely, that the risk,

premium is more than proportionately greater than the

risk-differential. 'Furthermore, there is evidence to

support the hypothesis that the skewness of price

expectations also enters into the risp premium associated with higher risk stocks.

6.4 .2

Intra-stock Comparisons of Investors:

The results of intra-stock comparisons of

the averagie mean, standard deviation, and skewness of

-infestors' price expectations are presented in Tables

6.1 . $6.16,6.17$ and discussed below as pair-wise compartsens of buyers/owners, sellers/owners, and buyers/. seilers expectations for each of the three stocks.

a) Buyers and owners

The evidence presented in the referenced Tables supports the hypothesis that the average magnitude and uncertainty of buyers' and owners! price expectations are not significanty different. That is, for each stock; 
Table. 6.15

INTRA-STOCK COMPARISONS OF SUMMARIZED

INVESTOR PRICE EXPECTATIONS *

Significance

Level of

Comparisons

Buyers (B) Sellers(S) Owners (O) B/S B/O $\mathrm{S} / \mathrm{O}$

Company'A

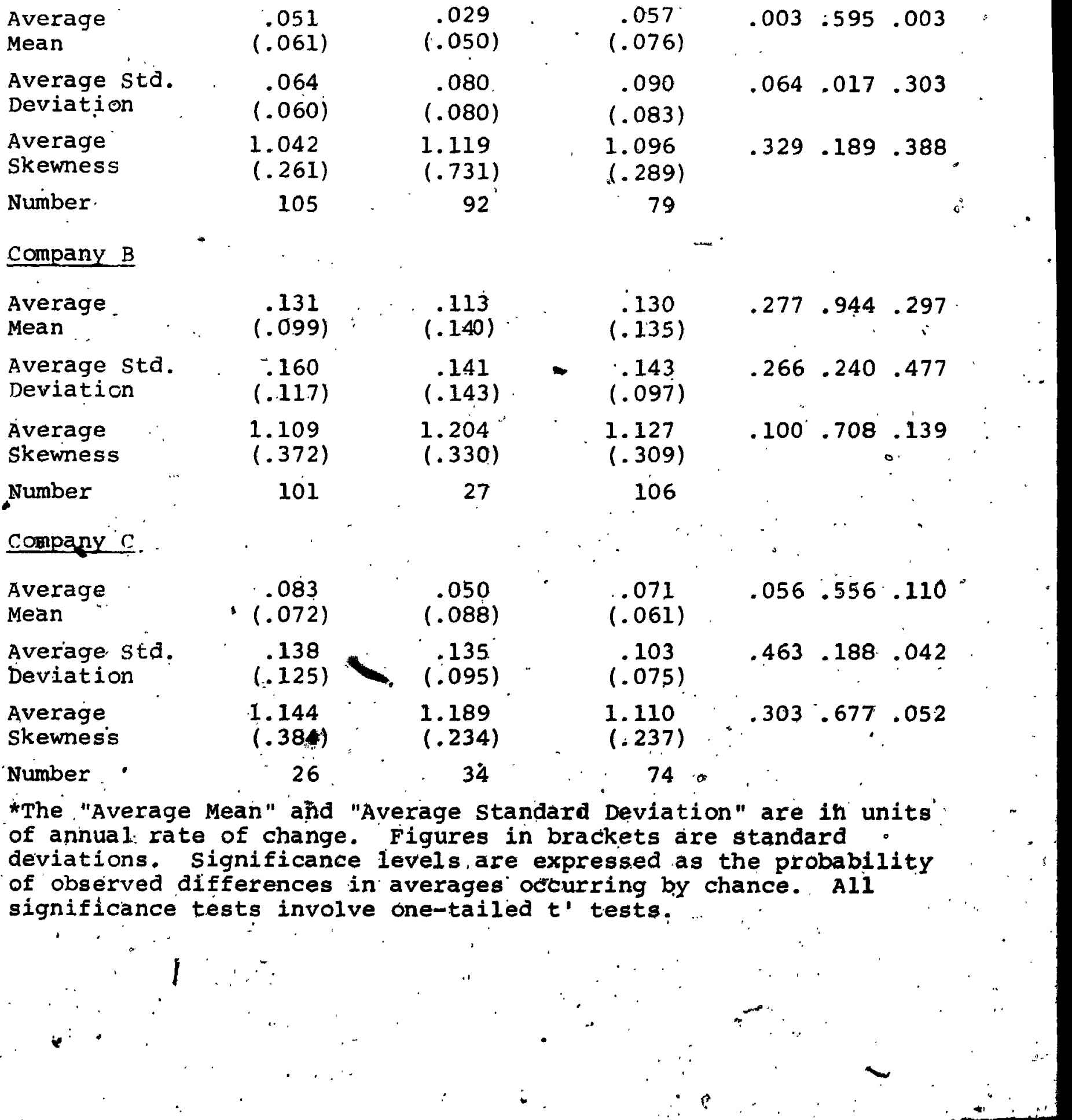


Table 6.16

\section{INTRA-STOCK COMPARISONS OF SUMMARIZED}

INVESTOR PRICE EXPECTATIONS: ONE-AND TWO-YEARS HORIZONS *

significarice

Level of:

Comparisons

Buyers(B). Sellers(S) Owners(O) B/S B/O $\underline{\mathrm{s} / 0}$

Company A

\begin{tabular}{|c|c|c|c|c|c|c|c|c|c|c|}
\hline $\begin{array}{l}\text { Average } \\
\text { Mean. }\end{array}$ & & $\begin{array}{l}.091 \\
(.095)\end{array}$ & . & $\begin{array}{l}.029 \\
(.060)\end{array}$ & & $\begin{array}{l}.086 \\
(.105)\end{array}$ & 0 & .001 & .086 & $.00 \%$ \\
\hline $\begin{array}{l}\text { Average std. } \\
\text { Deviation }\end{array}$ & ' & $\begin{array}{l}.122 \\
(.081)\end{array}$ & & $\begin{array}{l}.105 \\
(.095)\end{array}$ & &. .151 & & .300 & .209 & .016 \\
\hline $\begin{array}{l}\text { Average } \\
\text { Skewness }\end{array}$ & & $\begin{array}{l}1.124 \\
(.270)\end{array}$ & $\therefore$ & $\begin{array}{l}1.178 \\
(.923)\end{array}$ & & $\begin{array}{l}1.103 \\
(.269)\end{array}$ & & .346 & .766 & .292 \\
\hline $\begin{array}{l}\text { Number. } \\
\text { Company B }\end{array}$ & . & 28 & & 54 & a. & 32 & & . & . & ? \\
\hline $\begin{array}{l}\text { Average } \\
\text { Mean }\end{array}$ & & $\begin{array}{l}.156 \\
(.107 .)\end{array}$ & & $\begin{array}{l}.103 \\
(.141)\end{array}$ & & $\begin{array}{c}.171 \\
(.153)\end{array}$ & & .011 & .516 & .006 \\
\hline $\begin{array}{l}\text { Average std. } \\
\text { Deviation }\end{array}$ & & $\begin{array}{l}.198 \\
(.122)\end{array}$ & & $(.174$ & & $\begin{array}{l}.194 \\
(.092)\end{array}$ & & .305 & .848 & 328 \\
\hline $\begin{array}{l}\text { Average } \\
\text { Skewness }\end{array}$ & & $\begin{array}{l}1.101 \\
(.429)\end{array}$ & & $\begin{array}{l}1.199 \\
(.349)\end{array}$ & & $\begin{array}{l}1.153 \\
(.620)\end{array}$ & & .334 & .569 & .319 \\
\hline $\begin{array}{l}\text { Number } \\
\text { Company } c\end{array}$ & $\cdots$ & $\begin{array}{r}69 \\
.\end{array}$ & & . $17^{\circ}$ & & 61 & & & $\because$ & \\
\hline $\begin{array}{l}\text { Average } \\
\text { Mean }\end{array}$ & & $\begin{array}{l}.125 \\
(.084)\end{array}$ & & $\begin{array}{l}.041 \\
(.100)\end{array}$ & & $\begin{array}{l}.116 \\
(.081)\end{array}$ & $;$ & .006 & .747 & .004 \\
\hline $\begin{array}{l}\text { Average sta. } \\
\text { Deviation }\end{array}$ & . & $\begin{array}{l}.229 \\
(.129)\end{array}$ & & $\begin{array}{l}.164 \\
(.101)\end{array}$ & r. & $\begin{array}{l}.194 \\
(.083)\end{array}$ & & .073 & .571 & $145^{\circ}$ \\
\hline $\begin{array}{l}\text { Average } \\
\text { skewness }\end{array}$ & $\cdot$ & $\begin{array}{l}1.286 \\
(.499)\end{array}$ & & $\begin{array}{l}1.215 \\
(.238)\end{array}$ & & $\begin{array}{l}1.171 \\
(.235)\end{array}$ & & .325 & .532 & .272 \\
\hline Number. & & 12 & & 23 & & 20 & & & & \\
\hline $\begin{array}{l}\text { * The "Average } \\
\text { of annual rat } \\
\text { deviations. } \\
\text { of observed } \\
\text { significance }\end{array}$ & $\begin{array}{l}\text { Me } \\
\text { te } 0 \\
\text { Sig } \\
\text { diff }\end{array}$ & $\begin{array}{l}\text { on " and } \\
\text { of change } \\
\text { gificanc } \\
\text { Eerences }\end{array}$ & & $\begin{array}{l}\text { verage sta } \\
\text { Figures i } \\
\text { levels are } \\
\text { averages }\end{array}$ & $\begin{array}{l}b^{b r} \\
\text { exp } \\
\text { occu } \\
t^{\prime}\end{array}$ & $\begin{array}{l}\text { Deviati } \\
\text { ackets ar } \\
\text { ressed as } \\
\text { rring by }\end{array}$ & $\begin{array}{l}\text { con" } \\
\text { tha } \\
\text { cha }\end{array}$ & $\begin{array}{l}\text { " are } \\
\text { standa } \\
\text { he pro } \\
\text { ance. }\end{array}$ & $\begin{array}{l}\text { in } 1 \\
\text { ard } \\
\text { obab: } \\
\text { A1. }\end{array}$ & $\begin{array}{l}\text { ilcs } \\
\text { ity }\end{array}$ \\
\hline
\end{tabular}


Tabie 6:17

INTRA-STOCK COMPARISONS OF SUMMARIZED

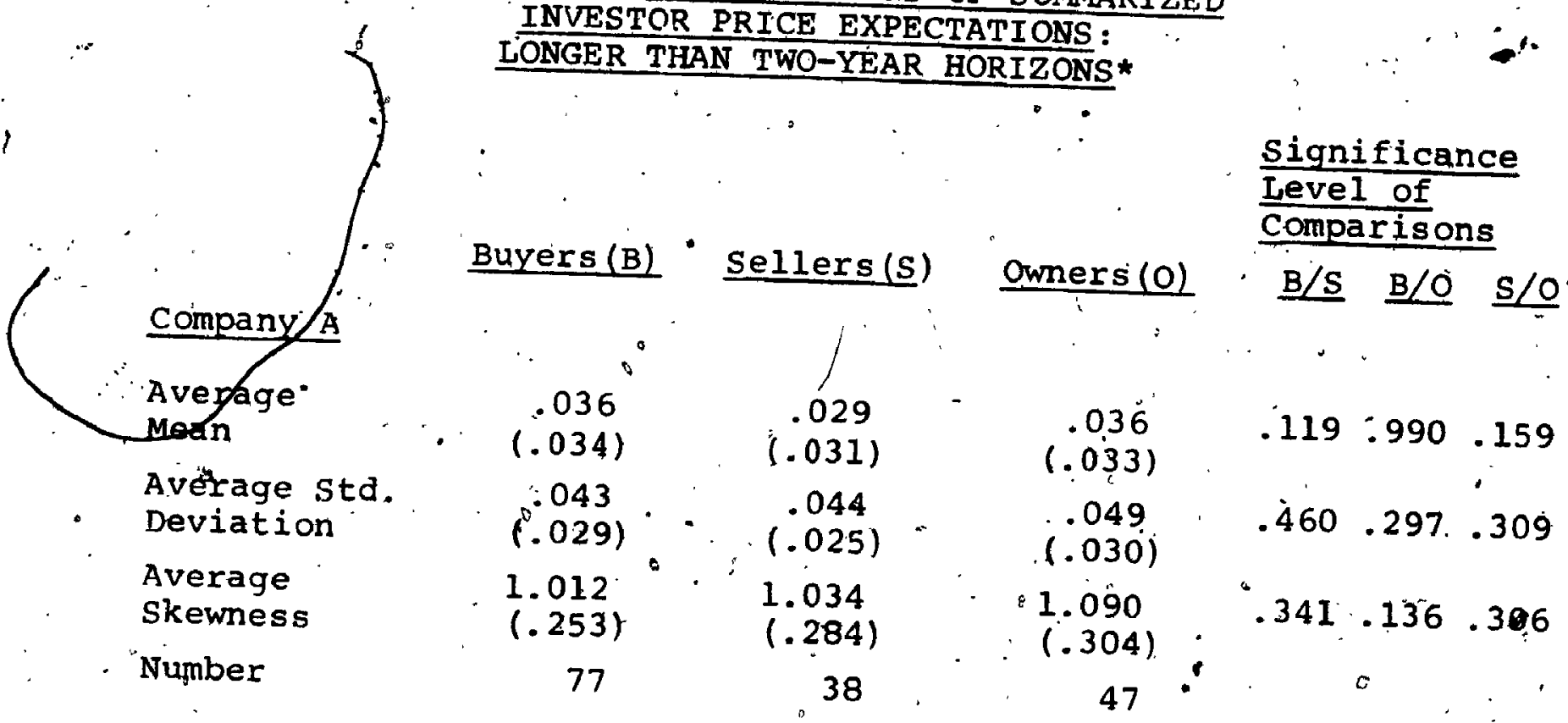

Company B $\cdot \odot$

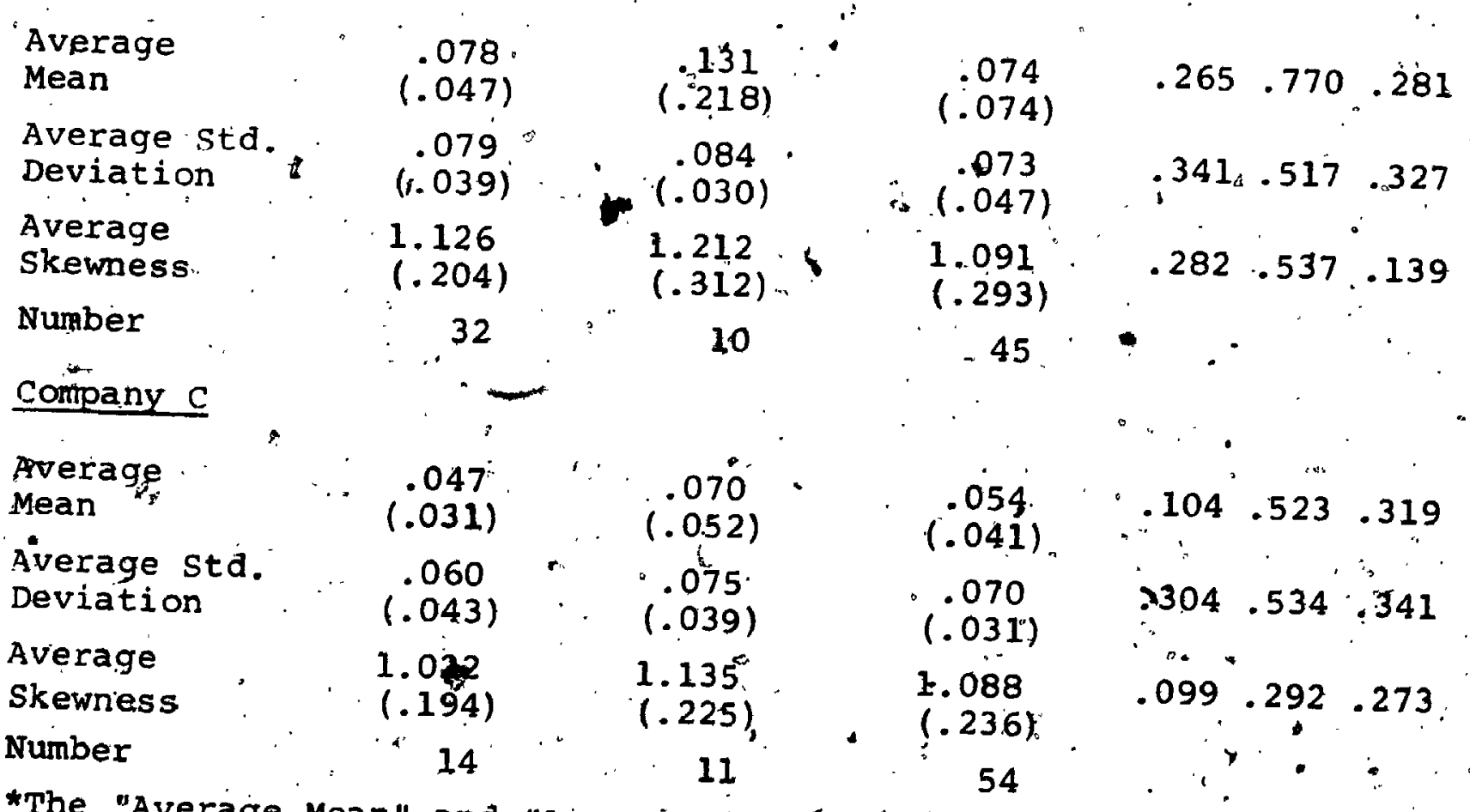

*The "Average Mean" and "Average Standard Déviation" are in standard deviations of change.. Figures in brackets are probability of observed ignificance levels are expressed as the chance. All significance testences in averages occurring by 
buyers' and owners' expectations' were of approximatelý - the same magnitude, uncertainty and asymmetry in the aggregate and over all time horizons.

b) Sellers and owners

The evidence in Table 6.16 supports the

hypothesis - over all three stocks - that sellers with

ta time perspective of one or two years are significantly more pessimistic than orners for the future rate of price appreciation of their stock. There is no consistent " ' evidence across all three stocks that sellers' and owners' price expectations differed significantily with respect to. their perceptions of risk and skewness.

\section{Hence, sellers' and owners' price}

expectations are, in general, distinguishabie only in terms of the pagnitude of the expectation and then only in the shorter-term.

c) Buyers and sellers

hypothesis for all three stpcks that sellers; with time perspectives of up to two years, are dignificantly more" pessimistic than buyers for the future rate of price appreciation of their'stock. "There is no consistent evidence 'upon which this hypothesis can be extenided to the risk and skewness, of buyers and seliers expectations. 


\section{Thus, buỹers', and seilers pice expectătions}

are in general, dișting tíshable oily in terms of the magnitude of the expectation and then only incthe shorter term.

d) Discussion

The foregoing comparişons of biyers:, seiler's' and owners' price expectations provide evidence supporting the hypothesis that for time perspectives of one-or two= years; sellers of each of thel three stocks are significantiy more pessimistic for the magnitude of the growth in the stock's price than both buyers and owners of the respective stock:

This conclusion can be put iñto perspective by noting the earlier finding that stock B was a signifi-

1 cantly higher risk-return situation than stack which in turn was a significantilu higher risk return ojtuation than stock is. phat is, the price determining corfilict of opinion regarding the mạnitude of the price expètations $\because$ for each stockwas occuring at different riskreturn levels for each of the three-stocks $\because$ Essentially buyers sellers, and owners for à particular stóck a ofe orjefing on basicaliy the same jevei ofguncertainty/ risk and ande differentiated accordjo to the magnitudes of their. expectations $:$ with" buyers and owper havin similar magnitudes that arê significanty ghtederothan those of

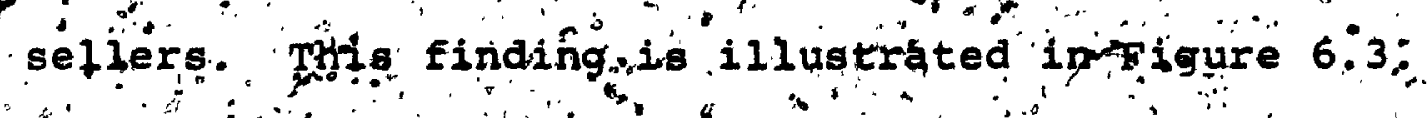


FIGURE $6.3 \because \cdots "$

1

9

AYERAGE RISK, AND RETURN OF

*

\section{PRICE EXPECTATIONS BY, TYPE OF}

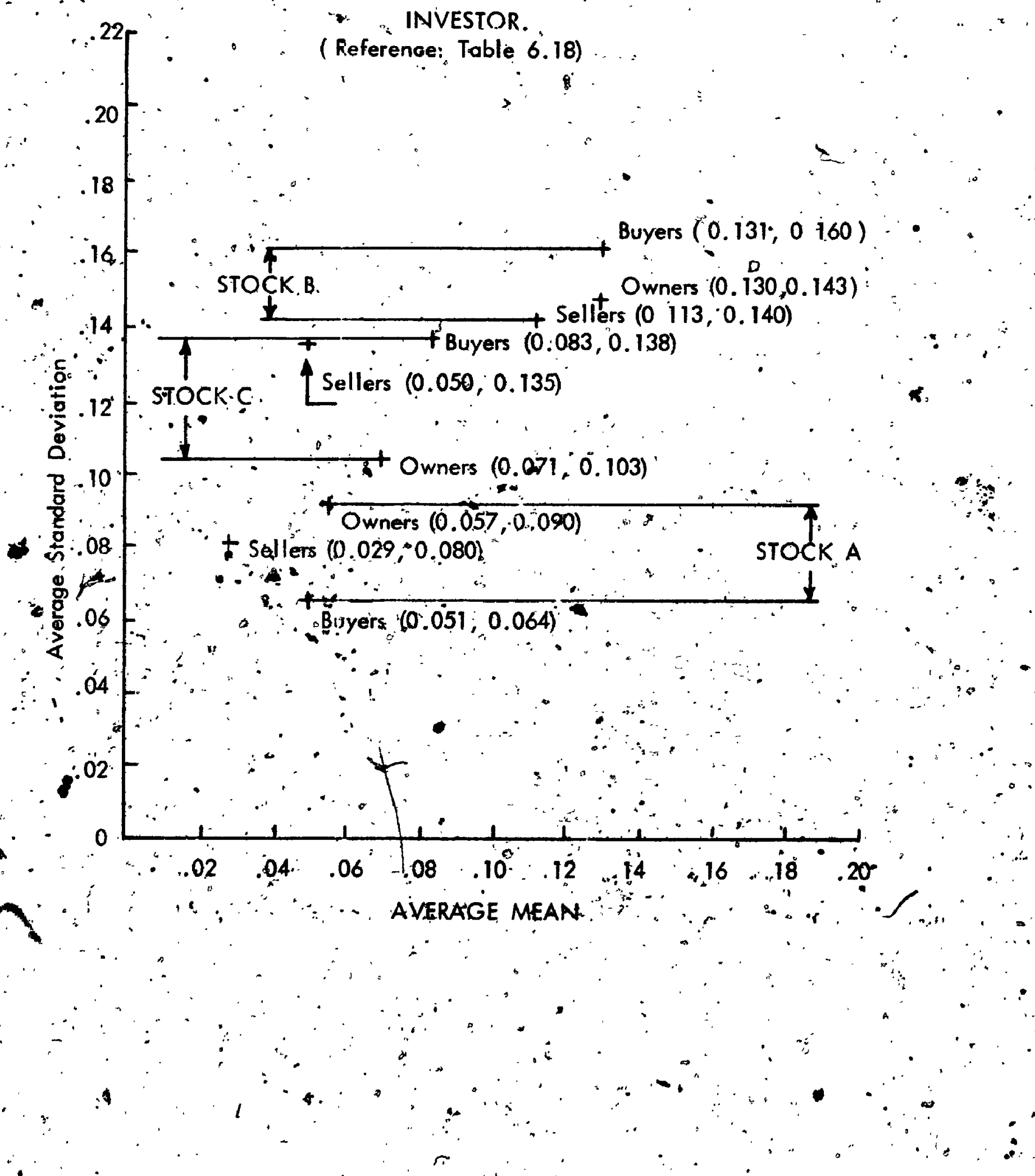



With Control For the Type of Investor and the Time Horizon

Recognizing the indicated differences in the magnitude of buyers' 'sellers' and owners' expectations, the earlier inter-stock comparisons of aggregates 'of investors' expectations were further analyzed with control for the type of investors and the time horizoit of the expectation.

The results of the analysis are presented in pables $6.18,6.19$ and 6.20 and discussed in the following paragraphs.

a) Stocks A and B

The dataj, in the referenced Tables indicates that in the aggregate and over both the short and longexterms, ail three types of inwestdrs associated with stock $\beta$ are significanty more optimistic and uncertain in their price expectations than their counterparts associated with stock A. Differençs in the-skewręs of price expectations were significant (. SO level) only for buyer and selier, comparisons pf investors with honger-term horlzons.

b) Stocks $A$ and

The evidence fin Table 6.18 indicates that all three types of investev associated with stock $c$ are more 
Table 6.18

INTER-STOCK COMPARISONS OF SUMMARIZED

INVESTOR PRICE EXPECTATIONS

- 'BY TYPE OF INVESTOR*

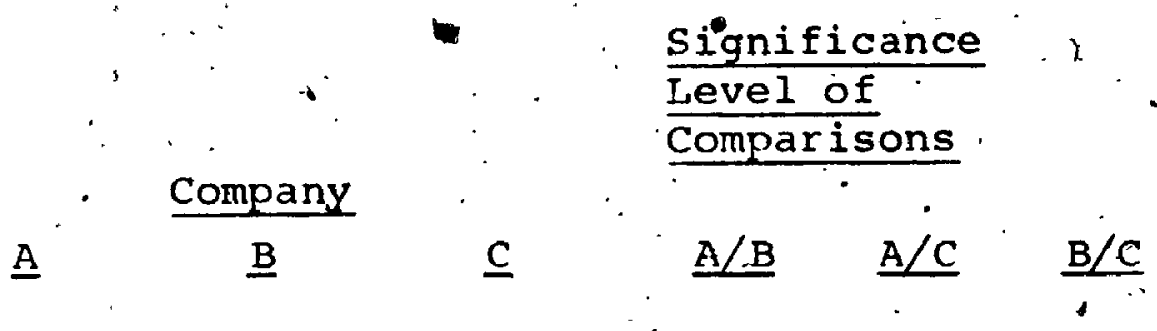

Buyers

\begin{tabular}{|c|c|c|c|c|c|c|}
\hline $\begin{array}{l}\text { Average } \\
\text { Mean }\end{array}$ & 1 & $\begin{array}{l}.051 \\
(.061)\end{array}$ & $\begin{array}{l}.131 \\
.099)\end{array}$ & $\begin{array}{r}.083 \\
(.073)\end{array}$ &.$\quad .008$ & .020 \\
\hline $\begin{array}{l}\text { Average std. } \\
\text { Deviation }\end{array}$ & & $\begin{array}{l}.064 \\
(.060)\end{array}$ & $\begin{array}{l}.160 \\
(.117)\end{array}$ & $\begin{array}{l}.138 \\
(.125)\end{array}$ & .008 & .003 \\
\hline $\begin{array}{l}\text { Avérage } \\
\text { Skewness }\end{array}$ & & $\begin{array}{l}1.042 \\
(.261)\end{array}$ & $\begin{array}{l}1.109 \\
(.372)\end{array}$ & $\begin{array}{l}1.144 \\
(.384)\end{array}$ & .066 & .102 \\
\hline Number & & 105 & 101 & 26 & . & \\
\hline
\end{tabular}

sellers

Average

Mean

.029

.113

$(.050) \cdot(.141)$

.050

.082

.094

.045

Average sta.

- Deviation

.080

.141

$(.080)$

(.143)

$1 / 35$

$\therefore .082$

Average

Skewness.

1. 119

1.204

(.095)

$.019 \quad .001 \quad .856$

Number

$(.731)$

$(.330)$

1.189

(.234)

92

27

34

Owners

- Average

Mean

.057
$(.076)$

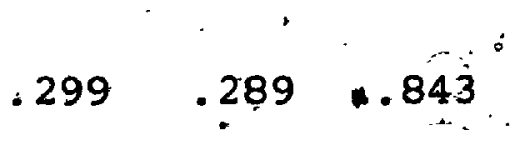

Average std.

Deviation

$$
\begin{gathered}
.090 \\
(.083) \\
1.096 \\
(.289)
\end{gathered}
$$$$
.130 \because .071
$$$$
(.135) \div(.061)
$$

.000

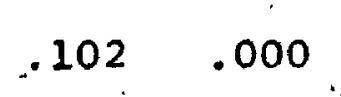

Average.

143

103

$(.097) \times \quad(.075)$.

Skewness

$1.127 \therefore 1.110$

$(309)$

$(.237)$

79

. 106

74

*The "Average Mèn" and "Averagé standard Deviation, are in units. of annual rate of change. Figures in brackets. are standard

deviations:- Significance levels are expressed as the probability of observed differences in averaqes occurring by chaifce. Stock A/stock $B$ and stock $A / S t o c k " C$ signíficance, tests involve oneftail $t$ " test: 
INTER-STOCK COMPARISONS OF SUMMARITED INVESTOR ERICE EXPECTATIONS BY TYPE OF INVFSTOR : ONF-AND TWO-YEAR HORIZONS *

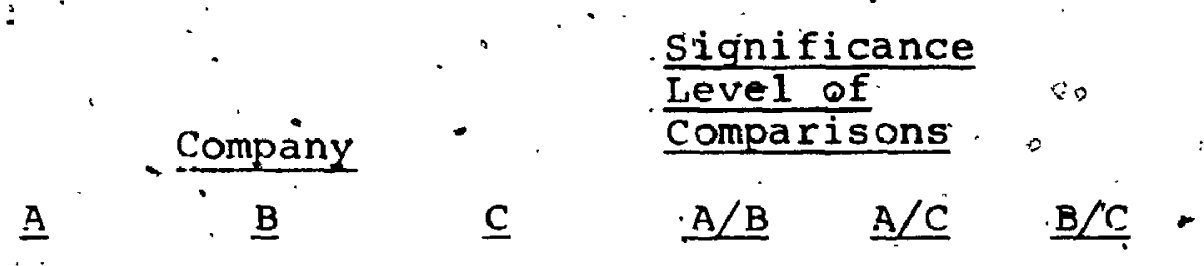

Buyers

Average

$\begin{array}{ll}.091 & .156 \\ (.095) & (.107)\end{array}$

.125

.002

$.126 \cdot .285$

Mean

.122

$(.084)$

Average std.

Deviation

(.081)

.198

.229

(.122)

(.129)

Average - )

1. 124 .

1. 101

1.286

Skewness

(. 270)

(.429)

(.499)

Number

28

69

12

Seliers

Average

Mean

.029

.103

(.060)

(.141)

.041

.000

.094

.027

$r$

Average std:

.105

.174

(.100)

neviation

$(.095)$

(.172)

.164

$: 061$

$.009 \dot{8} \quad \therefore 825$

Ãverage

Sikewness

1. $178^{\circ}$

1.199

(.101)

9

(. 923 )

(.349)

1. 215

(.238)

Number. .

54

17

23

Owners

Average

Meap

5

.086

(. 105)

.171

71)

$\because 116$.

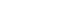

$444.39 i$

53.4

Average sta.

Deviation

$\therefore 151$

(. .153)

$(.081)$

.001

$.129: 039$

Arerage"

(..098)

.194

1. 103

(.092)

.194

(.083)

.021

1. 171

(. 269)

1.153

(.235)

Skewness

32

61

20

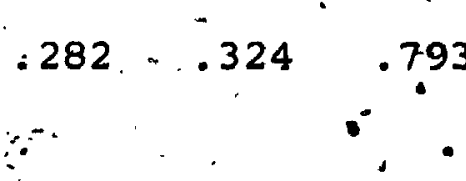

*The "Average Mean" and "Average standard Deviation" are in units of annual rate of change. "Figures in brackets are standard

deviations.' Significance levels are expressed as the probability of observed differences in averages occuxring by chance: stock $A / S t o c k$ and stock $A / S t o c k$. $S$ significance tests involve one-taij.t' tests: stock ij/stock c tests involve a nondirectional $t$ ' Lest". 
- Table 6.20

INTFR STOCK COMPARISONS OF SUMMARIZED

INVESTOR PRICE EXPECTATIONS BY TYPE OF INVESTOR:

LONGER TIIAN' TWO-YFAR HORIZOONS *

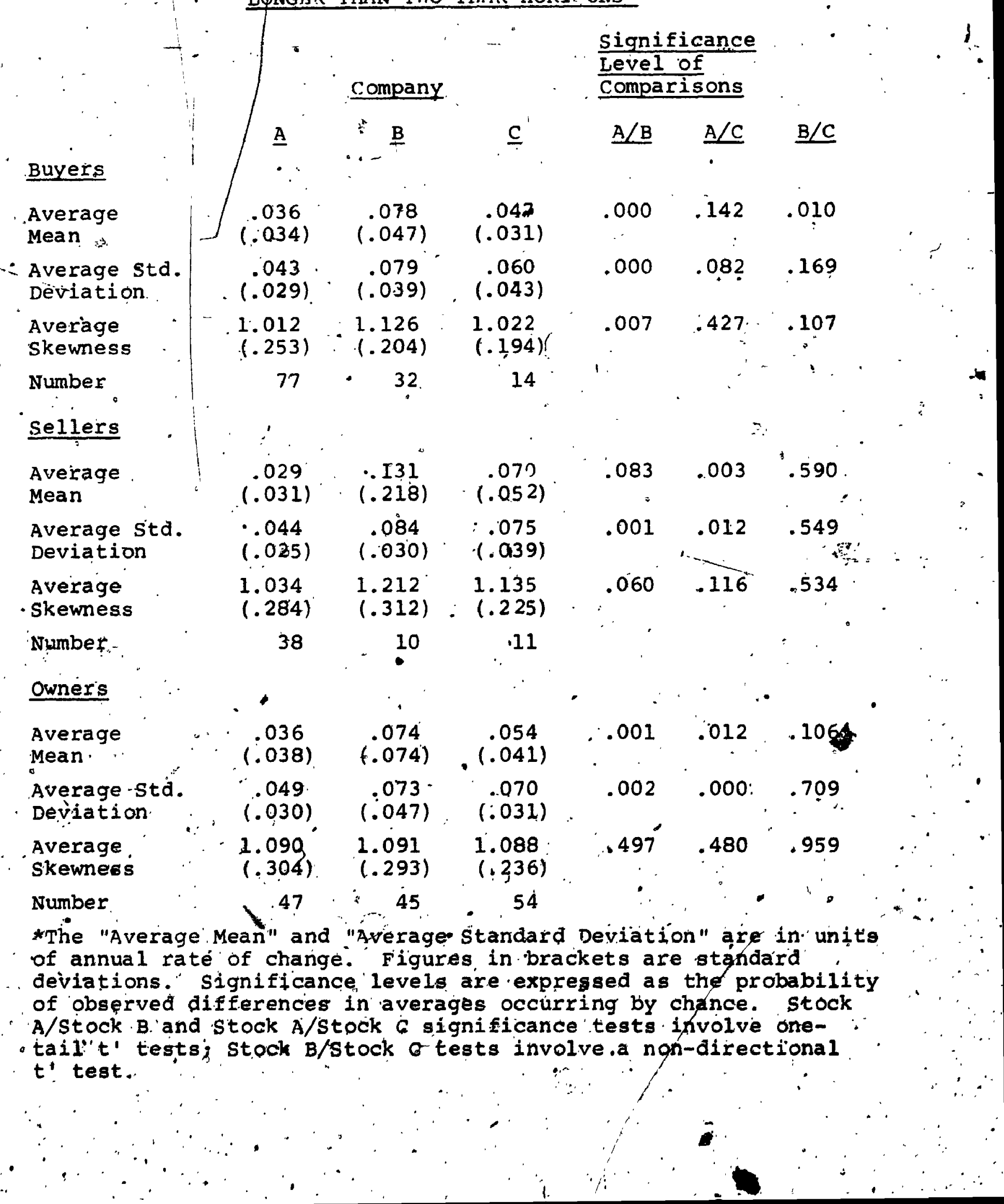


optimistic and uncertain in their expectations than the corresponding types of investors associated with. Stock A. Differences in the perception of risk and return were significant at the 0.1 level for buyer and seller comparisons? Similar results were found over both the short-and longer-. term horizons although the significance deteriorated, to the .142 level in tite case of the expected rate of mice appreciation. Significant differences in the skewness of price expectations were not found. Ke
c) Stocks B and $C$ more optimistic in their price expectations than their 'counter- parts associated with stock C: only the expectations of owners of stock B were significantly mare risky than the expectations of owners of stock $C$. similar results were found in the short-and lorg-term regarding the direction of the risk-return trade-off between stocks $B$ and $C$ but these fincings were not consistently significant at the .10 . levei or better. significant differences in the skewness of price $\because$ expectations were not found in the aggregate or over the short-or longer -terms. 
d) Discussion

The above findings add further support to the proposition that, of the three stocks, stock B is vịewed as being potentially the most profitable and tbe most risky; stock $A$ is potentialiy the least profitable and least risky; and stock $C$ is intermediate to stocks $A$ and $B$ in terms of expected price appreciation. That is, the foregoing inter stock comprisions of price expectations indicated that the highly significant risk-return tradeoffs noted in comparisons of aggregates of price expectations (Tahle 6.14) are not the result of any one type of investors or any particular expectation time horizon. As could he expected, the level of significance of differences in averages of expectation. characterisitcs deteriorated as sample size decreased; however, the direction of the risk-return tradeoffs was

consistent throughout the control comparisons.

$6 \cdot 4 \cdot 4$

Inter-and Intra-stock Comparisons Involving Security Analysts Price Expectations

Inter-stock comparisons of security analysts". price expectations were made to investigate the extent to which the risk-return trade-offs perceived by Individual investors were consistent with those perciefved by analysts. The results of comparing analysts expectations are presented in 
"Tabile 6.21. Comparisons of analysts' price expectations with those of aggregates of individual investors are presented in Table 6.22 .

a) Stiocks $A$ and $B$

As: in the case of individual investors, the price expectations of security analysts for stock B are " significantly more optimistic and uncertain than thosę for «. Sţock A. In fact the risk-return tradẹ-offinherent in analysts' expectations are essentially identical to that of individual investors. In contrast to the above consistency of findings, analyots price expectations for stock A werfe significantly more skewed to the right than those for stock B.

b) stocks A and $C$

The data in Table 6.21 indicate that anlaysts' expectations for stock $c$ are more optimistic and uncertain than those for stock A. Although only significantly different with respect to the uncertainty of therexpectations, the returt differèntial between stocks $A$ and $C$ as perceived by analysts, was essentialiy the same as that perceived py investors In contrast to investors' expectations; the risk differential pérceived by analysts was roughly "four times that observed by individuals. Analysts' price expectations were skewed in the expected direction but not significantly skewed at the .10 level or better. 
Table" 6.21

INTER-STOCK COMPARISONS OF

'SUMMARIZED SECURITY' ANALYSTS' PRICE EXPECTATIONS*:

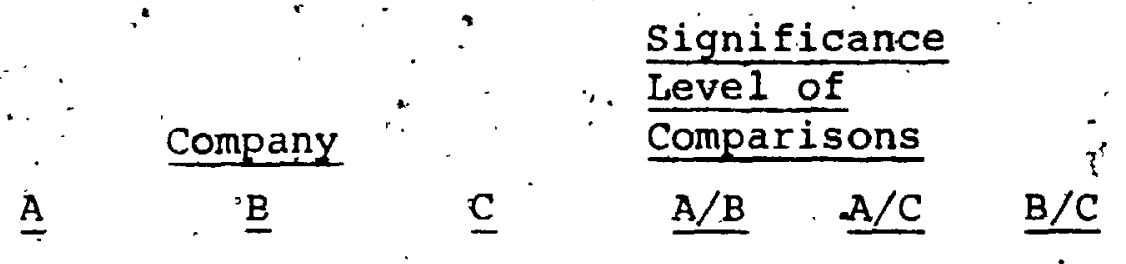

Average

Meán

$\begin{array}{lll}043 & .114 & 0066 \\ (.050) & (.071) & (.078)\end{array}$

$.003 \quad: 350 \quad .108$

Average std.

$.06 .4^{\circ}$

.124

$(: 047)$

$(.055)$

.202

$(.140)^{\circ}$

.001

.001

.074

Deviation

1.093

군

1. 186

(.192)

1.018

(.295)

.095

.327

.065

Skewness

$15^{\circ} \cdot .13$

$(.097)$

$(.295)$

INumber

13

*The "Average Mean" and "Average Standard Deviation" are in units of annual raţe of change.. Figures in brackets are standard deviations. Significance levels are expressed as the probability of observed differences. in averages occurring by chance. Stock $A / S t o c k ~ P$ and stock $A / S t o c k$ C significance tests involve one-tail t' tests; stock B/stock C tests involve a nọ-directionàl t $t^{\prime}$ test. 

c. It is interesting to not a that the risk ranking" generated by analysts' expectations is inconsistent with that provided by beta coefficients.

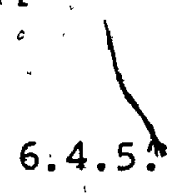

\section{Summary of Intèr. and Intra-stock comparisons Price Expectations}

A) Inter-Stock comparisons of Price Expectations The, risk-return characteristics of the three stocks as reflected in individual investors' price expectations indicated significant differences in the risk-return trade-offs associated with the stocks: In relation to Stock $A$ which had the lowest level of riskiassociated with its. expected price appreciatéd, stock c represented a $50 \%$ increase in risk and stock $B_{1}$, a $100 \%$ irçrease in rịk: correspondingly, stork $A$, was expected to provide the smallest annual rate of price appreciation, 5\%; Sfock $\mathrm{C}$ an -intermediate rate of $7 \%$; and stock $B$ the greatest rate of price appreciation, $13 \%$. Thus for a $50 \%$ increase in risk between stocks $A$ and $c$, the price-return differential. was greater by roughly $50 \%$ while for'a $100 \%$ increase in risk between stocks $A$ and $B$, the price-return differential was greater by roughty $150 \%$, Essentially these findings : support Hypotheses 1,1 and $1.2 i_{\text {n }}$ namely that investors expect a higher price return from more risky stocks and that as risk increased, a more then proportionate increase in. return is expected.

Investigations of the symmetry of price expectations indicated that the price expectations for 
for stocks $\vec{B}$ and $C$. for stock s. That is, the price expectations for stocks $B$ and $c$ incorporated $a . " I o n g-s h o t "$ possibility for an extremely largèppreciation in price, more so. than the price expectatiohs for stock.A. Thus', the higher:priceappreciation risk pelceived for stocks $B$ and $c$ was associated not only with a larger price expectation but alsowith a small chance of a very large price appreciation. $\therefore$ of the two higher risk stocks, price expectations for stock C were slightly mor aright-skewed than those for stock s: $^{\prime}$ when disaggregated, skewness was notia significant factor. The aboie findinas were. dorived from interstock comparisons of individual investors! price expectations, witl all buyers; selliers, and owners of jstock A being compared in the aggregate, "with corresponding aggre-" gates for stock B and stock Compariosons of analysts expectatión's yieldẹ somewhat differentresults.

\section{As in the case of individual inyestors.} analy'sts expectations indicated that stock $A$ was expected to provide the lowest annua rate of price appreciation, $4 \%$ stock $c$ an intermediate rate of $7 \%$ and stock $B$ the hiqhest rate $12 \%$. similarloy anabysts' expectations indjcated stock a to have thelleast risky price return and that stock was roughly $100 \%$ more risky thân stock $A$. However, where the price expectations of aggregates of individual "inwestors indicated that stóck $C$ was $50 \%$ more 
$=$ 
risky than stock $A$, the price expectations of analysts indicated that<stock $\mathrm{C}$ was more risky than stock $\mathrm{A}$ by roughly 200\% and more risky than stock B by roughly $100 \%$. Thus in terms of analysts expectations of the average rate of price appreciation and risk, stbck, $c$ was an inferior inveștment to stock $B$. It should also be noted however, that analysts price expectationsfor stock $c$ were significantly more right-skewed than analysts: price expectations for stock B indicating that although stock B was a higher risk (variability) situation than stock c the potential for a "iong-shot" extreme increase in ptice" was greater for stock $C$ than stock $B$.

The foregoing difference in analysts"and individual investor's expectations for stock $\mathrm{C}$ is centered on the assessment of the risk of the future expected rate' of price appreciation in the stocks's price. . Further analysis indicated that individuals and analysts were in agreement regarding the magnitude and syewness of expected price appre"iation for stock c. Furthérmore, individuais and analysts were in agreement regarding the magnitude and risk of expected price appreciation for both stocks $A$ and $\mathrm{B}$; however, in the case of stock B. individuals anticipated a greater chance for in extrene upside increase in price, than did.

1. analyats. Chese findings therefore support Hypotheses $3 \%$ regarding the consistancy of individupl investors' and security analysts price expectations for stocks A. 
Exceptions ' to this Hypothesis were evident for both. stocks $B$ and $C$.

B) Intra-stock Comparisons of Price Expectations

No evidence was found of significant differences in price expectations in comparisons of buyers' and ownerst. expectations for each of the three ftocks. That is, buyers' and owners price expectations were statistically indistinguishable in terms of the magnitude, risk, and skewness of expectations in both the aggregate and when djsaggregated by time horizon:

comparison of seliers' an'd owners' expectations and sellers' and buyers' price expectations did indicate significant differences in price expectations but onty for those investors with relatively short time horizons loneor two-years. . For all three stocks sellers with oneor two-year horizons expected a lower average rate of price appreciation than beth buyefs and owners with similar time horizons. Statistically significant risk or skewress differentials were genera $11 y$ not evident amorig buyersir seliers and owners.

Thus the above findings support only two of the four intra-stock hypatheses presented in chapter III (Hypotheses 2.1 and 2.3). That is, differences in opinion about the future price appreciation of these stocks did exist between buyers and owners, and sellers at the time of the study. However, this price-determining conflict of 
opinion was rimițed to differences regarding the rate of growth expected in the market price and was generally independent of investors perceptions of risk and skewness.

6.5 DIVIDEAP EXPECTATIONS

Investors: dividend expectations were analyzed for inter- and intra-stock differences in the sequence outlined in section 6.3 .

\section{5 .1}

Inter-stock Comparisons of Dividend Expectations The results of inter-stock pair-wise comparisoñs of the average mean, standard deviation, and skewness of

+. investors' dividend expectations are presented in Table.6.23 and discussed in the following paragraphs:
a) Stocks $A$ and $B$

8

1 1 $\therefore$ The evidence in Table 6.23 supports the hypo$\therefore$ thesis that the dividend expectationg for stock $B$ are significantIy more optimistic and uncertain than those for

3 stọk A. No significant differences in skewness of dividend expectations is evident although those for stokk A are more skewed than those for stock $B$.

b) Stocks $A$ and $C$

The data in Table 6.23 supports the hypothesis that the divideng expectations for stock $c$ are olgnificantly more optimistic and uncertain trian those for stock $A$ : The skewress of stock $A$ and $C_{\text {q }}$ dividend expectations are $\because j$ not signiffcantly different although those for stock $c$ are 


\section{Table 6.23 \\ INTER-STOCK COMPARISONSS OF SUMMARIŻED}

- INVESTOR DIVIDEND FXPECTATIONS ${ }^{(a)}$

Company.

Expectation

Average

Mean (b)

Average std.

Deviation

Average

skewness

(c)

Number
(1) $\underline{\text { A }}$

.029

$(.055)$

.069

$(.067)$

1.144

(.543)

268

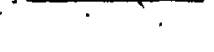

B

.107

(. 118$)$

.071
$(.095)$

.138

(.098)

.119

(.134)

I. $12 \dot{8}$

(.304)

215
1.155
$(.365)$

128
Significance Level. of Comparisons

(a). The "Average Mean" and "Average Ștandard Deviation" are in units of annual rate of change. Figures in brackets are, standard deviations. Significance levels are expressed as the probability of observed differences in averages occurring by chance. stock A/stock B and stock A/stock C significance tests involve one-tail $t^{\prime}$ tests; stock $\mathrm{B} / \mathrm{stock}$ $c$ tésts involve a non-directional t' test.

(b) On a historical basis the average annual rate-of dividend change for the period 1952-1972 are : stock A (.015). stock B $(.045)$, and stock $C(.059)$. These rates of change are not directly comparable with the figures presented in this. - table since the historic data does not incorporate the mix of time horizons inherent in the expectational däta.

(c) The skewness coefficients indicate that the percentages of the total squared deviations to the left of the arithmetic mean of the dividend digtributions are: $43.7 \%$ for stock $A_{1}-$ $44.3 \%$ for stock $B$, and $43.3 \%$ for stock $C$. 


\section{$+$}

more skewed than those for stock $A$.

c) stocks B and C

The evidence in Table 6.23 supports the

hypothesis that the dividend expectations for stock. B are

- significantly more optimistic than those for stock c. s The expectations for ${ }^{8}$ stock $B$ are also more uncertain than those for stock $C$, but significantly so at only the : 16 level. The skewness of expectations for stock $C$ is greater thain that for stock B but only significantly different at the .51 level. s

d) Discusston

The above findings indicate that of the three. stocks, the expectations af dividend growth for stock B are the most optimistic and most uncertain; those for . stock $A_{1}$ the least optimistic and most certain, and those for stock $C$ intermediate with réspect to stocks A and B. Thus, dividend expectations reflect, esentially the seme risk-returnorankings as provided by price expectation although the differentiation among qtocks is less pronounced with.

* dividend expectations.As in the case of price expectations the "sensitivity" of the average mean dividend expectation to changes" in the average standard deviation is less $(2.0)$ between stocks $A$ and $C$ than that between stocks $C$ and B. $(3.18)$ $\therefore$

- No significant differences in the skewness of dividend expectations were evident. 

6.5.2 - Intra-Stock comparisons of Investors ' Dividend

The results of intra-stock comparisons of the average mean, standard deviation, and skewness of investors' dividend expectations are presented below as pair-wise comparisions of buyers/owners, sellers/owners, and buyers/sellers expectations for each "of the three, stokcs. Summary data are presented in Table $6.24,6.25$ and. 6.26 .

a) Buyers and Owners.

As in the case of intra-stock comparisons of price expectations buyers' and 'owners" dividend expectations were generally indistinguishable in terms, of the magnitude, uncertainty, and skewness of their dividend expectations over both the "short-and langer-term.

i. b) Sellers and owners

v The data in the above rables supports the hypothesis that seliers dividend expectations are significantly less optimistic in terms of future dividend growth than those of owners'; but only in the case of stocks $A$ and ' $c$ and only for time horizons of one and two years." There was no consistent evidence across all three stǒcks that sellers and owners dividend expectations differed. significantly with respect to risk and skewness.

c) Buyers and.seliers

9

The data ptesented in the referenced rables are inconclusive with respect to the hypothesis that the 
Table 6.24

INTRA-STOCK CO̊MPARISONS OF SUMMARIZED INVESTOR

DIVIDEND EXPECTATIONS*

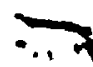

Buyersy) Sellers(s) Owners (O).
Significance

Level of

Comparisons

Company A

Average

Mean

Average sta.

Deviation

Average

Skewnes s.

Number

Company B

Averağe

Mean

Average std.

Diviziztion

Average.

Skewness

Number

.117

$(\cdot 127)$

.$\stackrel{\circ}{0} 29$

(.042)

.022

.057

$(.051)$

(.064)

.038

(.059)

B $/ \mathrm{S} \quad \mathrm{B} / \mathrm{O} \quad \dot{\mathrm{s}} / \mathrm{O}$

1:071

(.295)

.076

$(.070)$

.076

(.078)

1.153

(.603)

1..227

(.692)

89

79

$$
(: 086)
$$

$1: 119$

(.231)

96
.112

(.132)

.133

$(.136)$

1. 147

(. 448$)$

22
.095

(.105)

.136

(101)

1.133

(. 332$)$

9.7 $\begin{array}{ll}.433 & .195 \\ . & 295\end{array}$

.388 .667 .464

$.988 \cdot 741.442$

\section{- Company c}

Average

Mean :

Average stia.

Deviation

Average'

skewness

- Number

*The "Average Mean" and "Average standard Deviation are in

$\begin{array}{ccc}(.102 & .057 \\ (.120) & \cdots & -(.061) \\ .142 & .119 \\ (.122) & (.105) \\ 1.134 & \therefore(148 \\ (.321) & (.317) \\ 25 & \because 33\end{array}$

.066

$(.099)$

$.048 .185: 301$

111

(.150)

1.166

$(.405)$

$.288 \cdot .249 \cdot 049$

$.013^{-} .069 .486$

.122 .060 .264 units of annua i rate of change. Figures in brackets are standard deviatfon, stignificance levels are expressed as the probability of observed dfferences in averages occurring by chance.

A11 signiflcarcectésts involve one-tail t tests.

Ti, 

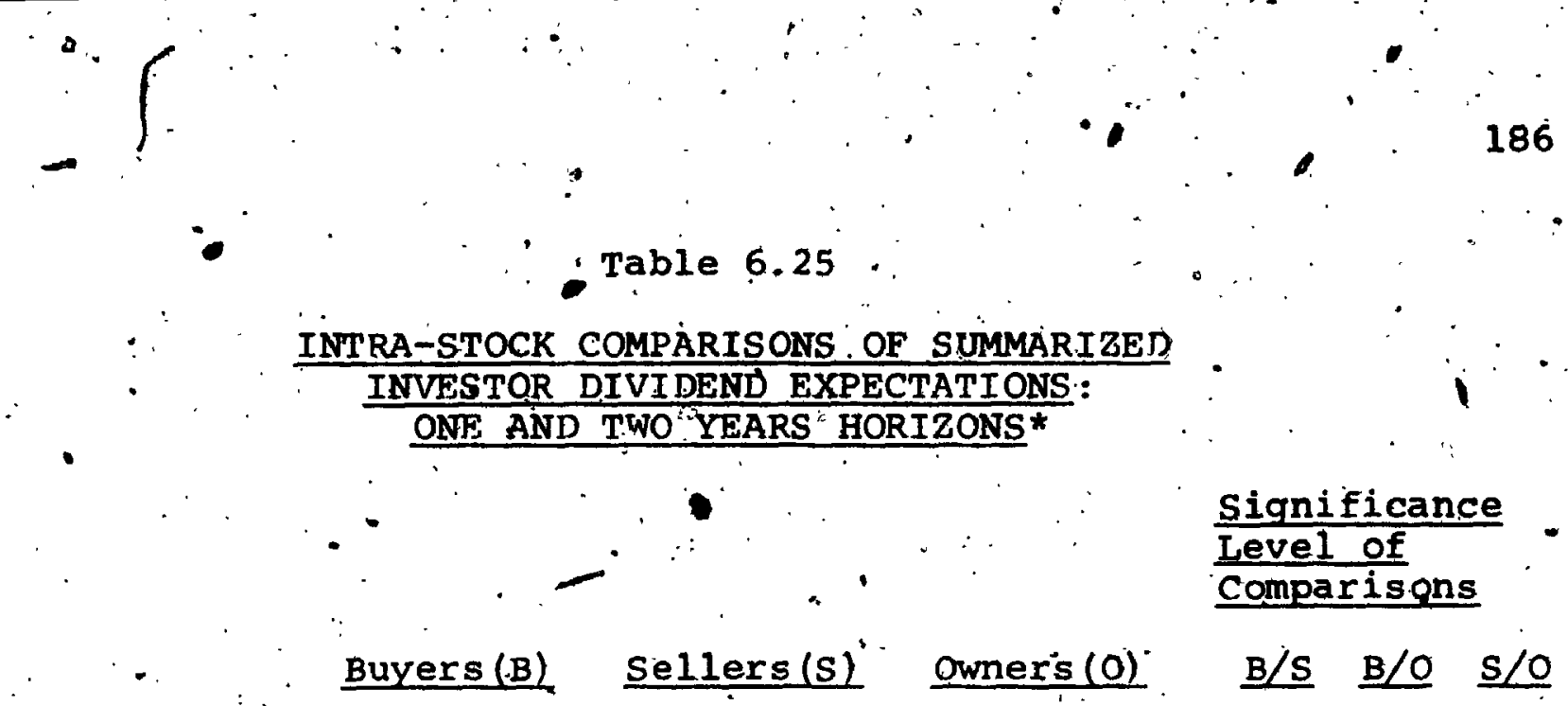

Company A

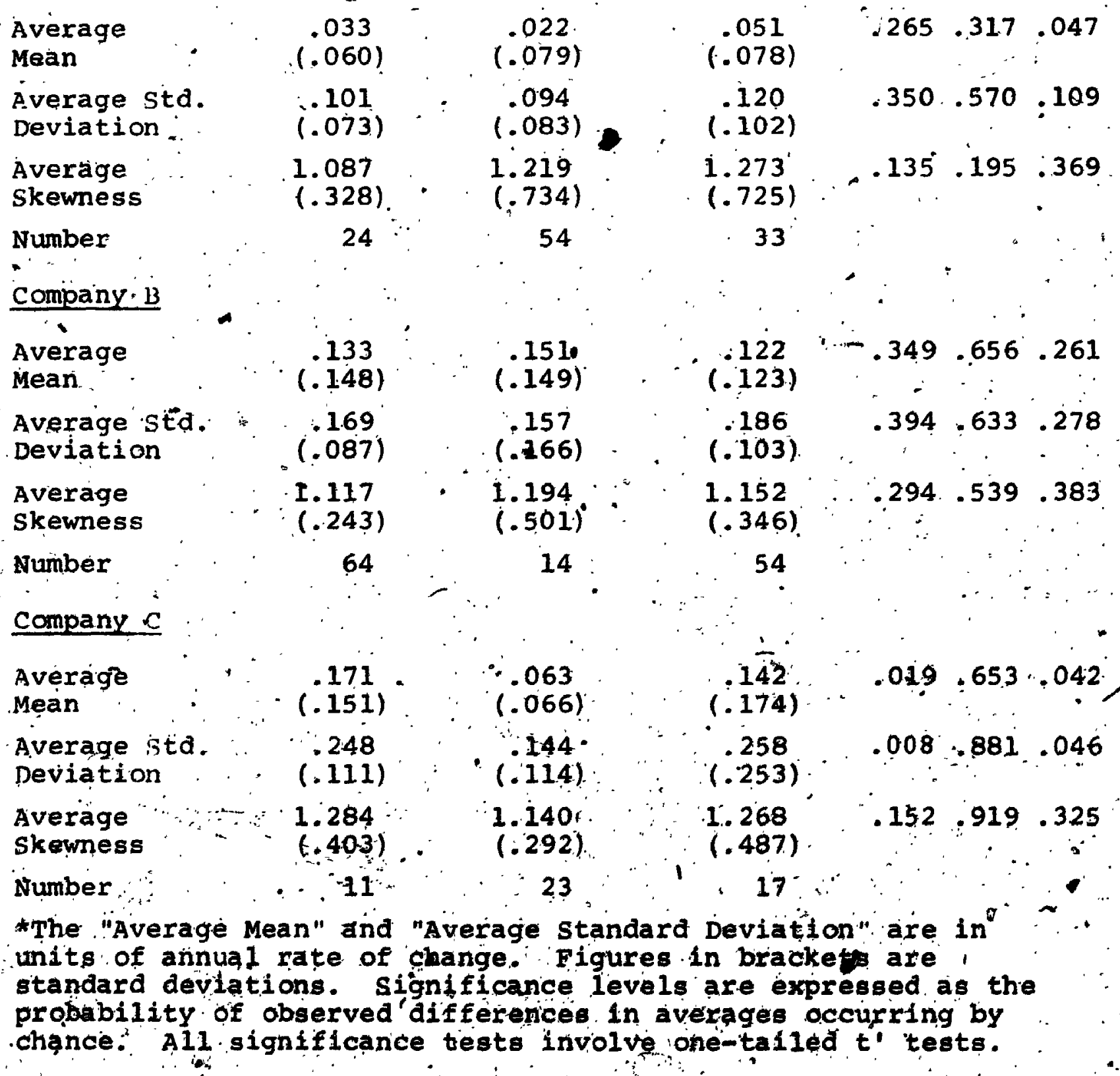




\section{Table 6.26}

INTRA-STOCK COMPARISONS OF SUMMARIZED

INVESTOR DIVIDEND EXPECTATIONS:

LONGER THAN TWO-YEAR HORIZONS*

Significance

Level of

Comparišons

- Buyers (B) Selleis (S) Owners (O) B/S B/O $\mathrm{S} / \mathrm{O}$

Company A

Average

Mean

.027

.022
$(.031)$

$(.028)$

$.288 \cdot 912 \cdot .277$

Average std.

Deviation

.043

(.032)

.049

1.066

Averag̀e *

$(.287)$

.$(.028)$.

.044

(.030)

$.310 .903 \quad .260$

skewness

$76^{\circ}$

1.049

(. 292)

1. 194

(.674)

Number

35.

36

Company B

Average

Mean

Average sta.

Eviation

Average

-Skewness

Number

Company. C

Average

Meä̀

Average sta:

Deviation

Averágé

- Skewnesp

Number "
.084

.087

$(.048)$

1.125

(.209)

32
.044

(.054)

.091

$(.035)$

1.066 .

(.354)

1. 8 .
.062

(.064)

$.073^{c}$
$(.051)$

109

$317)$

43
$.042 . .119 . .282$

.378 .254 .121

$.331 \cdot .794 \quad .374$

Number " . . 14

.047

(.041)

$\therefore 0.58$

(.030)

1.015

(.176)
.045
$(.048)$

.041
$(.032)$

.063

(, 048)

1.166

(.386)

10
.064 .

(.030)

1.133

$(.374)$

$.391 .224 \quad .098$

*The "Average Mean"

units of annual rate "Average Standacd Deviation "are in.

standafd deviat change, Figures in brackets are

the probabilitions significance; levels are expressed as

by chance. 


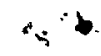

magnitude of sellers' dividend expectations is significantly less optimistic than that for buyers ' of the respective

' stocks. This hypothesis is supported only for Stock $A$ for time horizons of more than one year; for stock $B$ for time horizons of three and more years, and for stock $c$ for time horizons of one and two years. Hence, if the magnitude of dividend expectations do distinguish buyers and sellers, the occasions of this effect are unique for the particular stock.

Comparisons of the uncertainty of buyers and seller' dividend expectations indicate a similar pattern of significant differences. Where significant differences * in the magnitude of expectations were noted, significant differences in uncertainty were also noted with sellers being more certain than buyers, but only for stocks $A$ and $c$. No significant differences in the skewness of buyers and sellers dividend expectations were evident. The above findings indicate that buyers and sellers' dividend expectations are occasionally distinguishabie in terms of the magnitude and uncertainty of the expec-. tation. However, insta es of these differences appear to

- be uniquely determined by the particular stock. d) Discussion

Unilke the earlier comparisong of buyers, sellers is and owners' price expectations, the above analyeis of . dividend expectations does not generally support the 
the hypothesis that sellers" dividend'expectations are ." significantly more conservative, uncertain, or skewed than those of either buyers or owners. Instances of significant differences, appear to be unique to the particular stock. Buyers' and owners' dividend expectations were indistinguis able as in the case of price expectations.

Thus the above findings regarding sellers' vérsus buyers' or owners.' dividend expectations are inconclusive. That is, there is evigence of differences in the 'hypothesized direction but, these differences are not " " consistent across ail three stocks.

6.5 .3

Inter-stock Comparisons of Dividend Expectations With control for the type of Investor and Time Horizon The results of exterding the analysis to interstock comparisons of dividend expectations with controls'imposed on the type of investors and their time horizons is presented in Table $6.27,6.28$ and 6.29.

a) stocks $A$ and $B$

The data in the referenced Tables indicate that al1 three types of investors associated with stock.B - across all time horizoris - are significạntly more optimistic and more uncertain than their counterparts associated with 
Table 6.27

INTER-STOCK COMPARISONS OF SUMMARIZED INVESTOR:

DIVIDEND EXPECTATIONS BY TYPE OF INVESTOR*

Significance

Company

Level of

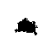

Buyers
$\underline{A}$
B
C
$\underline{\mathrm{A}} / \mathrm{B}$
$\mathrm{A} / \mathrm{C}$
B\%C

comparisons

Average

Mean

$(.029$

$\ldots .117$

Average Sta.

Deviation.

.057

(.127)

$: 102$
$(.120)$

Average

Skewness

Number

$(.051)$

.142

$: 142$
$(.122)$

.000

$\therefore 002$

$.580^{3}$

1.071

(.086)

$(.122)$

.000

.001

.987

1.119

(.231)

1.134

.097

.309

.830

100

96

25

Sellers

Average.

Mean

Average std.

Deviation

Average

․ Skewness

Number

.022
$(.064)$

.076

$(.070)$

$\begin{array}{ll}1.153^{\circ} & 1.147 \\ (.603) & (.448)\end{array}$

(.112

.057

.133

(.136)

.119

(:105)

89

22

1.148

$(.317)$

33

$.002^{\prime} \quad .003$

.076

Owners

Àverage

Mean

.038

.095

$(.059)-(.105)$

.066

.691

$.036 \quad .015$

. .480

$.478 \quad \because 289$

Average std.

Deviation

$$
.076
$$

$(.078):(.101)$

(.099)

.000

.018

.061

Average.

Skewness

1.227

1.133

$(.692): \&(.332)$

(.150).

.000

.037

.232

Number

79

97

1.166
$(.405)$

.135

.256

.588

*The "Average Mean" and "Average standard Deviation" are in units of annual rate of change. Figures in brackets are standärd deviations. Significance levels are expressed as the probability of observed differences in averages occurring by chance. stock $\mathrm{A} / \mathrm{St}$ ock $\mathrm{B}$ and stock A/stock $\mathrm{C}$ significance tésts involve onetail t' teșts; stock B/Stock $c$ tests involve a non-directional t 
INTER-STOCK COMPARISONS OF SUMMARIZED

INVESTOR DIVIDEND FXPECTATIONS BY

TYPE OF INVESTOR - ONE AND TWO YEARS HORIZONS *

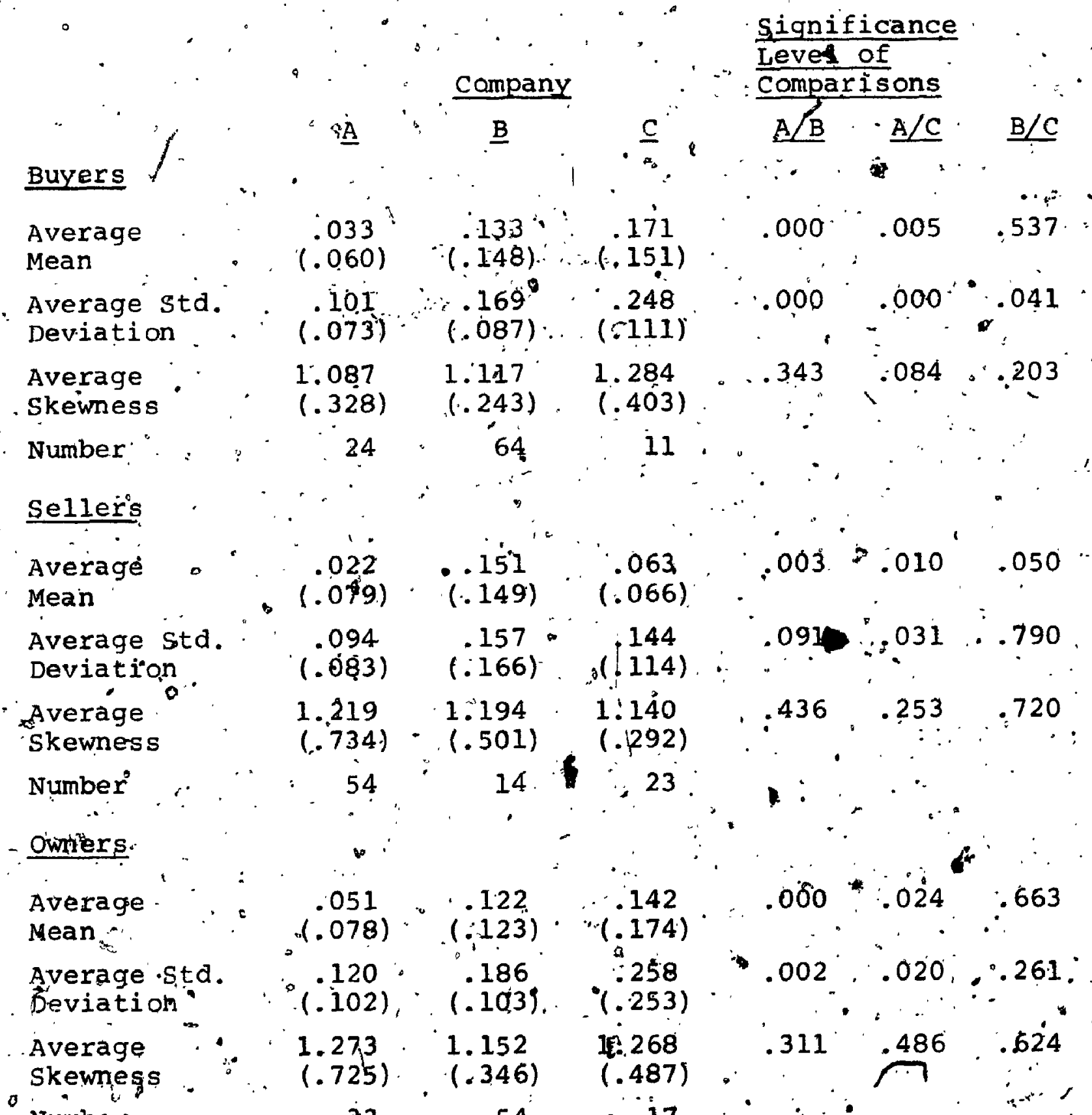

Number

33

54

17

*The "Average Mean" and "Average Standard Deviation." are in units of annual rate of change: Figures in brackets are standard.

deviations. Significance levels are expressed as the probability. of obgerved differences in averages oecurring by chance. Stock $\mathrm{A} / \mathrm{St}$ tock $\mathrm{B}$ and stock $\mathrm{A} / \mathrm{stock} \mathrm{C}$ significance tests involve one-". tailyt tests; stock $\mathrm{B} / \mathrm{Stock} \mathrm{C}$ tests involve a-non-directional t'. test: 


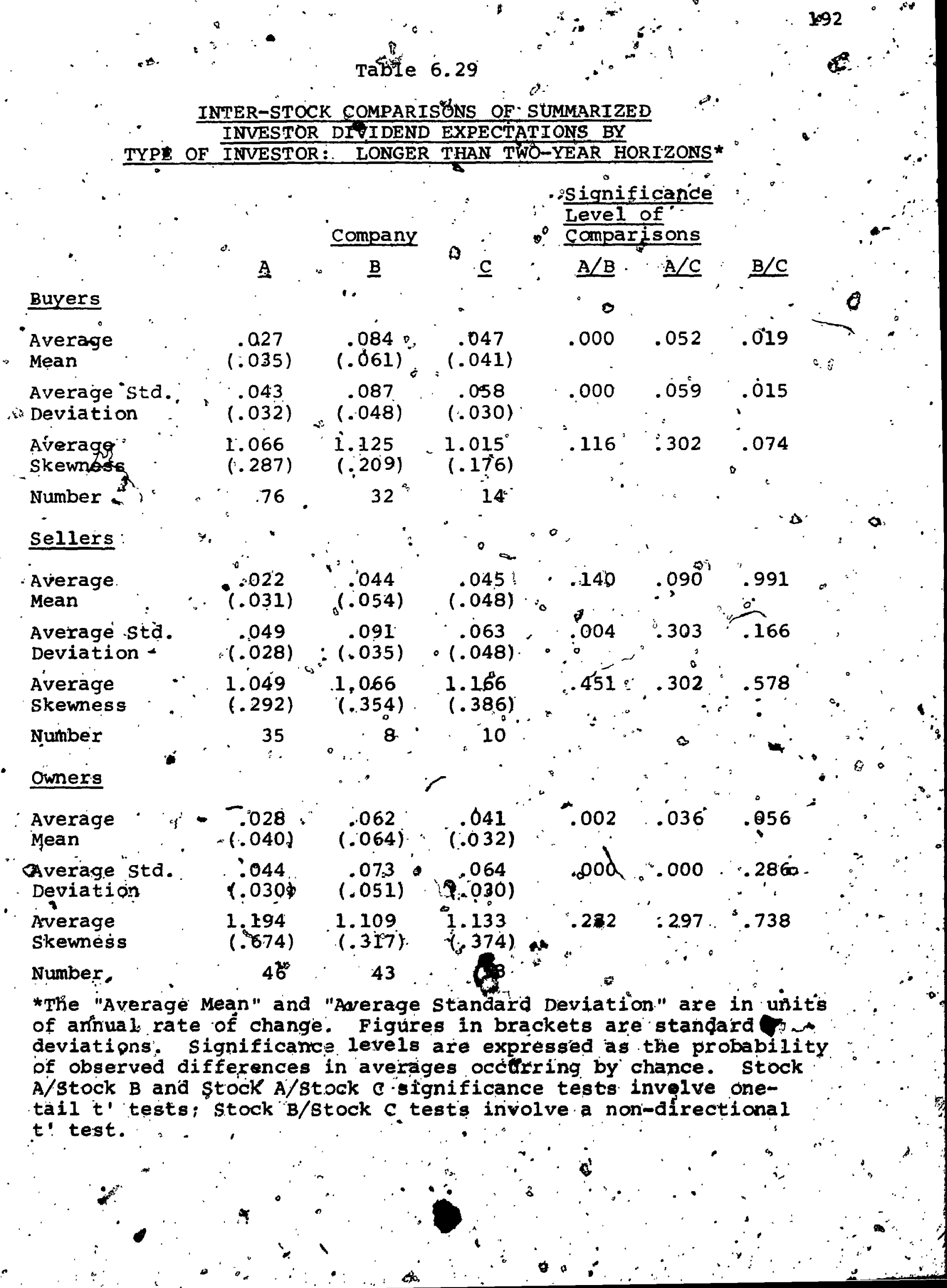


stock A for the expected annual growth in dividends. No consistent eviderte of differences in the skewness of expectations was found.

98 b) Stocks'A and

The data indicate that the expectations of all three typès of market participants associated with Stock $c$ were significantly more optimistic and more uncertain than those of their counterparts associated with stock $A$ in both the short and longer term. No consistent significant differences in the skewness, of the expectations were evident.

c) Stocks B and C

The data in the refereneed Tables indicate that the earlier noted more optimistic dividerid expectyations (Table 6.23) for stock $B$ in relation to stock $C$ is due, to a unique mix of investor types and time hortzons. That is, disaggregates of expectations show that only. sellers of stock $B$ with short-term horizons and buyers and owners with long-term horizons have significantly more 43 optimistic dividend expectations, than their counterparts, $\because$ $\therefore$ associated with stock C (although not significantly less ( optimistic). Instances of significant differences in risk. were inconsistent with those indicated in Table 6.23. similarly no - consistent differences in skewness were 
evident.

d) Discussion

The foregoing findings indicated that the earlier noted (Table $6.2 \dot{3}$ ) magnitude and uncertainty trade-offs between Stocks $A$ and $B$, and $A$ and $C$ are consistently foundin comparisions involving different types of market participants and time horizons: In contrast the earlier noted direction and significance of differences in the dividend expectations for stocks $B$ and $C$ wags found, to toe the result of an apparently unique combination of investor types and time horizons.

$.5 . \dot{5} \cdot \dot{4}$

Inter- and Intra-Stock Comparisions Involving Security Analysts ' Dividend Expectations.

The results of inter-stock comparisons of anaiysts' dividend expectatiohs are presented in Table 6.30 . Comparisons between analysts' and individual investors' expectations are presented in Tabie 6.31 .

a) Stocks $A$ and $B$

As in the case of individual investors, the dividend expectations of security analysts for stock B are significantly more optimistic and uncertain than those of analysts for stock A. similar to individuals "alvidend $\therefore$ expectations, analysts' dividend expectations for stock A 


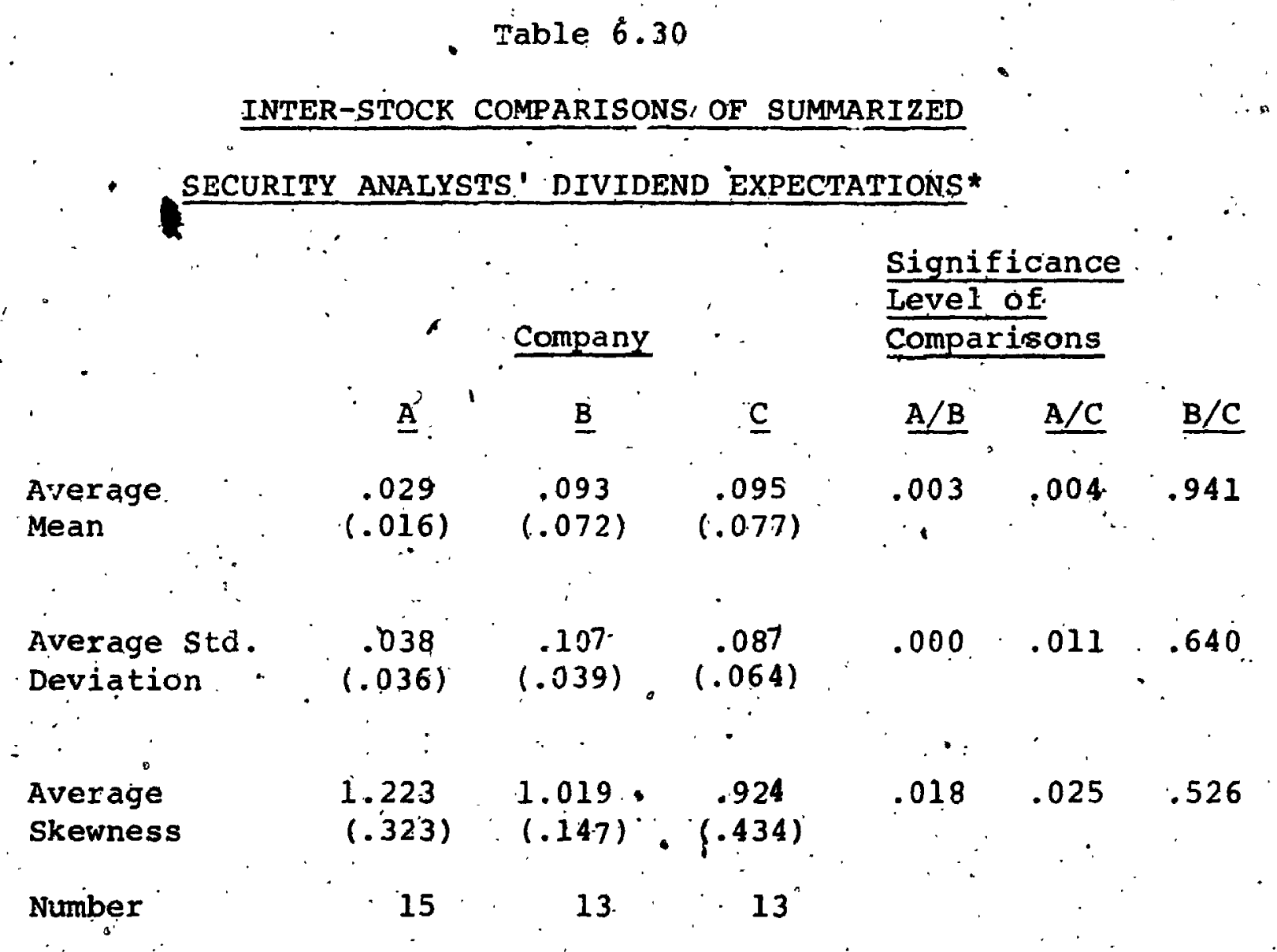

$\therefore$ *The "Average. Mẹan" and "Average Standard Deviation" are in units of annual rate of change. Figures in brackets are standard deviations. Significance levels are expressed as the . probability of observed differences in averages occurring by " chance. Stock $\mathrm{A} / \mathrm{stock} B$ and stock $\mathrm{A} / \mathrm{stock} \mathrm{C}$ significance tests involve a one-tail $t$ ' tests;lstock B/stock C tests involve a non-directional $t$ ' test. 
Table 6.31

COMPARISONS OF ANALYSTS' AND INVESTORS

- SUMMARIZÉD DIVIDEND EXPECTATIONS*

$\frac{\text { Company A }}{\text { Individual/ }}$

Average

Mean

Significance

Average std.

Deviation

$(.067)(.036)$

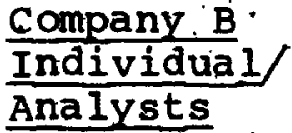

$.107 / .093$

$(.113)(.072)$

.504

$.138 / .107$

$(.098)(.03 .9)$

.006

Significance.

Average

skkewness

$$
1
$$

$1.144 / 1.223$

$(.543)(.322)$

significance .608

.025

.080

Number

$268 / 15$

$215 / 13$

$128 / 13$

.331

$.119 / .087$

$(.134)(.064)$
Company C Individua 1/ Analysts

$.071 / .095$

$(.095)(.077)$
$1.128 / 1.019$

$(.304)(.147)$

$1.155 \% .924$

$(.365)(.434)$

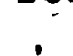

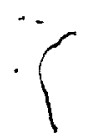

*The "Average Mean" and "Average standard Devimtion" are in units of annual rate of return. Figures in brackets are standard deviations. Significance levels are expressed as the probability of observed differences in averages occurring by chance. All significance tests involve a non-directional $t$ ' tesst. 
were more skewed to the right than those for stock $B$, an although individuals "skewness was not significantly. different analysts' skewness was.

b) Stocks $A$ and $C$

Dividend expectations for stock C were signifi-., cantiy more optimistic and more uncertain than those for stock $A$. which is identical to the finding. for individuals. However; while individuals did not differentiate between these two' stocks on the basis of the skewness of the expectation, analystsyida Here stock A is significantly. more skewed to the right than stock $c$. and on average; expectation for Stock $C$ are skewed to the left.. c) Stocks B and C

Whereas individuals' dividend expectations were more optimistic and more uncer (tain for stock B than stock $C_{\text {p }}$. - analysts expectations wote hot listinguishable between the - two stócks.
a) Discussion

The dividend expectations of individual investors and security analysts were generally consistent except in.

- the case of comparisons of stock B and stock C. Differences in analysts ' and Individuals' dividend expectations centered on the uncertainty and skewness of expectations and not on 
the magnitude of the expectations. A similarlfiading was noted in the case of price expectations.

$6 \cdot 5 \cdot 5$ Surmary of Inter- and Intra-stóck Comparisons of

A) Inter-fotock Comparison of Dividend Expectations Analysis. of individual investor ${ }^{2}$ s dividend expectations yielded results similar to those found for price expectations. Expectations for growth in the annual dividend were lowest for stock $A, 3 \%$ intermediate for stock $C_{;} 78 ;$ and most optimistic for stock B; 118. Correspondingly, the risk associated with these rates of change in the annual dividend was lowest for stock A, $70 \%$ greater for stock $C$, and $100 \%$ greater for stock B. Differences in the rate and risk of dividend growth were highly significant (.003 level in better) across stocks except in the case of the risk differential for stocks $B$ and $c$. Unlike the findings for price expectations significant differences in the skewness' of dyvidend expectation were not evident.

These findings support the hypothesis that greater dividend/growth is expected in the presence of greater dividend risk (Hypotmesis 1.1). However, the similar risk perceived for dividend growth in the cases of stock $B$ and $c$ does not support the hypothesis that rate of growth differenf 
tials increase more than proportionally with increasing risk. Analysts' dividend expectations for the three stocks were again somewhat different from those of individual investors with no significant differences being indicated between the dividend expectations for stocks $B$ and "C: Ans in the case of individual injestors, analysts" expectation's indicated that of the three stocks, Stack A's annual dividend was expected to grow at the lowest annuali 'ratee, 38', versus 9-108 for stopks B and C.' similarly, ". the risk associated with the average annual dividend glowth for stocks $B$ and $C$ was rough $1 y$. twice that expected for Stock A. However, inlike individuals expectations, analysts expectations for stock A. reflected significantly more rightskewness than in the case of stock $B$ and stocfer In relation. to the consistancy of analysts and individuals' price expectations, analysts and individuals': dividend expectations were more frequextiy inconsistent. These incorsistencies dealt with the risk and/or skewness of divided expectations but not with the magnitude of the expected growth in the diyidend. Thus these findings provide only 1 imited support for "the efficient market hypothesis" in so far as dividend expectations are concerned (Hypothesis 3 ). 
B) Intra-stock Compárisons of Dividend Expectations

Differences in dividerfd expectations among buyers selilers; and owners, for each of the thiree stocks were generally not às statistically distinct as those found for price expectations. Às in the case of price expectations, buyers' and owrers' dividend expectations were generally indistinguishable in terms of magnitude, risk, and skewness for all. three stocks in both the shortand longer-terms and in the aggregate. In contrast: differencés in sellers" and owners " and sellers" and buyers' expectations were not consistently found for each of the three stocks in the aggregate or when disaggregated by time horizon. That is;differences in dividend expectations among market participants were indicatedas being unique to the particular stock. "Thus these findings do not support the intra-stock hypotheses pertaining to differences in buyer' seilers' and owner' 'dividend expectations (Hypothëses $2.1-2.4$ \}. $\rightarrow \infty$

6.6 IOTAL RFTURN EXPECTATIONS

To investigate the relative optimism of the magnitude of iñvestor's cọbinéd price and dividend expectations the internal rate of return implicit in the price and dividend expectations was calculated in the mapnér indicated earljer. Two computations of the standard deviation of the internal rate of return were made, one employing the historical correlation between price and dividends and 
the second, enploying the correlations based on the expectations data.

It should be noted that comparisons across stocks of rates of change, in the market,price or dividend,are independent of the gelative magnitudes of the price or diyidend of the various stocks. However, comparisons afross stocks of the internal rate of return are not independent of the relative nonitudes of the dividends of the two stocks. That is, the internal rate of return is based on the cash flow from a security which by definition includes the dividends of the stock. Thus, two stucks for which price and - dividend expectations are identical and even with identical market prices will result in different internal rates of return if their dividends are of different magnitudes.

It should also be noted that the internal rate of return calculation makes the assumption of annual reinvestment of the proceeds from the security at a rate at least as great as.the computed internal rata.

6.6 .1 Inter-stock comparison of Invéstions The result of air-wise comparisons of total return expectations arf presented in Table $6,32$. are presented for the uncertainty of tatal returns based on both expectational and historical correlations.

a) stocks $A$ and $B$

The data in Table $6: 32$ supports the hypothesis 

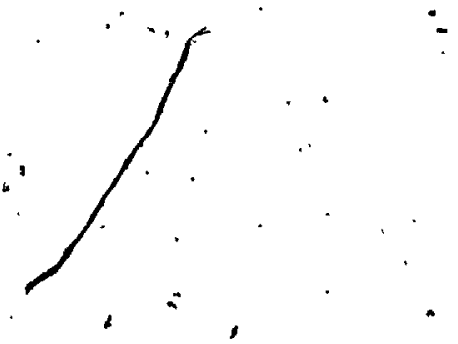

\section{INTER-STOCK COMPARISONS OF SUMMARIZED}

\section{INVESTOR TOTAL RETेURN EXPECTATIQNS*}

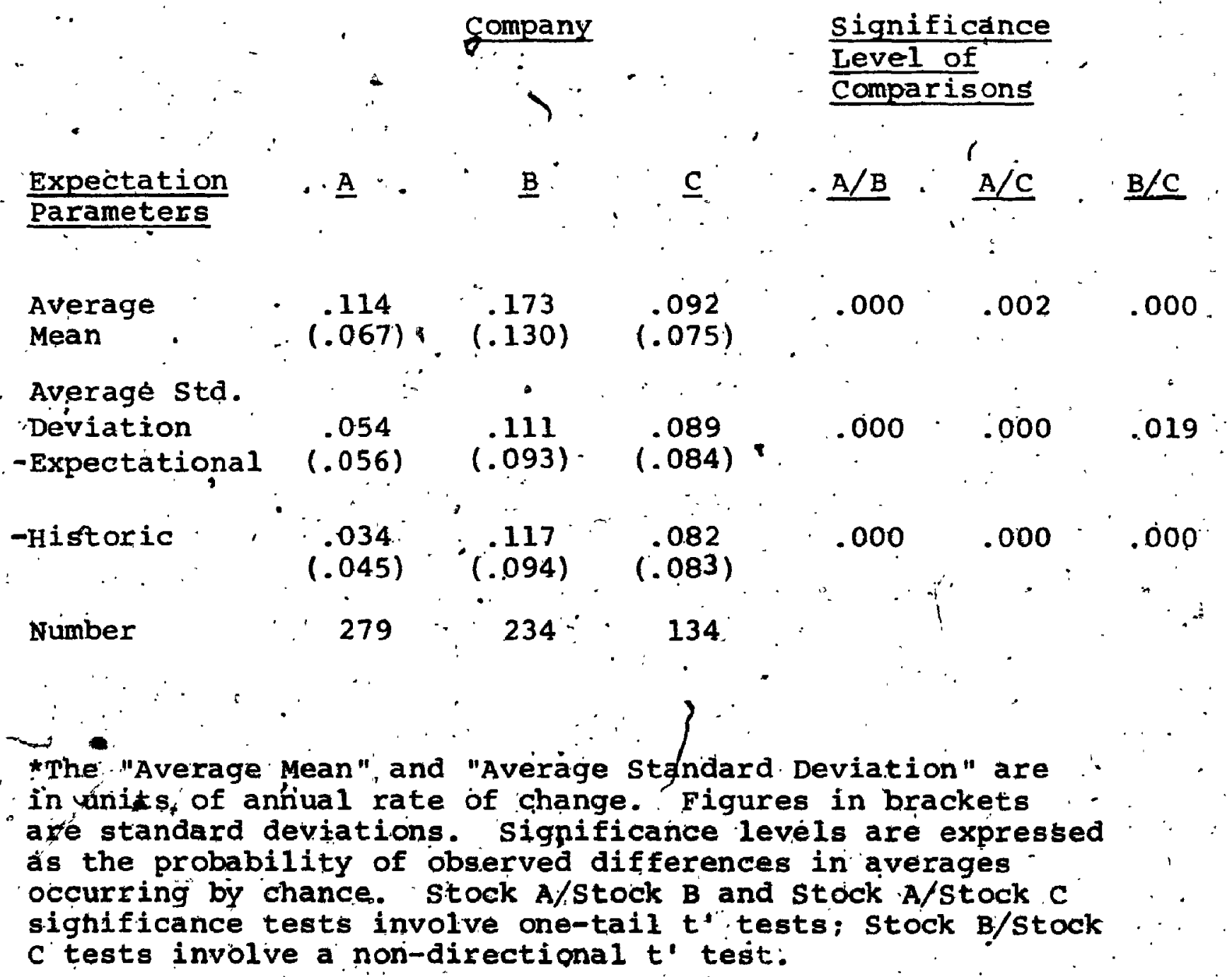




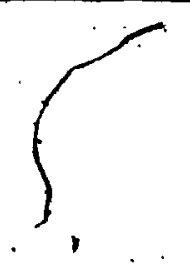

that the total return expected by investors associated with Stock $B$ is significantly more optimistic $117: 3 \%$ per annum) and uncertain (11.1\%) than that expected by investors associated with stock $\mathrm{A}$ (11.4\% per annum and $5.4 \%$ respectively). b) Stock $A$ and $C$.

The data in Table 6.32 supports the hypothesis that the total return expected, by investors associated with stock C is significantly less optimistic (9.2\% per annum) and more uncertain $(8.9 \%)$ than that expected by investors associated with stock ${ }^{4}(11.1 \%$ per annum and $5.4 \%$ respectively). c) Stocks $B$ and $C$

The evidence in Table 6.32 supports the hypothesis that the total return expected by investors associated with stock $B$ is significantly more optimistic ( $17.3 \%$ per annum) and uncertain (11.1\%) than those of investors associated with stock C $(9.2 \%$ per annum and $8.9 \%$ respectiveky).

\section{d) Discussion}

As a reeult of combining the price and dividend expectations for the three stocks; the risk-return tradeoff ordering found in the analysis of price and dividend expectations is altered. Here stock $c$ is indicated as being an inferior to stock $A$ in terms of the magnitude and variability of expected return. This findings is illustrated in Figure 6.4. 
204

- FIGURE 6.4

AVERAGE' RISK $K^{\circ}$ AND RETURN OF TOTAL RETURN EXPECTATIONS. ('Reference : Table 6.32)

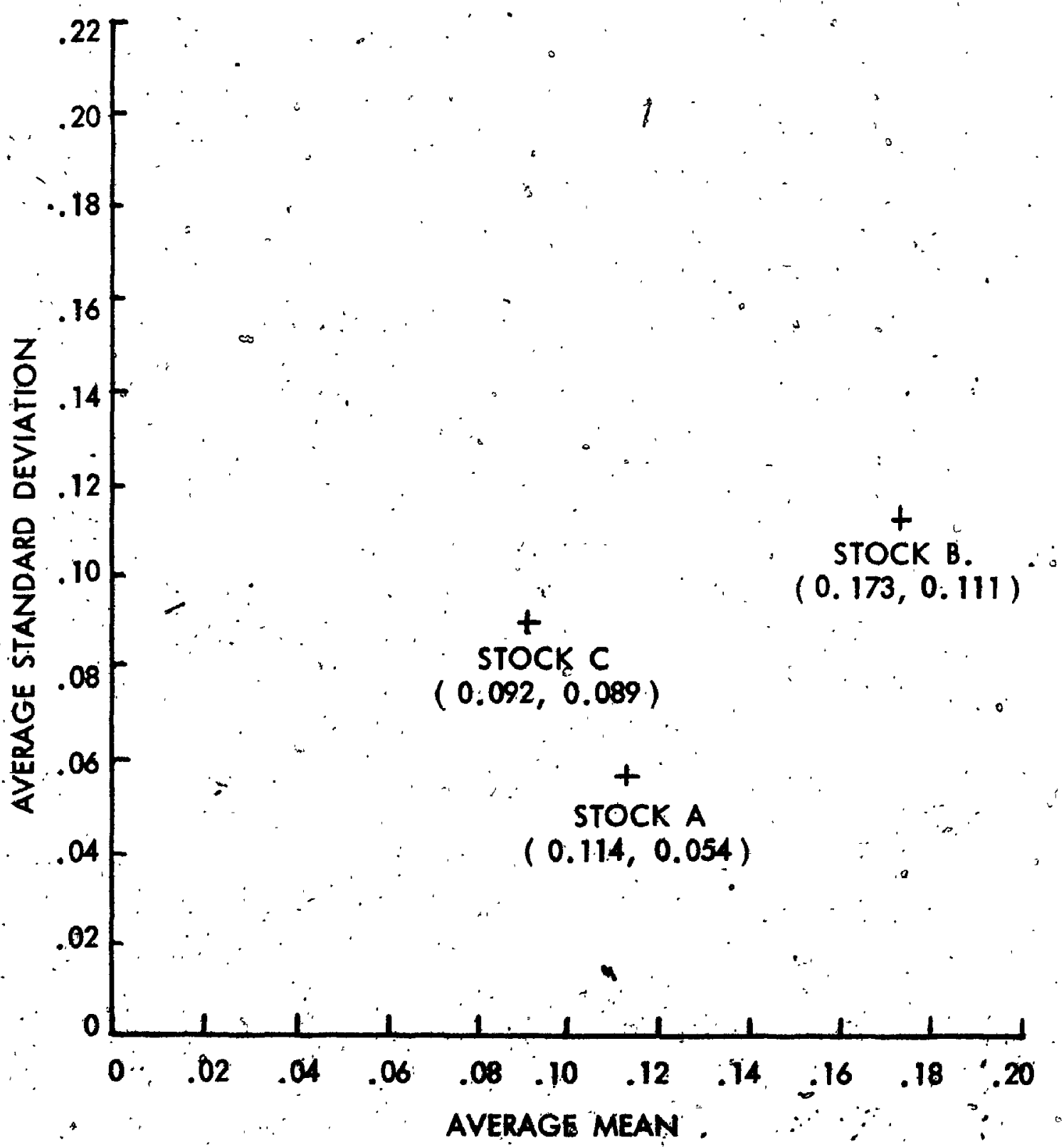


6.6 .2

Intra-stock Comparisons of Total Return Expectations The ${ }_{, 0}$ results of comparing the magnitude and uncertainty of buyers! opllers' and' ownexs' expectations of total return are presented in Table $633,6.34$ and 6.35 . a) Buyer's and Owners

The evidence presented in the above Tables supports the hypothesis that the average magnitude and uncertainty of buyers and owners çombined price and dividend expectations were not significantly different over all time horizons. That is, buyers, and owriers' expectations of total return are indistinguishably in that they are equaly op̉imistic and uncertain.

b) Sellers and Owners

In the referenced Tables; the data supports the hypothesis that the magnitude of seliers' 'xpectations are significanty less optimistic than that of gwners in the shorter term but not in the longer term. consistent significant differences in the uncer-
tainty of sellers, and owners expectation were not evident. tainty of sellers and owners' expectation were not evident. While sellérs weré generaliy more certain in thein expectations than owners in the short term for both historical and expectational correlations, difference in uncertainty . s. were only significant for stock $A$ and then only for expectational correlations. In contrast; short-term differ-

$\because$ ences weresighificant for stock C using histonical correlfition 


\section{Tábie 6.33 \\ INTRA-STOCK COMPARISQNS OF SUMMARIZED \\ INVESTOR TOTAL RETURN EXPECTATIONS*}

Company A

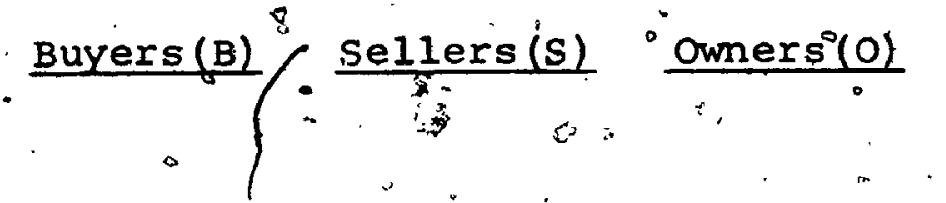

Significance

Lievel of

Comparisons

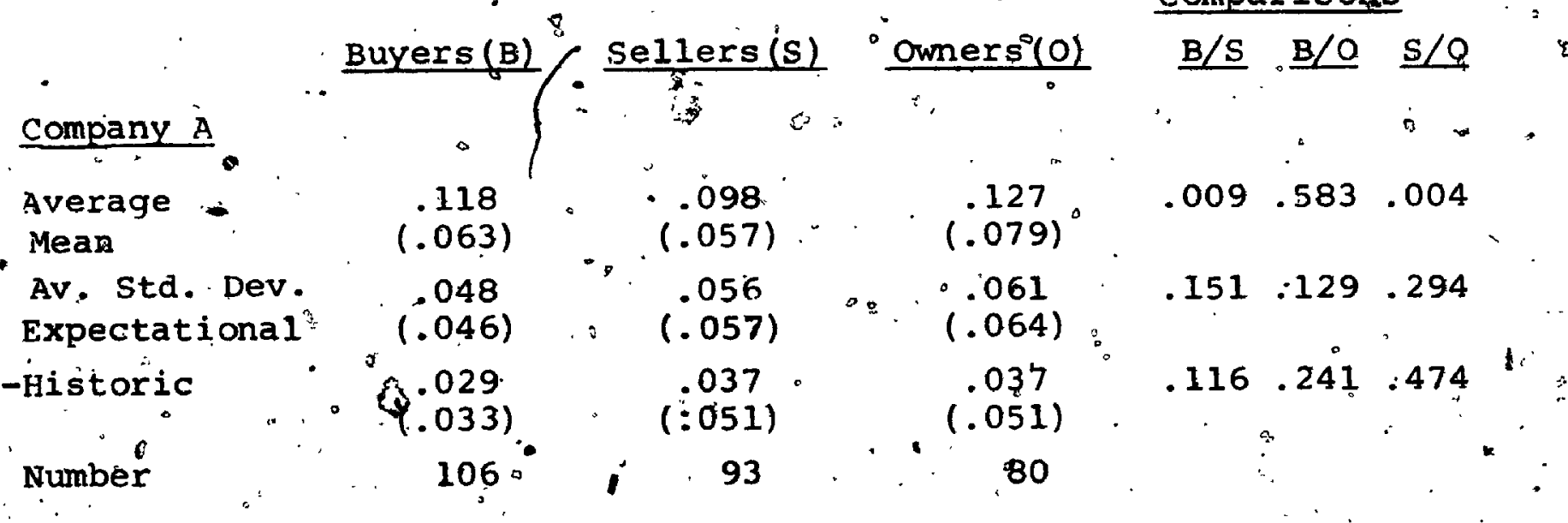

Company B

Average

Mean

.178

(.106)

.159

(.157)

.0173

$.280 \cdot 785+334$

Expectationa

.112

(.099)

109
$0120)$

$0(.143)$

.

-Historic

$(.126)$

.105

(.121)

(.110

$.452 \quad .865 \quad .486$
0

Number

101

27

(112)

$.282 .293 \quad .386$

company $\mathrm{C}$.

Average $\quad .120$

Mean

(.081)

a

106.

Av. Std. Dev

Expectational

.113

(.116)

.076
$(.089)$

.092

.065 )

$\gamma^{061} .310 .323$

-Historic

.102
$(.115)$

.099
$(.085)$

.076

(.069)

. $.298 \cdot 130^{\circ} .088$

Number

26

.093
$(.083)$

.070

$(.068)$

$.361 .189^{\circ} .088$

"The "Average Mean" and "Average Standard Deviation". are in units of annual tate of change. Figures in brackets are standard deviations. Significance levels are expressed as the probability of observed differences in averages occurring by chance. All sígnificance tests involve one-tailed 't' tests. 


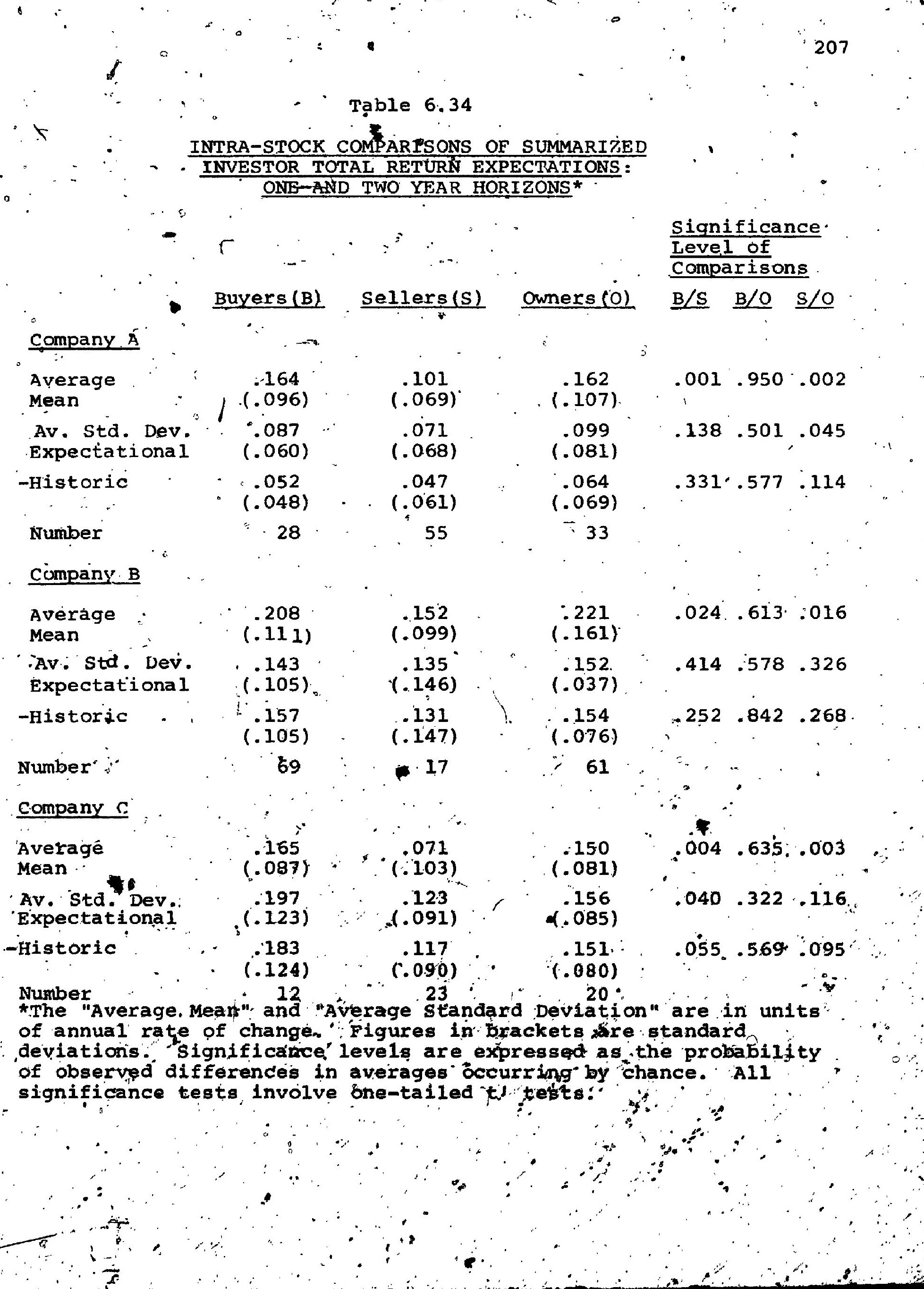


Table 6.35

INTRA-STOCK COMPARISONS OF SUMMARIZED

INVESTOR TOTAL - RETURN EXPFCTATIONS:

LONGER T.HAN TWO YFAR HORIZONS*

Significance

Level of

Comparisons

Buyers(B) Sellers(S) Owners (O) B/S B/O $\underline{\mathrm{s} / 0}$

Company A

Average

Mean

102

.094

.102

$(: .036)$

.$\$ 26.933 .145$

Av. Std. Dev.

Expectationa 1

.034

$(.030)$

.034

$(.029)$

.034

-Historite.

.021

$(.021)$

$(.026)$

.022

(.021).

(.019)

.018

$(.016)$

7.8

38

47

Number

Company B

Average

Meän

$\therefore 112$

(.049)

$: 169$

$(.232)$

.108

(.080)

$.266 \ldots .788 .280$

Av. Std. Dev

.046

.066

.054

(.023)

(.037.)

.018 .674 .098

-Historic

.062 .

(.023)

.056

.057
$(031)$

(.038)

10

45

Number

32

$\because$

10

$.480 \quad .939 \quad .487$

.426 .317 .146

Gompany C

Average

Mean.

.063

(.031)

$.087^{\circ}$

.071

$(.051)$

(.041)

.097 .522 .327

Av std. Dev.

Expectationa 1

.042

.0 .48

.047

(.034)

$(.027)$

$.341 .618 \quad .474$

-Historic

.032
$(.032)$

.042

$(.033)$

.040

$(.028)$

$.296 \quad .830 \quad .258$

11

54

Number

14.

.266 .602 .433

*The "Average Mean" and "Average standard Deviation" are in unitts of annual rate of change. Figures in brackets are standard.

deviations. Significance levels are expressed as the probability of observed differences in averages occurring by chance. All significance tests involve one-tálied $t "$ tegts. 
but not for expectational correlations. 'Furthermore, 'differences were significant for stock $c$ in the longer term.

Thus, there is some indication of, significant differences in uncertainty of seliers and owners! expectations of $\because \therefore$ total return (primarily in the short-term). However, the inconsistency of these findings prevents'a generalization.

c) Buyers and sellers

The evidence in the referenced Tables supports the hypothesis that sellers are "significantly more pessimistic than buyers for the future return from their respective stocks for time horizons of up to two years but not for longer horizons.

There is little evidence to indicate that these differences in expectations of the magnitude of the return are accompained by differences in the uncertainty of the expectations. As in the' case of sellers and owners' expectations, significant differences in the uncertainty of expectations are unique to the particular stock, although in the short-term, sellers' expectations are consistently mpertain than buyers. Thus, buyers' and sefilers expectations of financial return are generally only distinguishable in terms of their optimism for the magnitude of the expectation. .

\section{d) Discussion}

Differences in the total return expected by buyers, sellers and owners were imilar to those found for price 
FIGURE 6.5

AVERAGE RISK AND RETURN OF

TOTAL RETURN EXPECTATIONS BY

TYPE OF INVESTOR.

(Reference: Table 6.33)

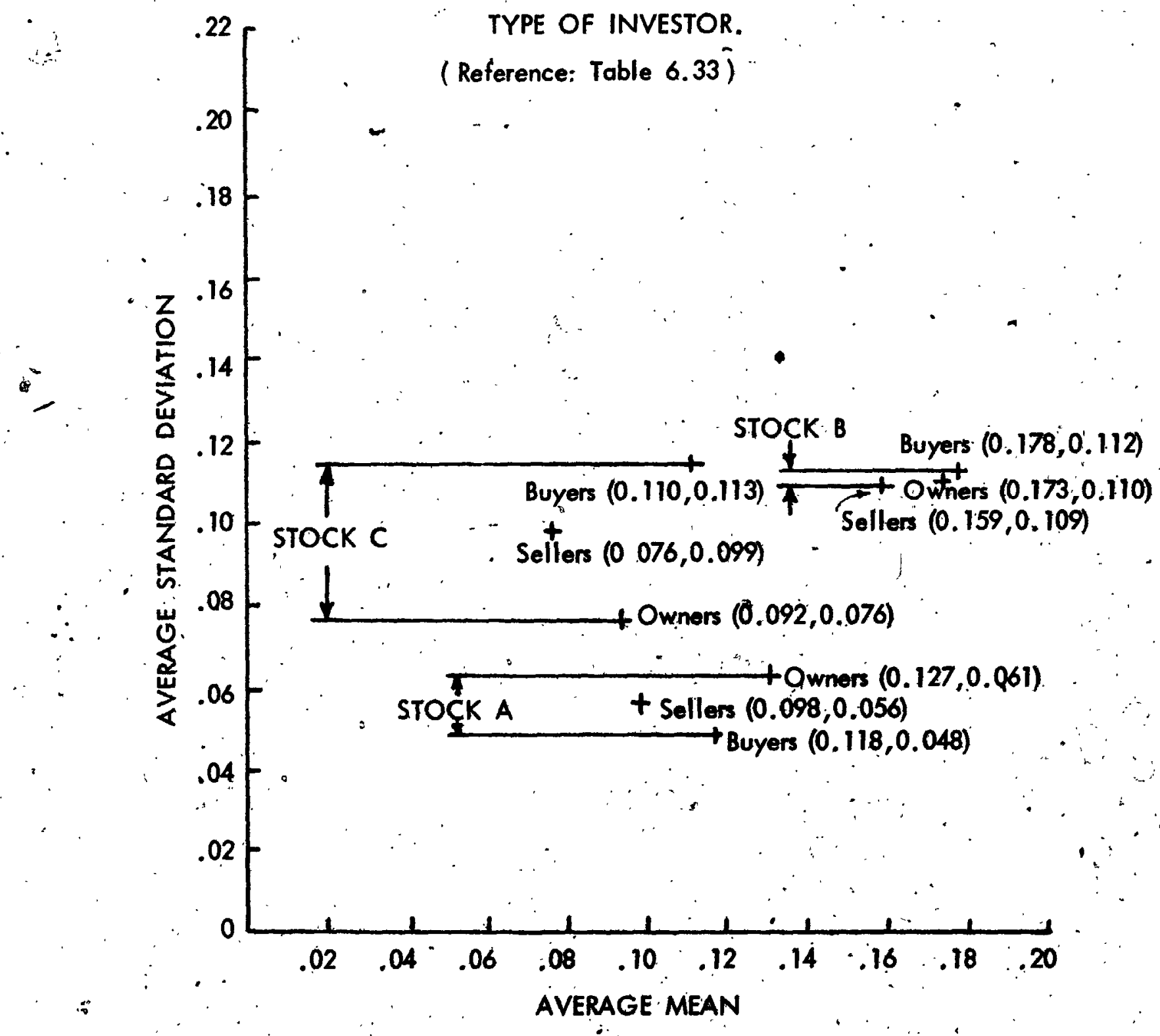


expectations. Essentially, buyers and owners had indistinguishable expetations for their'particular stọck while short-term sellers had consistently lower réturn expectations than either buyers or owners. Oniy.inconsistent evidence of signifi- cant differences in perceived risk were found: Thus, as in the case of price expectations, buyers, sellers, and owners, of a particular stock are, operating on essentially the same level of uncertainty/risk. This result is illustrated in Figure 6.5

$6 \cdot \overrightarrow{6} \cdot 3$

Inter-Stock Comparisons of Individual Investors' Expectations of Total Return with Control for frie Type of Investor and the Time Horizon

L. Results of further extending the above analysis to inter-stock comparisons of similar types of investors are presented in Tables $6.36,6.37$ and 6.38 .

\section{a) Stocks $A$ and $B$}

The data in referenced Tables indicate that in the aggregate and over both time horizons all three types of investors associated with stock $B$ are more optimistic and uncertain than their counterparts associated with stock. A. These, differences in magnitude and uncertainty are highly significant in the aggregate and short-term but only uncertainty is significantly different in the longer-term. 
Table 6.36

\section{INTER-STOCK COMPARISONS OF SUMMARIZED INVESTOR TOTAL RETURN \\ EXPECTATIONS BY TYPE OF INTESTOR*}

Significance

Level of

Company : Comparisons

$\underline{A} \quad \underline{B} \quad \underline{C} \quad \underline{A} / B \quad \underline{B} / C \quad \underline{B} / C$

Buyers

Average

Mean

$.118 \quad .178$

$(.063)$

$(.106)$

.110

.000

.326

.001

Av. Std. Dev.

.048

.112

Expectational

$(.046)$

(.099)

$(.08 .1)$

-Historic

.029

.126

$(.033)$

$(.100)$

.113

(.116)

106

101

.102 .

(.115)

Number

Seliers

Average

Mean

.098

.159

.076

.028

.089

.018

Av. Std. Dev.

$(.057)$

$(. .157)$

(.089)

.056

.109

.099

.015

.004

.716

ExpectationaI

$(.057)$

(.120)

$(.085)$

-Historic

.037
$(.051)$

.105

.09 .3

.003

.000

.665

Number

93

27

34

Owners

Average

Mean

Av. Std. Dev.

.127
.079

.173

$(.143)$

.092

$(.065)$

.002

.001

.000

Expectational

.06
$(.06$

.110

.076

.00

$.080-.002$

-Historic

.037
$(.051)$

$(.079)$

$(.069)$

.000

.000

$.900 \div .000 \because$

Number

80

.112

(.079)
.070

(.068)

\section{6}

74

*The "Average Mean" and "Average Stándard Deviation" are in units of annual rate of change:. Figures in prackets are standard deviations. Significance levels are expressed as the probability of. observed differences in averages occurring by chance. Stock A/Stock. $B$ and stock $A / S t o c k$ C significance tests involve one-tail $t$ tests; stock B/stock C tests involve a non-directional t' test. 


\section{Table 6.37}

INTER-STOCK COMPARISONS OF SUMMARIZED

INVESTOR TOTAL RETURN EXPECTATIONS BY TYPE OF INVESTOR:

$$
\text { ONE AND TWO YEAR HORIZONS* }
$$

$\underline{\text { A }} \frac{\text { Company }}{B} \quad \cdots \frac{\text { Significance }}{\frac{\text { Level of }}{\text { Comparisons }}}$

Buyers

\begin{tabular}{|c|c|c|c|c|c|c|}
\hline $\begin{array}{l}\text { Average } \\
\text { Mean }\end{array}$ & $\begin{array}{l}.164 \\
(.096)\end{array}$ & $\begin{array}{l}.208 \\
(.111)\end{array}$ & $\begin{array}{l}.165 \\
(.087)\end{array}$ & $\therefore 024$ & .485 & .139 \\
\hline $\begin{array}{l}\text { Av. Std. Dev } \\
\text {-Expectational }\end{array}$ & $\begin{array}{l}.087 \\
(.060)\end{array}$ & $\begin{array}{l}.143 \\
(.105)\end{array}$ & $\begin{array}{l}.197 \\
(.123)\end{array}$ & .000 & .004 & -.162 \\
\hline -Historic & $\begin{array}{l}.052 \\
(.043)\end{array}$ & $\begin{array}{l}.157 \\
(.105)\end{array}$ & $(.183)$ & .000 & & .510 \\
\hline
\end{tabular}

Number

28 .

69

12

Sellers

\begin{tabular}{|c|c|c|c|c|c|c|}
\hline $\begin{array}{l}\text { Average } \\
\text { Mean }\end{array}$ & $\begin{array}{l}.101 \\
(.069)\end{array}$ & $\begin{array}{c}.152 \\
(.099)\end{array}$ & $\begin{array}{l}.071 \\
(.103)\end{array}$ & .027 & .103 & .014 \\
\hline $\begin{array}{l}\text { Av. Std. Dev. } \\
\text { Expectational }\end{array}$ & $\begin{array}{l}.071 \\
(.068)\end{array}$ & $\begin{array}{l}.135 \\
(.146)\end{array}$ & $(.123)$ & .046 & .008 & .764 \\
\hline -Historic, & $\begin{array}{r}.047 \\
.(.061)\end{array}$ & $. \quad .131)$ & 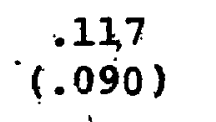 & .015 & .001 & .730 \\
\hline Number &.$^{55}$ & 17 & 23 & & ' & \\
\hline Owners & $\because$ & 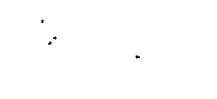 & . & . & i & \\
\hline $\begin{array}{l}\text { Average } \\
\text { Mean }\end{array}$ & $\begin{array}{l}162 \\
(+107)\end{array}$ & $\begin{array}{l}.221 \\
(.161)\end{array}$ & $\begin{array}{l}.150 \\
(.081)\end{array}$ & .017 & .310 & .01 \\
\hline $\begin{array}{l}\text { Av. sta Dev. } \\
\text { Expectational }\end{array}$ & $\begin{array}{l}.099 \\
(.081)\end{array}$ & $\begin{array}{l}.152 \\
(.037)\end{array}$ & $\begin{array}{l}.156 \\
(.085)\end{array}$ & .000 & .00 .9 & .834 \\
\hline Historic & $\begin{array}{r}.064 \\
.(.069)\end{array}$ & $\begin{array}{c}.154 \\
(.076)\end{array}$ & $(.151)$ & .000 & $\begin{array}{l}000 \\
\vdots\end{array}$ & .87 \\
\hline
\end{tabular}

number

33

n 61

20

*The. "Averáge Mean" aña "Average standard Deviation" are in units of annual rate of change. Ficures in brackets are standard deviations: Significance levels 'are expressed as' the probability of observed aifferences in averages occurring by chance. Stock $A / S t o c k, B$ and stock $A / S t o c k C$ significance tests involve onetall $t$. tests; stock B/stock $C$ tests linvolve a non-directional $t$ test. 
Table 6.38

INTER-STOCK COMPARISONS OF SUMMARIZED INVESTOR

TOTAL RETURN EXPECTATIONS BY

TYPE OF INVESTOR: LONGER THAN TWO-YEAR HORIZONS*

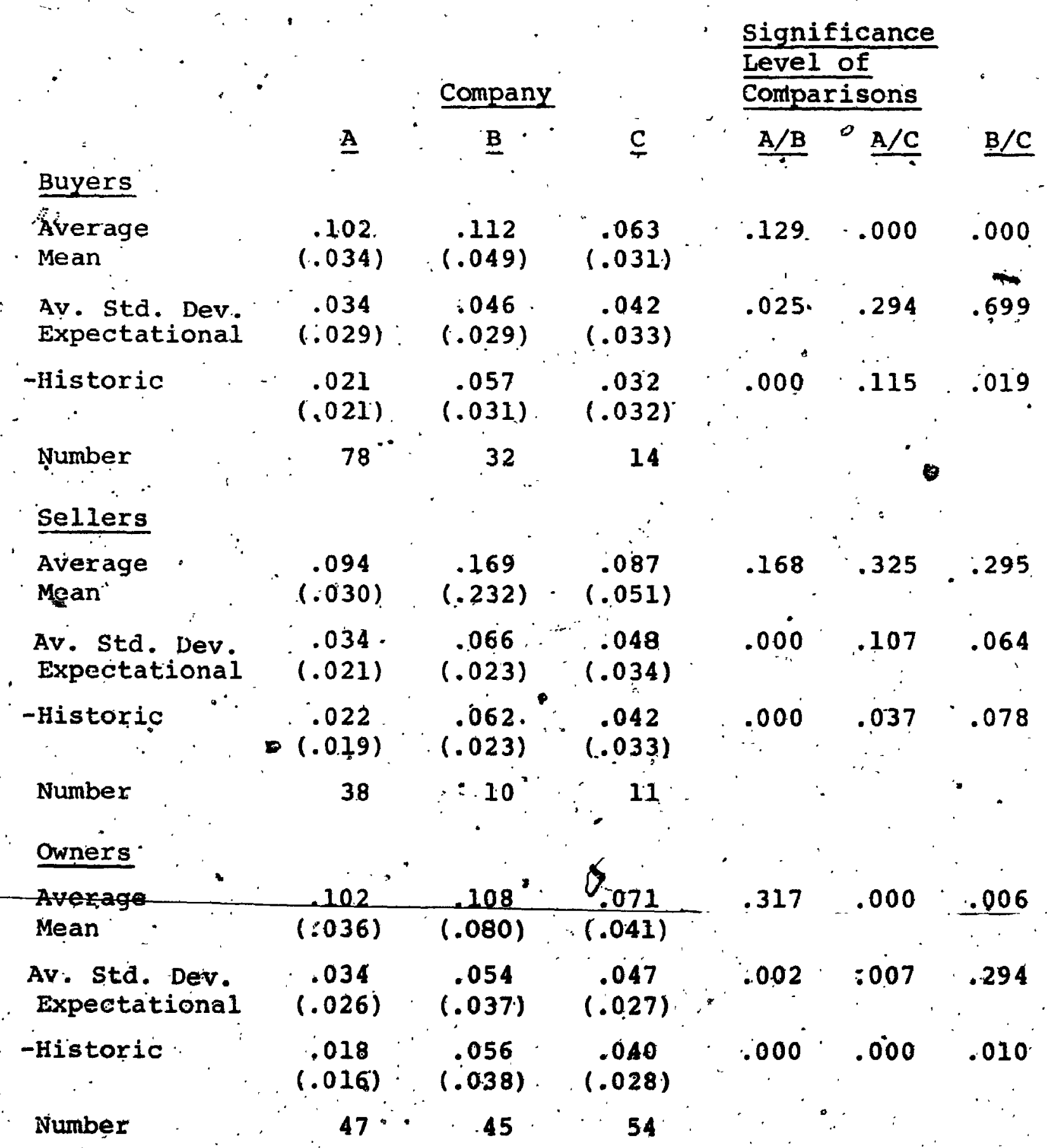

*The "Average Mean" and "Average Stañara Deviation" are in units: of annual rate of change. Figures in brackets are standard

deviations. Significance levels are expressed as the probability of observed differences in averages occurring by chance. stock A/stock $B$ and stock $A / S t o c k$ C sigh cance tests involve one-tail $t$ tests; stock B/stock : $C$ testśs involye a non-directtonal ' $t$ ' test. 
b) Stocks A and C

Ali three types of investors associated with stock

$C$ are equally or less optimistic and more unceptain than their counterparts associated with Stock A. Differences in the optimism and uncertainty are significant in an inconsistent manner over both horizons although in the short-term, all three types of investors associated with stock C are significantly more uncertain in their expectations than investors associated with stock A.

c) stocks B anc C

The data in the referenfed Taples indicate that

all three types of investars associated with. stock $B$ are more optimistic and ungertain than their counterparts associated with stock $\oint$. In general, the magnitudes are significantly different in both the short- and longer-terms while there are no insfances of the uncertainty being statistically different.

d) Discussion

The differences joted in comparisons of aggregates of investors: expectations were found among ail three types of investors and over the two selected time horizons. Some inçonsistencies were noted which reflect the dependence of these latter comparisons on the underlying price and dividend

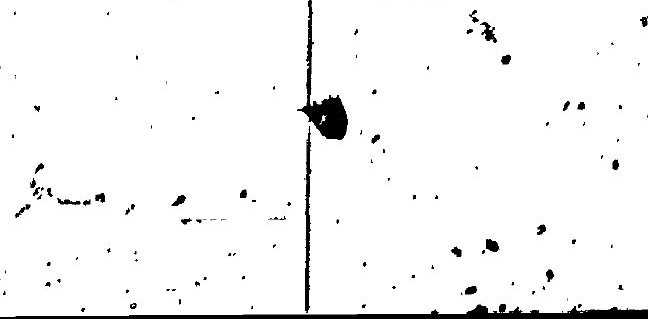


distributions and quite possibly on the assumptions regarding fhe correlation of these aistributions. However, the data do indicate that the direction of differences found in Table 6.32 is also found among all three types of investors and across the two time horizons.

\subsubsection{Inter-and Intra-Stock Comparisons Involving Analysts. Total Return Expectations} Inter-stock comparisons of ana]ysts' expectations of combined price and dividend return are proserted in Table 6.39. Comparisons of analysts' expectations with individuals' expectations of combilled return are summarized in Table 6.40.

a) Stocks $A$ and $B$

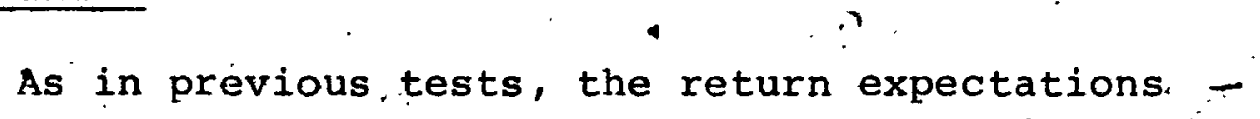
for stock $B$ are indicated as, being significantly more optimistic and uncertain than those for stock. A.

b) Stocks $A$ and $C$.

The return expected by analysts for.stock $C$ is significantly more uncertain than that for stock $A$ but of similar magnitude.

c) stocks B and C

The total return expected by analysts for stock. C. is indicated as being statistically indistinguishable from that for stock B although expectations for $C$ are on average more. 
Table 6.39

INTER-STOCK COMPARISONS OF SUMMARIZED

SECURITY ANALYSTS TOTAL RETURN EXPECTATIONS *

$0 . \quad 0$

$\underline{A}$

Average

Mean

Av. Sted. Dev.

Expectational

-Historic

Number
Company

3

Company

$\underline{\mathbf{B}}$
.107

$(.044)$
.152
$(.075)$

$15 \cdot \quad 13$

.104

c

$(.087)$

Significance

Level of

Comparisons

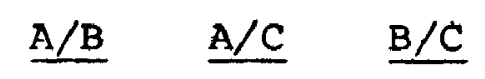

$\underline{A} B \quad \underline{B} \quad \underline{B} \quad \underline{B}$

$.034 \quad .454 \because .142$.

$\begin{array}{llcccc}.037 & .03 & .128 & .000 & .012 & .526 \\ (.037) & (.046) & (.129) & & & . \\ .025 & .097 & .136 & .000 & .004 & .316 \\ (.035) & (.045) & .0728) & .04 & & \end{array}$

13

*The "Average Mean" and "Average Standard Deviation" are in units of annual rate of change. Figures in brackets are standard deviations. Significance levels are epxressed as the probability of observed differences in averages occurring by chance. stock $A /$ Stock $B$ and stock $A / S t o c k ~ C$ significance tests involve one-tail $t$ ' tests; stock B/stock C tests involve a non-directionäl $t$. test. 
Table 6.40

CONPARISONS OF ANALYSTS' AND INVESTORS' SUMMARIZED, TOTAL RETURN EXPECTATIONS*

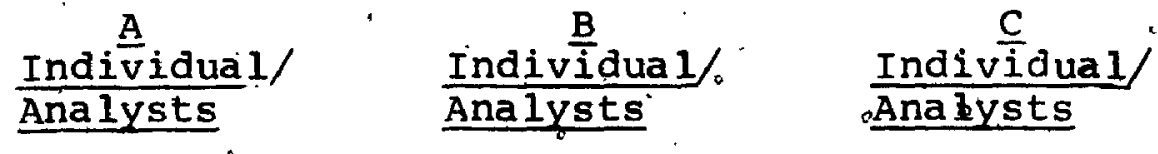

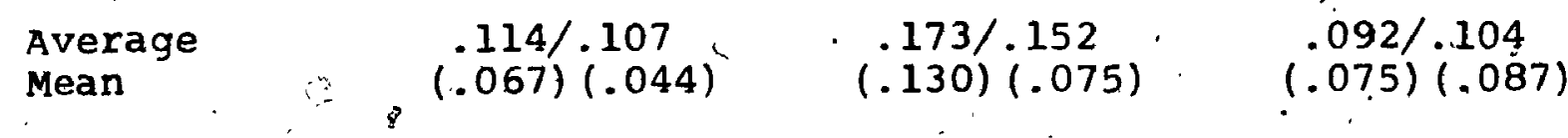

Significance $\quad .574$

$\therefore .669$

Av. Std: Dev.

$.054 / .037$
$(.055)(.037)$
.105

$.111 / .103$

$.089 / .128$

Expectationa 1

$(: 093)(.046)$

$(.084)(.129)$

significance

.105

$\$ 583$

.304

$\rightarrow$ Historic $\quad .034 / .025)$

$\leftarrow$

$.117 / .097$
$(.094)(.045)$
$.082 / .136$

Significance

.645

.162

.155

Number

$279 / 15$

$234 / 13$

$134 / 13$

*The "Average Mean" and "Average Standard Deviation" are in. units of annual rate of return. Figures in brackets are standard deviations." Significance levels are expressed as the probability of observed differences in avexages occurring by chance. All significance tests involve a non-directional $t$ ' test. 
uncertain and less optimistic than for seock $B$.
d) Discussian

Inter-Stock comparisons of analysts'. expectations

".. of combined return result in cleariy defined risk and return trade of $\mathrm{fs}$ between stocks $\mathrm{A}$ and $\mathrm{B}$. The distinctions between stocks $A$ and $C,{ }^{c}$ arrd stocks $B$ and $C$ 'were, however, less dëfinite than those obtained from investors expectations. As in pregious differences of this nature, analysts' expectations regarding the variability of expected return for stock c : tend to indicated that stock as being an inferior investment to both stöcks $A$ and $B$ if the relative skewess of the undẻrlying ṕrice distribution for stock $\mathrm{C}$ is ígnored.

The sensitivity of the average mean rate of return to changes in the ave standard deviation (expectational) is less $(-.298)$ between Stocks $A$ and $C$ than that between Stocks $C$ and $B(3.562)$.

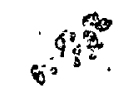

6.6.5 Summary ofinter- and Intra-Stock comparisons of Total $R$ zurn Expectations

a) Inter-stock Comparisons of Total Return Expectations

The result of combining the price and dividend expectations to yield an average annual rate of return internal rate of return) expected by individual investors indicates. that the expected return from stock $A_{3}$ is the least risky: - that from stock $c$, roughly $50 \%$ more risky than $A$, and that from 
stock $B$, roughily 1004 more risky than findings stock $B$ is expected to provide the largest annual rate of return, i7\%; however, unlike earlier. findings forfiprice and dividend expectations táken separately, stock A is expecţed to provide a higher annual rate of return. $(118)$ thán stock C (9\%). Thus, although the rate of growth in both the price and dividend for stock $C$ was significantly greater than that for stock $\bar{A}$ the relatively large dollar dividend povided by. Stock (roughly 5 times larger) and the longer time horizons of investors associated with stock $A$ outweighed the influence of growth expected in the two factors of total-return for stơk $\dot{C}$. Hence, from the stand- . point of average return and risk, stock A was indicated as being a superior investment in relation to stock $c_{\text {; }}$ although, as indicated eárbier, the expected price return for stock $c$ offers a.greater potential for an extreme increase in price than that for stock. A. These findings therefore provide contradictory support for Hypothesis 1.1 and reject the stronger hypothesis (fypothesis 1.2) that expected return differentials increase more than proportionately with risk differentials.

Comparisons of analysts" expectations of total return indicate that the return from stock a is least risky, that from stock B being roughly 2008 greater and that for stock 
C roughly 3008 greater. However, while stock $C$ is indicated as being the most risky, the return expected is sightily lower than that expected from stock $\dot{A}(10 \% \mathrm{vs}$. 'i18) and less than that expected from stock. B, 15\%. Thus, in terms of analysts' expectations, stocks $A$ and $B$ wquld be superior investments in relation to stock $C$ if the skewness of the underlying price expectations was ignored. Further analysis indicates that while analysts and individual investors differ in the relative risk of stock $C$ vis à vis stocks $A$ and $B$, they are in general agmeement regarding the magnitude of the annual rate of return expected and the magnitude of the risk. Thus these. findings support the efficient market hypothesis (Hypothesis 3.) that investors expectations are consistent with security analysts' expectations regarding the total return and risk potential of the three stocks.

b) Intra-stock Comparisons of Total Return Expectations Differences in the total return expected by 4 buyers, sellers, and owners generally followed the same pattern as that found for price expectations. That is, buyers "and owners expectations were statistically indistinguishable over all timé horizons: Comparisons of sellers and owners , expectations and sellers and buyers expectations indicated significant fifferences in total return expectations but.only 
for those investors with short-term horizons. For all three. stocks; sellers with one or two year horizons expected a. lower average rate of return than both buyers and owners with similiar time horizons. There was no consistent evidence of. significantly different risk differentials. Thus these -

findings support only Hypotheses 2.1 and 2.3 (partially) of the four intra'stock hypotheises.

\subsection{SUMMARY OF MAJOR FINDINGS} The major findings of this Chapter are classified as inter- or Intra-stock findings and are sumplarized. below.

\section{$6.7 .1 \%$ Inter-Stóck Findings}

I. Individual investors expeoted a higher rate of price appreciation and dividend growth for relatively more risky stocks. This result was also, found 'in expectations of total return for two of the three inter-stock comparisons. The exception to this finding indicated that the oil stock

- (C) was expected to provide a lower total return and greater. $\therefore 8$ risk than the utility stock (A).

2. only in the case of price and dividend expectations taken individually was there evidence that expected value differentials were more than.proportionately greater than expected risk differentials.

3. The skewness of stock market participants' 
price expectations was least for the relatively low risk utility stock (A) and significantly greater for the higher risk stocks (B and $C$ ): Significant differences in the skewness of dividend expectations were not found.

6.7 .2

\section{Intra-stock Findings}

1.: For all. three stocks, buyers' and owners' price, dividend and total return expectatations were statistically indistinguishable. The only consistent evidence of statistically different return expelctations among the three types of market participants was fqund in the case of shortterm price and total return expectations. In these instances sellers were found to hold expectations of a relatively low rate of return in relation th the price expectations of either buyers or owners.

2. Individual investors" and security analysts' expectations of the rate of price change, dividend change, and tọtal return were statistically indistinguishable for ch ch of the three 'stocks. Individuals' and analysts! expectations of risk were indistinguishable in the case of total return for all three stocks; in the case of price expectations for the utility stock (A) and the mineral resource stock (B): and, in the case of divilend expectations for the oil stock (C). Individuals! ana ana lysts' expectätions of skewness were

- indistinguishable for both priçe and dividend"expectations only in the case of the utility stock (A). 
In Chapter I three research questions were posed concerning the nature of investors' expectations of financiai return. These questions inquired about differences in expectations between stocks and among arket participants for any and stock. In Chapter III empirical hypotheses were proposed to investigate these inter- and intra-stock differences in expectations.

The results of testing these hypotheses-were presented in Chapter VI and are, sumarizlin.this. Chapter. . Conclusions based on these findings are presented and dis-cussed in the context of their implications for financial theory and research, corporate finance, and the investment industry. Finally, the implications of this study for further research are discussed.

7.1 LIMITATIONS OF THE RESEARCH DESIGN The findings discussed in Chapter vI are based on the measured expectations of a sample of market participaints and a selected group of three stocks. Conclusions awn from these findings and the implications of these conclustors 
are premised on the belief that similar results would have $\cdots$ obtained if larger samples of investors and more stocks had been inyolved in this study.

Three constraints on the external applicability of these findings (and subseguent conclusions) should however be noted.

(a) The response rate to the mailing of questionnaires was approximately $30 \%$; that. is, $70 \%$ of those investors who received questionnaires did not respond. 1 " In assessing the possible influence of the expectations of non-responders Jon the findings of this study the relevent question to consider is whether or not the return expectations of nonresponders are different from those of responders? For example, is there any reason to believe that the price expectations of non-responders would be more or.'less optimistic or uncertain than the price expectations of responders? In the absence of evidence relating to this issue the null hypothesis is assumed to hold.

(b) The sample of investors in this study excluded institutional investors. Again the question of the representativeness of the measured expectations hinges on the issue of whether or not there is reason to believe that instiutional investors'. expectations for the various stocks are somehow systematically different, from those of the individual investors or security analysts involved in see Chapter v.

A response rate of $25 \%$ had been anticipated. 
this'study. The nill hypothesis is assumed to hold.

(c) All three stacks involved in this study could reasonably be classified as being 'blue chip' eyen though two of the stocks involved resource companies. Thus the findings are open to the question of whether or not risk: and return differentials of the same general nature would be found for other, more risky classes of stocks. No. evidence is available that might resolve this issue..

7.2 SUMMA RY OF MAJÖR FINDINGS

The major findings presented in chapter VI are summarined below and classified as inter- or intra-szock findings.

\section{2 .1}

Inter-Stock Findings .

(a) Individual investors expected a higher rate of price appreciation and dividend growth for relatively more risky stocks. This result wers also found in expectations. ' of total return for two of the three inter-stock comparisons. The exception to this finding Indicated that the oil stock (C) was expected to provide lower total return and greater. risk than the utility stock (A).

(b) Only in the case of price and dividend expectations taken individualiy was there evidence that expected value differentials were more than propottlonately 
greater than expected risk differentials.

(c) The skewness of stock market participants' price expectations was least for the relatively low risk utility stock (A) and significantly greater for the higher risk stocks (B and $C$ ). significant differences in the skewness of dividend expectations were generally not found.

7.2 .2

\section{Inera-stock Findings}

(a) For all three stocks, buyers' and owners" price", dividend and total return expectations were statistically indistinguishable.

The only consistent evidence of statistically

different return expectations among the three types of market participants was found in the case of short-term price and total return expectations. In these instahces sellers werè found to holà expéctations of a relatively low rate of return in relation to the expectations of either buyers or öwners.

(b) Individual investors and security analysts expectations of the rate of price change, dividend change, and total return were statisticaliy indistinguishable for 'each of the three stocks. Individuals and analysts expectations of risk were indistinguishable in the case of total 
return for all three stocks; in the case of price expectations for the utility stock (A) and the mineral resource stock (B) ${ }^{2}$; and, in the case of dividend expectation's for the oil stock (C). Individua ls' and analysts' expéctations of skewness were indistinguishable for both price and dividend expectations only in the case of the utility stock (A).

7.3

\section{CONCLUSIONS}

The foregoing findings dealt with the results of inter- and intra-stock comparisons of expectations. This evidence, provides support for conclusions-regarding interand intra-stock similarities and differences in expectations.

7.3 .1

\section{Inter-stock conclusions}

The findings of inter-stock comparisons are consigtent with theoretical propositions regarding the. form; content, and behavior of investor expectations in the equity valuation process. Specifically, investors were founa to hold distributional expectations of price. and dividend changes"wich, on avérage, refiect a higher mean expectation in the presence of greater variance. The finding'

- It is worth noting that at the time of this gtudy there was considerable controvergy and uncertainty in the financial and general-interest press regarding the "energy crisis" and possible góvernmentai action involving Canadian petroleum companies.: Given this situation 1 t. is reasonable tó speculate that expectations for the ofl. stock (c) may have been in a'transitory state at the time of the study and that security analysts expectations reflected increaged uncertainty sooner than those of individual. investors 
that expectations of total return for the oil stock (c), on average, had a smaller expected vạlue and greater risk than those for the utility.stock (A) is contrary to the hypothesized behayior of investor expectations and therefore restricts the above conclusion to the case of price and dividend expectatilons taken separately. ${ }^{3}$ Alternatively stated, ex ante rikk premiums involving the expected value of expectations do exist for individual elements of return expectations.

The expected-return risk premiums found in this study are alsd consistent with the proposition that investors expect a more than proportionate difference in expectied return for a given fisk differential between two stocks. Again this conclusion must be restricted to the case of risk premiums reflected in price and dividend expectations taker individual1y: .

support the proposition that ex ante skewness of price. expectations is relevant in the valuation process. This conclusion however must be qualified by the assumptions

${ }^{3}$ Rationalizations for this instance of contrary findings could involve the inability of the research design to obtain investors: beliefs regarding the correlation between price and dividend expectations; the possibility that investors do not lexpect' in terms of an internal rate of return as employed in this atudy; the possibility that investors' perceptions: of risk are not in terms of the variability per se of the total expected return, etc. 
that value is a positive function of right skewness and and that investors do not ignore the right skewness that was observed in their price expectations. If these assumptions are correct then the total risk premium ${ }^{4}$ involved in the valuation process must be defined to include both the expected value and the skewness of the price and dividend expectations taken individually or in a joint distribution.

7.3.2 Intra-stock Conclusions.

The findings of intra-stock comparisons of individual investors' expectations are consistent with .. the proposition that sellers of a stock with relatively short. investment horizons are less optimistia about the future rate of price appreciation than buyers or owners of that stock: That is, expectations the marketplace for a particular stock are not homogeneous.

${ }^{4}$ As indicated in chapter III the total risk premium associated with a stock is also considered to be a function of the expected ovariance of a stock's return with the return from the market.

5 The possible relevance of the asymetry of price expectations in the valuation process could explain the earlier noted anomaly where the total return expected for the oil stock (c) -was smaller and more risky than that expected for the utility stock (A). The negative, expectedvalue risk premium implied by this finding did not reflect the significantly greater right skewness found in the price expectations for the oil stock. Had the skewness of the underlying price expectations been somehow combined with the expected value of the total return, the total risk. premium for the oil stock (in relation to the utility stock) may have been positve. 
The findings of intra-stock comparisons of individual investors' and security analysts' total return expectations and risk could be interpreted as the supporting the proposition that all publicly-available information was fuliy reflected in the market price of the three stocks at the time of the study. 6 However, in view of the eaxlier. noted instances of significant differences in the risk and skewness of analy'sts' and individuals'oprice and dividend expectations taken separately, the opposite conclusion is reached.

7.4 IMPLICATIONS

In answering the research questions put forward in Chapter I (section 1:2) this study yeilded results that have impliçations for financial theory and research, corporate financial practices, and the investment dealer industry. These implications are discussed in the following. sections.

$7: 4.1$ Financial Theory and Research - In chapter I Robichek was reported as questioning the extent to which the theory of valuation was consistent

This conclusion is based on the assumption that individual investors and security analysts have similar powers of perception and interpretation of information and that the only reason for differences in expectations is differences in information.". 
with the manner in wich stock valuation was actually practiced. This study investigated one aspect of valuation theory; namely, the nature of investors' expectations of financial return. The fact that investors held price and dividend expectations which were generally distributional in nature and evidenced expected- valye risk premiums supports existing valuation theory regarding investor expectations. Thus, although disparities between valuation theory and practice may exist, the representations of expectations in valuation theory is indicated as being consistent with the nature of expectations of investors. practicing valuation. addition to providing insight into the
disparity between valuation theory and practice, question of disparity between valuation theory and practice this study and its methodology have indicated the feasibility of quantifying invest or expectations in a consistent

: and objective manner.: As Friend has indicated, the direct measurement of investor expectations by survey methods is a necessary condition to achieving "any real progress" in the area of cost of equity capital estimation.

To achieve any real progress in this area in the near-term future, it seems to me to be necessary to survey a comprehensive sample of investors to determine the anticipated rates of return on individual stacks. which they buy, sell or otherwise foilow. It is of course the ex ante required rates of - return rather than the ex post reatred rates which are releyant to the measurement of the cost of capital.

${ }^{7}$ Friend, op. cit., p 270 . 
The internal rates of return implicit in

investors' priqe and dividend expectations as computed in this study are in fact.first approximations to the cost of equity capital (at a point in time) of the three firms. involved in thi study. $^{8}$ The term "first approximation". is employed in recognition of the as yet unresolved issues. involved in reflecting time horizons and, transaction or investment sizes of the various types of market participants, : in the computation of a representative absolute magnitude. $\vec{\nabla}$ for a firm's required rate of return. Notwithstanding these issues, the methodology employed in this study provides a means of estimating'a firm's cost of equity capital that is not directly dependent.on ex post data.

$8_{A}$ firm's cos of equity capital at a point in time is defined as the magnitude of the return expectations of the marginal irivestor. Collectively, marginal investors are referred to as the "market" and are defined as those investors who are just willing to hold the stock at the going market price. since, expectedreturn maximizing investors accept only these stocks which provide the highest level of return for a given level or , risk (variability), the minimum acceptable rate of return for a given level of risk is the maximum rate perceived to be available, Alternatively; investors dispose of a stock when the expected return is less.than the maximum perceived to be available. Thus the expectations of an 'appropriately' determined aggregate of market participants would provide a measure of the average marginal investor"s required rate of return. 
The significance of investor-based, futureorientated data to financial theory and empirical" research can be illustrated further by reference to two empirical studies employing ex post data to ingestigate ex ante phenomená.

$$
\text { Ardetfi. investigated the relationship }
$$

between the required rate of return on equity (dependentvariable) and two types of risk variables (independent variables) - those pertaining to the historical probability distribution of returns 'from a firm's stook (including the variance and skewness of the distribution), and those pertaining to a firms financial policies (the payout ratio and the debt-equity ratio). Ardetti's critical assumption was that "in the long run investors receive what they expect. That is, the actual and the required rates are one and the same". 10" This asumption is questionable since it is, unlikely that investors would expect to receive an average loss or even an average "super normal" return in thé long-run. ${ }^{11 .}$

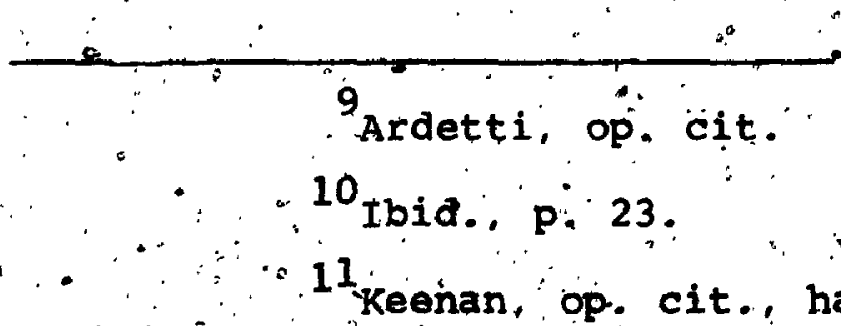
empirical valuation, studies tend to exclude anomalies such" as firms with negative earnings. 


\section{Bower and Bower ${ }^{12}$ investigated the hypothesis}

that normalized prices (dependent variable) of common * stocks were a function of differences in expectations about earnings growth, payout rate, and differences in investors' required rates of return (independent variable). The discount rate or the rate of return required by investors was not directly entered as an explanatory variable in the hypothesized model, instead it was represented as a function of four other variables; the "marketability", "price variability", co-movement with the market, and "firm effects". "13 Thus in contrast with Ardetti's study, Bower and Bower employed the réquired rate of return as an independent rather than a dependent variable. The foregoing two studies provide examples of the types of financial research that could employ. ex ante data to address patentiy ex ant research questions. This study has demonstrated the feasibility of obtaining, the necessary data inputs for such studies.

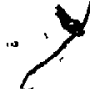

7.4 .2

\section{Corporate Finance}

By indicating the feasibility of measuring

the expectations of investors who buy,"sell, or otherwise

12 R:S. Bower and D.H. Bowter, "Risk and The valuation of common'stock", The Journal of Political Econony. (Yay, Jume, 1969). PR. 349-362. . ${ }^{13}$ stiocks were excluded from Bower and Bower's study if the calculated "normal earnings" were not positive in each of the required data years. 
follow'a particular common stock this study has indicated the feasibility of obtaining a "reasonably reliable"14 estimate of a firm's cost of equity capital. Such án estimate of the firm's cost of equity capital would be valuable in computing its overall cost of capital since friend has indicated that it is "relatively easy to measure the required rate for senior securities". 15

A very significant application of the direct. measurement of a firm's cost of equity capital arises, in the case of regulated industries. Rẹgulated companies are required to show that their rate of return on invested capital is inadequate before they are authorized'to increase their service charges. A primary element in rate hearings is the determination of the firm's cost of equity capital. 16

${ }^{14}$ Friend op. cit. " p. 270. As "indicated. in the preceding section, computation of an absolute magnitude for the average mafginal investors' reguired rate of return would involve weighting individual rates of return in an 'appropriate' manner. The development of such a weighting scheme is beyond the scope of this study.

$$
{ }^{15} \text { Loc: cit. }
$$

16 An indication of the substantial effort applied to the estimation of a regulated firm's cost of equity capital is evident from the testimony given in various. Bell Canada rate application hearings. For example, see Canadian Transportatión comnission, Telecommunication. Committee, Bell Canada evidence B-71-241 and $B-73-331$. 
Soldofsky and olive have reported that "the two most widely used methods of computing $k_{e}$ (the cost of equity capital) for the past decade have been the $\frac{E}{P}$ ratio (earnings/price) and the $\frac{D}{M P}+g$ formulations . . . Although the FCC (Federal Communications Commission) evidently accepted $\frac{D}{M P}+g$ as one reasonable method of establishing $k_{e}$ one FPC (Federal Power Commission) examiner rejected this approach because he believed that it required defining what buyers and sellers believed that the future earnings, payout ratios, and other factors would be". 17 Thus there is çonsiderable practical interest. and justification for the direct measurement of investors' required return on common equity.

A further corporate application of the direct measurement of return expectations is the identification of the dividend component of the total expeçted return. That is, it is possible to specify the rate of change in a company's annual dividend that is expected by investors who own, or, who are buying stock in a particular company: Such information would quite conceivabily be of interest to a firm that was faced with both a need for càsh and desire to maințain a steadily, growing annual divideñd.: confronted with such a situation and an awareness of the rate of growth that investors expected in the annual dividend:* a firm's board of directors would have an objective informa-

17R.M: soldofsky, and G.D: Olive, Financiai Management, cincinnati: South-Western Publishing $C o$. 1.974 , p. 295-296. 
tion input against which it could compare alternative dividend decisions.

7:4.3 The Investment Industry

This study found izhat analyst's' and investors! expectations were statistically indistinguishable in terms of the rate of price change; the rate of dividend change, and the total rate of return for all three stocks. However, it was also found that analysts', and investors' expectations frequent $\overline{1 y}$ differed in regard to the perceptions of risk and extreme changes in price and annual $\int$ dividend. If analysts and individuals had had identical expectations for the three stocks the implication would have been that, at the time of this study, all publicly available information was fully reflected in the prices of these stocks. Since expectations were 'mixed' rather than identical the implication is that the marketplace for these stocks was not efficient at the time of the study. However, the source of the inefficiency is not. identifyable from the data collected in this study. That is, there is no evidence to indicate whether differences in information or in the transformation of information (or both); was the cause of differences in expectations:

\section{${ }^{18}$ other information inputs are of course} involved in the dividend decision, e.g. Interest rates. investment opportunities, etc. 
The presence of differences between analysts' and investors! expectations raises the question of the existance of 'superior' expectors. 19 'if, for example., analysts!' expectations are more closely realized' than individual. investors then areas for improved communications between analysts and investors will be indicated.

7.5 . RECOMMENDATIONS FOR FURTHER RESEARCH

This study was designed to investigate ore element of valuation theory, namely, the nature of investors' expectations of financial return. The study focussed on the form, content, and behavior of price, dividend, and total returin expectations:?

In future studies involving the nature of investor expectations it would be worthwhile to explicitly investigate the expected dependency of price and dividends expectations rather than refy fon approximation to this correlation. Ideally, a joint distribution of price and dividend expectations would be obtained from investors although; to obtain such information; it would probably be necessary to interview investors rather than mail questionnaires.

ig since analysts and investors had the same expectations for the rate of price change, dividend change, and tota1 return, the superiority of expectątions could be investigated by comparing realized variations in price and dividends with expected variations in price and dividends. 
An issue similar to the price-dividend expected dependency question that was not investigated in this study was the expected correlation of a security's return with the investor's portfolio return. As a result, this research was limited to a definition of risk as 'variability' per se and did not addiress the question of the contribution af a particular stock's return-variance to the variance of an. individual's portfolio of marketable securities. Thus, the expected risk premiums reported in this study are a function only of the variance of a stock's expected return and not of the expected covariance of that return with an an expected portfolio return. Although the methodology of investigating: this broader definition of ex ante risk premiums would be formidable, an initial step might involve determining the extent to which individual investors' portfolio decisions are motivated by the expectations of reducing diversifyable (systematil) risk..

Ex ante data could also be employed in studies. designed to investigate the nature of factors associated with the expected rate of return and the risk (variability) of a stock!s future return.; For example, the expected. 'rates of return (dependent variabie)" for a cross-section of stocks could be investigated in terms of expected risk and skewness (independent variables). Additionally, the expected risk (variability) for a cross-section of stocksocouid be treated as a dependent variable in 
gression model with variables such as: the debt ratio. the payout ratio.. interest coverage, etc., being tréated as independent variables. - That is, expectational data could be integrated with published financial däta which conceivable would provide insight on the formation of expectations.

7.6 SUMMARY

The conclusions and implications of this study presented in the present chapter are summarized below. Essentially, the conclusions of this research invlove answers to the research questions posed in Chapter I (Sectión 1.2). Specifically it was concluded that: investors do expect higher return from higher risk stocks; differences do exist between buyers, seliers, and qwners expectations; and; all publicly available information was not fulky ręfleated in thermarket prices of the selected stocks at the time of this study. The conclusions are. however subject to qualifications regarding their applicability to different types of return (price, dividend, and total return), to different expectation time horizons, and"to" different parameters of return expectations.

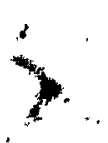


"The implications of this study were indicated as involving; financial theory and reséarch corporaté financial 2 practices and the investment industry. 'Implications for financial theory involve empirical guport for the parametric representation of investor expectation in valuation theory. - In tems of research methodology this stuigy had indicated the feasibility of obtaining ex ante data inputs from a crosssection of investors to investigate ex antë phenomena such as investors' required rate of return and perceptions of risk. Implications for corporate financial practices stem

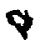
from the approximation of á firm's cost of equity by direct measurement. techiniques; academic and practical support for such àn approach was indicated.

Finally, the inconsistencies between security analysts $"$ and investors ' expectations implied that the marketplace for the selected stocks did not fully reflect all publicly available information and therefore was inefficient at the time of the study. 
Adler, M: "On Risk-Adjusted capitalization Rates and Valuation by Individuals, " Journal of Finance, XXY (September, 1990); 819-836.

Alderfer, C.P. and H. Bierman Jr. "Choices with Risk: Beyond the Mean \& Variance, " Journal of Business, vol., 43 (July, 1970), 341-353.

Angell, J.w. "Uncertainty, Likelihoods and Investment . Decisions," The Quarterly Journal of Economics. VLXXIV (February, 1960), 1-28.

Ardetti, F.N. "Risk and the Required Return on Equity," The Journal of Finance, Vol., 22 (March, 1967)\%. 19-36.

$\because$

Arrow, K.J. "Alternative Approaches To The Theory of Choice in Risk-Taking situations;" Fconometrica, vol., 19 (195i), 404-437.

Bowman, Mary Jean (ed). Expectations, Uncertainty, and Business Behavior. A conference held at carnegie Institute of Technology, Oct.., 27-29, 1955, under the Auspices of the Committee on Business Enterprise Research. New York: Social Science Research council, 1958.

Carter, C.F. "A Revised Theory of Expectations," The Economic Journal, Vol., 63, (December, 1953), 811-820.

Chambers, R.J. Accounting, Finance \& Management. Sydney: Buttefworth, \& Co., 1969.

Chambers, R.J. Accounting, Education, Economic Behavior. Englewood Cliffs: Prentice-Hall, 1966.

Coombs, C.H. and D.G. Pruitt." "Components of Risk in Decision Making: Probability and "Variance Preferences," Journal of Experimental Psychology; Vol., $60,2(19.60)$, 265-277.

Cragg J.G. and B.G. Malkiel. Whe Consensus and Accuracy of Some Predictions of the Growth of Corporate Earnings," Journal of Finance, Vol., 23. (March, $1968) .67-84$. 
Dixon, W.J. and F.J. Massey'Jr. Introduction to statistical Analysis. 3rd sd. New York: McGraw-Hil1, 1969

Elton; E.J. and M.V. Iruber. "Earnings, Estimates and the Accuracy of Expactational Data," "Management Science, Vol., 19 (Apri:, 1972), B-409-424.?

Fama, Eugene F. "Ef icient Capital Markets: A Review of Theory and Empirical Work," Journal of Finance, Vol., 25 (May, 1970), 383-423.

Fama, E.F. and M.H. Miller. The Theory of Finance. New York: Holt Rinehart \& Winstom, 1972.

Feather, N.T. "The Relationship of Expectations of Success to an Achievement and Tést Anxiety," Journal of Personality and sncial Psychology, Vol., 1, (1965), 118-126.

Friend, Irwin. "Mythodology iffinance," The Journal of Finance, Vol $\therefore$ 28, (May, 1973), 257-272.

Friend, I. "Critical Evaluation of Surveys of Expectations, Plans \& Investment. Behavior"," in Expeatations, M.J. Bowman

Georgescu-Roegen, N. "The-Nature of Expectations and UnCertainty," in Expectations, ed. M.J.rBowman

Henry $;$ W.E. "Personality Factors in Managerial Reaction
. to Uncertainty," in Expectatjons, ed. M.J. Bowman to Uncertainty," in Expectatipns, ed. M.J. Bowman

Hughes, G.D. and P.A. Naert." "A Computer-Controlled Experiments" in Consumer Behavior," Journal of Business, Vol: 43 ; (July, 1970); 354-372.

Jean, W.H. The Analytical Theory of Finance: New York: Holt Rinehart Winston, Inc. 1970

Katona; G. The Mass Consumption Society. New York: McGraw-Hi11, 1964 . 
Keenan, M. "Models of Equity Valuation: The Grear Serm Bubble," The Journal of Finance, Vol ; , May, 1970), 243-273

Iintner, John. "The Aggregation of Investor's 'Diverse Judgements and Preferences in Purely Competitive Security Markets," Journal of Financial and Quantitat1ve Analysis, IV (December, 1969); 347-400.

Letane; H.A. and D.L.. Tuttle. Security Analysis and Portfolio Management. New York: The Rondld Press Company: 1970 .

Markowitz, Harry Max. Bortfolio Selection: Efficient $\therefore \quad$ Diversifiction of Investments. Hew Ilaven, Yale University Press, 1970.

Malkiel, B.G. "Equity Yields", Growth and the structure of Share Prices," American Economic Review, Vol., LIII (December, 1963), 1004-1030.

Marschak, J.' "Money and the Theory of Assets," Econometrica, Vol.,. 6 (October, 1938), 311-325.

Meredith, G.P. "The Surpise Functions and the Epistemic Theory of Expectations," in Expectations, Uncertainty \&. Business 'Behavior, ed. Mary J: Bowman. New York:

Modigliani F." and G.A. Pogue. "An Introduction to Risk and Returns: Concepts and Evidence," Fiñancial Analysts Journal, Vol., 30, (March/April, 1974), 68-80

Ozga, S.A: Expectations in Economic Theory. London: Weidenfeld \& Nicolson, 1965.

Pratt, J.W. "Risk Aversion in the Samll \& Large," Econometrica; Vol.; 32; (Jänuary-Apri1, 1964), $122-136$

Pankoff, L.D. and R:L Virgil. "Some Preliminary Findlngs from a Laboratory Experiment on the Usefulness of Financial Accounting Infarmation to security Analysts," Empirical Research in Accounting; Vol., 8 (1970), $1-48$ 
Robichek, A. "Risk \& the value of Securities," Journal of Financial \& Quantitative, Vol., 4, (December, 1969); 513-538:

Smith, K.V. "Increasing Stream Hypothesis of Corporate Dividend Policy," California Management Review, Vol., 14 (Fall, 1971), 56-64.

Sauvain, H.C. Investment Management. , 2nd ed. Englewood Cliffs: Prentice-Hall, 1967.

Savage, Christopher, Ivor and John R. Small. Introduction to Managerial Economics. London: Hutchison, 1967.

Savage, I. Richard. Statistics: Uncertainty \& Behavior." Boston: Houghton Mifflen, 1968 .

Savage, Eeonard $\mathrm{J}$. 'The Foundations of Statistics. New York: Wiley, 1954 .

Savage, L.J. "Elicitation of Personal Probabilities and Expectations," Journal of the American Statistical Association. Vol., 66 (December, 1971), 783-801.'

Schlaifer, R. Analysis, of Decisions: under Uncertainty. Preliminary Edition, Vol., ix New York: McGraw-Hịll， 1967.

Shackle, G.I.S: Decision, Order, and Time in Human Atfairs. - Cambridge (eng.): Cambridge Press, 1961.

Siegel, S. "Nonparametric Statistics for the Behavioral. Sciences. New York: McGraw-Hill, 1956.

Smith, R.G. "Uncertainty, Information and Investment Decisions," The Journal of Finance, vol., 26, (March, 1971), 67-82...

Sprenkle, Case M. "Warrant Prices as Indicátors of Ex- " pectations and Preferences," in The Random Character of Stock Market Acices. ed. Paul H. Cootner, 412-474. M.I.T. Press; 1964 .

Turnoviky, S.J. "Empirical Expectations on the Formation of Price Expectations," Journal of the American Stafistical Association, Vol., 65, (December, 1970), 14411454 . 
247

U.S. Bureau of ,the Census, Consumer Buying Indicators:

Recent Purchase of Cor \& Other Durables \& Expectations

to Buy during the Months Ahead, Survey Data through

1969, Current Population Reports, Series p. 65, No.

25, March 11, 1969, (Washington, D.C.: Government

Printing office, 1969).

Van Horne, J.C. Financial Management \& Policy. ind ed.

Inglewood Cliffs: Prentice-Hall, 19.61.

Westerhill R. "A Behavioral Approach to the Investment Management Decision and to the Securities Markets." Unpublished PhD.' dissertation, The University of California, Los Angeles, 1968.

Winkles, R.L.' "The Quantification of Judgement: Some Methodological Suggestions," Journal of the

- American Statistical Association, Vol., 62 (December,

Williams ${ }_{2}$ John Burr. The Theory of Investment Value.
New York: A.M. Kelley, 1965. 


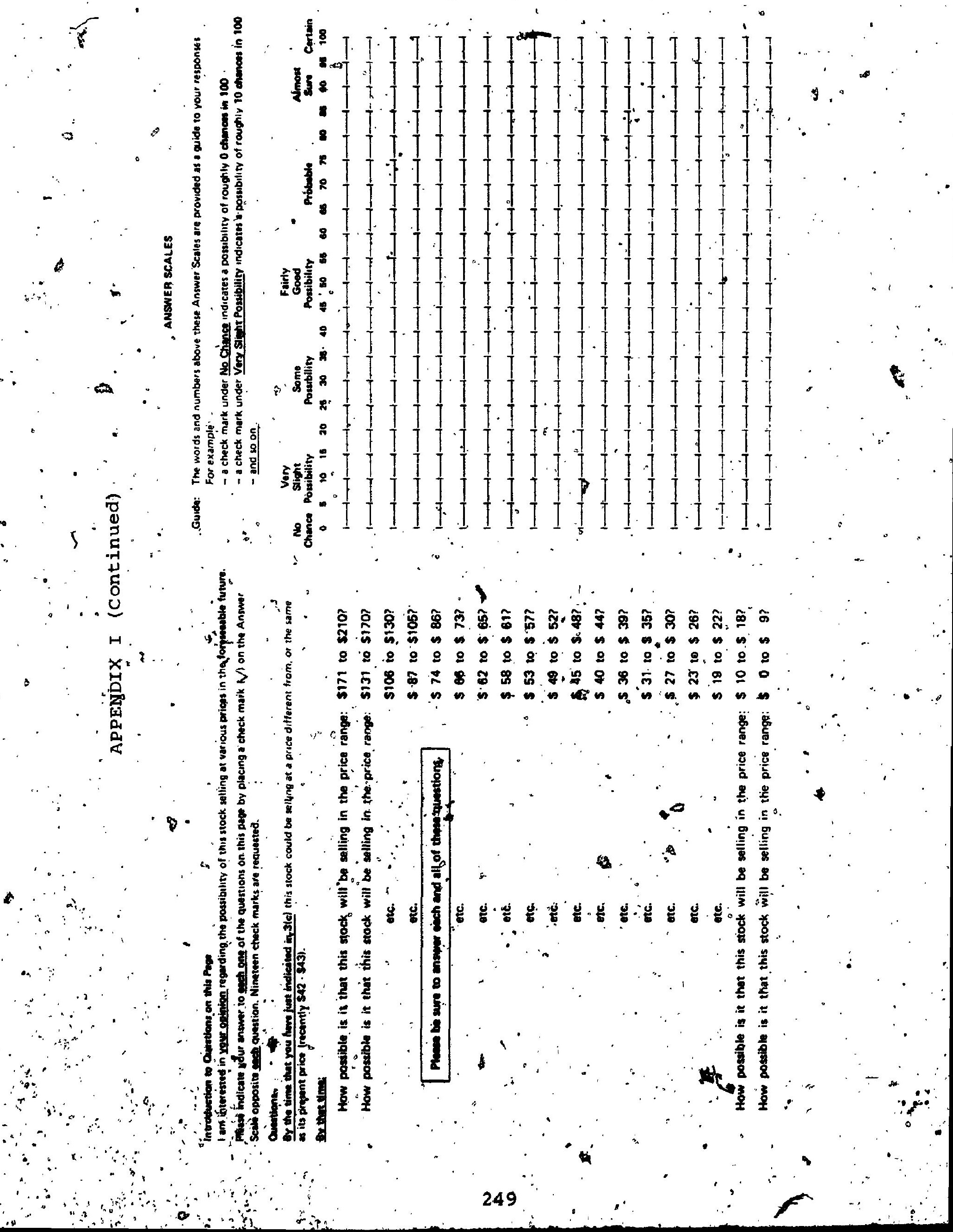




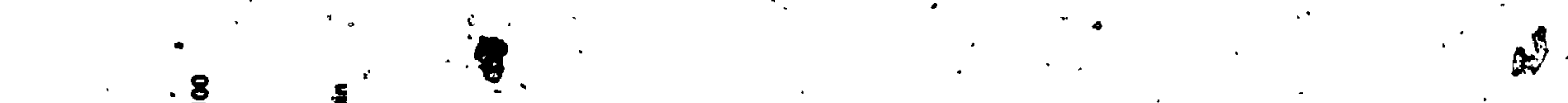

8
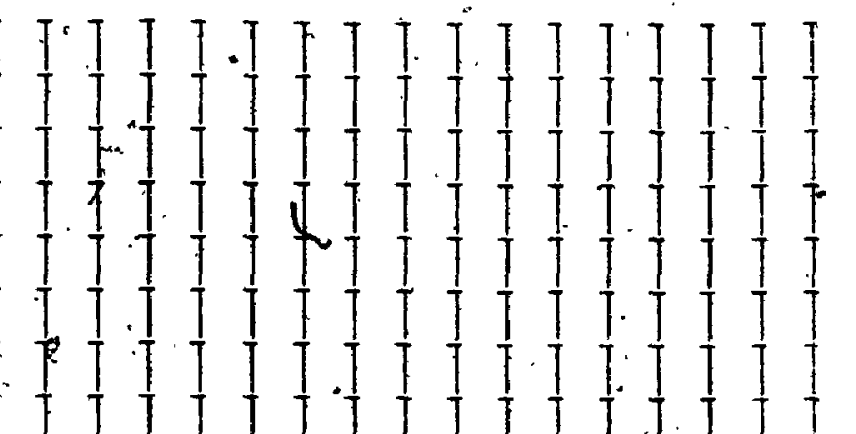

.

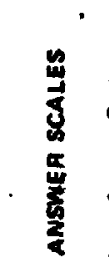

In:

․

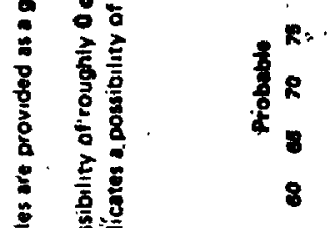

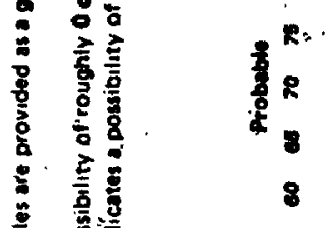

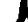

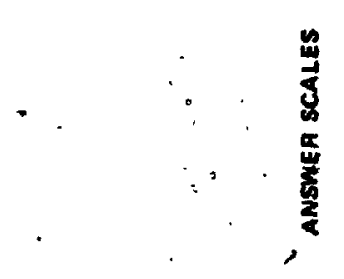

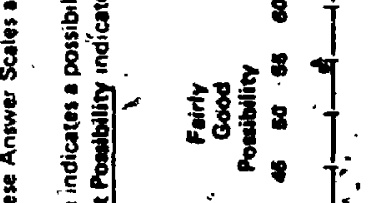

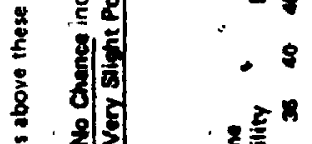

T:

T.

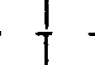

$T^{\circ} T \cdot T$

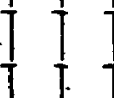

हैं

额

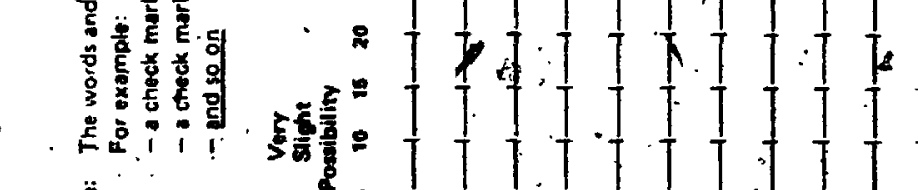

. . .

1
7
1
1

욜일

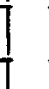

TITI.T.

年.

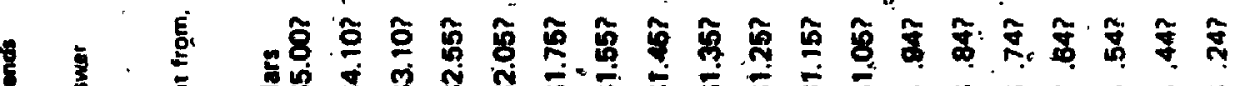
हैं

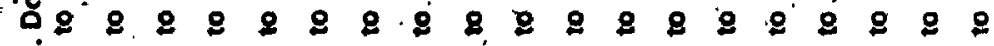

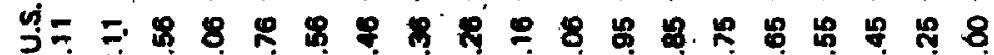

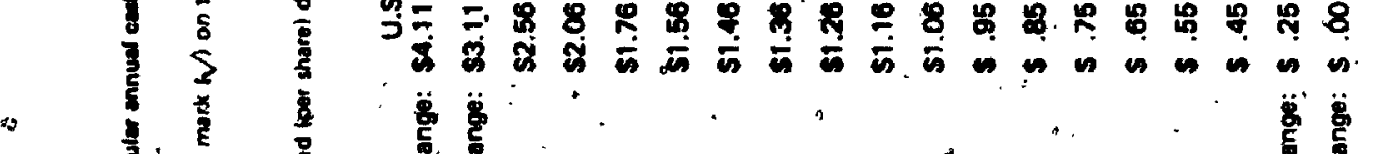

, 这

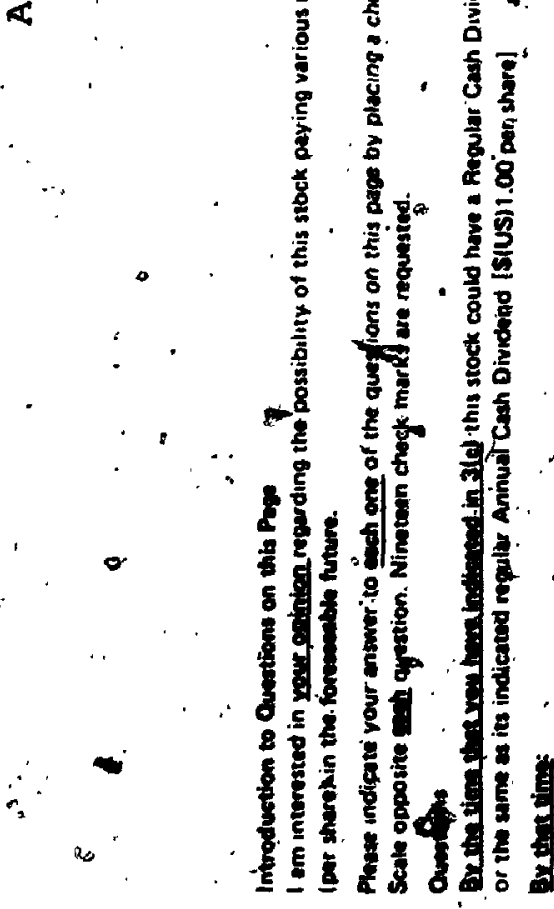

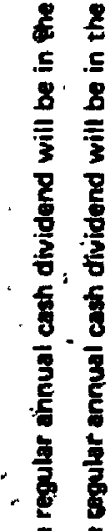

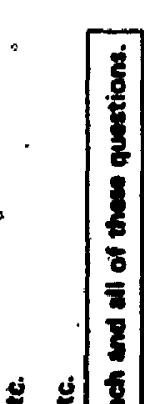

悹

$\frac{9}{2}$

. 5

$\cdot$

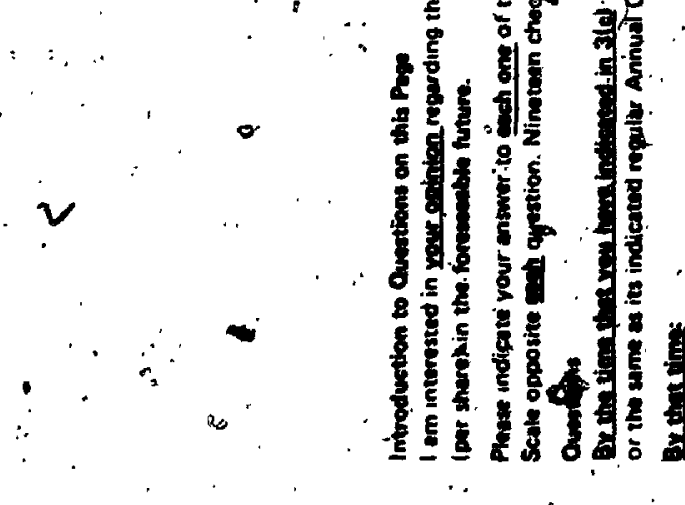

, 蛋

$\stackrel{*}{*}$

语寒

8 8

率

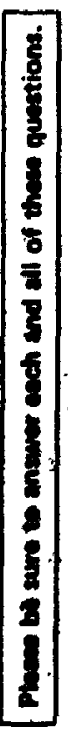
8 
APPENDIX II TYPES OF PRICE DISTRIBUTIONS OBTAINED
BY PANKOFF AND VIRGIL*

\section{Cं A A T 3}

Subjecls' Probabilily Disitibutions (Pirm 1, Peiriod 2)

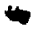
part 1
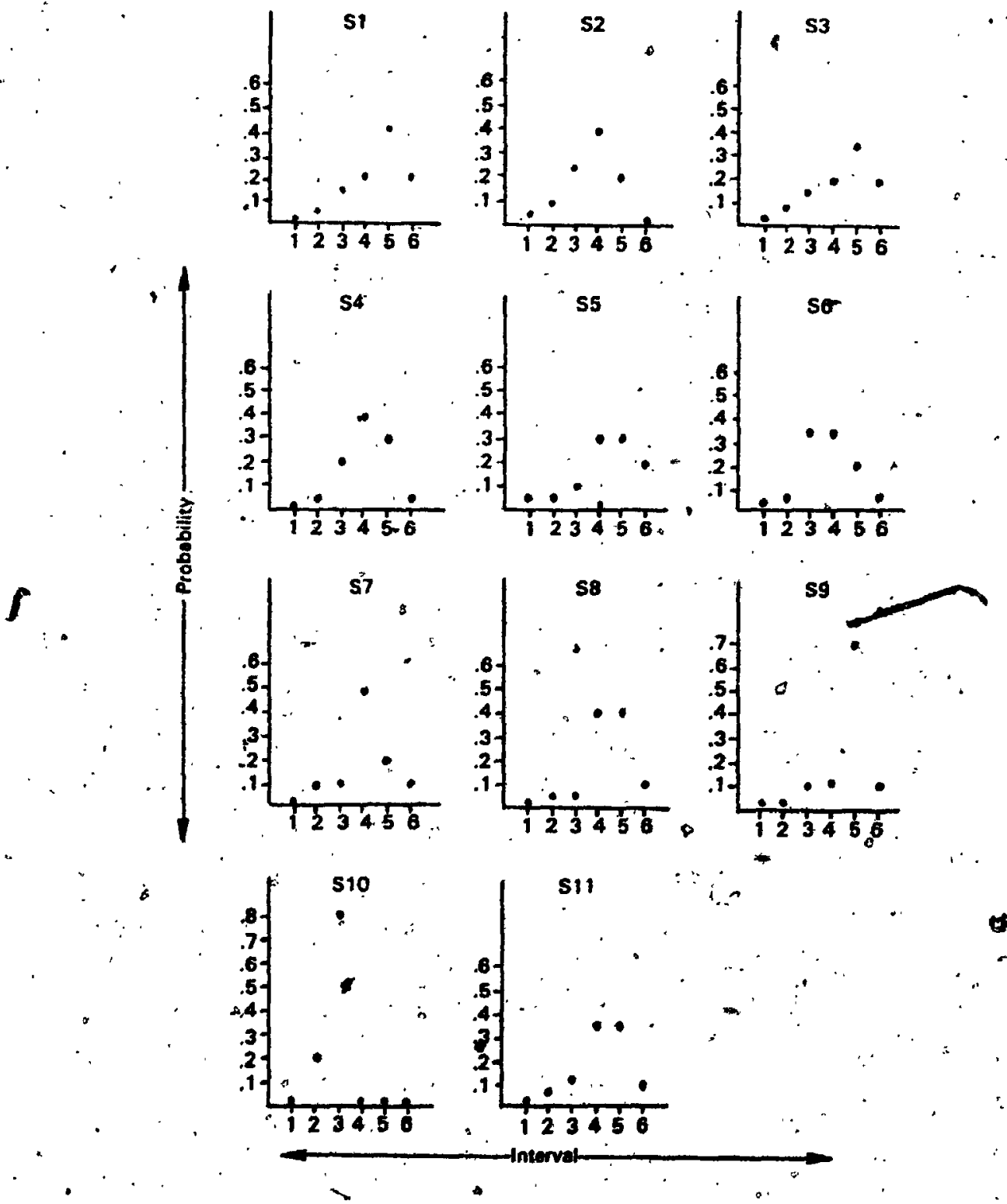

* Source: L.D. Pankoff and R.I. Virgil, "Some Preliminary Findings from a Laboratory Experiment on the Uséfulness of - Financial Accounting Information to security Analysts, "Empirica 1- Research in Accounting, 1970, pp. 41-43. 
252

2

I APPENDIX II (Continued)

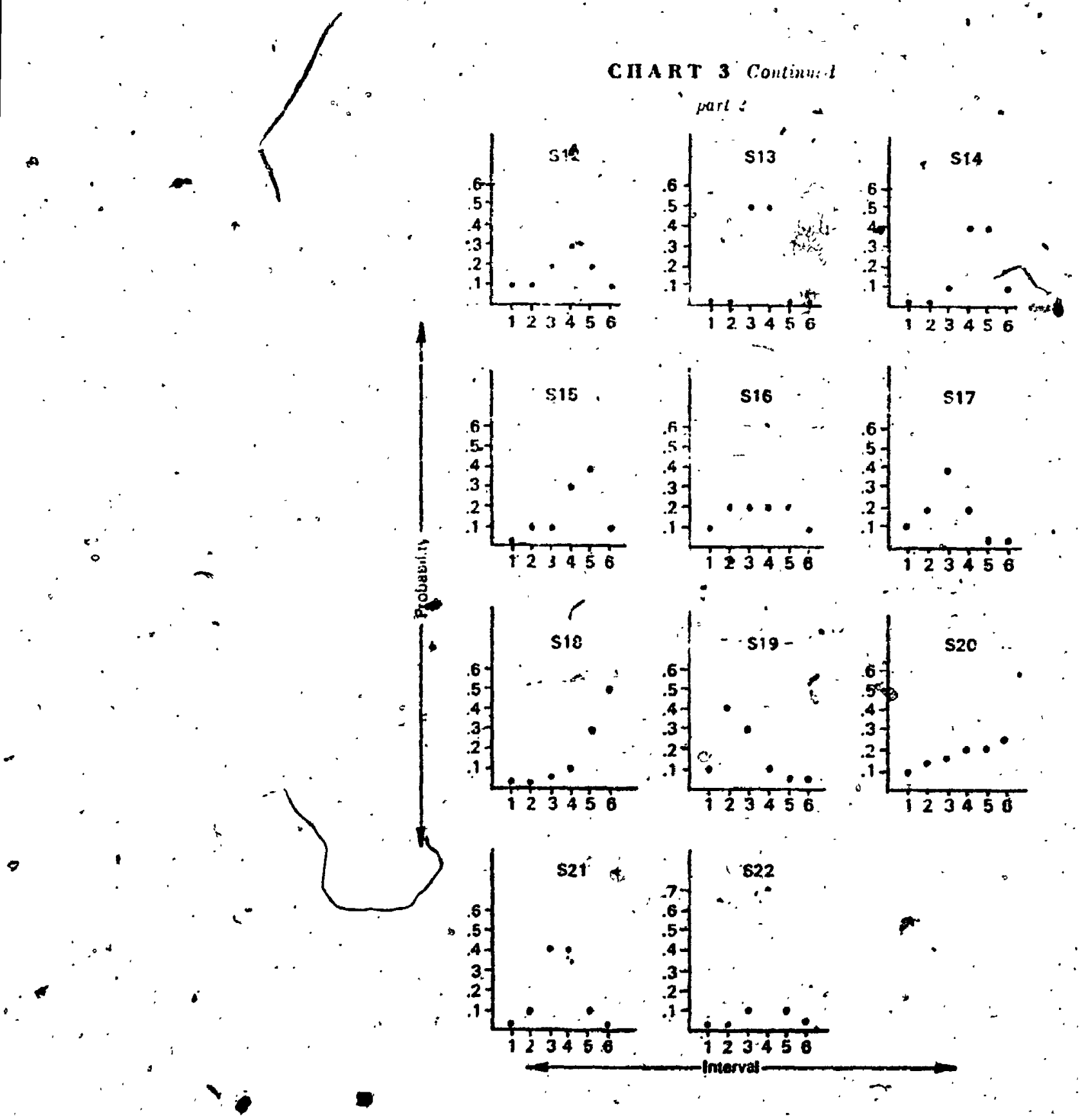


$\checkmark$

APPENDIX II (continued)

CIIA RT' 3 Continued

parl 9

-
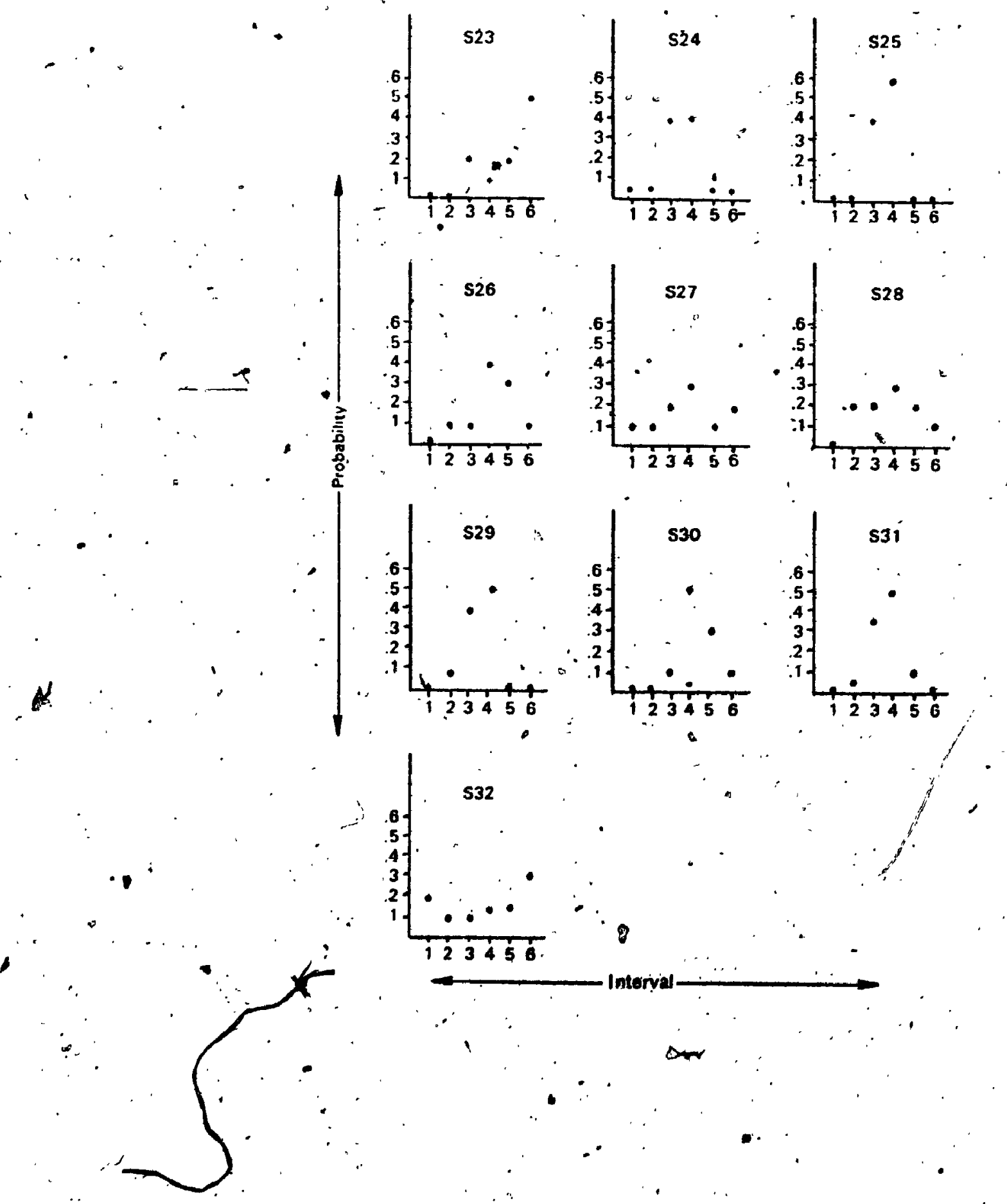

Interival

$\Delta$ 